\title{
YOUNG PEOPLE'S PERCEPTIONS OF FAMILIES AND EXPERIENCES OF FAMILY STRUCTURE CHANGE
}

By

Andrea Joy Rigg

\begin{abstract}
A thesis
submitted to the Victoria University of Wellington

in fulfilment of the requirements for the degree of

Doctor of Philosophy

in Psychology
\end{abstract}

Victoria University of Wellington

2009 


\section{ABSTRACT}

An increasing number of young people are faced with familial transformations. It is important to understand how young people conceptualise families before investigating their experiences of family transitions. Two mixed method studies were carried out in order to investigate young people's perceptions of families and experiences of family structure change. In Study One the perceptions of 111 children from different family structures and cultures were examined. Lone-parent families, stepfamilies, extended family, non-residential parents, and couples with children were highly endorsed. No great distinctions were made between married and cohabiting couples when the relationship included children. Definitions of 'family' frequently mentioned affective factors. In comparing ethnic groups and family structures some differences were noted, but in general children have many similarities in their family concepts. Comparisons with a recent study of adolescents did not reveal clear-cut developmental sequences in young people's perceptions. Overall, an inclusive and realistic view of families was expressed.

Most research regarding children and separation has focused solely on the impact of family change on young people. Furthermore, children's perspectives have frequently come from an adult perspective. Consequently, Study Two was a longitudinal investigation of young people's accounts of their own experiences of family transitions, in addition to their adjustment. Two interviews were conducted with 52 young people that formed either the early-stage separation group (ESG, 1-10 months since separation) or the later-stage separation group (LSG, 14-24 months). Approximately 18 months following the first interview (Time 1) a second interview (Time 2) was carried out. The interviews explored their experiences of separation, while eight instruments measured their adjustment in the domains of individual wellbeing and family dynamics.

The participants expressed a wide array of experiences. Some of these were shared experiences irrespective of the stage of separation. Both negative and 
positive experiences were reported. The majority of participants mentioned the reduction in parental conflict as a positive experience and missing their nonresident parent as a negative factor. Fewer negative experiences and more positive experiences were reported at Time 2 compared to Time 1. Similarly, at Time 2 the young people expressed fewer negative feelings about the separation and more positive feelings. The multivariate analysis of variance technique was used to analyse participants' adjustment to parental separation. From Time 1 to Time 2 the young people's individual wellbeing and family dynamics significantly improved. For those in the later stages of separation, family dynamics and individual wellbeing remained relatively stable over time. For those in the early stages of separation, time resulted in improved family dynamics and individual wellbeing levels that were comparable with those in the later stages of separation. This exemplifies their resiliency and is consistent with Amato's (2000) 'divorce-stress-adjustment' perspective.

In summary, in Study One the children were remarkably pragmatic in their acceptance of family diversity. In Study Two the young people voiced an array of individual and collective opinions and experiences of parental separation. For these young people parental separation was a process of negative and positive experiences and influences that over time resulted in improved adjustment. 


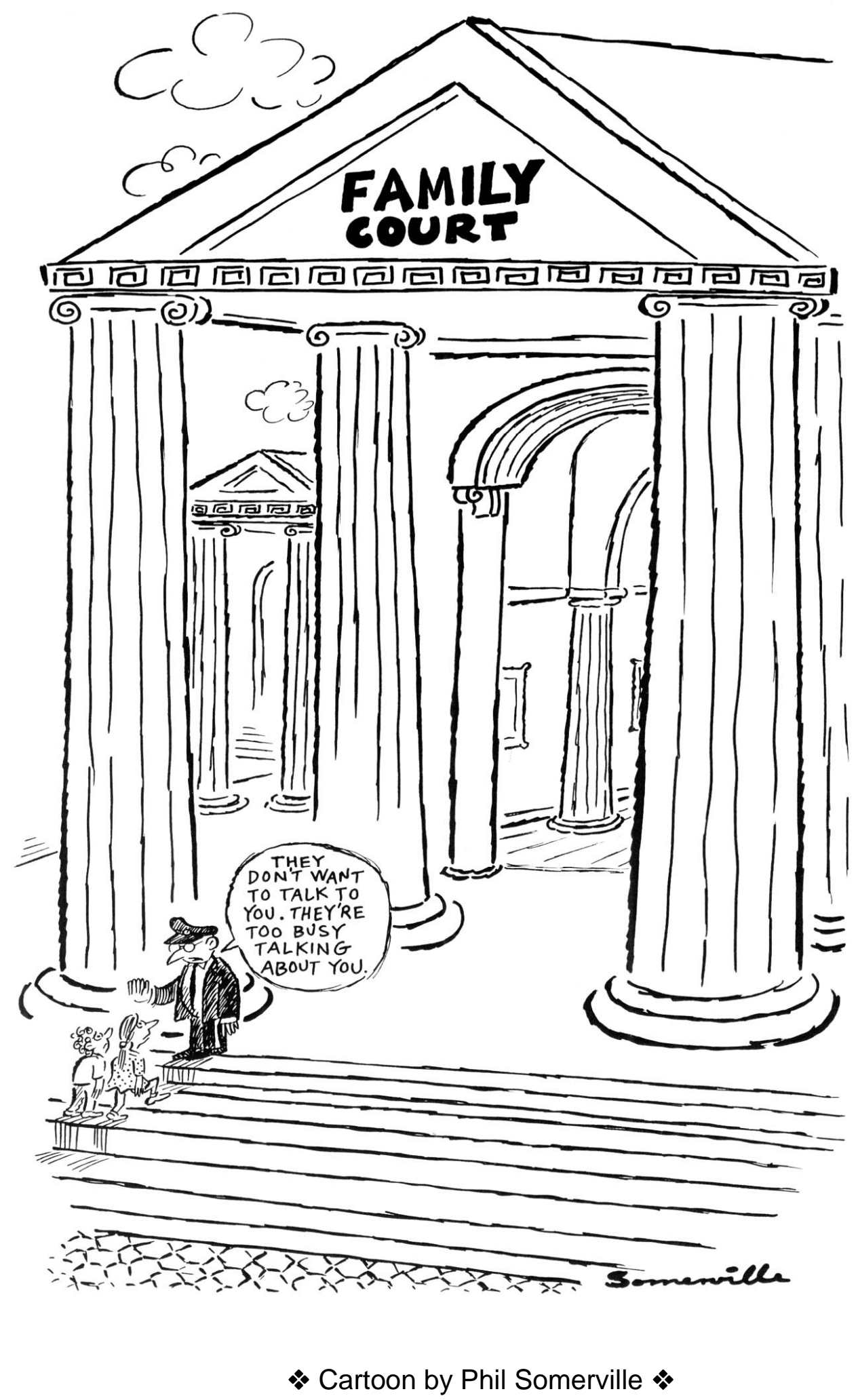




\section{ACKNOWLEDGEMENTS}

To Professor Jan Pryor - thank you for your steadfast support and for the knowledge I have accumulated. A past student of yours commented to me that she would be content in life if she was half the person you are.....and I wholeheartedly concur! You are inspirational on so many levels - thank you for your wisdom and friendship.

Thank you to Dr. Colleen Kelly for your impressive statistical expertise. Your time and knowledge was invaluable.

Thank you to Ngaire Lavery at the School of Psychology for your genuine kindness and support. To the Roy McKenzie Centre for the Study of Families for the wonderful work they do.

To Shona de Sain and Celia Simpson at the Faculty of Science - I am grateful for your encouragement and assistance throughout this process.

A special thank you to Dr. Kathryn Leslie and Dr. Paula King for their care and support throughout my time at Victoria University.

Dr. Sue Jackson - thank you for stepping up to take on the role of second supervisor.

A big thank you to Phil Somerville for generously sending me his wonderful cartoon, which perfectly depicts the importance of listening to children. We are fortunate that the Family Court in New Zealand recognises the value in hearing what children have to say.

To the team at Seasons for Growth and Skylight for their interest and enthusiasm for this research. 
I am grateful to the children in Study One that took the time to help me understand what family means to them. A special thank you to the young people in Study Two that so eloquently shared their views over the course of this research. I hope many children will benefit from your experiences and your expertise.

Thank you to the parents that were generous enough to open up their homes and their lives at such a difficult time. Most importantly, for giving their consent for their children to express themselves.

To my family, in particular Mum and Dad, and the 'outlaws' Mark and Trish. Thank you to my parents for never questioning my decision to jump head first into the world of academia for this many years. Thank you to Mark and Trish for encouraging Ryan and I to gain an education at the highest level. You have all been incredibly supportive and accepting with the choices we have made and I appreciate it immensely.

Finally and most importantly, to Ryan. We made the decision to undertake our doctorates at the same time to support each other, but we never dreamed it would be this trying. Despite the hurdles along the way I feel honoured and incredibly proud that we were both able to achieve the same dream that was ignited at Otago (a few burnt couches, late nights and lectures ago). Thank you for your unselfish support and resounding optimism. More than anything, I am grateful for your unwavering belief in me - it is the reason I made it to the end. I look forward to jumping many more hurdles together. 


\section{TABLE OF CONTENTS}

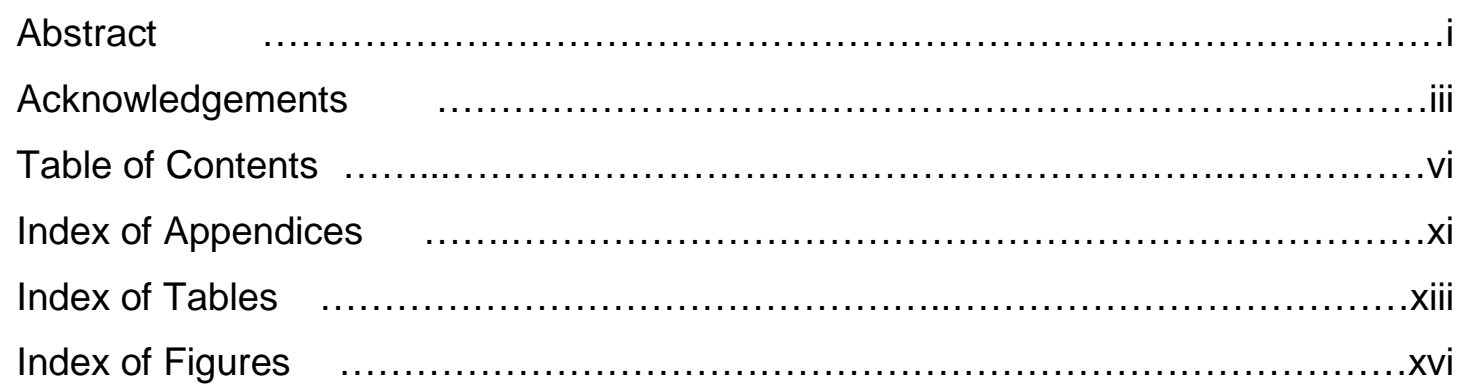

\section{INTRODUCTION}

\section{CHAPTER ONE - Family}

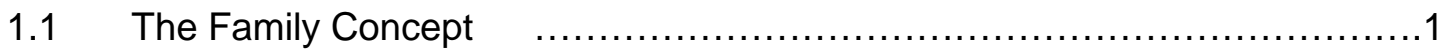

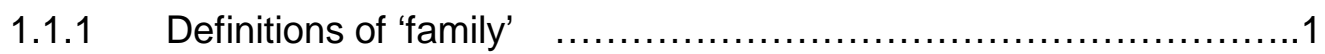

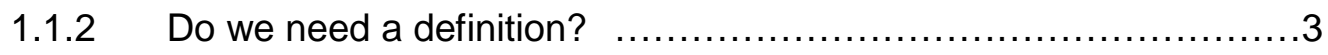

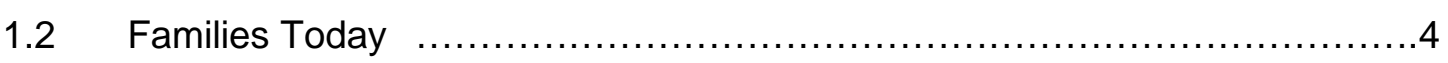

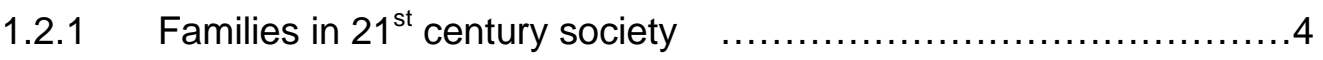

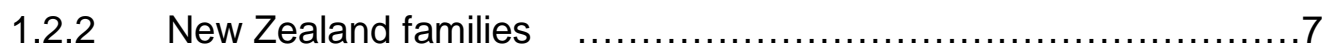

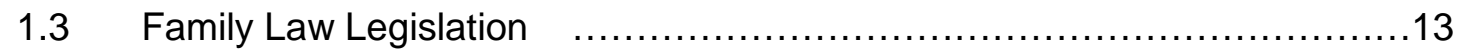

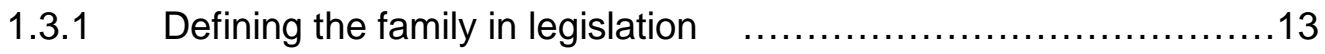

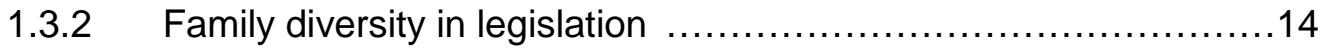

\section{CHAPTER TWO - Perceptions of Families}

2.1 Young People's Perceptions of Families: The Research to Date ...........17

2.1.1 The family concept: groupings of people $\ldots \ldots \ldots \ldots \ldots \ldots \ldots \ldots \ldots 17$

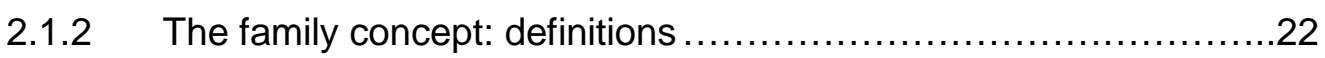

CHAPTER THREE - Experiences of Family Structure Change

3.1 Young People's Experiences of Parental Separation: The Research to

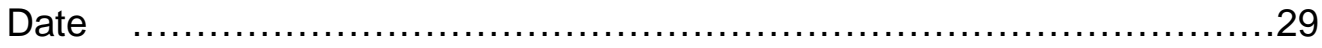

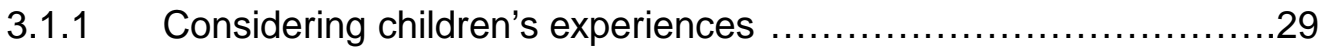

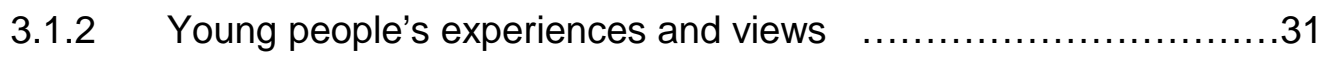

3.1.3 Overview of young people's experiences of separation ...........43

3.2 Young People's Adjustment to Parental Separation: The Research to Date 


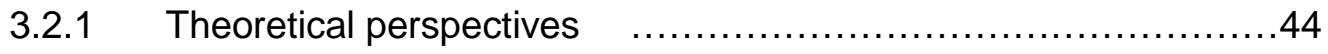

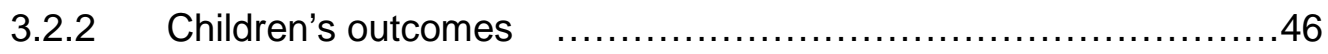

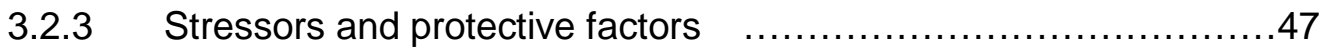

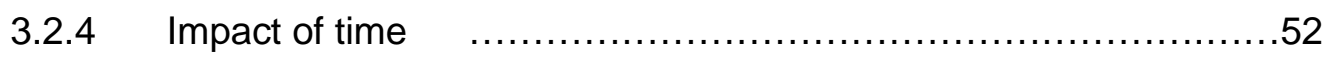

3.2.5 Overview of young people's adjustment to separation $\quad . . . \ldots \ldots . . . .54$

\section{CHAPTER FOUR - The Studies}

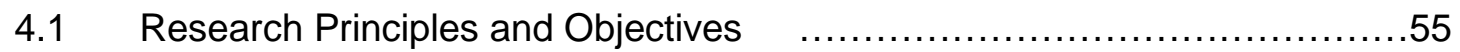

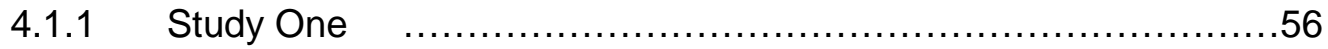

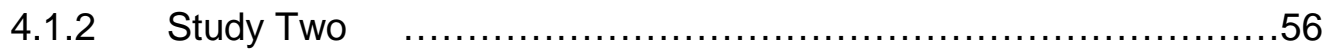

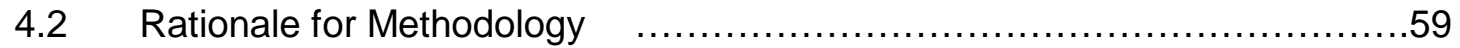

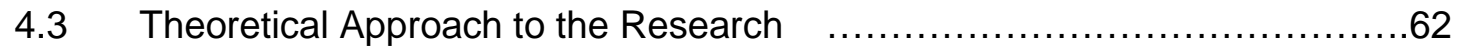

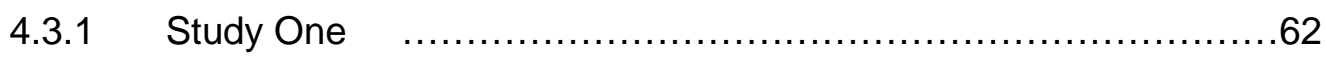

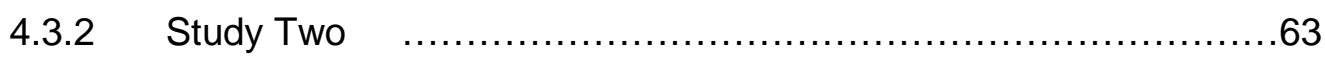

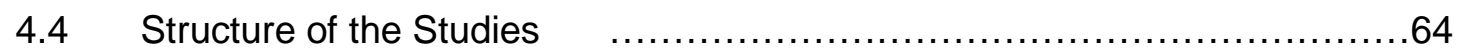

II STUDY ONE: YOUNG PEOPLE'S PERCEPTIONS OF FAMILIES

\section{CHAPTER FIVE - Method}

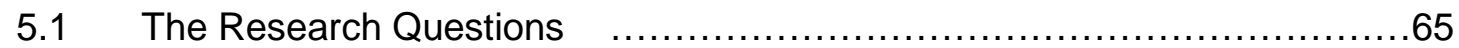

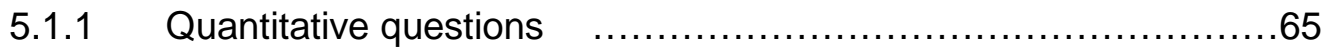

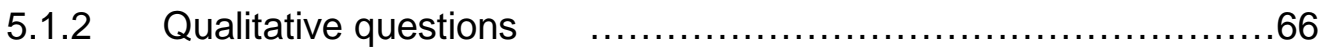

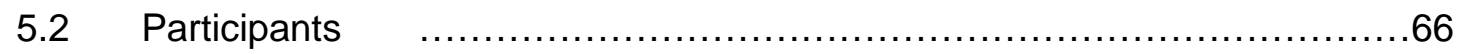

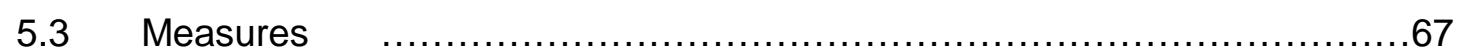

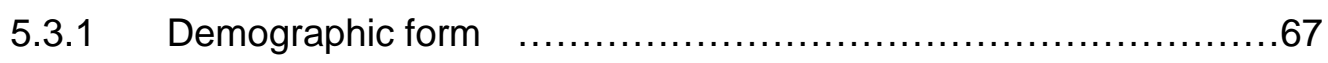

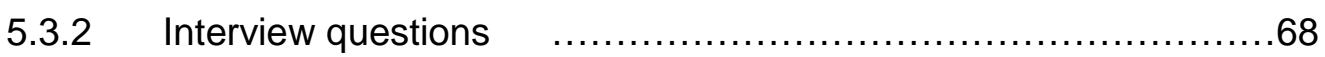

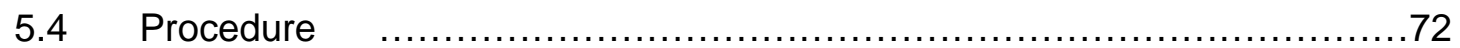

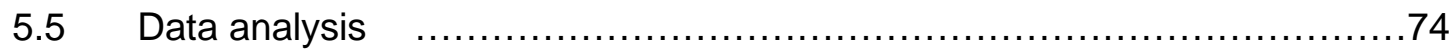

\section{CHAPTER SIX - Results}

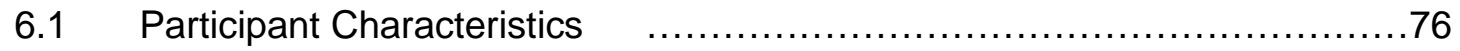

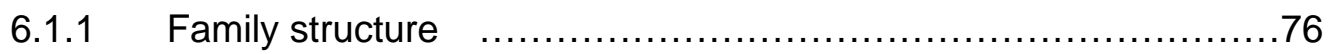

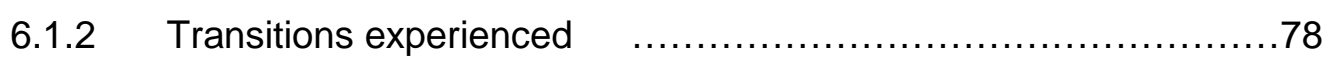

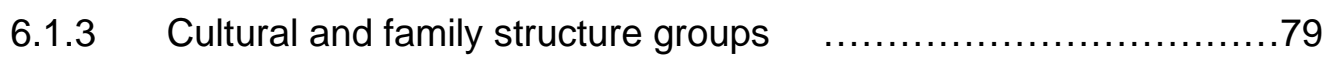

6.1.4 Separated and divorced parents sample $\quad \ldots \ldots \ldots \ldots \ldots \ldots \ldots \ldots . \ldots \ldots 2$ 
6.2 Endorsement of Family Groupings: Quantitative Analyses .84

6.2.1 Differences in endorsement by family structure $\ldots \ldots \ldots \ldots \ldots \ldots . \ldots 87$

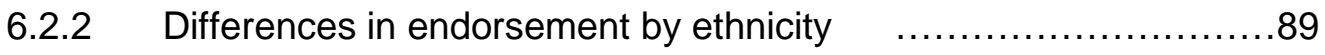

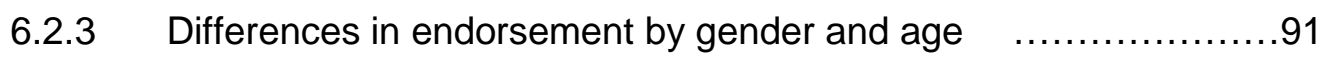

6.2.4 Differences in endorsement by transitions experienced ...........92

6.3 The Concept of Family: Qualitative Analyses $\quad \ldots \ldots \ldots \ldots \ldots \ldots \ldots \ldots \ldots \ldots . \ldots 3$

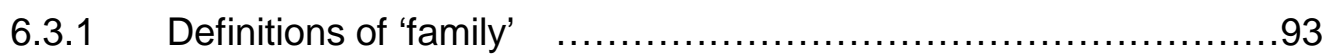

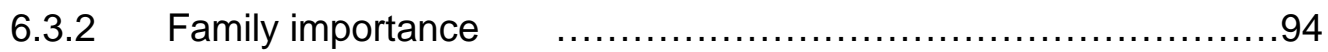

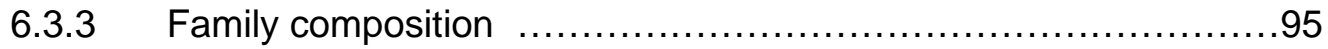

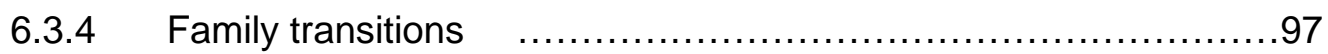

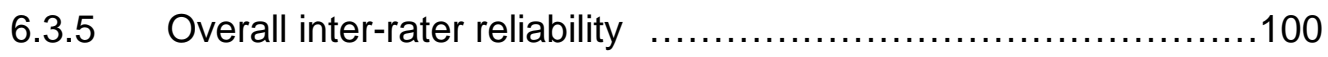

\section{CHAPTER SEVEN - Discussion}

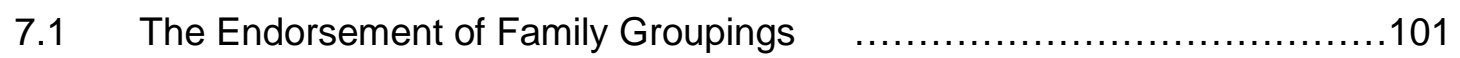

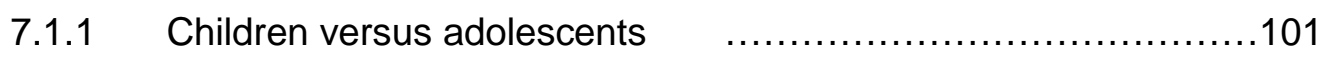

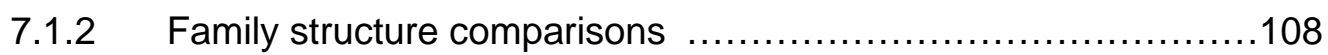

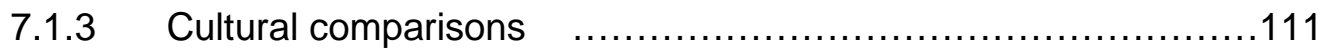

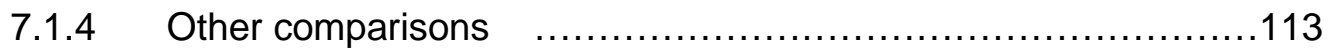

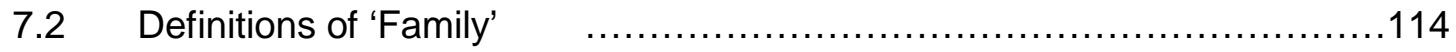

7.2.1 How do young people define the concept of family? .............114

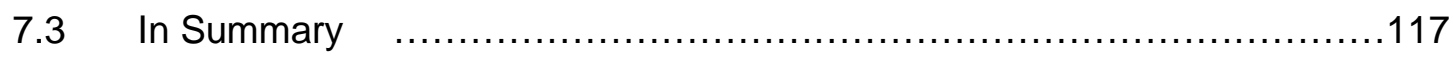

III STUDY TWO: YOUNG PEOPLE'S EXPERIENCES OF FAMILY STRUCTURE CHANGE

\section{CHAPTER EIGHT - Method}

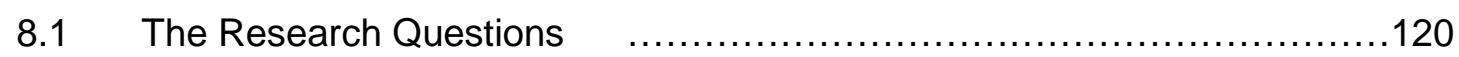

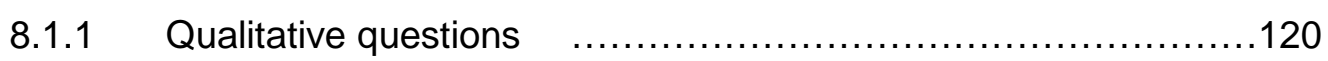

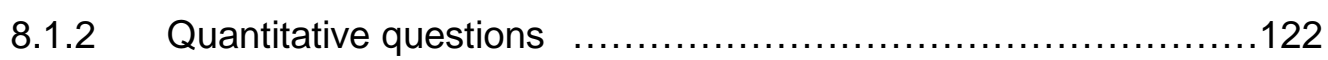

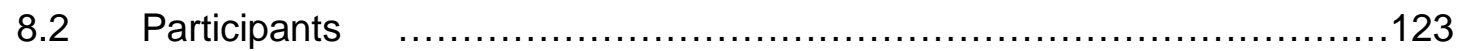

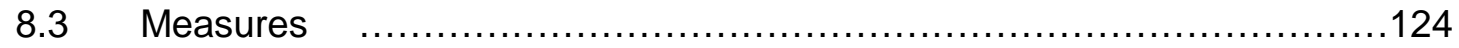

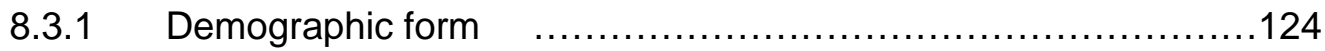

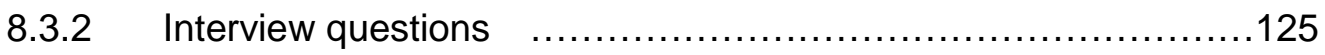

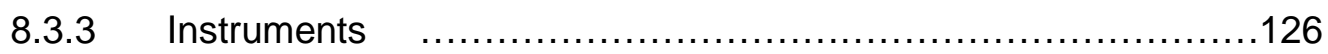

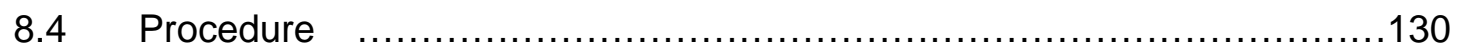




\section{CHAPTER NINE - Results}

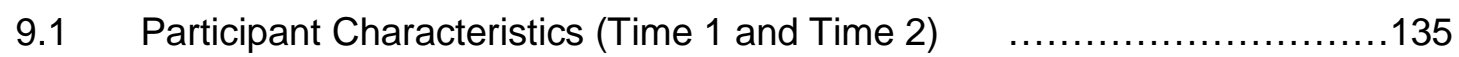

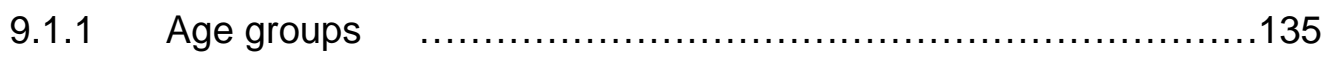

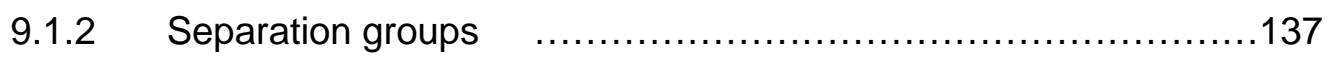

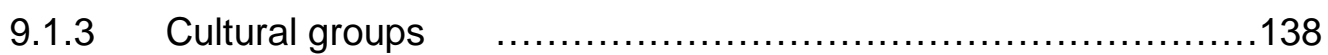

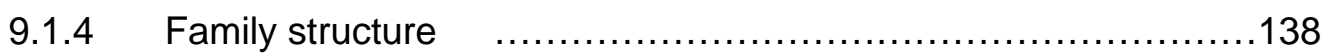

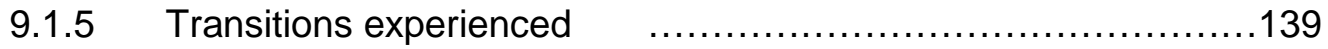

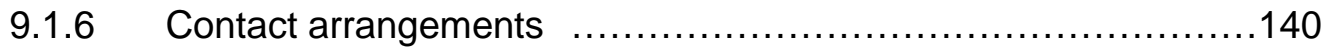

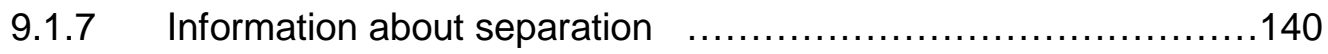

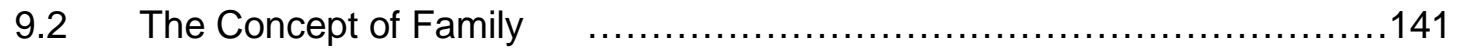

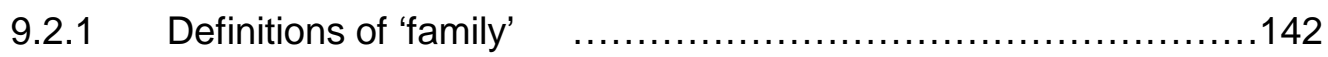

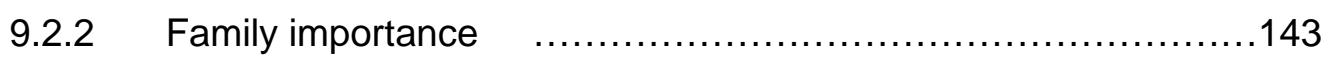

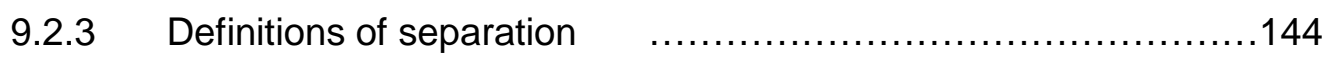

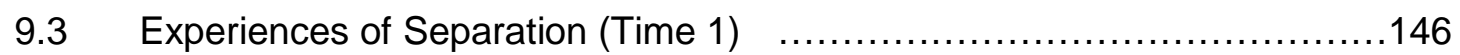

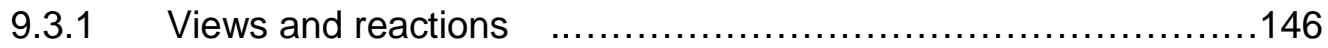

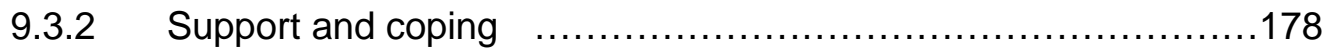

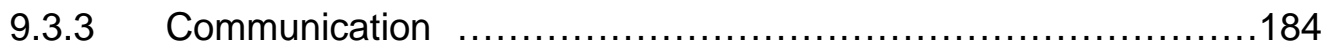

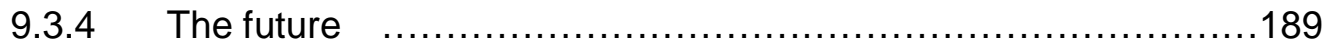

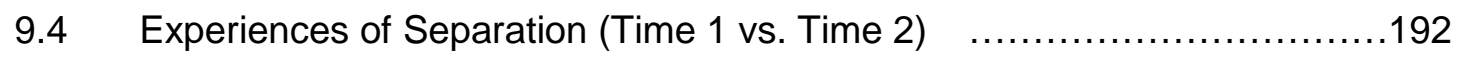

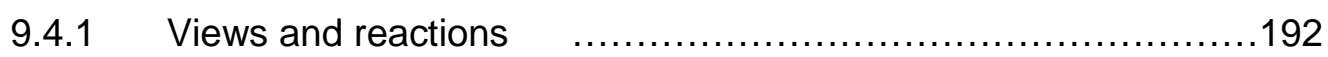

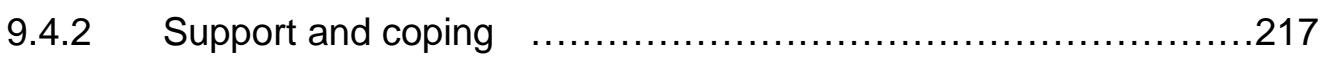

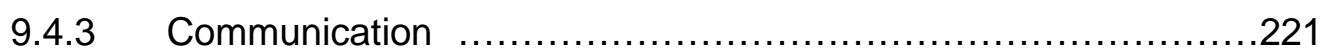

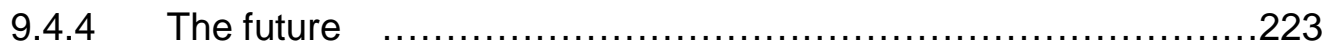

9.5 Reliability Analyses and Descriptive Statistics (Time 1 and Time 2) .....224

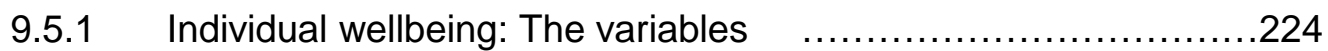

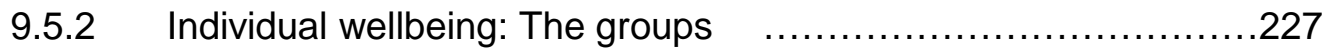

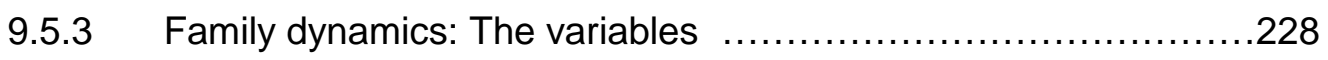

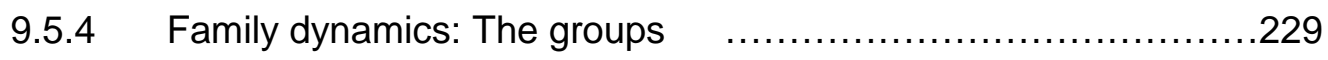

9.5.5 Perceptions of control: The variables ...........................230

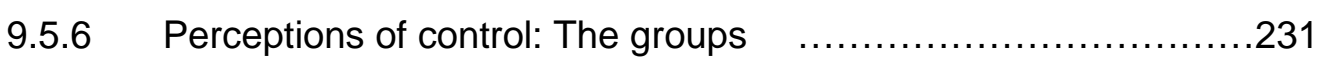

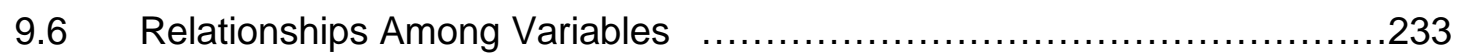

9.6.1 Correlations between family and individual variables f.........233

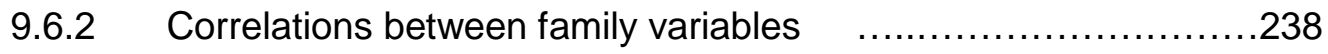

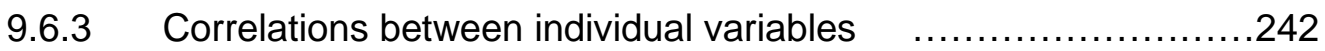

9.7 Young People's Adjustment to Parental Separation: Multivariate 


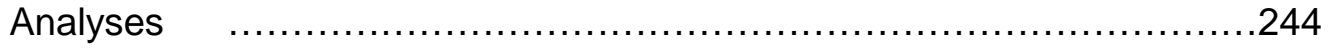

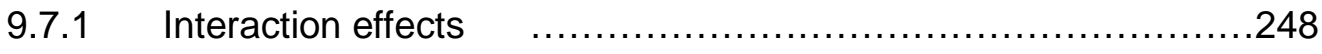

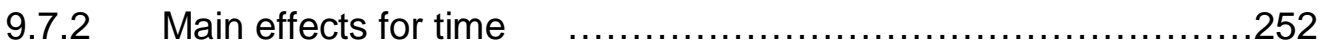

9.7.3 Main effects for the early-stage and later-stage separation

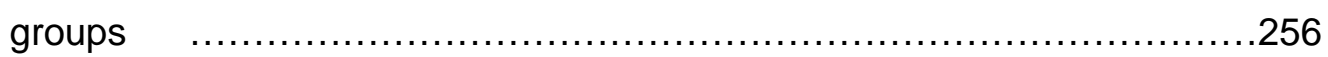

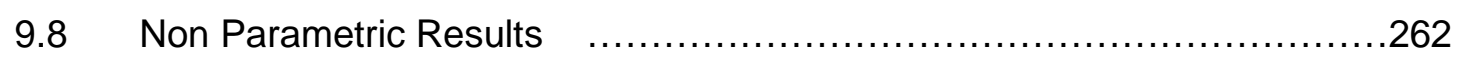

9.8.1 In summary: Non parametric results vs. parametric results $\ldots \ldots .262$

\section{CHAPTER TEN - Discussion}

10.1 Definitions of 'Family' and Separation f..................................263

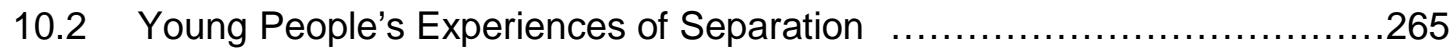

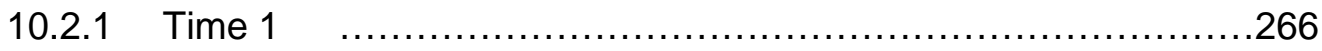

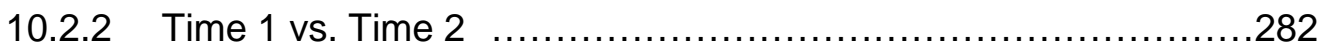

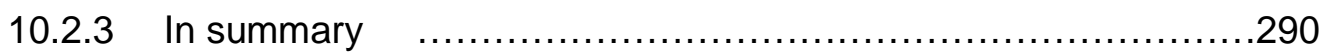

10.3 Young People's Adjustment to Separation ................................290

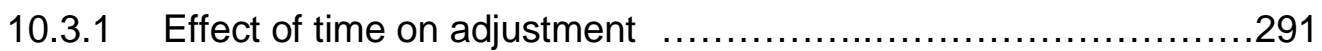

10.3.2 Stressors, protective factors and outcomes ....................293

10.3.3 'Crisis' vs. 'chronic strain' model ..................................295

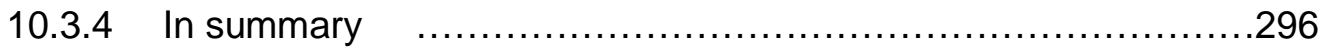

\section{CONCLUSIONS}

\section{CHAPTER ELEVEN - Overall Summary and Implications}

11.1 Young People's Perceptions of Families and Experiences of Family Structure Change: Study One and Study Two $\quad \ldots \ldots \ldots \ldots \ldots \ldots \ldots 297$

11.2 Research Limitations and Recommendations .............................301

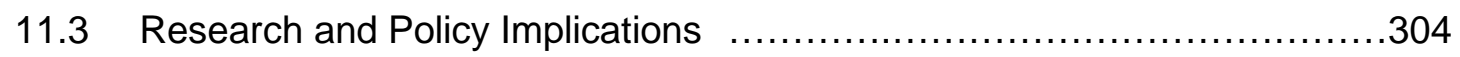

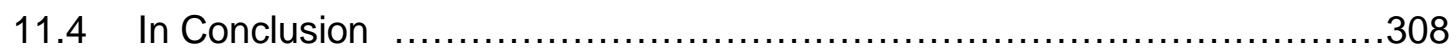

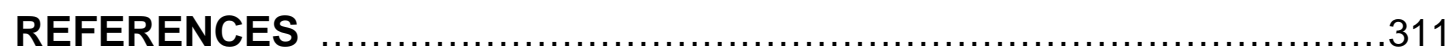




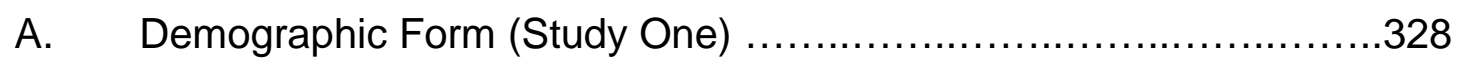

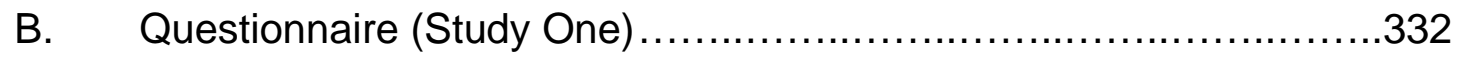

C. Examples of Vignette Pictures (Study One) ….......................336

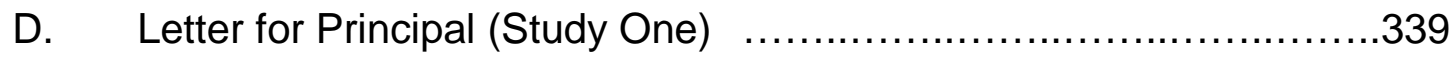

E. Letter for Parents/Caregivers (Study One) …........................341

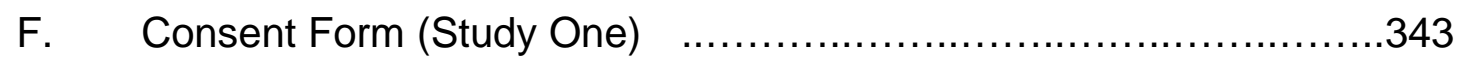

G. Letter for Parents/Caregivers (Study Two) ............................345

H. Consent form for Parents/Caregivers (Study Two) …..............347

I. Demographic Form for Parents/Caregivers (Study Two) …......349

J. Contact Details Form for Parents/Caregivers (Study Two) ..........353

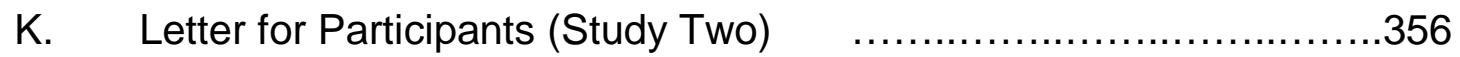

L. Consent Form for Participants (Study Two) ............................358

M. Demographic Form for Participants (Study Two) …...................360

N. Contact Details Form for Participants (Study Two) .......................364

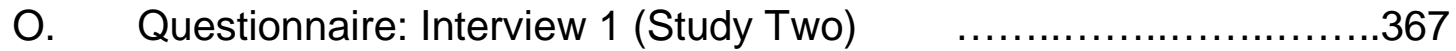

P. Questionnaire: Interview 2: (Study Two) …........................372

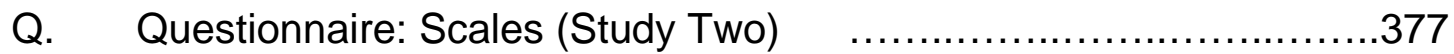

R. Estimated Marginal Means: Stage of Separation and Individual

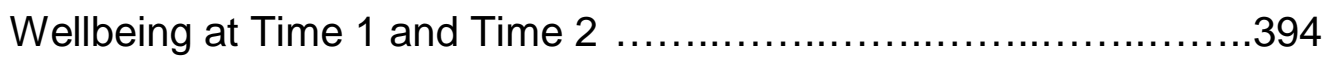

S. Estimated Marginal Means: Stage of Separation and Family Dynamics at Time 1 and Time 2

T. Estimated Marginal Means: Individual Wellbeing at Time 1 and Time 2 400

U. Estimated Marginal Means: Family Dynamics at Time 1 and Time 2 402

V. Estimated Marginal Means: Stage of Separation and Individual Wellbeing at Time 1 .404

W. Estimated Marginal Means: Stage of Separation and Family Dynamics at Time 1 406

X. Estimated Marginal Means: Stage of Separation and Individual Wellbeing at Time 2 
Y. Estimated Marginal Means: Stage of Separation and Family

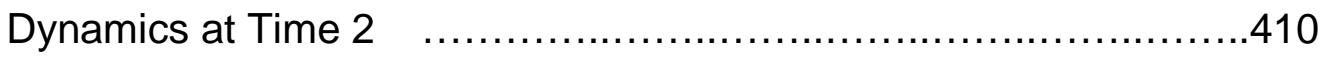

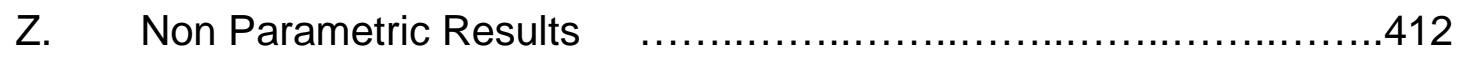

AA. Young People's Feelings about their Parents' Separation in Retrospect (as Reported at Time 1 and Time 2) .422

BB. Young People's Feelings about their Parents' Separation at Time 1 and Time 2 424

CC. Early-Stage Separation Participants' Feelings about their Parents' Separation at Time 1 and Time 2 .426

DD. Later-Stage Separation Participants' Feelings about their Parents' Separation at Time 1 and Time 2 .428 


\section{Chapter Six.}

Table 6.1 Characteristics of the Sample .77

Table 6.2 Ethnicity and Family Structure .80

Table 6.3 Family Structure and Family Transitions Experienced .81

Table 6.4 Ethnicity and Family Structure

Table 6.5 Characteristics of the Sample with Separated/Divorced

Parents

Table 6.6 Percentage of Total Sample Endorsing Situations as

Families

Table 6.7 Percentage of Total Sample not Endorsing Situations as

Families .86

Table 6.8 Percentages of Participants Endorsing Scenarios as

Families: Differences According to Family Structure

Table 6.9 Percentages of Participants Endorsing Scenarios as

Families: Differences According to Ethnicity .90

Table 6.10 Percentages of Criteria Mentioned in Definitions of 'Family' (Q.1)

Table 6.11 Percentages of Criteria Mentioned in Responses to Family Importance (Q.2)

Table 6.12 Percentages of Family Forms Mentioned in Responses

Relating to Family Composition (Q.3)

Table 6.13 Family Change - Stepfamily Relationship Questions:

Percentages of Criteria Mentioned in Reasoning 100

\section{Chapter Seven.}

Table 7.1 Percentages of Scenarios Endorsed as Families: Children vs.

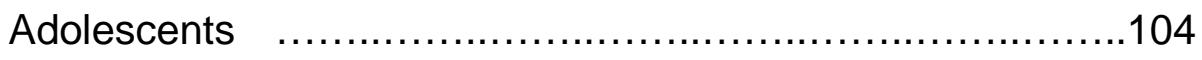

Table 7.2 Percentages of Criteria Mentioned in Definitions of Families:

Children vs. Adolescents 115 


\section{Chapter Nine.}

Table 9.1 Descriptive Statistics for Participant Characteristics .135

Table 9.2 Frequency Statistics for Participant Characteristics

Table 9.3 Percentages of Criteria Mentioned in Definitions of 'Family' (Q.1)

Table 9.4 Percentages of Criteria Mentioned in Responses relating to Family importance (Q.2)

Table 9.5 Percentages of Criteria Mentioned in Definitions of Separation (Q.11) 145

Table 9.6 Descriptive Statistics for Individual Wellbeing Variables at Time 1 and Time 2 .225

Table 9.7 Means for Individual Wellbeing Variables for the Early-Stage Separation Group and the Later-Stage Separation Group ....227

Table 9.8 Descriptive Statistics for Family Variables at Time 1 and Time 2 .229

Table 9.9 Means for Family Variables for the Early-Stage Separation Group and the Later-Stage Separation Group 230

Table 9.10 Descriptive Statistics for Locus of Control Variables at Time 1 and Time 2 231

Table 9.11 Means for Locus of Control Variables for the Early-Stage Separation Group and the Later-Stage Separation Group ....232

Table 9.12 Means for Locus of Control Variables for the Child Age Group and the Adolescent Age Group .232

Table 9.13 Pearson Product-Moment Correlations between Measures of Individual Wellbeing (Time 1) and Family Dynamics (Time $1 \&$ 2) .234

Table 9.14 Pearson Product-Moment Correlations between Measures of Individual Wellbeing (Time 2) and Family Dynamics (Time $1 \& 2$ ) .235

Table 9.15 Pearson Product-Moment Correlations between Family Variables at Time 1 and Time 2 .240

Table 9.16 Pearson Product-Moment Correlations between Individual Wellbeing Variables at Time 1 and Time 2 .243

Table 9.17 The Doubly Repeated Measures MANOVA results for the 
effect of stage of separation, age and time on individual wellbeing and family dynamics from Time 1 to Time 2

Table 9.18 The univariate results for the interaction effect of time and stage of separation on individual wellbeing

Table 9.19 The univariate results for the interaction effect of time and stage of separation on family dynamics

Table 9.20 The univariate results for the main effect of time on individual wellbeing 254

Table 9.21 The univariate results for the main effect of time on the family dynamics

Table 9.22 The MANOVA results for effect of stage of separation on individual wellbeing and family dynamics at Time 1 and at Time 2 .256

Table 9.23 The univariate results for the main effect of the stage of separation on individual wellbeing at Time 1

Table 9.24 The univariate results for the main effect of the stage of separation on family dynamics at Time 1 259

Table 9.25 The univariate results for the main effect of the stage of separation on individual wellbeing at Time 2

Table 9.26 The univariate results for the main effect of the stage of separation on family dynamics at Time 2 
Figure 9.1. The young people's feelings about their parents' separation in retrospect (as reported at Time 1)

Figure 9.2. The early-stage separation participants and the later-stage separation participants' feelings about their parents' separation in retrospect (as reported at Time 1)

Figure 9.3. The young people's feelings about their parents' separation now (Time 1) 153

Figure 9.4. The early-stage separation participants and the later-stage separation participants' feelings about their parents' separation now (Time 1)

Figure 9.5. The young people's feelings about their parents' separation in retrospect (as reported at Time 2)

Figure 9.6. The early-stage separation participants and the later-stage separation participants' feelings about their parents' separation in retrospect (as reported at Time 2)

Figure 9.7. The young people's feelings about their parents' separation now (Time 2)

Figure 9.8. The early-stage separation participants and the later-stage separation participants' feelings about their parents' separation now (Time 2) 


\section{INTRODUCTION}

\section{Chapter One}

\section{Family}

\subsection{The Family Concept}

The "family" has clearly emerged anew in the late 1970s as a central subject for discussion, debate, research and writing in both scholarly and popular arenas. Anxiety over whether or not the family as a basic social institution is dying has diminished. In its stead has emerged a fairly broad consensus around the position that the family is "here to stay," but that it certainly is changing. (Kamerman, 1980, p. 7).

\subsubsection{Definitions of 'family'}

A myriad of definitions have been developed that claim to adequately conceptualise 'family'. The veracity of these definitions has been questioned; and the debate and controversy surrounding the family concept continues. Not only are the defining characteristics of this concept an issue, but the need for a definition itself has been contested.

The existing array of definitions has evolved across cultures and across time. A traditional definition developed by Murdock (1949) defined the family as:

a social group characterized by common residence, economic cooperation, and reproduction. It includes adults of both sexes, at least two of who maintain a socially approved sexual relationship, and one or more children, own or adopted, of the sexually cohabiting adults. (p. 1)

Murdock recognised the ambiguous nature of the family concept and condemned the manner in which it had been haphazardly associated with a number of social groups. Consequently he coined the 'nuclear family' concept as a more specific, universal description of the family. Unlike our present understanding of the nuclear family, Murdock's early definition not only 
referred to a married male and female and their offspring, but also included combined nuclear families which he referred to as 'extended families' and 'polygamous families'.

Murdock's family definition can be described as exclusive, in that it identifies criteria that ultimately lead to the rejection or acceptance of certain situations as family. His definition is one of many which identify the nuclear family as a superior structure exclusively entitled to the classification of family (Stephens, 1963; Coser, 1964; Parsons, 1965; Reiss \& Lee, 1988). Such definitions do not fit the reality of many people's lives and consequently paint unrealistic pictures of the family.

In recent times family definitions have shifted away from 'the ideal', stereotypical, nuclear family image. Bernardes (1999) put forth the idea that “...'The Nuclear Family' does not exist except as a powerful image in the minds of most people" (p. 23). Indeed, we all know what 'the family' is supposed to look like because it has been imprinted in our mind from an early age (Zinn \& Eitzen, 1999); but this image does not necessarily match reality. Families come in many shapes and sizes. There is no longer one overriding image that personifies 'the family'. Hence, it is reasonable that the nuclear family concept is no longer employed in current family related discourse. Pryor (2005) has suggested that it may be more suitable to consider the word family as a verb rather than a noun, "Families are what families do, regardless of their composition. And what do families do? They provide emotional and practical support for their members; they nurture and socialise the next generation, and they transmit values between generations." (p.13).

The following definitions provide some examples of the vast collection of descriptions that have been espoused over time. Levin (1999) specified that the term family is generally used in reference to a biologically, legally and emotionally associated social group. Focusing more on affective connections, East (1980) interpreted family to be a group of people that care for one another. Gittins (1985) more broadly proposed that families are groups of individuals that are constantly changing. Similarly, Gubrium and Holstein 
(1990) adopted a social constructionist approach and perceived the family form to be under continuous construction. The more recent dictionary definition below reflects the fluid nature of family membership and function; it describes family as:

a basic unit of social structure, the exact definition of which can vary greatly from time to time and from culture to culture. How a society defines family as a primary group, and the functions it asks families to perform, are by no means constant. (The Columbia Encyclopedia, 2001).

This assortment of definitions illustrates the profound difficulty associated with defining the family concept across cultures, contexts and generations.

\subsubsection{Do we need a definition?}

Broadly speaking the concept of family encompasses a diverse blend of individual perspectives and experiences with cultural, social and historical components. The complex and inclusive nature of this concept gives some indication of how difficult definition consensus is. Settles (1987) suggested that scholars are unlikely to agree on the meaning of the family. Similarly, Trost (1999) proposed that scholars do not understand the concept of family, and are therefore unable to agree on a definition. In actual fact, the wide array of perspectives and contexts in which the term can be used ensures that general consensus is unachievable.

The family concept has been condemned as one of the most misused concepts of our time (Peters, 1999). In effect many of the definitions that have been proposed over the years have been flawed. Trost (1990) argued that anyone claiming to know what 'the family' is displays a severe lack of knowledge. Trost's statement can be explained by the fact that people hold a diverse range of perspectives relating to family; hence it would be overambitious for anyone to declare such a comprehensive understanding. The question 'what is family?' is obviously far more perplexing than was first understood. As Davidson (1991) fittingly remarked, questions we assess as simple to answer often end up being far more complex. 
For the purposes of empirical investigations, do we need a definition? It is likely that the task of producing an adequate definition of family will continue to evade even the most accomplished of scholars. The focus should, then, be on understanding people's perceptions of families, not on achieving definition consensus. As Peters (1999) recognised, researchers will use the term family to suit their purposes. Therefore the absence of a definition should not be seen as a barrier; "we can live (and do research) with this ambiguity." (p. 65).

The intention in this thesis is to avoid the temptation to adopt a definition. Any one definition would not encapsulate the wide array of meanings individuals associate with family. In effect the extensive range of public perceptions implies that 'the family' is fundamentally whatever an individual or a researcher interprets it to be.

\section{$1.2 \quad$ Families Today}

Marilyn Duckworth (New Zealand writer) 1935-

Extended families are becoming as exotic as passenger liners. The nuclear family survives only in fractionated bits. It is referred to by its dismembered parts, as if it exists. And it does, of course, in the collective unconscious. Family feeling, trust and loyalty - even love perhaps - are all running around in society like chickens with their heads cut off.

(Weir, 1998, p. 80).

\subsubsection{Families in $21^{\text {st }}$ century society}

This quotation by Marilyn Duckworth implies that the family is a waning, nigh on extinct phenomenon. The opposite of this view is that the family does exist, not in the exclusive nuclear family sense, but as an evolving phenomenon. In the late 1930s a world renowned anthropologist, Bronislaw Malinowski, professed that even though the family appeared to be in crisis, its state was not fatal and the family was here to stay (Keller, 1974). Similarly Moxnes (1999) acknowledged that a family does not cease to exist once it has undergone a transition; instead the face of the family changes. It is naive to 
perceive the family as a static universal structure; it has always undergone change and will continue to experience change. As Keller (1974) recognised, the family cannot be sheltered from the social changes that take place around it. It is fair to say that the family will continue to evolve as society continues to evolve.

In the 1970s Keller made a number of projections about the future of the family. In particular she predicted greater diversity in marital and sexual experiences and decreased levels of negative emotions associated with these relations. She also suggested there would be more personal freedom surrounding the type and duration of intimate relationships, as well as new forms of shared living arrangements where several people contribute to the upbringing and financial support of the children (Keller, 1974). Keller was accurate with her forecast for families in the future. Her predictions are apparent in the variety of relations and family structures that are in place today.

In a present day classroom it is possible to find children residing in original two-parent families, single parent families, stepfamilies, equal share families, extended families, foster families and families with same-sex parents - to name just a few. The $21^{\text {st }}$ century family is a multi-faceted structure. Pryor (2005) identified a number of features that are characteristic of today's families. The first feature is the tendency to delay family formation by marrying and having children later in the lifecycle. Associated with this is the increased likelihood that couples will live together and develop their relationship before entering into marriage or before having children, which is the opposite of the past practice of marrying and then developing the relationship. As Dharmalingam, Pool, Sceats and Mackay (2004) reported, cohabitation is replacing marriage as the preferred first union in today's society. There is also a tendency for couples to remain in de facto relationships and bear children without marrying. Rates of childbearing outside of marriage have risen, and almost all teenage mothers in New Zealand now give birth outside of marriage (Dharmalinghan et al., 2004). In regard to fathers, Pryor (2005) noted that there is a tendency for fathers to have both more and less 
involvement in their children's lives. To be exact, there are fathers who spend much more time with their children and take on more of a nurturing role than they did in past times, and there are also children who are raised without fathers.

Another feature mentioned by Pryor is that more time is spent in the workforce in $21^{\text {st }}$ century society, which has created more pressure and tension within families. There has been an obvious rise in women's workforce participation and a change in women's economic role in the family (Ministry of Social Development, 2004). It is now extremely common for both parents to be in paid employment. Connected to this is the increasing number of young women and men who spend a longer period in education. They enter the workforce later with higher levels of debt and a career path ahead of them, which may all be linked to the tendency to form families and have children later, or even remain childless.

Rising life expectancy has also played a significant role in families today. Since the 1930s life expectancy at birth has increased in all industrialised nations (Baker, 2001). There is also an increasing gap between the life expectancy of males and females, with females outliving males. When it comes to our ageing population, increasing numbers of those moving into the older age groups are divorced and have experienced changes to their family structure (Ministry of Social Development, 2004).

With regard to family diversity, Pryor (2005) noted that children today are raised by one, two or many parents. These parents may not necessarily be married, in an opposite sex relationship, or biologically related to the child/ren. Pryor also recognised that this increased diversity in families means that children may experience one or more transitions as their family structure undergoes change. Increased rates of separation and repartnering have fuelled the growth of sole-parent families and blended families (Dharmalingam et al., 2004). Furthermore equal share or joint custody families are more prevalent now than in the past. The increased diversity in families has also come about through migration and a wider range of cultures living in New 
Zealand. This has resulted in relationships and marriages of people with diverse cultural backgrounds, which in turn has led to children with multi ethnic backgrounds (Pryor, 2005 July).

A final point made by Pryor about families in $21^{\text {st }}$ century society is the difference in power that children have today, including legal and economic power and emotional and psychological power. Children have more rights than ever before, and this is not only reflected in the law but also in the family, where they have certain influence over their relationships and their experiences. As Smith and Taylor (2000) commented, the United Nations Convention on the Rights of the Child (UNCROC) has "....given prominence to the rights of children and their role as active participants in the construction of their daily lives." (p. 1).

It is apparent that a multitude of factors have played a part in shaping the family into its present configurations. One can only speculate on the formation of families in the future. But what we do know is that the family has changed and will continue to change, as it has thus far. Revisiting the quotation by Marilyn Duckworth, it is fair to say that interpreting the family as failing and on the verge of extinction is an extreme position. A more realistic assessment is that the family is very much alive and well in the twenty-first century, albeit different to and more diverse than the family of years gone by.

\subsubsection{New Zealand families}

Families today are clearly different to families in past centuries. In order to paint a picture of present day New Zealand families it is important to look at the way that family is generally defined in our society and culture. Every five years a Census of Population and Dwellings is carried out by Statistics New Zealand. The purpose of the census is to provide information on the number of people living in New Zealand, the number of dwellings, and associated information on the people that make up the country. Statistics New Zealand have avoided defining family and instead focus on the phrase "family nucleus", which they describe as a couple with or without child(ren), or one 
parent and their child(ren) usually living together in a household (Statistics New Zealand, 2008).

The census asks a limited number of questions relating to families, and as a result inadequately explores the variety of family groupings within New Zealand. In particular the census fails to adequately explore families that are increasingly more commonplace, such as step and blended families, shared care (joint custody) families and other scenarios involving more than one household. Such a simplistic analysis of family structures provides unrealistic data on the make up of New Zealand families in contemporary society, which is reflected in their rudimentary definition. Some amendments were made to the most recent census in 2006, including the addition of cohabiting (also referred to as de facto) same-sex partnerships and both opposite sex and same-sex civil union partnerships, which is attributable to the Civil Union Act 2004. However, the 2006 version still failed to examine families across households. It also asked about sons and daughters but failed to distinguish between biological sons/daughters and step sons/daughters. Future censuses that are cognisant of the dynamic nature of families would significantly improve our knowledge of families in New Zealand. Furthermore, if Government policies are to serve the interests of families in their diverse forms then the census must adequately measure them.

The population in New Zealand on census night in 2006 was just over four million (4,143,279 people). New Zealand has a diverse population. The largest ethnic group is European; 68 percent of the population identified themselves as European in the most recent census. Other ethnic groups made up 11 percent of the total population. The majority of the people in the 'other' ethnic group described themselves as a New Zealanders (99\%); other ethnicities made up the remainder of the group. Nine percent of people identified themselves as Asian and seven percent described themselves as 'Pacific peoples'. The second largest ethnic group was Māori, which made up 15 percent of the population on census night (Statistics New Zealand, 2008). It is important to note that Census 2006 was not priority coded. The ethnicity 
total is more than 100 percent because all ethnic groups that the respondents identified with were counted.

Māori are the indigenous people of New Zealand who are often referred to as the tangata whenua (people of the land). The official language of New Zealand is the Mãori language, although in the 2006 census only one in four Māori spoke the language (Statistics New Zealand, 2008). The Māori word whānau is regularly referred to in New Zealand society. The modern meaning of whānau is family. In comparison whānau, in its traditional form, is the basic unit of Māori society and is defined as an extended family group. The extended family tends to span three to four generations and is headed by male and female elders that have immense mana (status) for their wisdom and for their nurturing of the children (Te Ara: The Encyclopaedia of New Zealand, 2006). The Māori word whānau has regularly been adapted and extended over the years and has subsequently evolved into a broad concept with multiple meanings (Metge, 1995). A number of Māori words are commonly used in New Zealand 'English'. The term whānau is one of those frequently used by both Māori and European New Zealanders. Despite the specific definition attached to the word whānau it tends to be utilised in a similar fashion to the word family. Both terms are wide ranging and equivocal by nature. They are used by different people in different contexts in accordance with their individual interpretation.

It is obviously challenging to define New Zealand family, given the diversity of family forms that exist. It is possible though to paint a picture of families in New Zealand by outlining the rates of marriage, cohabitation and divorce, the number of children in families and the type of households. As mentioned earlier, it is important to be aware that the following statistics may not provide an entirely accurate portrait of New Zealand families due to the lack of indepth census questions relating to changing family forms. Therefore, in addition to the census information data from the 1995 Survey of New Zealand Women: Family, Education and Employment will also be utilised. It is 
important to note that for the 1995 Survey of New Zealand Women there is no comparable survey data on New Zealand men.

The number of marriages in New Zealand over the past decade has been relatively stable, although the marriage rate has declined from 15.7 per 1,000 of the population (not-married and over 16 years of age) in 1997 to 13.6 per 1,000 in 2007. Couples today are marrying later, with the mean age of first marriage rising from 21 for females and 23 for males in the early 1970 s, to 28 for females and 30 for males in 2007. Similarly the age of first time mothers has gradually increased over the years. Women now have children approximately five years later than their counterparts in the mid-1960s. The probability of being a first time mother from the age of 30 has increased; the median age of New Zealand women giving birth is 30 years. The birth rate was 2.2 per woman in 2007, up from 2.0 in 2006 (Statistics New Zealand, 2008).

In terms of de facto relationships, at least four in 20 partnered men and women aged 15 years and over were not legally married in 2006. Nine out of 10 partnered women aged between 15 and 19 years were living in a de facto union on the evening of the census. Thus a number of children are raised by couples in de facto relationships. In 2006 the percentage of children born to parents outside of marriage was 47 percent, compared to just eight percent in 1962 (Statistics New Zealand, 2008).

In the 2001 census there were 1,356 same-sex couple with children families, 960 of which were female couples and 396 male couples (Statistics New Zealand, 2002b). Recently in New Zealand legislation has been enacted to allow de facto couples in heterosexual and homosexual relationships the right to have their partnerships legally recognised through civil union. There were 316 resident civil unions registered in 2007 of which 80 percent were samesex unions (Statistics New Zealand, 2008). 
New Zealanders were identified as belonging to three family types in the 2006 census: couple with children families, couple without children families and one parent with children families. A couple with children made up 42 percent of families, couple only families made up 40 percent and 18 percent were one parent with children families (Statistics New Zealand, 2008). From 1991 to 2001 couple with children families decreased from 48 percent to 42 percent, whereas couple only families increased from 35 percent to 39 percent. Oneparent families showed a small increase from 17 percent to 19 percent in the ten years to the 2001 census (Statistics New Zealand, 2002b). The number of one-parent families is, however, projected to increase by 28 percent between 2001 and 2021. Couple without children families are the fastest growing type of family household and are forecast to easily outnumber two-parent families by 2021 . More specifically, couples living together without children are projected to make up 48 percent of all families, compared to the 33 percent of two-parent families (Statistics New Zealand, 2005).

The number of divorces in New Zealand increased sharply in 1981 after the family proceedings Act was passed. The Act enabled couples to dissolve their marriage by citing irreconcilable differences. Today, one in three marriages end in divorce and approximately half of these involve young people. In 2007 there were 11.3 divorces for every 1,000 estimated existing marriages. New Zealand's divorce rate is similar to Australia (12.0 for women and 12.2 for men in 2006) and with England and Wales (12.2 in 2006). A quarter of all divorces in 2007 were couples that had been married for between five and nine years, 18 percent were married for 10 to 14 years and 15 percent for 15 to 19 years. Less than half of all marriages that were dissolved involved couples with children under the age of 17 years. In 1997 the proportion of divorces involving children was 48 percent; ten years later this figure had fallen to 45 percent. In 2007 there was an average of 1.8 children per divorce (Statistics New Zealand, 2008).

There has been an increase in the proportion of one-parent families over time, as mentioned above, but there has also been a change in the number of fathers who are sole parents. In the 1995 Survey of New Zealand Women 
approximately half of the children from separated families lived with their mother in a sole-parent arrangement and half lived with their mother in a stepfamily (Ministry of Social Development, 2004). Thus, none of the children's fathers were their primary caregivers. In contrast, 17 percent of the parents in one-parent families were fathers in 2001 and 82 percent were mothers (Statistics New Zealand, 2002b).

Just over one in three marriages in New Zealand are remarriages for one or both partners. Between 1995 and 2005 remarriages made up 36 percent of all marriages. Thus, the number of remarriages has remained relatively stable over the past decade. In 1971 the percentage of people that had remarried was 67 percent, compared to 2007 where 90 percent of those remarrying were divorced (Statistics New Zealand, 2008). Hence, step and blended families have become more prevalent as increasing numbers of couples divorce and re-partner. The 1995 Survey of New Zealand Women found that one-fifth of all women with children had been part of a stepfamily. The survey also showed that of the children living with their mother in a one-parent family, 40 percent experienced the re-partnering of their mother within five years of the separation (Ministry of Social Development, 2004). Given the absence of official step and blended family data in New Zealand it is difficult to provide a detailed account of these family structures.

As the statistics show, family life in New Zealand is changing, as it is in many countries across the globe. Couples are entering into marriage and having children later in life. It is more common for couples to cohabit before marriage or to live in a de facto partnership. The number of children born to unmarried couples has increased. Couple without children families have increased and there is more diversity in family structures. The incidence of separation, repartnering and remarriage indicates that a number of young people are experiencing one or more family transitions in their early or adolescent years. This in turn provides further momentum for the analysis of their perspectives in relation to families and family change. 


\subsection{Family Law Legislation}

We can debate the merits of diverse families for as long as we like, but it is utterly and completely meaningless when we pretend that it would be all right to exclude family relationships that exist in fact, but that some people would prefer did not. (Hon Lianne Dalziel, First Reading of the Care of Children Bill, 23 June 2004, p. 6539)

\subsubsection{Defining the family in legislation}

As discussed, trying to define the family is an exercise fraught with difficulty. Understandably Parliament has been reluctant to pass laws that specifically define 'family'. A survey of New Zealand's statute book since the mid- $19^{\text {th }}$ Century found only nine instances in which family had been defined (Henaghan, 2002). Attempts to define family in traditional nuclear family terms inevitably meant difficult decisions as to the limits of its membership. For example, should 'family' include children who are biologically or legally related to only one parent rather than both? Would it include a long-term de facto partner, grandparents, aunts and uncles? By defining family on the basis of the nuclear family model, law-makers risked excluding persons who in practice made up a family, thereby undermining the purpose of the Act in question. This explains the traditional reluctance on the part of Parliament to define family.

The Children, Young Persons, and Their Families Act 1989 was significant in that the Act effectively adopted a wide definition of family, although it did so under the guise of the 'family group'. Under section 3 of the Act a family group includes extended family consisting of at least one adult with a biological, legal, or significant psychological relationship with the child or young person, or the child or young person's whānau or other culturally recognised group. This approach avoids having to define the family, while ensuring that decisions about care and protection can be made with the assistance of those people who in practice make up a child or young person's family. The Care of 
Children Act 2004 also uses the family group concept, although the Act does not actually define the term.

In 2004 the Families Commission was established to give a voice to New Zealand families and to promote family related issues to government and the wider community. The Commission's objectives include promoting awareness and understanding of issues that face families today, carrying out family related research, and assisting with new policies that are supportive of families (Families Commission, 2005). Interestingly, when it comes to the concept of family the Commission has resisted the adoption of a definition. Criticism could be levelled at its decision to refrain from defining the concept that is the key focus of the organisation. One could, for example, question the Commission's ability to research and inform if its core concept remains loosely defined. Such criticism, however, is unwarranted. The Commission prefers to define the functions of family groups rather than the concept itself. It is judicious to take an open view of a phenomenon that is by nature wideranging and ever-changing.

Indeed this is the approach taken in the Families Commission Act 2003. The Act defines a family to be "... a group of people related by marriage, civil union, blood, or adoption, an extended family, two or more persons living together as a family, and a whānau or other culturally recognised family group." (section 10(2)). At the time the Act was passed this definition was criticised as being too wide and overly inclusive (English, 2003). However, any definition founded on the nuclear family model would have seriously undermined the value of the Commission's work. In this instance, Parliament decided that if 'family' was defined, it had to be done in a way that took account of the complex, varied and fluid nature of families in contemporary society.

\subsubsection{Family Diversity in Legislation}

The increased diversity of family structures has been reflected in changes to family related laws in recent years. In 2001, the Matrimonial Property Act 1976 was substantially revised and renamed as the Property (Relationships) 
Act 1976. The new Act extended the presumption of equal sharing of property upon the break-up of a relationship from married couples to de facto couples (opposite or same-sex) living together for three or more years. Likewise, all de facto couples became liable for maintenance obligations. Previously liability only existed if an applicant for maintenance had custody of a child from the relationship. The Relationships (Statutory References) Act 2005 amended a raft of existing legislation so that the rights and obligations contained in the affected Acts were broadened to cover de facto couples and civil union partners (Atkin et al., 2007). Collectively these law changes amounted to recognition by Parliament of the increasing number of couples who are not married and whose legal interests need to be protected to the same extent as couples who are.

In 2004, Parliament passed the Civil Union Act. It provides opposite and same-sex couples the option of entering into a civil union. As in a number of other countries that have legislated to create civil unions, the Act was controversial. Critics claimed that civil unions would undermine the institution of marriage purportedly by legalising "gay marriage" (Smith, 2004). However, as Atkin et al. (2007) make clear, same-sex marriage remains impossible under the law. Civil Unions provide a legal alternative to marriage. By providing this alternative, Parliament remedied an inequality in the law that had denied same-sex couples the opportunity to have their relationship legally recognised.

Increasing family diversity was also recognised in the Care of Children Act 2004. The Act replaced the Guardianship Act 1968. As the explanatory note to the Care of Children Bill 2003 openly acknowledged, the 1968 Act was based on the nuclear family model. Three points in particular are worth noting. Firstly, section 23 of the Act allows an eligible spouse or partner of a child's parent to be added as a guardian. This reflects the blended nature of many families in which a spouse or partner assumes responsibility for the day-today care of a child with whom they previously had no legal or biological relationship. Secondly, parenting orders made by the Family Court set out who is responsible for the day-to-day care of a child, as well as establishing 
such matters as who can have contact with the child. Under section 47(1) of the Act, a wide group of persons can apply to the court for a parenting order, including the spouse or partner of a parent, as well as any other person who is a member of the child's family, whānau, or other culturally recognised family group. Third, the welfare and best interests of the child are to underpin decisions made under the Act.

Importantly, in making those decisions, section 6 of the Act requires the Family Court to take into account the views expressed by the child who is the subject of the proceedings (Ludbrook \& de Jong, 2005). This is consistent with the United Nations Convention on the Rights of the Child (UNCROC). Ratified by New Zealand in 1993, article 12 of the Convention gives children the right to freely express their views about matters affecting them, and for those views to be given due weight (Jamison \& Gilbert, 2000). Both the Care of Children Act 2004 and UNCROC underscore the importance of this research which seeks to understand children's views of what family means to them, and to gain insight into their perception and experiences of parental separation. 


\section{Chapter Two \\ Perceptions of Families}

\subsection{Young People's Perceptions of Families: The Research to Date}

A family is made up of some relatives. They can get through hard times together and happy times, and manage to live with each other... People who love each other, so you will be cared for and helped. The human race would stop without families.

- Ten year old child (Fu, Goodwin, Sporakowki \& Hinkle, 1986, p. 163)

\subsubsection{The family concept: Groupings of people}

What kind of relationships do young people endorse as constituting families? In order to achieve a more in-depth understanding of the family concept it is important to ask children whether certain groupings of people represent a family. Research in this area has fallen into specific categories. Firstly, many investigations have focused on one factor of interest, primarily the developmental changes in children's understanding of families. Other studies have concentrated on two factors, by examining developmental influence alongside family structure differences, or by focusing on developmental influence alongside cultural diversity. In turn this has led to more interest in simultaneously examining all three of these factors; developmental influence, family structure difference, and cultural diversity.

The studies mentioned here have investigated young people's perceptions of family in a variety of ways. Of particular interest are their findings in relation to the family groupings and roles that young people interpret as constituting family. In the following section titled 'The Family Concept: Definitions' the studies will be discussed further in relation to their findings regarding young people's definitions of family.

Developmental differences. The role of developmental influences has often been examined in relation to young people's perceptions of family (Gilby \& 
Pederson, 1982; Watson \& Amgott-Kwan, 1984; Fu, Goodwin, Sporakowki \& Hinkle, 1986). Many researchers have also explored developmental stages alongside one or more other factors that are potentially impacting on young people's views of family, including gender, family structure or culture (Powell, Wiltcher, Wedemeyer \& Claypool, 1981; Wedemeyer, Bickhard \& Cooper, 1989; Borduin, Mann, Cone \& Borduin, 1990; Newman, Roberts, \& Syre, 1993; O’Brien, Alldred \& Jones, 1996; Brannen, Heptinstall \& Bhopal, 1999; Morrow, 1998; Diez-Martinez Day \& Remigy, 1999; Anyan \& Pryor, 2002). A number of researchers who have adopted a developmental approach have reported findings that support Piaget's framework that cognitive development influences children's understanding of family (Piaget, 1928). Piaget's research in relation to children's definitions of family is reported in section 2.1.2.

In the early 1980s, Gilby and Pederson (1982) explored the scenarios young people considered to be families by constructing vignettes depicting various groupings of people. They focused on four age groups. Three of the groups were interviewed and ranged in age from approximately five to nine years old. The fourth group was made up of university students. The child participants created a family from 18 cardboard figures, while the young adult sample constructed a family via questionnaire. The aim of the task was to establish who the children and young adults defined as 'typical' members of a family and whether the constructed group mirrored their own family composition. Gilby and Pederson found that the young people's constructions tended to mirror the traditional 'nuclear' family image; 64 percent of the participants included two parents and their children, while a further 26 percent included grandparents. Very few participants (10\%) constructed a family which strictly mirrored their own family grouping. The authors found that the young child's concept of family revolved around cohabitation and contact, whereas biological and legal factors took precedence in the descriptions of older participants.

Gilby and Pederson's (1982) findings show that the participants constructed family forms that resembled the original two parents with children family form. 
Clearly the participants' responses did not deviate far from the traditional family image or the extended family form. Considering that the research was undertaken 20 years ago it is possible to conclude that their findings were relative to the time. However, a questionable aspect of Gilby and Pederson's study was the use of the word 'typical'. Part B of their family concept interview and questionnaire asked the participants to construct a typical family from the 18 figures presented. By specifying that the family should be a typical representation the researchers were essentially informing their participants to construct a 'normal' family structure instead of a grouping that represented their personal perceptions. In retrospect the researchers could have asked the children who they think the members of a family are, with the aim of eliciting a verbal response on its own or a verbal response combined with the cardboard cut-out display. This form of questioning may have allowed for a more open and balanced expression of family composition.

Some developmental differences were also found by Fu et al. (1986) when they investigated children's perceptions regarding family membership. Their sample consisted of three age groups of middle class children (four, six and 10 years of age). One aspect of Fu et al.'s study involved the children being asked whether particular groupings of people constituted a family, for example, "Here is a father and his children. Is this a family? Why? Why not?" The questions were asked in conjunction with cut-out figures that depicted each scenario. The older children were more likely to recognise numerous functions of families and the various roles of parents, than their younger counterparts. However, Fu et al., also found that when it came to the children's perceptions about whether or not the scenarios represented a family, there were many similarities across the age groups. Unfortunately only four configurations of family groupings were presented to the children: a father and mother with children scenario; a mother with children; a father with children; and a husband and wife scenario. As a result Fu et al. were unable to provide insight into the variety of other family groupings present in society at that time. 
In a more recent investigation Morrow (1998) focused on how 'contemporary children' make sense of family in contemporary society. The children that participated in her study were between eight and 14 years of age, from a variety of socio-economic backgrounds. Morrow found that younger children were more likely to see children, marriage and contact as crucial components of family, compared with their older counterparts who tended to focus on the nature or quality of relationships. Research findings in this area have clearly supported the influence of cognitive maturity on classifications of families, but it is also essential to investigate whether other variables are influencing young people's perceptions.

Family structure differences. Family structure is one such variable, reflecting the possibility that a child's personal experience of family life forms the basis of his or her perceptions. Findings have been mixed when it comes to the impact of family background. Funder (1996) focused on children and adolescents that had experienced parental separation. She investigated their perceptions of family membership by using the family sculpture technique. The technique involved wooden figures that the children used to represent family members and a checkerboard to represent family membership and closeness. Funder found that 19 percent of the young people from separated families still considered their family to include the same members as before the separation, more specifically these members were the original family members and biological relations. Many of the participants included their original family members and biological kin as well as their new family members - their stepfamily (41\%). Original family members and stepfamily members (resident and non-resident) were included as family by 16 percent of participants. Just under a quarter of participants included a wide range of individuals in their family grouping.

It is important to note that Funder (1996) examined young people's perceptions of their own family membership after separation; she did not explore young people's perceptions of family membership in general postseparation. Clearly these young people's responses revolved around their own circumstances and experiences of family, as opposed to exploring their 
hypothetical views regarding family membership. In summary, Funder reported that some of the children in her study who had experienced parental separation referred to only select groupings as families, while others from similar backgrounds included a wide array of scenarios.

The complexity of the family grouping was also mirrored in O'Brien et al.'s (1996) study. They examined the perceptions of family of children and adolescents from original two parent households and separated families. In contrast to Funder, they used vignettes instead of personal circumstances to gain insight into the participants' perceptions of family membership. O'Brien et al., (1996) found that young people from separated families were less likely to include non-resident fathers and children as members of families compared with those from original two parent households. In contrast, other studies have recognised that there are no great variations in perceptions of families across children who have experienced separation and children who have not (Powell et al., 1981; Wedemeyer et al., 1989; Borduin et al., 1990; Horm-Wingerd, Groves \& Nekovei, 1992; Newman et al., 1993). More recent research by Brannen et al. (2000) has suggested that children who have experienced parental separation are more open-minded when deciding whether particular groupings constitute families. Overall, there seems to be little agreement amongst studies so far.

Cultural differences. How much of an impact does cultural context have on young people's understandings of family? Few researchers have examined the impact of cultural context. However, Diez-Martinez Day and Remigy (1999) have made some progress by focusing on children from different ethnic backgrounds living in separate countries. The children were between five and 11 years of age and the interview questions included vignettes. After comparing Mexican and French children's conceptions of families they dismissed the view that children's perceptions are primarily dependent on cognitive development. When endorsing families the Mexican children referred to biological ties, whereas the French children were more likely to cite affective connections. Diez-Martinez Day and Remigy also found that the younger children's classifications of families were more concrete than the 
older participants. They therefore concluded that children's understandings of family are as influenced by social and cultural factors as they are by cognitive maturity.

Morrow (1998) also focused on cultural variations, but compared children of different ethnic backgrounds living in the same country. The participants were of Pakistani or British Muslim descent and resided in either a town or village in the United Kingdom. Morrow found that the Pakistani children's perceptions were more likely to be influenced by their religious and cultural beliefs. However, she concluded that there were more similarities in the children's perceptions of families across cultural groups than there were differences.

Developmental, family structure and cultural influences. It is difficult to find research that has investigated all three factors in relation to young people's perspectives on families. Most of the research in this field has clearly centred its focus on children. While some have delved into the area of comparing the family concepts of adolescents and children, they have tended to ignore family make up and cultural context. However, a New Zealand study undertaken by Anyan and Pryor (2002) investigated family structure and cultural variations amongst an adolescent sample. They used vignettes to examine how 16 to 20 years olds conceptualise families. Few differences were found across adolescents in various family structures, but several differences were noted when it came to comparisons across cultural groups. In particular Māori New Zealand adolescents were more likely to interpret the groupings as family, whereas the Chinese participants endorsed the scenarios at significantly lower levels. Later, in chapter seven, the perceptions of Anyan \& Pryor's adolescent sample will be examined more in-depth and will be compared to the children in this study. Thus, not only will family structure and cultural influences be explored in this thesis but developmental comparisons will be carried out.

\subsubsection{The family concept: Definitions}

Understanding how children define the concept of family is as important as understanding which relationships children endorse. When children describe 
the concept of family which criteria do they refer to in their descriptions? Two forms of questioning have generally been used in order to answer this question. Some researchers have simply asked "what is a family?", while others have invited the children to construct a family. Both methods achieve definitions; the first by gaining a description of the characteristics they associate with family, and the second by focusing on the members identified as part of a family structure.

Piaget (1928) was one of the first researchers to ask young people to define the concept of family. His investigation led to the conclusion that children's definitions undergo distinct developmental change. Cohabitation was found to be predominantly mentioned in the preoperational stage (7-8 years old), while the biological connections of those cohabiting were referred to in the concrete operational stage (9-10 years old). By the formal operational phase (11-12 years old) the older children had broader definitions that included all biological relations irrespective of cohabiting status.

Fu et al., (1986) focused on developmental factors and gender in their investigation of children's interpretations of family. One component of their research was to enquire, "What do you think a family is?" The characteristics most commonly mentioned by the male and female subjects across all three age groups were nurturance/socialisation and cohabitation. Of note, over half of the children in the oldest group endorsed affective factors in their definitions of family; however cohabitation, nurturance/socialisation, and family as a 'group of people' were also common references.

The children in Piaget's (1928) study that were approximately 9 to 11 years of age were more likely to refer to biological relationships in their definitions of family. In comparison it appears that very few of Fu et al.'s (1986) sample mentioned biological factors in their definitions. A criterion referred to as biological/sexual factors had been included by the researchers but there was no indication that any responses to that effect had been made. Therefore the children in their sample appear to have placed less emphasis on biological factors when defining the family. This was similarly the case when Horm- 
Wingerd et al.'s (1992) investigated the family definitions of middle class children.

Fu et al.'s (1986) interview questions were adopted and adapted in HormWingerd et al.'s (1992) investigation into children's concepts of family. Their sample consisted of children between five and 11 years of age, although the researchers did not examine age differences. In a variation of Fu et al.'s (1986) study, Horm-Wingerd et al. (1992) investigated the meaning of family for children with intact families and children with divorced parents. It appears that no consideration was given to the family structures formed as a consequence of parental separation or divorce. Similarly, the intact family participants were lumped together as one homogeneous group solely on the basis of their current family structure. Future research would benefit from more in-depth family structure breakdowns and profiles (Anyan, 1998). In fact, future investigations should record all family transitional experiences and related participant information in order to achieve a clearer outline of participants, and to assess whether these factors have an impact on the young person's cognisance of family.

The criteria most often alluded to in Horm-Wingerd et al.'s (1992) family definition question (nurturance/socialisation, affective factors and cohabitation) are similar to Fu et al.'s (1986) findings. Also of note was the absence of any references to biological factors in the children's definitions, and the absence of gender differences, also similar to the findings of Fu et al. Overall the family definition question elicited similar responses from the children irrespective of gender and family structure, although Horm-Wingerd et al. (1992) found one significant difference between the definitions given by the intact and divorced family samples; participants from intact two-parent families referred to the presence of children more often in their definitions of family. The authors suggested that the absence or presence of children may be a prominent feature for intact family participants, but in comparison participants with divorced parents may place more emphasis on two adults being present. This is an acceptable argument when considering the results in their entirety. However, when focusing solely on the family definitions it is 
clear that the intact family participants not only mention the presence of children more often than the divorced parent sample, but they also mention the presence of two adults more frequently. None of the children in the divorced parent sample referred to the presence of children or the presence of adults in their descriptions of family.

In their examination of children's perspectives Watson and Amgott-Kwan (1984) and Newman et al. (1993) employed open-ended stories where information on how to identify families was requested. In both studies the open-ended story involved an earth bound alien (or foreigner) that needed information on how to identify families. The function of this scenario was to elicit open definitions of family (Watson \& Amgott-Kwan, 1984). A strategy of this nature possibly appeals to younger children as it has the potential to grab their attention and stimulate their thought processes. A major difference between these two studies is that Watson and Amgott-Kwan's general focus was on children's development of family role concepts, compared to Newman et al. who centred their research on children and young adults' perceptions of the family concept.

Watson and Amgott-Kwan's (1984) sample consisted of children aged between six and 12 years of age, whereas Newman et al.'s (1993) sample was made up of four year olds through to university aged students. Watson and Amgott-Kwan focused on age and cognitive factors, whereas Newman et al. broadened their focus to include gender and family structure components. Watson and Amgott-Kwan (1984) found that most of the children mentioned specific individuals and referred to family roles and functions in their openended definitions. However, the children that scored higher in terms of their cognitive skills were found to define family by role relations and functions using more abstract terminology. The younger participants were clearly more concrete in their interpretation of family.

Similarly Newman et al. (1993) found that children aged between 10 and 12 were more likely to refer to family roles compared to their younger and older counterparts. Participants aged between 13 and 15 and the university 
students were more likely to mention biological relationships in their definitions. Older participants and those with a higher cognitive level were found to mention affective factors more frequently than the other age groups. Overall, affective factors was the most frequently mentioned criterion in the definitions of more than half of the child and young adult participants. The second most commonly referred to criterion was cohabitation, followed by family roles and biological connections. In terms of gender differences there were very few; however the females were more likely to mention shared activities, and family roles. In comparing participants from intact families and those who had experienced parental separation or divorce, it was clear that those from intact two-parent families were more likely to mention affective factors in their definitions. This is in contrast to Horm-Wingerd et al.'s (1992) finding that intact family participants were more likely to mention the presence of children in their definitions. Nevertheless sample variations may account for any differences in findings, as Newman et al.'s (1993) study comprised much older participants.

The majority of the children and young adults in Newman et al.'s (1993) sample were Caucasians living in intact families; only 21 percent of the sample was from a background of separated/divorced parents. Criticism could be levelled at Newman et al.'s classification of subjects as original two-parent family participants or as separated/divorced family participants. No other family structure information and analyses were provided, as was the case in Horm-Wingerd et al.'s (1992) study. Identifying that an individual is from a separated/divorced family does not provide adequate details about their current family structure. Family research would benefit from larger samples of participants from family structures other than intact two-parent families, as well as from various ethnic groups.

More recently Morrow (1998) asked children between eight and 14 years of age "what is a family?" and "what are families for?" The primary focus was to investigate the children's family related ideas, interpretations and language. Morrow deliberately avoided any communication relating to the children's own experiences of 'family'. This is important in the context of hypothetical family 
based interviews or questionnaires, as the participants answer questions that relate to 'family' in general, not 'family' on a personal level. For this reason discussing personal circumstances could cloud the children's perspectives. However, the researcher's decision not to enquire about the family backgrounds of the children is a limiting factor. By establishing which family structures the participants are living in at the time of the study, it is possible to compare the children's responses in terms of their current family circumstances. Being aware of any family transitions the participants may have experienced is equally important. Again comparisons can be made between those who have experienced family structure changes and those who have not. To avoid delving into the children's personal circumstances Morrow could have gathered this information from parents/caregivers by using a demographic information form. Language and cultural factors may have presented a barrier but ideally the forms would be tailored for the target ethnic groups.

In contrast to Piaget (1928), Morrow (1998) found that the children's definitions referred to an extensive range of people, and did not reflect biological relatedness or the traditional 'nuclear' family form. This is a finding that is becoming increasingly prevalent in recent research (Anyan \& Pryor, 2002; Brannen et al., 2000; Smart, Neale \& Wade, 2001). Morrow also established that irrespective of gender, age and ethnicity the children were inclined to use affective descriptions of family. Similarly, Anyan and Pryor (2002) found that 80 percent of their adolescent sample referred to affective factors, while less than half mentioned biological factors, cohabitation or legal factors. Clearly facets of love, care, respect, support and nurturing were being acknowledged as essential features of families, more so than standard structural aspects.

Morrow (1998) did, however, find some developmental differences in her participants' responses, reporting that the older the child the greater the complexity of their definitions. Other studies have also supported the more concrete nature of the younger child's definition versus the abstract 
constructions of the adolescent (Newman et al., 1993; Watson \& AmgottKwan, 1984).

In summary, the studies discussed here have spanned a period of almost 80 years. In this time the staunchly 'nuclear' definitions of family have evolved into more inclusive and realistic descriptions, and family structures have become more diverse. The methodology of Study One in this thesis is similar to Anyan and Pryor's (2002) research, where adolescents' perspectives surrounding the concept of family were examined, as were the kinds of relationships they endorsed as family. Instead of focusing on adolescents' perceptions, Study One aims to investigate children's views and compare perceptions across family structures and cultural groups. 


\section{Chapter Three \\ Experiences of Family Structure Change}

\subsection{Young People's Experiences of Parental Separation: The Research to Date}

“...I don't like it when my parents say mean things about each other. Mostly they are fighters using me as their gun. Sometimes they are friends.

But I know it's not for too long. I don't believe it when

they tell me everything will be O.K.".

(Spann, 1998, p. 11)

\subsubsection{Considering children's experiences}

Social agency. This research is premised on the notion that young people are competent social agents with the ability to reflect on and influence their experiences. This approach is consistent with a shift in thinking that advocates that young people whose parents separate are not passive victims who must be sheltered from the separation (Smart, Wade \& Neale, 1999; Smart \& Neale, 2000; Sviggum, 2000; Butler, Scanlan, Robinson, Douglas \& Murch, 2002; Smith, Taylor \& Tapp 2003). Instead, most young people can digest information, make critical judgements based on what they see and what they are told, and can attempt to modify their own behaviour and the behaviour of others around them (Wade \& Smart, 2002).

Young people are best thought of as active participants in the separation process. The more recent research in the children and separation field demonstrates this quite clearly. More specifically many of the studies show young people reacting to parental separation, reflecting on it, seeking information, and influencing thinking and behaviour, in much the same way as an adult might but at their own developmental stage. Before young people's views and experiences of parental separation are conveyed, the reasons why it is important to listen to children's perspectives are identified. 
Listening to children. As rates of divorce have increased across Western countries in recent decades, researchers have focused on the impact of family change on young people. However within this body of work comparatively little attention has been given to the views and experiences of the very subject that concerns them (Highet \& Jamieson, 2005). Of the research that does consider young people's separation experiences much of it is based on adults' estimations of children's experiences, rather than coming from young people themselves (Dunn, 2004; O'Connor, 2004). Both approaches are problematic because they provide an incomplete picture. Young people's own experiences offer valuable insights into the way in which they cope with separation. Their perceptions of the separation process may also influence the effect separation has on them (Kurdek \& Siesky, 1980; Kalter \& Plunkett, 1984). It is crucial therefore that young people's views of family transitions are heard directly, rather than being constructed from the accounts of others, or worse, ignored altogether.

In addition, society is increasingly recognising the right of young people to express their views on issues that affect them. This right is guaranteed to children from signatory states under the United Nations Convention on the Rights of the Child (Article 12). In New Zealand, this principle now carries over into a number of domestic laws and family court processes (Smith et al., 2003). Hence it is imperative that researchers consider the separation experiences of young people from the point of view of young people themselves. Their views are no less important than others involved in the process. It cannot be assumed however that all young people want to discuss their experiences of separation. Reluctance to do so may be based on the preferences of the individual, or on other factors such as cultural norms. For example, Morrow (1998) found that children of Pakistani origin were less inclined than children of other ethnicities to adhere to the idea that young people have a legal right to express their views in relation to family decisionmaking.

Finally, no two separations are the same. The circumstances of each separation will differ depending on a variety of factors, including the reasons 
for it, the manner in which the separation is handled, and the personalities and coping abilities of those involved. The nature of the separation process may also depend on socio-economic realities and religious and ethnic factors (Wade \& Smart, 2002). Given these variables, it is to be expected that young people who experience parental separation will have different feelings, views and opinions on the process. The only way researchers can properly identify these differences is to directly ask young people themselves.

\subsubsection{Young people's experiences and views}

Reactions and feelings. Parental separation can be traumatic for young people. Feelings of shock, anger, sadness, and confusion are common (Walczak \& Burns, 1984; Neugebauer, 1989; Amato, 1987; Smith et al., 1997; Pritchard, 1998; Burns \& Dunlop, 1999; Butler et al., 2002). Feelings of loneliness may be heightened if a young person has deliberately chosen not to take sides when parents are involved in a hostile separation (Wallerstein \& Kelly, 1980; Butler et al., 2002).

Reactions are not always negative. Young people may view a separation as a release, particularly if it brings to an end verbal, emotional or physical conflict between parents (Amato, 1987; Pritchard, 1998). In Hogan, Halpenny and Greene's (2002) study, 43 percent of participants reported feelings of relief when their parents separated, on account of the conflict between parents prior to the separation and because the decision to separate alleviated some of the pressure and uncertainty pertaining to their parents' relationship.

Young people's emotional reactions to parental separation can stabilise over time (Pryor \& Rodgers, 2001). As the separation becomes more of a historical chapter in their lives rather than a current event, perceptions can change and views tend to be characterised less by negative, acute emotions. Amato (1987) found that 44 percent of younger children and 43 percent of older children reported a negative response when asked how they felt at the time their father left. When asked how they felt now about their father leaving, negative responses decreased to 27 percent for the younger children and 12 
percent for the older children. Neutral or positive responses increased from 11 percent to 69 percent for the younger children and from 27 percent to 93 percent for the older children.

Comparable results were found by Burns and Dunlop (1999) in their longitudinal study. They recorded the feelings of young people at the time of their parents' divorce (Time 1), three years later (Time 2), and 10 years later (Time 3). The authors found that on average feelings of sadness, disbelief and shock had declined by Time 3 . They concluded that for most participants the shock and upset associated with parental separation had a limited life span. Feelings of relief increased sharply between Time 1 and Time 2, and then decreased slightly between Time 2 and Time 3, while feelings of gladness increased at both Time 2 and Time 3. It was more common for young people to be angry at one parent rather than both parents and for this anger to still be present at Time 3. In their study, Wallerstein and Kelly (1980) noted that older children often sided with the parent of the same-sex. This was often the case with older boys, especially if they felt their father had been unfairly asked to leave the home.

As discussed below, a reduction or loss of contact with a non-resident parent is frequently cited by young people as one of the major downsides to parental separation (Kurdek \& Siesky, 1980). It can also mean missing family outings and holidays (Fleming, 1999), and losing contact with extended family and friends (Highet \& Jamieson, 2005). Other perceived negatives include being in a worse financial situation than before the separation (Gollop, Taylor \& Smith, 2000), moving to a smaller house (Hogan et al., 2002), a negative impact on schooling (Gorell Barnes, Thompson, Daniel \& Burchardt, 1998), and increased domestic responsibilities (Keep \& Pegram, 1998). The major benefit of parental separation can be a reduction in conflict by virtue of parents living apart (Kurdek \& Siesky, 1980), although post-separation conflict remains a reality for many young people (Highet \& Jamieson, 2005). Other benefits can include increased personal freedoms (Kurdek \& Siesky, 1980; Gollop et al., 2000), greater personal maturity (Walczak \& Burns, 1984), and better timemanagement skills as young people learn to juggle commitments between 
different households (Butler et al., 2002).

The majority of young people in Plunkett and Kalter's (1984) study expressed a desire for their parents to resume their relationship (95\%). Smith et al. (1997) noted that of the two thirds of children in their study who wanted their parents to get back together, most were 10 years of age or younger. Despite this, most young people are realistic enough to consider it unlikely. This was the case with 92 percent of participants in Kurdek and Siesky's (1980) study who believed that their parents would not live together again. Over two-thirds of participants thought the same in Hogan et al.'s (2002) study.

Care and support. Pryor and Rodgers (2001) suggest that children want to be able to talk to their parents about aspects of the separation process as it happens. Yet parents' availability to act in a supporting capacity can be diminished during this time. Parents that are trying to cope with their own emotional problems may find it difficult focusing on the emotional needs of their children (Pryor, 1999). New or increased work commitments to cope with changed financial circumstances may also mean less time is available to spend with children (Wallerstein \& Kelly, 1980). In Dunn and DeaterDeckard's (2001) research mothers ranked third behind extended family and friends as intimate confidants in the first few weeks following the separation. Fathers were rarely confided in at an intimate level. As a number of researchers have found, young people who find their parents emotionally unavailable to them may end up dealing with the process alone (Mitchell, 1985; Neugebauer, 1989; Gollop et al., 2000).

The evidence regarding the extent to which young people find support from their siblings is mixed. The shared experience of parental separation can provide a reciprocal source of comfort and help (Hogan et al., 2002). However mutual support between siblings may be weak or absent (Gorell Barnes et al., 1998). Butler et al. (2002) noted that many children in their study did not turn to brothers or sisters for support. The reasons included age differences between the children, siblings that did not get on well, and a perception that a sibling had reacted differently to the separation or had coped better with the 
change in circumstances.

A young person's extended family can provide care and support during the separation process (Hogan et al., 2002). This is particularly so in the case of grandparents who assume greater responsibility for grandchildren during times of family transition (Cherlin \& Furstenberg, 1986; Gorell Barnes et al., 1998; Brannen, Heptinstall \& Bhopal, 1999; Dunn \& Deater-Deckard, 2001; Pryor \& Rodgers, 2001; Butler et al., 2002). The emotional and physical availability of extended family members for young people experiencing parental separation will differ between families. Wallerstein and Kelly (1980) found that approximately 75 percent of the children in their study were not helped through the separation by grandparents, aunts, or uncles, many of whom lived in different parts of the United States.

Support sources also lie outside the family. Friends can act as confidants and can offer support and encouragement (Dunn \& Deater-Deckard, 2001; Butler et al., 2002; Hogan et al., 2002). Other research has suggested some reluctance on the part of children to talk to friends about parental separation (Wallerstein \& Kelly, 1980; Kurdek \& Siesky, 1980; Gollop et al., 2000). For some young people, especially older boys, friends are valued not so much for what they can offer in terms of support, but for the distraction they can provide from events transpiring in their personal lives (Wallerstein \& Kelly, 1980; Gollop et al., 2000).

School teachers and counsellors tend to be considered unappealing sources of support by young people (Wallerstein \& Kelly, 1980; Pritchard, 1998; Gorell Barnes et al., 1998; O'Quigley, 2000; Butler et al., 2002; Hogan et al., 2002). This may be due to an underlying preference to resolve issues within the family rather than being open to help from 'outsiders' (Smart \& Neale, 2000). It may be more common where the dominant cultural norm is not to openly discuss family matters, as was the case in Hogan, Halpenny \& Greene's (2003) study of Irish children. Young people can find support programmes beneficial to the extent that they provide an environment of understanding and shared experience (Hogan et al., 2002). Lyon, Surrey and Timms (1998) 
noted that young people expressed a preference for information about coping with separation and divorce to be readily accessible, for example over the internet, and to be available before it was needed. Recognising young people's information preferences when establishing support programmes was a key recommendation of the Hawthorne, Jessop, Pryor and Richards (1999) review of separation services and interventions in the United Kingdom.

It should be recognised too that young people have their own coping mechanisms. Butler et al. (2002) found that children distracted themselves by writing down their thoughts, playing games and sport, and spending time with friends. These activities also provided an emotional outlet. The ability to cry, albeit in private, was highly valued. Wade and Smart (2002) concluded that activities such as cuddling toys, sleeping, and angry outbursts were means by which young people sought to make themselves feel better and to actively cope with events transpiring around them.

Information. One of the strongest themes to emerge from the research on young people's experiences of separation is their desire to be kept well informed. This includes being told that the separation is occurring, why it is occurring, and what it will mean in practice. Despite this, studies have shown that it is more common for young people not to be given adequate information about the separation (Wallerstein \& Kelly, 1980; Mitchell, 1985; Gorell Barnes et al., 1998; Brannen et al., 2000; Gollop et al., 2000; Butler et al., 2002). These studies are in contrast to the Plunkett and Kalter (1984) study where 44 percent of participants agreed with the proposition that they would not want to know why parents in a vignette scenario had separated. It is possible that this figure was affected by the inclusion in the study of children from intact families who had not experienced parental separation and the uncertainty associated with it.

Existing research details numerous instances of a child finding out about their parents' separation through one parent suddenly leaving the family home (Wallerstein \& Kelly, 1980; Brannen et al., 1999), or through one parent's acquisition of new living premises (MacLeod, 1998; Gollop et al., 2000). Many 
children will in fact be aware of their parents' relationship problems prior to the separation, whether it is through witnessing parental conflict, stonewalling, or behaviour changes (Amato, 1987; Hogan et al., 2002). However even if there is an awareness of relationship difficulties, the separation may still come as a shock, leaving the young person uncertain as to the reasons for the separation and what it will mean in practice (Wallerstein \& Kelly, 1980; Hogan et al., 2002).

Even if young people are told by their parents that they are separating, children may find the information inadequate. Of the young people who provided an account of being told about the separation in Dunn, Davies, O'Connor and Sturgess' (2001) study, 77 percent were provided with limited or very limited information. Only 5 percent stated that they were fully informed about the events transpiring and encouraged to ask questions. Young people prefer that information about the separation be given to them on more than one occasion, with the opportunity to consider what they have been told and to ask further questions (Sviggum, 2000). Research shows that it is more common for a mother alone to tell a young person about the separation (Hogan et al., 2002). In Dunn and Deater-Deckard (2001), 44 percent of participants reported being told of their parents' separation by their mother alone, 17 percent were told by both parents together, and eight percent were told by their father. A further 23 percent of participants reported that no one had talked to them about the separation.

Parents' reluctance to provide young people with information may be sourced in their own uncertainty as to what the future holds (Butler et al., 2002), and in their unwillingness to openly discuss emotionally difficult subjects in the hope of sheltering children from the impact of the separation (Wallerstein \& Kelly, 1980; Smart et al., 1999). Irrespective of motivation, withholding information is contrary to what the research shows young people want, and it may result in added distress and confusion (Butler et al., 2002; Hogan et al., 2002). Age appropriate information is crucial when it comes to the circumstances surrounding the separation. This means finding a balance between answering a child's questions and providing them with suitable information for their age 
and stage of development. Withholding the reasons for a separation may cause a child to speculate as to what those reasons might be. As the research by Kurdek and Siesky (1980) and Kalter and Plunkett (1984) shows, children's perceptions of the causes of parental separation can include an array of different reasons. Self-blame can be one such reason (MacLeod, 1998). One third of the participants in Kalter and Plunkett's (1984) study believed that children held some responsibility for parental separation. Wallerstein \& Kelly (1980) found a similar proportion of participants taking responsibility for their parents' decision to part, with this view more common amongst children under 8 years of age. Other studies have shown self-blame to be less prevalent, for example Kurdek and Siesky (1980) and Burns and Dunlop (1999).

Kurdek and Siesky (1980) asked participants what it means when two people get a divorce. Almost half of the group cited affective factors (48\%), with this response more common amongst older children, children with a high locus of control, and children that registered high in the measure for knowledge of relationship dynamics. Younger children tended to focus on the physical separation between parents, whereas this was the case for only 5 percent of participants that were between 15 and 19 years of age. Other responses focused on the dissolution of marriage, the feelings and reactions of the child, and legal consequences. Mazur (1993) found that children's understanding of marriage, divorce and remarriage did not differ depending on a child's gender or personal experience of parental separation. Mazur, Kurdek and Siesky (1980) and Smith et al.'s (1997) found that the understandings of older children were characterised by more complex and abstract reasoning.

Asking for young people's views. Closely connected with the provision of information, the research to date indicates a strong preference on the part of young people to be consulted over such matters as custody and access arrangements (Smart et al., 1999; Brannen et al., 1999; Smith \& Gollop, 2001). This is consistent with the general willingness on the part of young people to express views on matters of importance to them in everyday life (Stafford, Laybourn, Hill \& Walker, 2003). Yet it is more common for young people to be excluded from custody and access decisions despite wanting to 
have their voices heard, and despite those decisions having a major impact on their lives (Fleming, 1999; Pryor \& Rodgers, 2001; Butler et al., 2002). Smart and Neale (2000) noted that asking children their thoughts on aspects of the separation process means that parents may have to factor more opinions into the decision-making mix. One of the benefits of doing so however is that young people are more likely to express satisfaction with living arrangements if they feel that their views were taken into account when key decisions were made (Dunn \& Deater-Deckard, 2001; Pryor \& Daly-Peoples, 2001; Parkinson, Cashmore \& Single, 2005).

Some caution may nevertheless be required when it comes to young people and their views. In Hogan et al.'s (2003) study many children were adamant that they would not want to be asked their views on matters of custody. Given that divorce only became legally available in the Republic of Ireland in 1996, it is possible that cultural factors may have contributed to their reluctance to want to voice opinions on matters involving family breakdown. Smart and Neale (2000) found that younger children in their study were more comfortable with parents making custody decisions without their input. It has also been well documented that while children generally appreciate the opportunity to articulate their views on living arrangements, they do not relish being put in the position of sole decision-maker (Morrow, 1998; Smart \& Neale, 2000; Pryor \& Rodgers, 2001; Parkinson et al., 2005).

Maintaining family relationships. Young people generally want to have a relationship with both parents and are determined to maintain regular contact with their non-resident parent (Pryor \& Seymour, 1996; Hogan et al., 2002; Wade \& Smart, 2002). Many young people express a concern that they will never see their non-resident parent following the separation (Pryor \& Rodgers, 2001). When asked what some of the bad things are about parents not living together anymore, the most frequent response from Kurdek and Siesky's (1980) participants was losing daily contact with their non-custodial parent. This is a concern repeated throughout much of the literature on children's experiences of separation (Lamb, Sternberg \& Thompson, 1997; Keep \& Pegram, 1998; Gollop et al., 2000; Sviggum, 2000; Dunn \& Deater- 
Deckard, 2001; Butler et al., 2002; Pryor, 2004; Parkinson et al., 2005).

The desire to have a continuing relationship with a non-resident parent can remain strong even when there are barriers in place. The research by Brannen et al. (1999) revealed that a number of children still wanted to be close to their non-resident father despite their father showing little reciprocal interest. There may be a tipping point however where repeated failures by a non-resident parent to honour promises, or persistent unacceptable behaviour, causes a loss of faith in that parent (Highet \& Jamieson, 2005). In addition, if the parent/child relationship has deteriorated, young people are less likely to endorse spending equal time with both parents (Pryor \& DalyPeoples, 2001). On a practical level, if a young person feels unwelcome in the non-resident parent's home, bored, or too far away from friends, they may be less likely to want to spend time with that parent (Gollop et al., 2000).

As discussed, the separation process can be an emotionally difficult period for young people, particularly at the point when a parent leaves the household. Yet parental separation may be perceived as a rational decision given the circumstances (Reinhard, 1977). As well as bringing an end to verbal, emotional or physical conflict between parents, some young people find that their relationship with their resident parent improves as parent and child act as a source of support for one another (Kurdek \& Siesky, 1980; Kurdek \& Berg, 1987). There is nevertheless a risk that a young person bears too much responsibility for supporting a parent, in which case they may feel pressured and over-burdened (Pritchard, 1998; Pryor \& Rodgers, 2001). While the time spent together between a young person and a non-resident parent may be less in quantity than before the separation, it may be of a higher quality, and therefore considered to be a better overall outcome (Kurdek \& Siesky, 1980). Partaking in organised outings with a non-resident parent can be particularly enjoyable for young children (Gollop et al., 2000).

Young people commonly report that maintaining family relationships following a separation is complicated when their parents' relationship is strained (Smith \& Gollop, 2001). MacLeod (1998) observed that a parent's expectations of 
support can also extend to an assumption that their children will support their separation stance, thereby fuelling feelings of being stuck in the middle between two parents in conflict. Young people dislike it when parents talk disparagingly about each other, when they have to act as the go-between for parents who refuse to communicate, and when they are asked to provide information on aspects of a parent's life (Wallerstein \& Kelly, 1980; Burgoyne \& Clarke, 1984; Pryor \& Seymour, 1996; Smith \& Gollop, 2001; Butler et al., 2002). Being pressured by a parent to take sides in the context of legal proceedings can be particularly difficult (MacLeod, 1998). Young people prefer that their parents cooperate and treat each other with respect (Smart \& Neale, 2000; Sviggum, 2000; Hogan et al., 2002).

New relationships. Young people can react to a parent's new partner both positively and negatively. In Gorell Barnes et al. (1998), one half of the participants disliked their stepparent or regarded them as marginal figures in their lives, while the other half reflected favourably on them. Flowerdew and Neale (2003) noted that for some young people what was an 'extraordinary' family situation may have become settled and relatively 'ordinary' over time. A stepparent may be seen as an unwanted disturbance to this newly restored order. A new partner may also be perceived as a threat to the closeness of the parent/child relationship, resulting in feelings of hurt, isolation, and jealously (Fleming, 1999; Cartwright \& Seymour, 2002; Parkinson et al., 2005). These feelings may be exacerbated by the arrival of a new baby into the household (Dunn \& Deater-Deckard, 2001).

For a young person a stepparent may mean new rules to obey. Gorell Barnes et al. (1998) found that positive responses were more likely to be associated with stepfathers, and that strong hostility was reserved almost exclusively for stepmothers, partly because they were expected to assume responsibility for discipline. Other research has shown reluctance on the part of stepmothers, as well as many stepfathers, to take on a parenting role, preferring instead to act as a friend or 'quasi-parent' (Coleman, Ganong \& Fine, 2000). When a stepparent follows existing discipline practices the likelihood of hostility between stepchild and stepparent is reduced (Gorell Barnes et al., 1998). 
Equally, a young person may consider the arrival of a stepparent to be a positive development. A number of studies reported stepchildren having a good relationship with their stepparent, for whom they cared a great deal (Gorell Barnes et al., 1998; Brannen et al., 1999; Smith, Robertson, Dixon, Quigley \& Whitehead, 2001; Pryor, 2004). Some young people also recognise the increased financial security that a stepparent can bring (Smith et al., 2001). The emotional happiness of a parent is likely to be an important factor that influences the perception of a new partner (Dunn \& Deater-Deckard, 2001). If the young person considers the person to be good for their parent, they may view the relationship positively (Smith et al., 2001; Flowerdew \& Neale, 2003). If however the young person regards him or her to be unreliable or untrustworthy, the reaction may be one of disapproval, even outright hostility (Keep \& Pegram, 1998).

Research on the effect of time on the stepchild/stepparent relationship has produced different results. Two studies found that most relationships deteriorated with time (Bray \& Kelly, 1998; Hetherington \& Clingempeel, 1992). Another study found varied results, with some children experiencing improved relations, others experiencing a decline in relations and some remaining largely unchanged (Ganong \& Coleman, 1994). Pryor (2004) found that conflict between a resident parent and stepparent will tend to undermine the development of the relationship between stepchild and stepparent. Hall (1998) observed that for some young people the development of a positive relationship with a stepparent can be accompanied by feelings of guilt as they grapple with issues of loyalty to both parents.

The arrival of stepsiblings can be perceived by young people as an invasion of their home space (Fleming, 1999). Stepsiblings also open up the perception of inequitable treatment if a stepparent's children are thought to be subject to less stringent rules than other children in the household (Hall, 1998; Fleming, 1999). On the other hand, many young people enjoy the friendship of other children who have entered their lives following the formation of a parent's new relationship (Fleming, 1999). Complaints from young people as to the difficulties associated with living in two households are relatively 
common (Gollop et al., 2000; Butler et al., 2002). Smart, Wade and Neale (2000) reported practical problems such as repacking bags, forgetting items and the attractiveness of one house over another, for example because of access to a computer or issues of cleanliness. Emotional difficulties included missing the other parent, moving between two homes where parents were hostile with each other, and being away from friends. Despite these challenges, the majority of the children felt that their situations were relatively normal once routines had become established. Similarly in Dunn and DeaterDeckard's (2001) study more than half of participants considered that living in two households either had some positive aspects or no major negative aspects. Noticeably the age of the participants did not affect their view of living in two households.

In terms of future relationships, there does not appear to be a link between experience of parental separation and a young person's attitude to marriage and divorce (Pryor \& Rodgers, 2001). Kurdek and Siesky (1980) reported that 61 percent of participants thought that they would get married, 23 percent thought that they might marry or did not know if they would, and 16 percent believed that they would not get married. Children that measured high on the locus of control scale were notable for their endorsement of marriage. Mazur (1993) found that expected gender differences in relation to children's attitudes to marriage and divorce did not materialise. However older children were more open to the concept of divorce, which Mazur attributed to a greater understanding of the complexities of personal relationships. Kurdek \& Siesky (1980) noted that there was little concern amongst participants regarding the possibility of their own divorce. This was due to their determination, reinforced by their parent's experiences, to find a compatible partner.

Fairness. One clear indication of the considered and mature views young people are capable of expressing is their promotion of fairness within the context of the separation process. As discussed, young people generally have high expectations that they will be provided with adequate information, be asked their views on custody, access and family life, and expect to have equal time with both parents. The research on young people's views of separation 
also shows that young people have an underlying concern with equitable outcomes for others and in particular their parents. Several studies have shown that young people recommend that children spend equal time with both parents (Smart et al., 1999; Smith \& Gollop, 2001; Parkinson et al., 2005). In Pryor and Daly-Peoples' (2001) study participants were presented with eight vignettes that differed on the age and gender of the child depicted, as well as the presence of conflict in the household. For all eight vignettes a majority of participants responded that the child would want to spend equal time with both parents. This underlying desire for fair treatment may stem in large part from a desire to avoid hurting parents' feelings (Hogan et al., 2002).

Parkinson et al. (2005) asked participants to consider fairness in the context of financial arrangements between separated parents. Young people in the study suggested that there should be a fair separation of family assets upon separation, and that maintenance obligations should be fairly imposed to ensure that one parent is not disadvantaged. As a further example of young people's agency, 'fair' treatment over financial matters was not always equated with 'equal' treatment, as parent's respective financial needs and contributions to household wealth were factored into some participants' responses. Smart et al. (1999) commented that the young people's concern for the wellbeing of their parents, challenges commonly held notions that the fairness ethic is a one-way relationship from parent to child rather than a relationship based on mutual concern.

\subsubsection{Overview of young people's experiences of separation}

The existing research on young people's experiences of parental separation demonstrates their social agency in a number of areas. While the separation can be an upsetting and uncertain time, the passing of time facilitates more detached and reflective views of changed family circumstances. Where care and support is not available from parents, young people may choose to utilise external sources of support, such as siblings, extended family, friends and professionals. But they will do so carefully, selecting sources they consider will be beneficial to them and with whom they feel comfortable talking to. 
Clearly young people want information about the events that are transpiring, why they are happening and what they will mean in practice. Many young people also want to express views as to living arrangements, and importantly, for those views to be taken into account when decisions are made. Young people express a strong desire to be part of both parent's lives, even in a situation where there is disinterest from one parent. The introduction of stepparents can be seen as an unwanted disturbance to the reformed family unit, especially if a young person feels they have become less important to their parent. Yet they have sufficient insight to recognise that a new person in their parent's life can bring benefits, not least of which is the emotional happiness of their mother or their father. Finally, young people's desire for fair and equitable outcomes demonstrates clearly both their moral reasoning and their awareness of the needs of others.

\subsection{Young People's Adjustment to Parental Separation: The Research to Date}

Overall, the findings are inconclusive and to some extent ambiguous. In addition, contextual changes of a historical, social, cultural, economic and legal nature invariably mean that children's experiences of divorce will differ over time. Many factors interact to contribute to the adjustment of children and need to be viewed in combination.

(Bagshaw,1998, p. 2)

\subsubsection{Theoretical perspectives}

The literature considering the effects of parental separation on young people has produced several theoretical perspectives. These perspectives provide a contextual framework for the research and in some cases signal that the authors have based their analysis on particular assumptions and value judgements (Fine \& Demo, 2000; Pryor \& Rodgers, 2001).

Broadly speaking, there are three main perspectives. First, there are those that view separation as a single event having causative responsibility for future outcomes. These approaches are grouped under trauma (or deficit) 
theories, and include theories of loss and abandonment (Amato, 1993; Pryor $\&$ Rodgers, 2001). Negative outcomes generated by separation are attributed to the loss of a central figure in a child's life, the loss of an important source of emotional support, and feelings of being abandoned. Trauma theories have been challenged by research that has questioned the true impact of the physical separation of parents. For example, studies have shown that children who have experienced the death of a parent tend to have higher levels of wellbeing than children whose parents have separated (Amato \& Keith, 1991; Rodgers \& Pryor, 1998). This suggests that factors beyond the physical absence of a parent can influence children's adjustment. In addition, research has shown that behavioural and academic problems can be detected in children well before parents have actually separated (Cherlin et al., 1991; Booth \& Amato, 1996; Sun, 2001).

A second perspective, which includes life-course and ecological theories, views separation as one part of a longer process where outcomes are influenced by a number of pre and post-separation factors. Life-course theories account for outcomes on the basis of the transitions people experience within the course of their various social trajectories (Elder, 1998). The impact of family transitions on children's outcomes may be influenced by the time and place in which those transitions occur. For example, two countries may have different social mores around separation and divorce, which may in turn influence whether children are stigmatised as 'children of divorce'. Also relevant may be the timing of the separation within children's lives as there is a risk that they assume adult roles and responsibilities at an early age, and the personal characteristics, interpretations and temperaments of individual children (Elder, 1998; Pryor \& Rodgers, 2001).

Ecological theories are connected with life-course theories, but differ to the extent that they emphasise development within an environmental context rather than development across time. Bronfenbrenner (1979) established an ecological theory whereby the development of a child is determined by four sets of interacting influences, each operating at a progressively overarching level. The microsystem refers to children's family environment, while the 
mesosystem extends to wider networks that involve children, including neighbours, friends and health professionals. The exosystem (level three) and macrosystem (level four) include factors that have a less tangible connection with children, but nevertheless affect the microsystem and mesosystem variables. For example, the establishment of paid parental leave in New Zealand in 2001 is a factor that exists at the exosystem level of influence, but is designed to assist individual families at a microsystem level. The social capital theory (Coleman, 1988) advances the view that outcomes can be influenced by the quality of relationships within families, and between families and their communities. In this respect, social capital theory represents an extension of ecological theory at the microsystem and mesosystem levels (Pryor \& Rodgers, 2001).

A third perspective is the 'risk and resilience' framework, which draws on aspects of life-course and ecological theories. This perspective suggests that children's resilience can depend on the nature of the risks they face and their ability to overcome adversity (Rutter, 1987; Werner \& Smith, 1982; McCubbin \& McCubbin, 1991; Cowan, Cowan \& Schulz, 1996; Rodgers \& Rose, 2002; Jenson \& Fraser, 2005). The risk and resilience framework fits comfortably with Amato's (2000) 'divorce-stress-adjustment' perspective which views the separation process as creating stressors (mediators) that are linked with negative outcomes. A child's adjustment will be determined not only by the number and nature of these stressors, but by the availability of protective (moderating) factors, such as coping skills and the availability of support networks, that can shield a child from the risks associated with parental separation. The divorce-stress-adjustment perspective is a useful framework for researchers as it facilitates investigation into the association between particular mediating and moderating factors and their impact on child adjustment.

\subsubsection{Children's outcomes}

A large number of studies have found associations between parental separation and negative child outcomes. Of the 92 studies reviewed by Amato 
and Keith (1991), over two-thirds found that children whose parents had separated had lower levels of wellbeing compared to children from an original two-parent family. Rodgers and Pryor's (1998) meta-analysis found that the risk of adverse social, psychological and physical outcomes was approximately twice as high for children from separated families than for children from original two-parent families.

Both pairs of authors emphasised that the magnitude of the differences in outcomes were relatively small. Amato and Keith (1991) reported that the effect sizes in the literature were mostly weak. Emery (1999) observed that the majority of children whose parents separate do not experience negative outcomes despite the number and intensity of stressors children can be exposed to. In addition, parental separation can bring positive developments for children, for example a reduction in exposure to parental conflict (Kelly \& Emery, 2003) and increased personal maturity and skills (Demo \& Acock, 1988; Butler et al., 2002). Nevertheless, negative outcomes for children who have experienced family transitions are higher in many cases than for children living in an original two-parent family. From a divorce-stress-adjustment perspective, the explanation for the differences in outcomes lies in the combination of the stressors children are exposed to during the separation process and the existence or availability of certain protective factors.

\subsubsection{Stressors and protective factors}

Researchers have devoted considerable attention to the interrelationship between stressors associated with family transitions, protective factors and children's adjustment (Wallerstein \& Kelly, 1980; Kurdek \& Sinclair, 1988; McLanahan \& Booth, 1989; Kitson, 1992; Emery \& Forehand, 1994; Booth \& Amato, 1994; Simons, Lin, Gordon, Conger \& Lorenz, 1999; Dekovic, 1999; Amato, 2000; Rodgers \& Rose, 2002). It should be noted that different studies may treat the same factor as a stressor, a protective factor, or an adjustment outcome (Emery, 1999). A low standard of living, for example, could be considered a stressor when it is linked with negative child outcomes. However, a different study may consider the links between separation and 
reduced standards of living, in which case standard of living is treated as an outcome (Amato, 2000). In addition, there is some debate as to what exactly constitutes a protective factor (Dekovic, 1999; Jenson \& Fraser, 2005). For instance, Pedro-Carroll (2005) suggested that lack of parental conflict should not be treated as a protective factor but as the absence of a stressor.

Two other points should be made regarding stressors, protective factors and children's adjustment. First, as noted, longitudinal research has shown that some negative adjustment outcomes in children can be detected before parents separate (Elliot \& Richards, 2001; Cherlin et al., 1991). If the connection between stressors and negative adjustment holds true, then some of the stressors linked with those outcomes should also be present before parents separate. Research by Sun (2001) addressed this point by examining pre-separation wellbeing data. His analyses showed that more behavioural, psychological and academic problems were present in children whose parents would go on to separate compared to children who remained in an original two-parent family. Crucially, those families whose parents would separate were marked by problematic parent-parent relationships, less intimate parentchild relationships, and fewer economic resources. There are all identified in the literature as posing risks to children's adjustment. A further issue is whether stressors present before separation are a consequence of the breakdown of the relationship, or as suggested by proponents of the 'selection' perspective, whether they are the result of personality traits of persons predisposed to dysfunctional relationships (Amato, 2000).

Second, such is the nature of family transitions that it is common for children to be subject to multiple stressors. As the number of stressors increase, so too does the likelihood of negative outcomes (Rodgers, 1990). Not only is this because there are more individual pressures, but the collective impact of the stressors can multiple with each additional risk factor that a child must cope with (Hetherington, Stanley-Hagan \& Anderson, 1989; Pryor \& Rodgers, 2001).

Socio-economic status. Economic hardship is associated with parental 
separation, especially amongst lone-parent families (Raschke, 1987; Garfinkel \& McLanahan, 1986; Morgan, 1991; Bradshaw, 1998; Thompson \& Amato, 1999). Reduced income can mean an increase in parental stress, having to shift to lower socio-economic neighbourhoods with fewer community resources, and reduced educational opportunities (McLanahan \& Booth, 1989). Several studies have found associations between economic hardship and negative child outcomes such as internalising and externalising behaviours, lower academic achievement, and substandard nutrition and health (Guidubaldi, Cleminshaw, Perry \& McLoughlin, 1983; Gerard \& Beuhler, 1999). By contrast, Wadsworth and Maclean (1986) found no links between a post-separation reduction in family income and children's emotional wellbeing.

Parental adjustment. Parental adjustment is also considered a risk factor for children's adjustment (Pryor \& Rodgers, 2001). Research has shown that adult psychological distress can increase following separation, as can involvement in a range of anti-social behaviours (Menaghan \& Lieberman, 1986; Lahey et al., 1988; Kitson \& Morgan, 1990; Temple et al., 1991). Parental psychological distress and anti-social behaviour have both been found to be negatively correlated with the quality of parenting and children's adjustment (Hetherington et al., 1982; Kline, Tschann, Johnston \& Wallerstein, 1989; Capaldi \& Patterson, 1991; Simons, 1996).

Stressful life events. Parental separation can be a distressing experience for children (Wallerstein \& Kelly, 1980). While initial feelings of shock and anger generally stabilise, children can face a variety of additional hurdles along the way. The challenges of living in step/blended families, and of moving between two households, have been mentioned. Amato (1993) found that studies considering outcomes for children whose parents entered into a new relationship were split as to whether average wellbeing had increased or decreased. In their meta-analysis, Rodgers and Pryor (1998) found that children in stepfamilies were at increased risk of adverse outcomes compared to lone-parent families, although this was more so for older children than for younger children. Children whose parents separate can also face an 
assortment of potentially unsettling events, such as moving to a new house and school, and having to leave family, friends and pets (Wolchik, Sandler, Braver \& Fogas, 1985). The greater the frequency of family transitions the higher the risk of adverse outcomes (Capaldi \& Patterson, 1991; DeGarmo \& Forgatch, 1999).

Support and coping. Support from outside the family can moderate the risks associated with parental separation. Children benefit from having supportive peers they can confide in (Kurdek \& Sinclair, 1988; Hetherington, 1989;

Rodgers \& Rose, 2002), and schools that can offer structured and supportive academic environments (Rutter, 1983; Werner, 1992). However, as noted earlier, children can be reluctant to discuss parental separation openly with friends and teachers. Different individual characteristics can also moderate the risks children face. Children with a difficult temperament may find adjustment more challenging (Hetherington et al., 1989), while children that are patient and self-assured may find family transitions easier to come to terms with (Kurdek \& Berg, 1983; Ruschena, Prior, Sanson \& Smart, 2005). Children with high internal locus of control and an understanding of relationship dynamics are likely to have greater insight into the reasons behind their parents' separation, which may in turn assist adjustment (Kurdek \& Siesky, 1980).

Age and gender. Earlier research into the effects of separation on children reported higher risks of negative outcomes for younger children compared to older children (Douglas, 1970; Wadsworth, 1979; Kalter \& Rembar, 1981). Subsequent studies have shown mixed results on the effect of age (Amato \& Keith, 1991; Rodgers \& Pryor, 1998). One difficulty in this area is that children whose parents separate when they are young are likely to be exposed to more stressors over a longer period, making it difficult to isolate the effect of age as an individual variable (Rodgers \& Pryor, 1998). The view that boys suffer more from parental separation than girls is well entrenched in the literature (Wallerstein \& Kelly, 1980; Rutter, 1980; Emery, 1982). However, several studies have found gender to have little predictive value in terms of children's outcomes (Amato, 1993; Zill, Morrison \& Coiro, 1993; Woodward, 
Fergusson \& Belsky, 2000). An Australian longitudinal study comparing children whose parents had separated with children from an original twoparent family found that girls were more likely to show signs of anxiety and depression than boys (Ruschena, Prior, Sanson \& Smart, 2005). However, these differences were found in both groups and reflected wider population gender differences.

Contact with non-resident parent. Frequency of contact with a non-resident parent, particularly fathers, is cited as a moderating factor for children (Acock \& Demo, 1994; Simons, 1996; Emery, 1999). Regular contact is said to facilitate emotional involvement in a child's life and help establish and enforce standards of conduct and discipline (Simons et al., 1999). Amato (1993) tested the hypothesis that increased frequency of contact with a non-resident parent would be positively associated with children's wellbeing. He found an equal split between studies that supported the hypothesis and those that did not. Hetherington, Cox and Cox (1982) and Hetherington and Kelly (2002) found that frequent contact with a non-custodial parent was associated with positive outcomes when accompanied by low-levels of parental conflict, but that frequent contact was associated with negative outcomes in a high-conflict situation.

Family dynamics. Deterioration in the quality of parenting and parent-child relationships before and after separation has been well documented (DeGarmo \& Forgatch, 1999; Emery, 1994; Booth \& Amato, 1994; Simons, 1996; Dunn \& Deater-Deckard, 2001). Hetherington (1983) concluded that mothers in lone-parent families found it more difficult to monitor and discipline their children compared to mothers from other family types, and that relations with sons could be particularly fraught. Reduced quality of parenting and a decline in parent-child relationships have both been linked with negative child outcomes (Hetherington, Bridges \& Isabella, 1998; Gerard \& Beuhler, 1999; Simons et al., 1999; Amato, 2000; Videon, 2002; Dunn, 2003). An open and expressive family environment can also predict positive child adjustment. Using the Moos and Moos (1981) Family Environment Scale, Kurdek and Sinclair (1988) found that family cohesion and communication were positively 
correlated with goal setting in children from stepfamilies, and negatively correlated with maladjustment and school problems.

Conflict. It is well established that inter-parental conflict is a significant risk factor for children's adjustment (Grych \& Fincham, 1990; Emery, 1982; Johnston \& Roseby, 1997; Cummings \& Davies, 2002; Harold, Shelton, Goeke-Morey \& Cummings, 2004). Separation may bring about a reduction in conflict as parents live apart in separate households. Alternatively, conflict may increase on account of ongoing anger and emotional hurt, disputes over children, and acrimonious legal proceedings (Wallerstein \& Kelly, 1980; Kelly \& Johnston, 2001; Bream \& Buchanan, 2003). Some research has suggested that pre-separation conflict is more harmful to children (Buehler et al., 1998). Others have identified post-separation conflict as having a greater impact on adjustment (Hetherington, 1999). Amato and Booth (1995) found that wellbeing of children from high-conflict families increased following parental separation, but that wellbeing declined sharply for children from low-conflict families. This suggests that conflict that is sudden and unexpected can be especially difficult for children to deal with (Booth, 1999).

Conflict that directly involves children, that make them feel pressured to take sides, or denigrates the other parent, may also be particularly damaging (Hawthorne et al., 2003). While research has traditionally focussed on verbal and physical forms of conflict, the impact of emotional conflict has recently come under greater scrutiny (Tschann, Flores, Pasch \& Marin, 1999; Wild \& Richards, 2001). In Pryor and Pattison's (2007) study participants were aware of 'silent conflict' between their parents, which included changes in parental behaviour, heightened emotions, and lack of conflict resolution. This in turn generated feelings of uncertainty, anxiety and loss of control.

\subsubsection{Impact of time}

What impact does the passing of time have on children's adjustment to parental separation? Several studies have shown that children's problems generally diminish given sufficient time (Bussell, 1995; Frost \& Pakiz, 1990; Goldberg, Greenberger, Hamil \& O'Neil, 1992; Jekielek, 1998). Hetherington 
(1989) is commonly cited as the authority for the view that it takes two to three years for most children to adjust to their parents' separation. Other studies have found that time since separation either has little impact on children's outcomes (Mauldon, 1990; Machida \& Holloway, 1991; McLanahan \& Sandefur, 1994; Ruschena et al., 2005), or that negative outcomes increase over time (Cherlin, Chase-Lansdale \& McRae, 1998).

Given the mixed results on the effect of time, two different models have been developed within the divorce-stress-adjustment perspective (Amato, 2000). The 'crisis' model advocates that the separation process is a disturbance that most children will adjust to in time, given the right balance of stressors and protective factors. Alternatively, the 'chronic strain' model argues that because many stressors persist long after parents separate, children's wellbeing will generally not return to pre-separation levels. The differences between these two models are more apparent than real. What separates them is not necessarily their position on children's post-separation outcomes, but their views on the number, intensity and duration of stressors and protective factors children are generally exposed to. The former model assumes that environmental influences will ultimately facilitate improved child outcomes, while the latter assumes that wellbeing will suffer long-term because the stressors are too many, and the protective factors too few.

When considered in this way, it is unrealistic to view one model as 'right' and the other as 'wrong'. The stressors children must cope with and the resources available to them will inevitably vary between different families and different communities. Furthermore, the presence and strength of stressors and protective factors may change over time within the same family. For example, while the quality of parenting and parent-child relationships may initially decline following separation, both can improve as new circumstances become more familiar and changed roles and routines are established (Wallerstein \& Kelly, 1980, Hetherington, 1989). In addition, levels of conflict may remain constant for some families, while fluctuating for others. For instance, Losoncz (2008) found that 19 percent of resident parents reported decreased levels of conflict with a non-resident parent over a two year period, while 15 percent 
reported increased conflict, and 53 percent reported no change. The effect of time, therefore, is a factor that will tend to show contrasting results across different studies because its impact depends to such an extent on the individual circumstances of the participants.

\subsubsection{Overview of young people's adjustment to separation}

There is some consensus among researchers on the impact of parental separation on children's wellbeing. There is, however, less agreement on the causes of negative outcomes in children. This is not unexpected given the volume of literature that addresses this topic. It also reflects the diversity of theoretical frameworks that guide the research. To some extent diversity of findings exist because researchers seek answers to different questions. The meta-analyses of Amato and Keith (1991) and Rodgers and Pryor (1998) provide a valuable overview of findings in this field. Both reviews found that, overall, children whose parents separate are at risk for more negative psychological, social and physical outcomes than children from original twoparent families. Tellingly, however, both reviews found that differences between the groups tend to be small, with the implication that most children who experience a family transition are able to adjust to their changed family environment. Nevertheless, differences in children's adjustment do exist, and some children can experience diminished wellbeing into their adult years (Pryor \& Rodgers, 2001).

The divorce-stress-adjustment perspective accounts for these differences in terms of the balance of the risk and protective factors that are associated with parental separation. There is some agreement as to what those factors are, for example lower socio-economic circumstances or frequent contact with a non-resident parent. However, different studies have drawn different conclusions as to their ability to predict children's outcomes. In light of findings in this area, the quality of parenting, parent-child relationships, and the intensity of inter-parental conflict, appear especially important variables. Contrasting findings on the impact of time on children's adjustment reflects the variability of mediating and moderating factors in children's lives. 


\section{Chapter Four \\ The Studies}

A life lived is what actually happens. A life experienced consists of the images, feelings, sentiments, desires, thoughts and meanings known to the person whose life it is... A life as told, a life history, is a narrative, influenced by the cultural conventions of telling, by the evidence, and by the social context.

(Bruner, 1984, p. 7).

\subsection{Research Principles and Objectives}

This research project consists of two studies undertaken in New Zealand in the early stages of the twenty-first century. The overall purpose was to gain an understanding of young people's perceptions of families and experiences of family structure change. This basic objective is elaborated further in the overview of both Study One and Study Two below.

Fundamental to both studies is the acceptance of young people as active participants in their family lives, and as active and capable participants in research. There is a tendency to focus on adults' perspectives on how children think and feel. For that reason, focusing on children's voices in an area so central to their development - families - is the priority. The desire to achieve a greater understanding of young people's subjective perceptions of families and experiences of parental separation, therefore, provides the momentum for this research.

The School of Psychology Human Ethics Committee at Victoria University of Wellington granted approval for both studies to be carried out. Approval was sought and obtained for each study in separate applications that outlined the nature and duration of the research and specific details of the project. 


\subsubsection{Study One}

Young people's views of families. The purpose of this concurrent mixed methods study was to understand how children perceive family. Their perceptions were measured both qualitatively and quantitatively via semistructured interviews. Of particular importance were the children's definitions of family and the type of relationships they endorsed as families. Furthermore, the study examined whether ethnic or family structure differences existed in children's perceptions of families.

The research aims for Study One were:

- To gain an understanding of children's definitions of family, the importance of family, and the relationships they interpret as representing a family.

- To understand how children from different family structures perceive family.

- To gain insight into how children from different cultural backgrounds perceive family.

- To explore differences in terms of gender, ages of the children and transitions experienced.

- To ascertain if there are any differences in the way that the adolescents in Anyan and Pryor's (2002) study define and perceive family, compared to the children in this study.

The associated research questions for Study One are outlined in chapter five.

\subsubsection{Study Two}

Young people's experiences of family transitions. The purpose of this concurrent mixed methods study was to gain an understanding from young people of their experiences of parental separation. The study was a longitudinal investigation that used semi-structured interviews to explore young people's experiences of parental separation following the separation, and again 18 months later. Of particular importance was to focus on the subjective experiences and meaning of parental separation using qualitative interviews, and to explore their experiences and adjustment using quantitative measures. Participants in a younger and older grouping were compared in 
order to examine whether there were any differences in the experiences and adjustment of children versus adolescents. Comparisons were also made between those who were in the earlier stages of parental separation (1-10 months) and those who were in the later stages of the separation (14-24 months).

This study was based on a number of underlying principles:

- That the term family is an inclusive concept (based on a finding from Study One).

- That the nature of the relationships within a family and presence of affective factors are more important than the configuration or status of the grouping (also based on a finding from Study One).

- That the voice of young people is an essential component when researching their experiences; young people are active and capable participants in research.

- That young people are social agents who have the ability to reflect on and influence their experiences.

- That separation is interpreted as a process, as opposed to a single event, which involves many factors that contribute to the experiences of young people.

- That it is important to not pre-empt children's experiences of separation as entirely negative; but accept that negative and positive experiences may occur.

The key concept in this study is young people's 'experiences' of parental separation. When used in this context the word 'experiences' is extremely vague. In order to eliminate this ambiguity it is important to clarify the way the term was used in this study. Young people's 'experiences' of separation included their perspectives, understandings and adjustment in relation to the break-up, which were measured both qualitatively and quantitatively. A briefing prepared for the Families Commission by the Ministry of Social Development found that there is an absence of research with regard to longitudinal studies of families and children. More specifically, they stated that 
one of the knowledge gaps in family research is "Children's perspectives of their experiences, particularly in relation to family transitions and their impacts." (Ministry of Social Development, 2004, p. 134). Study Two is a minilongitudinal investigation rather than a long-term study. However, young people's subjective experiences of family structure change have been thoroughly examined qualitatively and quantitatively, thus providing a plethora of information to help fill the knowledge gap.

The qualitative interview questions, which focus on participants' 'experiences', were grouped into specific categories. Firstly, the family concept of the participants was explored by enquiring about their family definitions and the importance of family. Secondly, details about their family structure were sought, including the composition, living arrangements, and contact arrangements. Young people's views and reactions in relation to the separation were examined, and included finding out about the break-up, reactions and feelings, reasons for the separation, expectations, blame, positive and negative aspects, the challenges faced, and reminiscing. Support and coping were explored by discussing their needs, their support sources, coping strategies, whether they had sufficient support, accessing support and resources, and ideas on coping.

Another key area explored was communication; more specifically, the young people discussed being informed, being involved in decision making, and giving advice. The final theme was the future; in particular, their attitudes towards their family, marriage and children. In addition to these qualitatively explored categories, the participants 'experiences' of separation were also examined quantitatively by measuring young people's views surrounding their family, and via perceptions of themselves. These included measures of the family environment, perceptions of their parents, parental conflict, perceptions of their own strengths and difficulties, feelings, locus of control, psychological wellbeing, and their personal strengths.

The research aims for Study Two were: 
- To gain an understanding of young people's initial experiences and perceptions of parental separation.

- To gain an understanding of young people's experiences and perceptions of parental separation after 18 months.

- To explore the adjustment of young people experiencing separation, over an 18 month period, by examining their individual wellbeing and family dynamics.

- To establish if there are any differences in the adjustment, over an 18 month period, of children versus adolescents by examining their wellbeing and family dynamics.

- To establish if there are any differences in the adjustment, over an 18 month period, of those in the early stages of separation and those in the later stages of separation by examining their wellbeing and family dynamics.

The associated research questions for Study Two are outlined in chapter eight.

\subsection{Rationale for Methodology}

As mentioned earlier, more families are experiencing changes to their composition, and consequently a rising number of young people are faced with familial transformations. The way that they cope with such change depends to a great extent on the meaning that family has for them. By accepting young people as capable contributors to research and talking openly with them, we are better able to grasp their concept of family (Smart, Wade \& Neale, 1999; Sviggum, 2000; Smith, Taylor \& Tapp, 2003). This in turn allows for a greater understanding of the world of a young person confronted with family change.

Study One and Study Two were undertaken in order to provide much needed insight into young people's own perceptions of family and their own experiences of family structure change. The lack of New Zealand based research exploring children's family concepts provided the incentive for Study One. Little attention has been given to the various cultural groups within New 
Zealand; for that reason it was essential to investigate how children see families from different cultural backgrounds. Children today reside in a variety of family groupings; therefore, it was also beneficial to examine children's family structure experiences and compare perceptions across family groupings. Previous New Zealand based research carried out by Anyan and Pryor (2002) has provided valuable insight into what family means to adolescents. Their research presented the opportunity to compare the perceptions of their adolescent sample with the current sample of children; which in turn provided the opportunity to understand what family means to both children and adolescents in New Zealand today.

The majority of research in the field of children and separation has tended to place its focus solely on the impact of family change on children and adolescents. Furthermore, children's experiences have frequently come from an adult perspective. Consequently Study Two aimed to explore young people's accounts of their own experiences of family transitions over time, as well as their adjustment. However, in order to fully understand young people's experiences it was important to understand how they perceive family in general. Neglecting to take the fundamental step of firstly investigating what family means to young people leaves a profound gap in our level of understanding. This is pivotal, because the way that young people cope with family transitions may be influenced greatly by their perceptions of what families are. Hence, the importance of combining these two studies.

Researching children's perspectives and experience provides a valuable, albeit complex, insight into how young people understand their worlds. Both Study One and Study Two were in essence exploratory; neither of the studies set out to test specific hypotheses or assumptions relating to young people's perceptions and experiences. Instead both studies were driven by research questions which aimed to explore young people's perspectives and experiences - free from expectation.

The practice of researching children's experience has been described as a highly inferential process (Greene \& Hill, 2005). It is important to note that the 
researcher responsible for carrying out these studies did not have personal experience of parental separation and was, therefore, able to remain substantially more objective during the data collection and analysis phases, than a researcher au fait with the experience of separation. Remaining objective is a difficult task; there is always a risk that a researcher inadvertently includes his or her subjective experiences. Greene and Hill mentioned the need for researchers to be aware of the limitations surrounding the accessibility of an individual's experience, and to recognise the confines of what experiences can actually tell us about a person. Clearly there are both weaknesses and strengths surrounding the study of children's experiences. It is important, however, to be aware of the limitations in order to successfully access and analyse children's views and experiences, and provide research of worth.

A mixed methods research approach was adopted in both Study One and Study Two in order to provide a holistic picture of young people's perceptions and experiences. Qualitative methods allow for insight into the actual experiences and perceptions of participants due to the open-ended, varied and descriptive nature of the data, whereas quantitative methods provide a numerical summary of the essential features of an individual's experience (Greene \& Hill, 2005). There has been extensive debate surrounding the notion of research crossing the qualitative/quantitative spectrum; nevertheless, increasingly more researchers are opting for a mixed methods approach.

Of particular note is the longitudinal qualitative design which is an important feature of Study Two. Longitudinal qualitative methodologies have long been overlooked, in favour of longitudinal quantitative designs. Thompson, Plumridge, and Holland (2003) commented that longitudinal quantitative research monitors change, but longitudinal qualitative designs examine how those changes are experienced. Qualitative and quantitative methods each consist of a number of strengths and weaknesses in the empirical world. Therefore, both methods have been employed in these studies so that the weaknesses inherent in one method are counterbalanced by the strengths of 
the other (Brannen, 2005). In summary qualitative and quantitative methodologies are both important techniques that, when used together, strengthen the collection and interpretation of data.

The samples in Study One and Study Two were both self-selected and the studies utilised mixed methods and concurrent data collection. Study Two contains a longitudinal element with two phases of data collection. The interviews in Studies One and Two were both semi-structured, with some questions having predefined codes (structured) and others being analysed in terms of their qualitative content (unstructured), which also included some quantitative reporting of the thematic content. In both studies the demographic information was quantitatively analysed. In Study Two there were eight instruments that were also quantitatively analysed.

The qualitative components of Study One and Two were adopted in order to provide a richness of data to enhance our understanding of the individual meaning of family and subjective experience of parental separation for young people. In comparison, the quantitative elements provided measurable data on young people's perceptions of families and young people's experiences and adjustment relating to parental separation. In Study One and Study Two the mixed methods approaches provided complementary results. Brannen (2005) describes 'complementarity' of results as qualitative and quantitative results that differ but that also create insights when analysed together.

\subsection{Theoretical Approach to the Research}

\subsubsection{Study One}

Piaget's (1928) theory of cognitive development underpins much of the research on children's perceptions of family. Piaget identified four consecutive stages of development: sensori-motor, preoperational, concrete operational, and formal operation. According to his theory, children's cognitive abilities are limited to the stage they have progressed to, eventually culminating in an ability to think in abstract terms. If new experiences cannot be understood in terms of existing thought structures (assimilation), new structures will emerge 
to make sense of those experiences (accommodation) (Smith, 1992).

Although Piaget's core theory remains influential it has been widely criticised. Particular attention has been directed at his alleged failure to acknowledge the importance of learning through social interaction, and the effect of cultural influences (Lourenco \& Machado, 1996).

The developmental differences Piaget himself noted in children's definitions of families have nevertheless continued to be examined by researchers (Fu, Goodwin, Sporakowki \& Hinkle, 1986; Gilby \& Pederson, 1982). In light of Anyan and Pryor's (2002) research into New Zealand adolescents' perceptions of family, comparisons will be made with the perceptions of family held by children in this study. The primary focus of Study One though is to examine differences in children's understanding of the family concept based on family structure and cultural differences. This approach mirrors other studies that have considered family structure differences (O'Brien, Alldred \& Jones, 1996; Funder, 1996; Brannen et al., 1999), and ethnic and cultural variables (Morrow; 1998; Diez-Martinez Day \& Remigy, 1999; Anyan \& Pryor, 2002), alongside developmental influences.

\subsubsection{Study Two}

Study Two considers young people's perceptions and experiences of parental separation. It is premised on them being active participants in the separation process rather then passive victims (Smart, Wade \& Neale, 1999; Butler, Scanlan, Robinson, Douglas \& Murch, 2002). Adopting a 'social agency' perspective assumes that young people have opinions, and that they are entitled to express them. This approach is at odds with more conservative perspectives, which disapprove of asking children their views on important matters for fear it may unfairly burden them with adult issues (Pryor \& Rodgers, 2001). Nevertheless, as international conventions and domestic laws increasingly adopt a children's rights based focus (Smith, Taylor \& Tapp, 2003), listening to children's voices becomes less of a personal value judgement, and more a case of adherence to orthodox practice. 
Young children's experiences of parental separation will be considered from the 'divorce-stress-adjustment' perspective as outlined by Amato (2000). This perspective sits within the risk and resilience framework. The divorce-stressadjustment perspective allows researchers to consider the significance of particular stressors and protective factors that may determine children's wellbeing. By identifying the variables that can impact on children's outcomes, policies that mitigate risk factors, and promote protective factors, can be implemented. This study also considers the impact of time on children's adjustment and the part it potentially plays in children's resilience.

\subsection{Structure of the Studies}

This thesis consists of 11 chapters. The following three chapters (five, six and seven) are related to Study One, while chapters eight, nine and ten focus on Study Two. Both Study One and Study Two contain chapters that outline the method, the results, and a discussion of the findings. The final section, chapter eleven, provides an overall summary of the findings and analysis of the studies in relation to each other. This section also focuses on the research limitations and considers the implications for research and policy. 


\section{STUDY ONE: \\ YOUNG PEOPLE'S PERCEPTIONS OF FAMILIES}

\section{Chapter Five}

\section{Method}

\subsection{The Research Questions}

In Study One there are seven research questions which focus on young people's perceptions of families, both qualitatively and quantitatively.

\subsubsection{Quantitative questions}

The first two questions are central to this study; they examine whether there are family structure and cultural differences in children's perceptions of family. The following three questions investigate whether there are any gender, age or family transition differences. The final question explores whether any developmental differences exist in young people's perceptions of family. Family structure differences:

1. Are there any differences in the way children from diverse family structures perceive family?

\section{Cultural differences:}

2. Are there any differences in the way children from diverse ethnic backgrounds perceive family?

\section{Gender differences:}

3. Are there any differences in the way boys and girls perceive family? Child age group differences:

4. Are there any differences in the way children from different child age groups perceive family?

Family transition differences:

5. Are there any differences in the number of family transitions the children have experienced and their perceptions of family?

Developmental differences: 
6. Are developmental sequences found when Anyan and Pryor's (2002) findings, based on New Zealand adolescents' perceptions of 'family, are compared with the current findings on children's perceptions of 'family'?

\subsubsection{Qualitative questions}

The first question explores children's concept of family, while the second question focuses on children's perspectives regarding the composition of family, including the composition of families experiencing change.

The family concept:

7. What are children's definitions of family and family importance?

8. What kind of relationships do children perceive as constituting a family?

\subsection{Participants}

Interviews were conducted with 111 children, 64 (58\%) of whom were female and $47(42 \%)$ male. The sample ranged in age from 9.9 years to 13.5 years, with a mean age of 11.9 years. A total of 45 children (41\%) were living in an original two-parent family, 26 (23\%) were part of an extended family arrangement, 17 (15\%) were residing in a one-parent family, $11(10 \%)$ in a stepfamily (or blended family) and the same number in a shared care (joint custody) family $(10 \%)$, while one participant was residing in another arrangement which was described as the 'other' family structure (1\%).

The sample was urbanised, and New Zealand's multicultural society was well represented with 50 (45\%) European New Zealanders, 30 (27\%) Māori, 17 (15\%) Pacific peoples, and 14 (13\%) from other cultural groups. All of the European, Māori, and Pacific Island participants were born and raised in New Zealand. Traditional Māori culture is more collective than individualistic, which is also true of most Pacific Island cultures. Therefore, even though the Pacific peoples sample was not a homogenous group, and was not analysed by its subgroups, there are likely to be similarities between them. It is also important to acknowledge that although the participants were identified as belonging to 
the abovementioned cultural groups, it was not possible to examine how active they actually were in their respective cultures.

Participants were Year 5, Year 6, Year 7, and Year 8 students from primary and intermediate schools in the Wellington region. The six schools which participated in the study represented a wide range of socio-economic groups. The decile ratings for the schools were ' 1 ', ' 3 ', ' 5 ', ' 8 ', '9' and '10'. Decile rankings are devised by the New Zealand Ministry of Education to determine the allocation of funding each state school receives. The schools are ranked into decile (10 percent) groupings. Schools defined as 'Decile 1' draw their students from areas of greatest socio-economic disadvantage and those with a 'Decile 10' rating draw their students from areas of least socio-economic disadvantage. The decile ranking is based on ethnic data from school roll returns, as well as census information for households with children in school catchment areas (Education Review Office Publication, 1998). The schools involved in the study represent the multicultural and socio-economic diversity of New Zealand society.

\subsection{Measures}

The data were collected using a demographic questionnaire and an interview comprising three sections of questions.

\subsubsection{Demographic form}

A demographic form was developed for the participants' caregivers to complete (refer to Appendix A). The purpose of this form was to compile background information on each participant so that gender, age, ethnic, family transition, and family structure comparisons could be made. The questions focused on the participant (age, gender, ethnicity), his/her current family structure (who the child's caregiver/s are at home, ethnicity of caregivers, number of full/half/step siblings, and number of adults in the household). Also of importance, were any changes the participant had experienced to his/her family structure (the type of family structures the child has lived in, the number of transitions the child has experienced). Further questions investigated whether the participants' parents had separated or divorced (and if so, the 
age of the child at the time of the separation, the amount of contact the child has with the non-resident parent, if the parents were given any support or information relating to the wellbeing of their child/ren at the time of their separation, the amount and type of information provided, and the usefulness of the information).

\subsubsection{Interview questions}

An interview style questionnaire was developed to ascertain how children perceive family and family transitions (refer to Appendix B). The questionnaire consisted of three sections that investigated what kind of relationships the children considered to constitute family, and analysed the way the children defined the term family. Both section $A$ and section $B$ of the questionnaire focused on children's perceptions of family. In section $B$ a vignette methodology was adopted. Vignettes were also employed in section $\mathrm{C}$ to investigate children's perceptions of family change. The questionnaire contained 31 interview style questions.

The questions in all three sections were formulated by taking into account the related literature, which focused on children's, adolescents', and adults' perceptions of family. Fu, Goodwin, Sporakowki, and Hinkle (1986), O’Brien, Alldred, and Jones (1996), and Diez-Martinez Day and Remigy (1999) studied children's perceptions of family. Gilby and Pederson (1982) focused on children's and young adults' understandings of family. Anyan (1998) investigated the family concept from an adolescent point of view, and Trost (1990) assessed perceptions of family from an adult perspective.

Almost all of the questions required the participant to justify his or her answer. Gollop (2000) recommended the use of 'How come?' instead of 'Why or why not?' because it encourages a better response from child interviewees. 'Why' questions may cause the interview process to feel like an interrogation, or it may suggest to the child that his/her answers are inappropriate and require justification. The question 'How come?' was, therefore, adopted in the present study to act as a tempered prompt to encourage the children to provide reasons for their affirmative or negative responses. 
Children's definitions of 'family'. In section A the first two questions were general queries aimed at eliciting definitions of family from each participant. The first question asked, 'What do you think 'family' is?', and the following question enquired, 'Do you think 'family' is important? How come?' By focusing on family definitions and family importance, it is possible to assess the criteria that each child adopts in their explanations of what a family is, and what makes a family important or unimportant.

A component of Gilby and Pederson's (1982) Family Concept Interview involved children being asked to construct a 'typical family' using 18 cardboard figures. The aim of the task was to investigate the type of family groups constructed, and to establish whether participants formed a family group which mirrored their own family composition. In the present study the third question asked the children to identify who they think the members of a family are. The question was designed to establish which family structures are predominantly identified when the participants verbally construct a family group, rather than visually constructing a family. It is important to point out that the participants were asked who they think the members of a family are, not who they think the members of a 'typical family' are, as they were in Gilby and Pederson's study. This is because the use of the word 'typical', in the context of the present study, may have misled the children and placed expectations on their family group construction. Finch and Mason (1993) commented that hypothetical questions about third parties allow individuals to voice publicly expressed norms about what is correct and acceptable in society. The aim in this study was to avoid focusing on the 'typical' or standard family, but to allow young people to express their individual perspectives whether they were influenced by societal norms or not.

The next four questions were included as testers to familiarise the children with the hypothetical style of questioning present in section $\mathrm{B}$ and section $\mathrm{C}$. It is important that the child being interviewed has an understanding of, or experience with, the interview process (Gollop, 2000). Two of the questions were hypothetical vignettes which referred to the participant's own family. The scenarios involved a non-residential family member, and a co-residential non- 
family member. The final two questions in this section were general queries concerning male and female lone-parenting.

Vignettes depicting family groupings. In section B there were 12 questions in the form of vignettes. The questions were employed to investigate children's perceptions of family. Each vignette outlined a situation involving a minimum of two people. The vignettes were accompanied by a booklet of drawings which depicted the people described in each scenario. The pictures were labelled with the names of the individuals referred to in the vignettes (for examples of the pictures refer to Appendix $\mathrm{C}$ ). The booklet of pictures was created by the author to assist the children in the process of visualising and interpreting the relationships and scenarios put before them.

The vignettes and pictures included a range of scenarios: a cohabiting couple without children, a married couple without children, a co-residential non-family member, a child's grandparents, grandparents who have no contact with their grandchild, a child's relatives, children with no parents, a same-sex couple without children, and a same-sex couple with a child. Eight of these vignette scenarios were followed up with a question asking the participant whether the previously described relationship constitutes a family. Four of the vignette questions asked the participant whether they perceived the person or people described to be part of the family. In both cases affirmative or negative answers, and the reasoning for their responses, were requested.

Anyan (1998) suggested that the vignettes include individuals from a variety of ethnic backgrounds. The current study is a culturally comparative investigation; therefore, it was important that people from a variety of cultural backgrounds were represented in the scenarios. The vignettes and vignetterelated pictures include European, Māori, Pacific, and Asian individuals. Culturally relevant names were given to each character, and the pictures were drawn so that the ethnicity of the individuals was apparent.

O'Brien et al. (1996) noted that the children in their study appeared concerned about the lack of children in the household groupings. The authors 
recommended that future vignette based research should involve more than one child. It was decided for this study, however, that it is as equally important to include household groupings with one child, as it is to include groupings with two or more children.

Same-sex couples were the focus of four of the vignettes in section B. The vignettes did not specify that the individuals were in a homosexual relationship; the scenarios were vague and open to interpretation. There are a number of reasons for this omission. First, the participants are children and it is not the interviewer's place to be explaining homosexuality to any child who is uninformed. Second, if the children were unsure or uncomfortable about any of the questions they could choose not to answer them. Finally, the ambiguity of the questions is not a negative factor. O'Brien et al. (1996) recommended that the children are left to make their own interpretations, and draw their own conclusions, about the situations. Once the participants interpret the scenario they will then be able to decide whether the relationship constitutes a family. Any reasons given for their decision will inevitably provide insight into the child's interpretation of the vignette.

Vignettes depicting family change. In section $C$ there were 12 questions in the form of vignettes. The questions were employed to investigate children's perceptions of family transitions. Each vignette was accompanied by an associated drawing.

The first two vignettes described a cohabiting couple with a child, and a married couple with a child. Neither of these vignettes portrays a situation of family change. Both questions were designed to set the scene before the scenarios involving family change were introduced to the participants. Family transition was the focus of the remaining ten vignettes. The scenarios involved: a lone-parent, a non-resident parent, repartnered parent, remarried parent, a newly blended family, a blended family of ten years, a stepsibling relationship, a recent stepfather relationship, a stepfather relationship after ten years, and a stepmother relationship after ten years. Seven of these vignette scenarios were followed up with a question asking the participant whether the 
previously described relationship constitutes a family; for example, "Mrs Stephens's new husband, Mr Ngati, has a daughter called Hinemoa. Mrs Stephens and her son Sam move in with Mr Ngati and his daughter, Hinemoa. Are they a family?" Five of the vignette questions asked the participant whether a familial relationship exists between the people specified in the blended family scenarios; for example, "Now that Mrs Stephens's son Sam, and Mr Ngati's daughter Hinemoa live in the same house are they brother and sister?" In both cases affirmative or negative answers, and the reasoning for their responses, were requested.

\subsection{Procedure}

The questionnaire was pilot tested on eight children between 10 and 12 years of age (four males, four females). The children gave their verbal consent to participate in the study. A parent/caregiver of each child completed the consent and demographic forms, in order to ensure that the forms were understood and completed correctly. Additionally, the aims of the pilot study were to assess the children's understanding of the questionnaire questions, to time the interviews, and to assess whether accompanying pictures would elicit more information than verbal questions by themselves.

The participants were interviewed individually by the researcher. The four children who answered the interview questionnaire, without pictures, took on average 17 minutes to complete the interview. The four children, who completed the questionnaire with pictures, took an average of 21 minutes. The booklet of pictures was viewed by each child as the vignettes were read to them. The pictures assisted the children in their understanding and interpretation of the questions. There was less confusion and fewer requests for questions to be repeated than when the questions were asked by themselves. It was also apparent that the children interviewed with the vignette pictures provided more reasons in support of their answers than the children interviewed without pictures.

Two of the children involved in the pilot study asked additional questions about the vignette scenarios. An example of this is when a child questioned 
about the cohabiting couple asked, "How long have they been together?" This occurrence led to the decision to create more information about the relationship depicted in each vignette. The aim of this preparation was to ensure that all participants that asked questions about the scenarios would be given consistent information.

Once the pilot study was completed ten school principals were sent letters outlining the research project and requesting their assistance (refer to Appendix D). The schools were randomly chosen from a list of Wellington regional schools. The letters were followed up by phone calls one week later. Meetings were arranged to discuss the research with principals from six schools. With each principal's consent and co-operation letters containing information about the research, a consent form, and a demographic form were sent home with nine to 13 year old children (refer to Appendix $E, F$, and $A$ ). Parents who consented to their child's participation were asked to complete both the consent and demographic forms and return them in a sealed envelope to the school office.

The researcher arranged convenient times to undertake the interviews in school time. Information was provided to each participant verbally by the researcher. The verbal information included an introduction about the researcher and the research project. The participants' verbal consent to participate in the interview was discussed. They were informed of their right to withdraw from the interview at any time, that there were no right or wrong answers, and that they could pass on any questions they could not or did not want to answer.

Before the interview commenced the interviewer asked each participant a number of questions about his/her school. This conversation was employed due to a recommendation made by Gollop (2000) that the interviewer should not launch directly into the questions without trying to establish rapport and assurance with the child. It was also suggested that the interview process should begin with factual questions that the child can answer so that $s /$ he feels more confident and comfortable about the ensuing interview. The 
questionnaire, with pictures, took 111 children on average 24 minutes to complete. The children's responses were recorded in writing by the researcher.

\subsection{Data Analysis}

With regard to the qualitative analyses of the young people's definitions of families, the participants' responses to the open-ended questions were coded and organised categorically. The data were analysed in keeping with the qualitative research questions identified in section 5.1.2.

More specifically, the children's transcripts were analysed in full using Content Analysis. The data was quantified by creating codes and themes qualitatively that were then counted (Bryman, 2001). Each of the responses the children gave were analysed for its content and then coded for the specific themes mentioned in the response. For instance, if a child described 'family' as "People that love each other and live together" then the part of the response that mentioned love was coded as a reference to affective factors and the part that referred to living together was coded as cohabitation. The categories (i.e. affective factors, cohabitation etc.) were not predefined; they evolved out of the children's responses. The participants' answers that were coded in terms of select criteria were additionally analysed as frequency data.

All statistical analyses were performed by the Statistical Package for Social Sciences (SPSS 10) computer programme. The answers (yes, no, maybe/don't know) that the participants provided in the interview questionnaire were analysed in terms of the response frequencies for each question. The characteristics of the total sample were analysed as frequency data. The ages of the children in the sample were analysed as descriptive data.

In order to establish whether group differences existed in the endorsement of the various situations as family, chi-square analyses were performed. The between-groups comparisons involved children from original two-parent families, lone/step/shared care families, and extended families. Additionally 
comparisons were made of the children from European New Zealand, Māori, Pacific, and 'other' ethnic backgrounds.

Between-groups comparisons were also made of the participants with regard to sex, age, and where relevant, age at the time of parental separation. Again, chi-square analyses measured any group differences relating to the endorsement of the various situations as family. An independent samples ttest was performed to assess whether there were any differences between the number of transitions participants had experienced and their endorsement of situations as family. 


\section{Chapter Six}

\section{Results}

\subsection{Participant Characteristics}

For an outline of the participant characteristics refer to Table 6.1.

\subsubsection{Family structure}

The majority of the children resided in an original two-parent family, a oneparent family, a step or blended family, a shared care family, or an extended family. The extended family category referred to any family with a cohabiting relative or relatives, other than immediate family members. Of those participants who were identified as belonging to an extended family, $15 \%$ were living without parents and had extended family members as their primary caregivers. The remainder of the extended family participants were residing in an additional family grouping. In fact, $58 \%$ were living in an original two-parent family within the extended family structure, and $27 \%$ were living in a loneparent family within the extended family structure.

The lone-parent family category consisted of a single parent or a lone-parent with a non-resident partner. In $100 \%$ of the lone-parent sample the mother was the child's primary caregiver. The step/blended family group included all situations where there was a remarried or a repartnered parent. In the case of a repartnered parent, the partner had to be residential in order for the situation to be defined as a step/blended family. In $82 \%$ of the step/blended family sample the biological mother was the child's primary caregiver, and in $18 \%$ of the cases the biological father was the primary caregiver.

Children residing in a shared care family had separated or divorced parents who equally shared the care giving responsibilities. The shared care arrangement is an intricate family structure. Children living in this situation are experiencing two additional family structures as a result of the equal share living arrangement. In the present sample, $27 \%$ of children experiencing shared care family structures were spending equal amounts of time in a 
Table 6.1

Characteristics of the Sample

Gender Percent

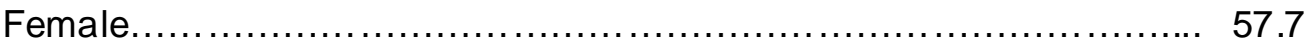

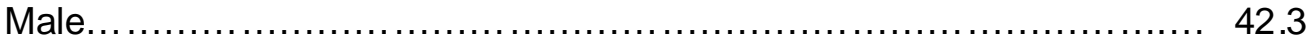

\section{Ethnicity}

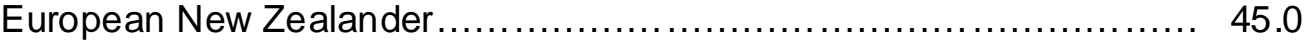

Māori.................................................................. $\quad 27.0$

Pacific peoples......................................................... 15.3

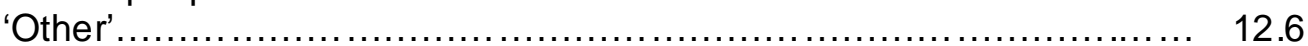

Family structure

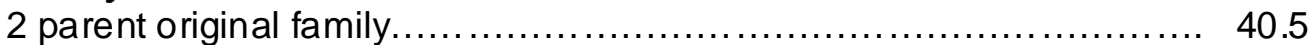

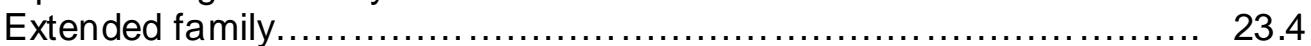

Lone-parent family ......................................................... 15.3

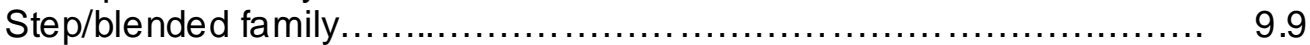

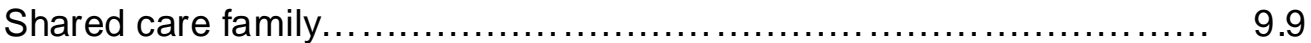

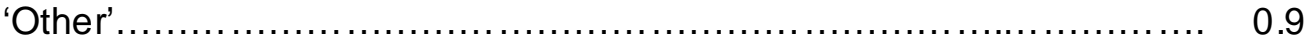

Full siblings

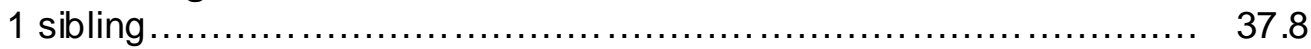

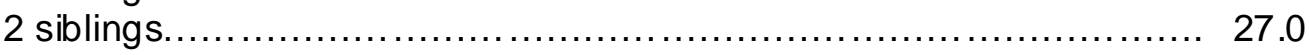

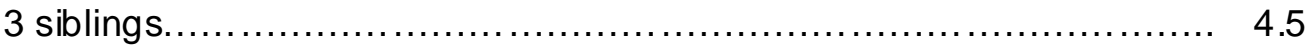

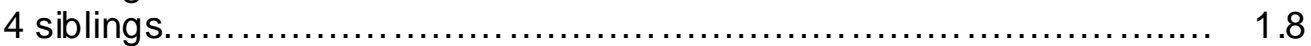

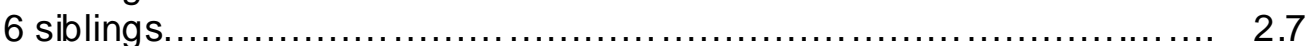

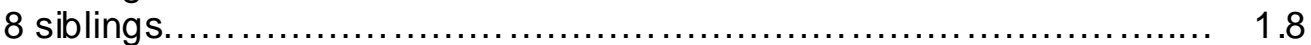

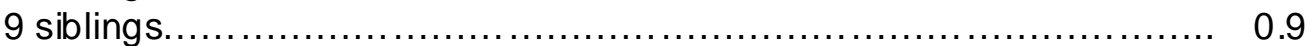

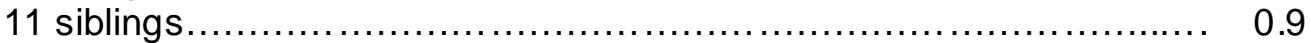

No full siblings......................................................... 22.5

Step siblings

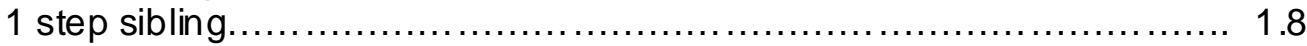

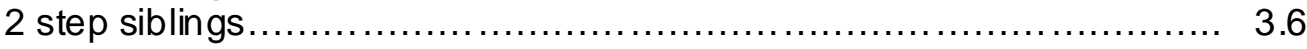

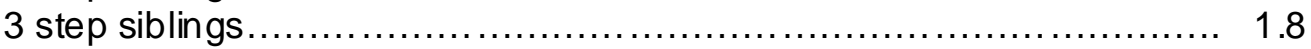

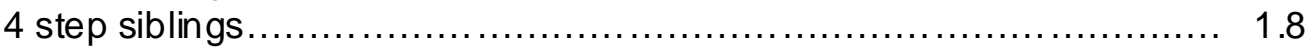

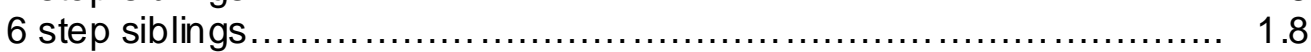

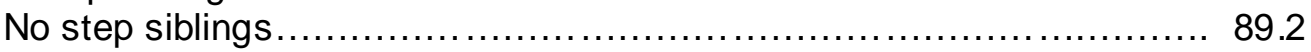

Half siblings

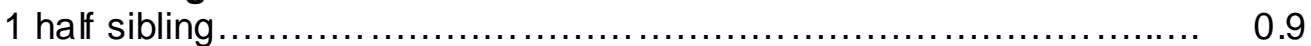

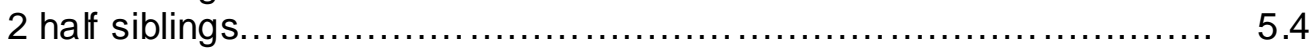

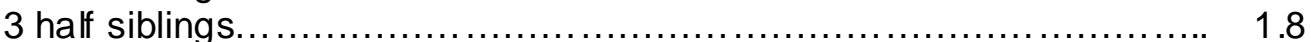

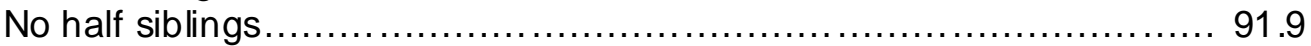

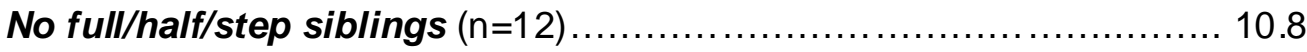




\section{Number of caregivers}

1 caregive

2 caregivers

3 caregivers

4 caregivers.

5 caregivers

Number of family transitions experienced

1 transition.

2 transitions.

3 transitions.

5 transitions.

Note. $n=111$, unless otherwise specified.

one-parent family household and in a stepparent family household. It was also found that $27 \%$ were spending equal time in two separate one-parent family structures, and $27 \%$ were residing in two separate stepparent family structures. Finally, $18 \%$ were living in a stepparent family structure, and an extended (lone-parent) family structure. The 'other' family structure category consisted of $1 \%$ of the sample; for example, a fostered child with legal guardians was placed in the 'other' family structure grouping.

Over half of the sample had one or two full siblings, $38 \%$ had one sibling, and $27 \%$ had two siblings. Only $8 \%$ of the sample had half-siblings and $11 \%$ had stepsiblings. Overall $11 \%$ had no full, half, or step siblings. The 'child's caregivers' was interpreted to include all regular providers of care, across all relevant households. Therefore, it is important to note that the person who completed the demographic form may have interpreted siblings, friends, relatives, foster parents, a parent's partner, or many others, as regular providers of care. Almost half of the children had two caregivers, $21 \%$ had three, $19 \%$ had four to five caregivers, and $12 \%$ had one caregiver.

\subsubsection{Transitions experienced}

Half of the sample had experienced changes to their family structure. Close to a quarter of the sample (22\%) had lived in two family structures and had, 
therefore, experienced one family transition; while $16 \%$ had undergone two family transitions. The highest number of family transitions was experienced by $12 \%$ of participants who had lived in four or more family structures and had, consequently, experienced three or more changes to their family structure.

\subsubsection{Cultural and family structure groups}

The majority of participants were European New Zealanders, Māori or Pacific peoples. The participants in the 'other' ethnic group were South African, Nepali, Sri Lankan, Chinese, German, Yugoslavian, Fijian, Weel Somalian, and Korean.

In the case where a child was identified as part Māori, or as part Māori and part another ethnicity, they were added to the Māori ethnic group. This may account for the high percentage of Mãori participants in the present study compared to the national ethnic demographic. The 2001 Census reports that $15 \%$ of people in New Zealand identify themselves as Māori, and $8 \%$ of Wellington city's population are identified as Māori. Compare these Census figures to the present study which attracted $27 \%$ Māori. Another factor which could account for this difference is the ethnic makeup of the schools which participated in the study.

All but one of the participants from the four ethnic groups were categorised into the five family structures: original two-parent family, shared care family, lone-parent family, stepfamily, and extended family. Table 6.2 presents a complete ethnic and family structure comparison.

For three out of four of the ethnic groups the highest percentages of participants were residing in an original two-parent family. The Pacific Island sample had the highest number in an original family structure. Of particular note are the high percentage of Māori and 'other' ethnic group participants residing in an extended family structure. A chi-square analysis revealed a significant difference $(p=.016)$ in ethnic groups and family structures. This 
difference may be explained by the fact that all the children in the shared care family category were European New Zealanders.

Table 6.2

Ethnicity and Family Structure

\begin{tabular}{|c|c|c|c|c|c|}
\hline \multirow{2}{*}{ Ethnicity \% } & \multicolumn{5}{|c|}{ Family Structure \% } \\
\hline & $\begin{array}{l}\text { Original } \\
n=45\end{array}$ & $\begin{array}{l}\text { Shared } \\
n=11\end{array}$ & $\begin{array}{l}\text { Lone } \\
n=17\end{array}$ & $\begin{array}{l}\text { Step } \\
n=11\end{array}$ & $\begin{array}{l}\text { Extended } \\
n=26\end{array}$ \\
\hline $\begin{array}{l}\text { European NZer } \\
n=50\end{array}$ & 40.0 & 22.0 & 12.0 & 12.0 & 14.0 \\
\hline $\begin{array}{l}\text { Māori } \\
n=29\end{array}$ & 37.9 & 0.0 & 24.1 & 3.4 & 34.5 \\
\hline $\begin{array}{l}\text { Pacific peoples } \\
n=17\end{array}$ & 58.8 & 0.0 & 11.8 & 11.8 & 17.6 \\
\hline $\begin{array}{l}\text { Other } \\
n=14\end{array}$ & 28.6 & 0.0 & 14.3 & 14.3 & 42.9 \\
\hline
\end{tabular}

Note. $n=110$.

For statistical and interpretation purposes the five family structures were recoded into three family structure groupings: an original two-parent family group, an extended family group, and a lone-parent family/stepfamily/shared care family grouping. The merge of the three family structure groupings was decided upon because of the common feature amongst these participants of family transitional experiences. In fact, $95 \%$ of the lone/step/shared care sample had experienced between one and six family transitions. Compare this to the children in the original family grouping that had not experienced any transitions; and the extended family group, where just under half of participants had experienced between one and three transitions (42\%). Refer 
to Table 6.3 for a comparison of family structure and the number of family transitions experienced.

Table 6.3

Family Structure and Family Transitions Experienced

\begin{tabular}{|c|c|c|c|}
\hline \multirow[b]{3}{*}{$\begin{array}{l}\text { No. of family } \\
\text { transitions \% }\end{array}$} & \multicolumn{3}{|c|}{ Family Structure \% } \\
\hline & $\begin{array}{l}\text { Original } \\
n=45\end{array}$ & $\begin{array}{c}\text { Lone+Step+Shared } \\
n=39\end{array}$ & $\begin{array}{l}\text { Extended } \\
n=26\end{array}$ \\
\hline & & & \\
\hline $\begin{array}{l}1 \text { transition } \\
n=24\end{array}$ & 0.0 & 33.3 & 24.2 \\
\hline $\begin{array}{l}2 \text { transitions } \\
n=17\end{array}$ & 0.0 & 33.3 & 11.3 \\
\hline $\begin{array}{l}3 \text { transitions } \\
n=11\end{array}$ & 0.0 & 23.1 & 6.5 \\
\hline $\begin{array}{l}5 \text { transitions } \\
n=1\end{array}$ & 0.0 & 2.6 & 0.0 \\
\hline $\begin{array}{l}6 \text { transitions } \\
n=1\end{array}$ & 0.0 & 2.6 & 0.0 \\
\hline $\begin{array}{l}\text { No transitions } \\
n=56\end{array}$ & 100.0 & 5.1 & 58.0 \\
\hline
\end{tabular}

Note. $n=110$.

For the recoded ethnic and family structure comparison refer to Table 6.4.

The above mentioned merge of family groupings clearly illustrates that almost half of the European New Zealand participants were residing in a lone-parent family, a stepfamily, or a shared care family and, therefore, had experienced between one and six family transitions. 
Table 6.4

Ethnicity and Family Structure

\begin{tabular}{llcc}
\hline \hline & \multicolumn{3}{c}{ Family Structure \% } \\
\cline { 2 - 4 } & $\begin{array}{l}\text { Original } \\
n=45\end{array}$ & $\begin{array}{c}\text { Lone+Step+Shared } \\
n=39\end{array}$ & $\begin{array}{c}\text { Extended } \\
n=26\end{array}$ \\
\cline { 2 - 3 } & & & \\
Ethnicity \% & 40.0 & 46.0 & 14.0 \\
$\begin{array}{l}\text { European NZer } \\
n=50\end{array}$ & 37.9 & 27.6 & 34.5 \\
$\begin{array}{l}\text { Māori } \\
n=29\end{array}$ & 58.8 & 23.5 & 17.6 \\
$\begin{array}{l}\text { Pacific peoples } \\
n=17\end{array}$ & & & \\
$\begin{array}{l}\text { Other } \\
n=14\end{array}$ & 28.6 & 28.6 & 42.9 \\
\hline \hline
\end{tabular}

Note. $n=110$.

\subsubsection{Separated and divorced parents sample}

For an outline of the characteristics of the children from separated or divorced parent families refer to Table 6.5. Of these children, $70 \%$ were five years old or younger when their parents separated and $22 \%$ experienced their parents' separation when they were between nine and 11 years of age.

At the time of the interview, 33\% of the children whose parents had separated or divorced were residing in a shared care arrangement and $30 \%$ were living in a stepfamily. The number of children living in a shared care family structure seems to be unusually high, although it is difficult to know the actual number of children residing in equal share arrangements in New Zealand due to the lack of statistics. Also of note were the $27 \%$ of children who were in a loneparent family and the $9 \%$ who were living with a lone-parent in an extended family structure. The $27 \%$ of children residing in lone-parent families is similar 
Table 6.5

Characteristics of the Sample with Separated/Divorced Parents

Current family structure

Shared care family

Step/blended family

Lone-parent family.

Extended family (Lone-parent)

Age at time of separation

Prenatal-2 years

3-5 years

6-8 years

9-11 years

Amount of contact with non residential parent

Shared care (joint custody)....

Weekly.....

Fortnightly....

Once a month.

Once every six months.

Once a year or more.

No contact.

Frequency of contact $(\mathrm{n}=16)$

Very frequent (weekly/fortnightly)

Infrequent (once a month or less)....

Gender of residential parent

Female

Male....

Shared care

Was information provided for parents at the time of separation/divorce? Yes.

No.

Of those who were provided with information how much was provided? $(\mathrm{n}=8)$

"Not enough"

In between "Not enough" and "About right"........................... 50.0

"About right".....

Of those who were provided with information how useful was it? $(n=8)$

"Not at all useful"....

In between "Not at all useful" and "Moderately useful".

Note. $n=33$, unless otherwise specified. 
to the actual number in New Zealand's population.

A third of the sample spent equal time with their mother and father as a result of the shared care living arrangement. Of those children residing in a step, lone, or extended family the majority were living with their biological mother. Just over a quarter of the sample had no contact with their non-resident biological parent.

In terms of the parents who experienced separation or divorce, only $24 \%$ were provided with information or support relating to the wellbeing of their child/ren. Out of these parents, $88 \%$ assessed the information to be 'not at all useful' or 'moderately useful'. No one evaluated the information they were provided with as 'extremely useful'.

\subsection{Endorsement of Family Groupings: Quantitative Analyses}

Of the 22 vignettes, 14 were perceived to be families by between $85 \%$ and $100 \%$ of participants. For a complete and ranked list of situations endorsed as family refer to Table 6.6. The participants unanimously endorsed the married couple with child scenario as a family. Also frequently endorsed was the nonresident biological father; $99 \%$ perceived him to be part of the family.

Question 6 enquired whether a mother and child constitute a family. It was one of the tester questions aimed at familiarising the participants with the hypothetical style of questioning. Question 22 was in the form of a vignette, but in terms of content it was similar to question 6 . It is interesting to note that the subjects responded at the same rate to both questions, with $89 \%$ endorsing question 6 as a family and $90 \%$ endorsing question 22 . Therefore, irrespective of the style of the questions the participants responded in the same manner.

The opposite, however, was found with question 5 (a tester question) which enquired whether an unrelated person that is residing with a family becomes part of the family, and question 10 (the vignette) which focused on a child that is residing with his friend's family. The subjects did not respond at the same 
rate to both questions, with only $56 \%$ endorsing question 5 and $65 \%$ in question 10. This difference may be explained by the fact that the content of the questions was quite different and, therefore, the participants were more likely to respond differently. In comparison, questions 6 and 22 were very similar in content.

Table 6.6

Percentage of Total Sample Endorsing Situations as Families

\begin{tabular}{|c|c|c|}
\hline 1. & Married couple + child (Q. 21). & \\
\hline 2. & Non-residential biological father (Q. 23). & \\
\hline 3. & Non-residential immediate family member (Q. 4). & \\
\hline 4. & Blended family of 10 years (Q. 29). & \\
\hline 5. & Grandparents (Q. 11). & 93. \\
\hline 6. & Grandparents, no contact (Q. 12). & 9 \\
\hline 7. & Aunt, uncle and cousins (Q. 13). & 93. \\
\hline 8. & Lone mother + her child + partner (recently married) (Q. 25). & 92. \\
\hline 9. & Children, no parents (Q. 14).. & 92. \\
\hline 10. & Lone-mother + children (Q. 22). & 9 \\
\hline 11. & ple + child (Q. 20) & 88 \\
\hline 11. & no children (Q.9) & 88 \\
\hline 13. & Lone-fa & 87. \\
\hline 14. & nded family (Q. 27). & 84 \\
\hline 15. & Residential unrelated person & 64 \\
\hline 16. & out love (Q.15). & 62. \\
\hline 17. & uple, no children (Q. 8). & 49 \\
\hline 18. & Cohabiting same-sex couple (female) + child ( & 48 \\
\hline 19. & Cohabiting same-sex couple (male) + child (Q. 17). & 48 \\
\hline 20. & Cohabiting same-sex couple (female), no children ( & \\
\hline 21. & same-sex c & \\
\hline & er + her child + non- & \\
\hline
\end{tabular}

Note. $n=111$.

The participants were equally divided on some of the vignette situations; namely, whether a cohabiting couple without children depicted a family and whether a cohabiting same-sex couple with children constituted a family. Refer to Table 6.7 for percentages of children who did not endorse situations as family, and for 'maybe' or 'I don't know' responses. The scenario least likely to be endorsed as family was a vignette describing a child, his lonemother, and her non-resident partner; $67 \%$ believed that this situation did not depict a family group. 
Table 6.7

Percentage of Total Sample not Endorsing Situations as Families.

\begin{tabular}{|c|c|c|}
\hline & $\begin{array}{c}\text { No } \\
\%\end{array}$ & $\begin{array}{c}\text { Maybe/ } \\
\text { Don't know } \\
\%\end{array}$ \\
\hline 1. & 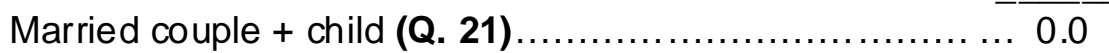 & 0.0 \\
\hline 2. & Non-residential biological father (Q. 23).... & 0.0 \\
\hline 3. & Non-residential immediate family member (Q. 4) .............. 2.7 & 1.8 \\
\hline 4. & 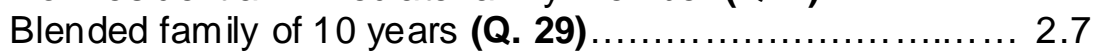 & 2.7 \\
\hline 5. & 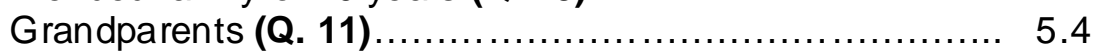 & 0.9 \\
\hline 6. & Grandparents, no contact (Q. 12) $\ldots \ldots \ldots \ldots \ldots \ldots \ldots \ldots \ldots \ldots .4 .5$ & 1.8 \\
\hline 7. & Aunt, uncle and cousins (Q.13)...... & 0.9 \\
\hline & Lone mother + her child + partner (recently married) (Q. 25). 1.8 & 5.4 \\
\hline & 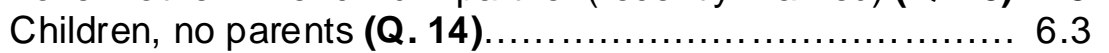 & 0.9 \\
\hline 10 & 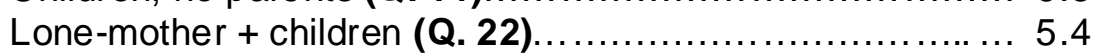 & 4.5 \\
\hline & Cohabiting couple + child (Q. 20). & 6.3 \\
\hline & Married couple, no children (Q. 9). & 0.0 \\
\hline & 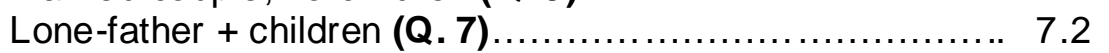 & 5.4 \\
\hline & 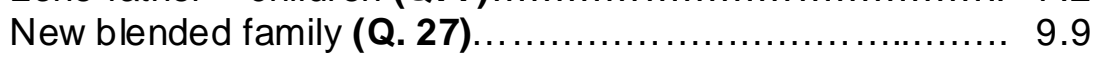 & 5.4 \\
\hline & Residential unrelated person (Q. 10)... & 6.3 \\
\hline & 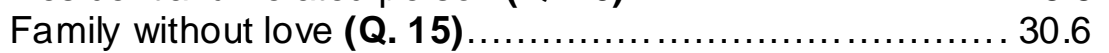 & 7.2 \\
\hline & Cohabiting couple, no children (Q. 8) $\ldots \ldots \ldots \ldots \ldots \ldots \ldots \ldots \ldots \ldots \ldots \ldots \ldots \ldots \ldots$ & 3.6 \\
\hline & Cohabiting same-sex couple (female) + child (Q. 19)......... 41.4 & 9.9 \\
\hline & Cohabiting same-sex couple (male) + child (Q.17).... & 10.8 \\
\hline & Cohabiting same-sex couple (female), no children (Q. 18)...58.6 & 5.4 \\
\hline & Cohabiting same-sex couple (male), no children (Q. 16).....60.4 & 4.5 \\
\hline 22 & Lone-mother + her child + non-residential partner (Q. 24)...66.7 & 13.5 \\
\hline
\end{tabular}

Note. $n=111$.

Of particular note is the low percentage of 'maybe' and 'I don't know' responses, indicating that the majority of participants expressed an unequivocal opinion about family. For three of the vignette questions none of the participants responded 'I don't know' or 'maybe', and for 16 of the questions between $1 \%$ and $7 \%$ of the sample responded 'I don't know' or 'maybe'. For three of the vignette questions between $10 \%$ and $14 \%$ responded 'I don't know' or 'maybe'. The highest percentage of 'I don't know' or 'maybe' responses (14\%) occurred when the participants were questioned whether a child, his lone-mother, and her non-resident partner constitute a family. 


\subsubsection{Differences in endorsement by family structure}

Chi-square analyses were performed to assess family structure group differences in the endorsement of situations as family. For statistical and interpretation purposes the chi-square analyses included 'yes' and 'no' answers only. The 'I don't know' and 'other' responses were disregarded. Before the analyses were carried out the data were examined and found to meet the assumptions of chi-square testing.

Refer to Table 6.8 for the percentage of children from original families, extended families, or from the lone/step/shared care grouping that either endorsed or did not endorse the various scenarios as family. Of the 24 scenarios, five revealed significant differences between the children from the three family structures and their endorsement of the situations as family.

These differences were found in question 9 which described a married couple without children, question 13 which involved an aunt, an uncle and two cousins, question 14 which referred to three cohabiting siblings without parents, and question 20 which described a cohabiting couple with a child. Children from original two-parent families were more likely to endorse these situations as family. In fact, all four questions were unanimously endorsed by the original family sample.

The final question, question 8 , involved a cohabiting couple without children. Very few participants from the extended family sample endorsed this situation as family compared to the original family sample and the lone/step/shared care grouping. 
Table 6.8

Percentages of Participants Endorsing Scenarios as Families: Differences According to Family Structure

Family Structure (percent)

$\begin{array}{lcc}\begin{array}{l}\text { Original } \\ (n=45)\end{array} & \text { Lone }+ \text { Step }+ \text { Shared } & \begin{array}{l}\text { Extended } \\ (n=26)\end{array}\end{array}$

Situation Yes ranking No Yes ranking No Yes ranking No $\boldsymbol{p}$

\begin{tabular}{|c|c|c|c|c|c|c|c|c|c|c|c|}
\hline Q4. & $\mathrm{n}=108$ & 100 & $(1=)$ & 0 & 95 & $(4=)$ & 5 & 100 & $(1=)$ & 0 & .165 \\
\hline Q7. & $\mathrm{n}=104$ & 88 & (6) & 12 & 95 & $(4=)$ & 5 & 96 & $(3=)$ & 4 & .377 \\
\hline Q8. & $\mathrm{n}=106$ & 53 & (11) & 47 & 62 & (13) & 38 & 27 & (13) & 73 & $.034^{\star}$ \\
\hline Q9. & $n=110$ & 100 & $(1=)$ & 0 & 74 & (10) & 26 & 89 & (6) & 11 & $.001^{*}$ \\
\hline Q10. & $n=103$ & 76 & (8) & 24 & 66 & (12) & 34 & 62 & (11) & 38 & .393 \\
\hline Q11. & $n=109$ & 100 & $(1=)$ & 0 & 90 & $(6=)$ & 10 & 92 & (5) & 8 & .106 \\
\hline Q12. & $\mathrm{n}=108$ & 100 & $(1=)$ & 0 & 90 & $(6=)$ & 10 & 96 & $(3=)$ & 4 & .082 \\
\hline Q13. & $n=109$ & 100 & $(1=)$ & 0 & 87 & (7) & 13 & 96 & (2) & 4 & $.035^{\star}$ \\
\hline Q14. & $\mathrm{n}=109$ & 100 & $(1=)$ & 0 & 92 & (5) & 8 & 85 & (8) & 15 & $.037^{\star}$ \\
\hline Q15. & $n=102$ & 64 & (9) & 36 & 72 & (11) & 28 & 62 & $(10=)$ & 38 & .676 \\
\hline Q16. & $\mathrm{n}=105$ & 42 & (13) & 58 & 37 & (17) & 63 & 23 & $(14=)$ & 77 & .298 \\
\hline Q17. & $\mathrm{n}=98$ & 60 & $(10=)$ & 40 & 60 & (14) & 40 & 35 & $(12=)$ & 65 & .105 \\
\hline Q18. & $\mathrm{n}=104$ & 43 & (12) & 57 & 40 & (16) & 60 & 23 & $(14=)$ & 77 & .248 \\
\hline Q19. & $\mathrm{n}=99$ & 60 & $(10=)$ & 40 & 58 & (15) & 42 & 35 & $(12=)$ & 65 & .119 \\
\hline Q20. & $n=103$ & 100 & $(1=)$ & 0 & 95 & $(4=)$ & 5 & 83 & (9) & 17 & $.022^{\star}$ \\
\hline Q21. & $\mathrm{n}=110$ & 100 & $(1=)$ & 0 & 100 & $(1=)$ & 0 & 100 & $(1=)$ & 0 & - \\
\hline Q22. & $n=105$ & 91 & (5) & 9 & 97 & (2) & 3 & 96 & $(3=)$ & 4 & .376 \\
\hline Q23. & $\mathrm{n}=105$ & 98 & (2) & 2 & 100 & $(1=)$ & 0 & 100 & $(1=)$ & 0 & .467 \\
\hline Q24. & $\mathrm{n}=96$ & 30 & (14) & 70 & 24 & (18) & 76 & 12 & (15) & 88 & .264 \\
\hline Q25. & $\mathrm{n}=104$ & 100 & $(1=)$ & 0 & 97 & (3) & 3 & 96 & (4) & 4 & .428 \\
\hline Q27. & $n=104$ & 93 & (3) & 7 & 86 & (8) & 14 & 88 & (7) & 12 & .543 \\
\hline Q29. & $\mathrm{n}=98$ & 100 & $(1=)$ & 0 & 95 & $(4=)$ & 5 & 96 & $(3=)$ & 4 & .332 \\
\hline
\end{tabular}




\subsubsection{Differences in endorsement by ethnicity}

Chi-square analyses were also carried out in order to ascertain whether there were ethnic group differences in the endorsement of scenarios as family. Similarly the chi-square analyses included 'yes' and 'no' answer only. Before the analyses were carried out the data were examined and found to meet the assumptions of chi-square testing.

Refer to Table 6.9 for the percentage of European New Zealand, Māori, Pacific peoples, and 'other' children that either endorsed or did not endorse the various situations as family. Of the 24 scenarios, five revealed significant differences between the children from the four ethnic groups and their endorsement of the situations as family.

These differences were found in question 8 which described a cohabiting couple without children, question 16 which involved a same-sex (male) couple without children, and question 18 which depicted a same-sex (female) couple without children. In all three questions the Māori participants were less likely to endorse the situations as family compared to the European New Zealand, Pacific peoples, and 'other' ethnic groups.

Question 14 described a scenario involving three cohabiting siblings who were without parents. The participants from the 'other' ethnic group were less likely to refer to this situation as family compared to the European New Zealand, Māori, and Pacific participants.

Finally, question 27 described a newly blended family. The Pacific Island sample was less likely to endorse this scenario as family compared to the three other ethnic groups. However, when the blended family had been together for ten years the Pacific Island children unanimously endorsed the situation. Less importance was placed on the time the family had been together by the European New Zealand, Māori, and 'other' ethnic groups. 
Table 6.9

Percentages of Participants Endorsing Scenarios as Families: Differences According to Ethnicity

Ethnicity (percent)

European NZer

$(n=50)$
Māorì

$(n=30)$

\section{Pacific peoples}

$(n=17)$
Other

$(n=14)$

Situation Yes ranking No Yes ranking No Yes ranking No Yes ranking No $\boldsymbol{p}$

\begin{tabular}{|c|c|c|c|c|c|c|c|c|c|c|c|c|c|}
\hline 4. $n=109$ & 100 & $(1=)$ & 0 & 93 & $(2=)$ & 7 & 100 & $(1=)$ & 0 & 100 & $(1=)$ & 0 & .147 \\
\hline 7. & 90 & (9) & 10 & 00 & $=)$ & 0 & 82 & $\Rightarrow$ & 18 & 0 & $=)$ & 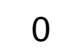 & .106 \\
\hline 107 & 55 & (14) & 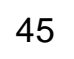 & 29 & ) & 71 & 7 & ) & 29 & 62 & $\Rightarrow$ & 38 & $27^{\star}$ \\
\hline . $n$ & 86 & (10) & 14 & 83 & (5) & 17 & 100 & 1 & 0 & 90 & $\Rightarrow$ & 7 & .320 \\
\hline 10. $n=104$ & 74 & (12) & 26 & 60 & (7) & 40 & 71 & $(4=)$ & 29 & 71 & 5) & 29 & .617 \\
\hline 11. $n=110$ & 92 & $(6=)$ & 8 & 93 & $(2=)$ & 7 & 100 & $(1=)$ & 0 & 100 & $(1=)$ & 0 & .463 \\
\hline 109 & 90 & (8) & 10 & 100 & $(1=)$ & 0 & 100 & $(1=)$ & 0 & 100 & $(1=)$ & 0 & .103 \\
\hline 0 & 92 & $(6=)$ & 8 & 100 & $(1=)$ & 0 & 100 & (1 & . & 86 & 3) & 14 & .137 \\
\hline 0 & 92 & $(6=)$ & 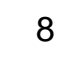 & 100 & $(1=)$ & 0 & 100 & $(1$ & 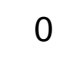 & 79 & 4) & 21 & $.032^{\star}$ \\
\hline 03 & 68 & (13) & 32 & 82 & (6) & 10 & 50 & (6) & 30 & 50 & $(9=)$ & 50 & .113 \\
\hline 106 & 44 & (16) & 56 & 10 & (12) & (5) & 43 & $(7=)$ & 57 & 50 & $(9=)$ & 50 & $.009^{\star}$ \\
\hline $17 \cdot n=99$ & 59 & $(14=)$ & 41 & 43 & $(8=)$ & 57 & 55 & $(5=)$ & 45 & 67 & (6) & 33 & .466 \\
\hline 18. $n=105$ & 46 & 15) & 54 & 10 & (11) & 90 & 43 & $(7=)$ & 57 & 50 & $(9=)$ & 50 & .008 \\
\hline 100 & 59 & $(14=)$ & 41 & 43 & $(8=)$ & 57 & 55 & $(5=)$ & 45 & 62 & $(8=)$ & 39 & .556 \\
\hline 20. $n=104$ & 94 & (6) & 6 & 100 & $(1=)$ & 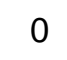 & 88 & (-) & 12 & 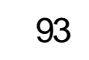 & $(2=)$ & 7 & .436 \\
\hline 21. $n=111$ & 100 & $(1=)$ & 0 & 100 & $(1=)$ & 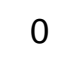 & 100 & $(1=)$ & 0 & 100 & (1-) & 0 & \\
\hline Q22. $n=106$ & 94 & (4) & 6 & 100 & $(1=)$ & 0 & 82 & $(3=)$ & 18 & 100 & $(1=)$ & 0 & .074 \\
\hline Q23. $n=111$ & 98 & (2) & 2 & 100 & $(1=)$ & 0 & 100 & $(1=)$ & 0 & 100 & $(1=)$ & 0 & .746 \\
\hline Q24. $n=96$ & 18 & (17) & 82 & 19 & (10) & 81 & 43 & $(7=)$ & 57 & 27 & $(10)$ & 73 & .248 \\
\hline Q25. $n=105$ & 96 & (3) & 4 & 100 & $(1=)$ & 0 & 100 & $(1=)$ & 0 & 100 & $(1=)$ & 0 & .507 \\
\hline Q27. $n=105$ & 94 & (7) & 6 & 90 & (3) & 10 & 71 & $(4=)$ & 29 & 100 & $(1=)$ & 0 & $.034^{\star}$ \\
\hline 29. $n=108$ & 54 & $5=)$ & & 100 & $(1=)$ & 0 & 100 & $(1=)$ & 0 & 100 & $(1=)$ & 0 & .294 \\
\hline
\end{tabular}




\subsubsection{Differences in endorsement by gender and age}

Chi-square analyses were performed to assess further group differences in the endorsement of the various scenarios as families. The categories that were explored were gender, age at the time of the interview, and age at the time of parental separation. The chi-square assumptions were met.

First, in terms of gender it was found that out of the 24 scenarios three revealed significant differences between the male and female participants and their endorsement of the situations as family. In all three questions the female participants were more likely to endorse the scenarios compared to their male counterparts. Question 13 enquired whether an aunt, uncle, and two cousins were family, $98 \%$ of the female participants endorsed them as family compared to $89 \%$ of the males. In question 17 , which described a cohabiting same-sex (male) couple with a child, $64 \%$ of the female sample endorsed the situation as family compared to only $40 \%$ of the male participants. Similar results were found for question 19 , which described a cohabiting same-sex (female) couple with a child.

To test for response differences in terms of age, the participants were divided into two groups: nine to 10 year olds and 11 to 13 year olds. Out of the 24 situations only two revealed significant differences. In both questions the older participants were more likely to endorse the scenarios as family compared to their younger counterparts. Question 10 enquired whether an unrelated person that lives with his friend's family is interpreted to be part of the family. In the 11 to 13 year old group, $75 \%$ endorsed the situation as family, compared to only $45 \%$ of the nine to 10 year olds. Question 15 investigated whether a mother, father, and son that do not love each other are a family. In the 11 to 13 year old group, $72 \%$ stated that they were family. In comparison only $48 \%$ of the nine to 10 year olds endorsed the scenario as representative of a family.

Finally, to test for any differences in the separated/divorced parent sample it was decided to look at each child's age at the time of his/her parents' separation, as well as the number of family transitions experienced. Four 
groups were constructed to test for any differences between age at the time of parental separation and endorsement of the scenarios as families. The four groups were composed of: prenatal to two year olds, three to five year olds, six to eight year olds, and nine to 11 year olds. Out of the 24 questions only one significant difference was found in question 15. It is feasible that this lone significant finding could be explained by chance.

\subsubsection{Differences in endorsement by transitions experienced}

An independent-samples t-test was performed to assess whether there were any differences in the number of family transitions participants had experienced and their endorsement of the situations as family. Of the 24 situations, three revealed significant differences. In all three cases those who had experienced a greater number of changes to their family structure were less likely to endorse the situations as family. Question 4 investigated whether a non-resident family member still belongs to the family. Out of the separated/divorced parent sample the 51 subjects who endorsed the situation as family had experienced a mean number of 1.7 transitions, whereas the three subjects who did not endorse the situation had experienced a mean number of 3.0 transitions $[t(50)=-12.22, p=.000]$.

Question 10 investigated whether an unrelated person cohabiting with his friend's family is interpreted to be part of the family. A total of 35 subjects with a mean number of 1.6 transitions endorsed the situation as family; compared to the 15 subjects with a mean number of 2.3 transitions that did not endorse the situation $[t(48)=-3.09, p=.003]$. Finally, question 27 investigated whether a newly blended family was interpreted by the children to be a family. A total of 45 subjects who had experienced a mean number of 1.6 family transitions endorsed this situation as family; whereas, five subjects with a mean number of 2.4 transitions did not endorse the situation as family [ $t(48)=-2.20, p=.033]$. Thus, it appears that in these four scenarios the fewer transitions the child had experienced the more likely they were to endorse the situation as family. For the majority of the vignettes there were no significant differences between the children's family transitions and their endorsement of the vignettes. 


\subsection{The Concept of Family: Qualitative Analyses}

\subsubsection{Definitions of 'family'}

One of the interview questions enquired, "What do you think 'family' is?" The participants' answers were coded in terms of the criteria derived from their responses. The following categories emerged: affective/nurturing factors, family members, biological factors, cohabitation, legal factors, 'I don't know' and 'other' responses.

Affective factors were defined as love, care, support, companionship, closeness, and nurturing. An example of an answer coded as affective/nurturing is: "Family is people who care for and love you, and are there for you." (Māori female, aged 10). The family member's category included responses which listed individuals or relationships. For example, "Family is your parents and your brother and your sister and your aunts and uncles and cousins and grandparents and friends. Well it's really anyone that you want as part of your family" (New Zealand European female, aged 12).

Biological factors included responses which mentioned blood relatedness; for instance, "Family is made up of blood relations." (Pacific Island male, aged 12). The legal factors category included marriage or other law related responses, such as: "Family is marriage and children." (Māori female, aged 9). Answers which referred to people living together in the same dwelling were classified as cohabitation; for example, "Family is a group of people who live together in a house." (New Zealand European female, aged 9). The final category attended to all uncertain ('I don't know') responses as well as all 'other' responses that did not fit the mould of the identified categories. An example of a response classified in the 'other' category is, "Family is great!" (Weel Somalian female, aged 12).

The participants' answers, which provided qualitative data, were coded independently by two individuals in order to test the inter-rater reliability of the criteria. In question 1 it was found that $92 \%$ of the coded responses were agreed upon between the two raters. The two individuals discussed the 
remaining $8 \%$ of responses; the differences in coding were resolved by mutual agreement. A large number of the participants $(78 \%)$ mentioned one criterion in their response, $15 \%$ mentioned two criteria, $7 \%$ mentioned between three and four criteria. When defining family, $55 \%$ of the sample referred to affective/nurturing components. Also commonly mentioned were family members, biological factors, and cohabitation. The children's definitions rarely contained legal references. For an outline of the criteria mentioned in the participants' definitions of family refer to Table 6.10.

Table 6.10

Percentages of Criteria Mentioned in Definitions of 'Family' (Q.1)

Criteria

$\%$ that mentioned the criteria

1. Affective/nurturing factors............................................ 55.0

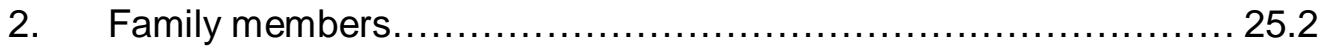

3. Biological factors..................................................... 24.3

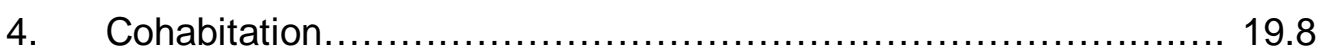

5. Don't know + Other................................................. 5.4

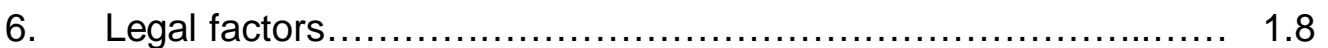

Note. $n=111$.

\subsubsection{Family importance}

The participants were also asked the question, "Do you think 'family' is important? How come?" Of the sample, 100\% unanimously endorsed family as important. The children's reasoning was coded by the criteria that emerged from their responses. Their answers covered a limited range of criteria: affective/nurturing factors, biological factors, and the 'I don't know' and 'other' responses. The majority of the sample (96\%) mentioned just one criterion, and $4 \%$ mentioned two criteria. Again, the participants' answers were coded independently by a second individual to test the inter-rater reliability. It was 
found that $98 \%$ of the coded responses in question 2 were agreed upon between the two raters. The remaining $2 \%$ of participants' responses were resolved through discussion and mutual agreement.

The most frequently referred to criterion was affective/nurturing factors, with $78 \%$ of the children responding that family is important because of affective or care related components. For example, "You need family to give you love, support and care." (New Zealand European male, aged 11), also "Parents look after you when you are sick, and they love you because they brought you up." (Pacific Island male, aged 11).

Also of note was the large percentage of 'I don't know' and 'other' responses for this question. For example, the following answer was classified as belonging to the 'other' category: "If there is a family two people can do all the work and everyone else can play." (New Zealand European male, aged 10). Only $7 \%$ of the sample mentioned biological factors in their answers, such as: "Family is important because they are the ones that made you and are related to you." (Māori female, aged 12). For an outline of the criteria mentioned by the participants when they were asked why family is important refer to Table 6.11 .

\subsubsection{Family composition}

In order to understand children's beliefs surrounding family makeup, the participants were asked "Who do you think the members of a 'family' are?" The children's responses were coded into four categories: immediate family, immediate family and relatives, anyone you consider to be family, and finally the 'I don't know' and 'other' category. All participants mentioned just one criterion in their response. The inter-rater reliability for question 3 was $100 \%$ agreement between the two raters.

The immediate family category contained responses that referred to two parents and their children. Married parents with children (i.e. the traditional 'nuclear family' image), as well as parents who were not married but were a cohabiting couple with children, were incorporated into this category. For 
example, "The members of a family are a mum, dad, and children." (Pacific Island male, aged 12). The immediate family and relatives category included two parents, their children, and relatives. This category referred to immediate family and relatives who were living together as well as those who were not cohabiting. For example, "Family members are grandparents, great grandparents, parents, sisters, and brothers." (Nepali male, aged 12).

Table 6.11

Percentages of Criteria Mentioned in Responses Relating to Family Importance (Q.2)

Criteria

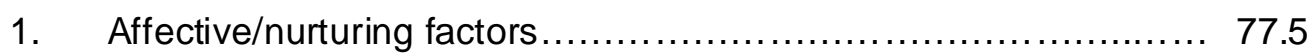

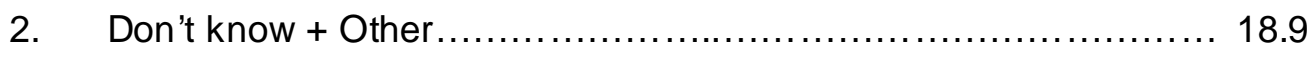

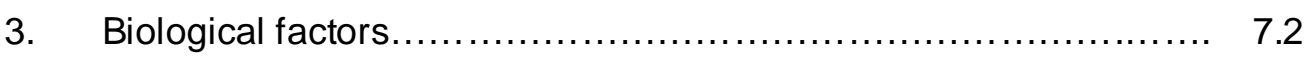

Note. $n=111$.

The 'anyone you consider to be family' category was created out of a range of responses. Generally the responses referred to family members as: a wide range of people, anyone you are close to, anyone you want as family, anyone who has joined the family such as a parent's new partner, a family friend, a stepparent, stepsiblings, and so on. For example, "The members of a family are a mother and father, brothers and sisters, step mum or dad, any relatives really, and any people you want to be part of your family. Family members can be heaps of different people." (New Zealand European male, aged 11).

When asked who they think the members of a family are, the largest percentage of participants (37\%) specified that the members of a family could be anyone that an individual considers to be family. The immediate family form was endorsed by a quarter of the sample; compared to $32 \%$ that referred 
to immediate family and relatives as family members. For an outline of the family forms that the children mentioned when they were questioned about family composition refer to Table 6.12.

Table 6.12

Percentages of Family Forms Mentioned in Responses Relating to Family Composition (Q.3)

Family categories

$\%$ that mentioned

the category

1. Anyone you consider to be family ............................. 36.9

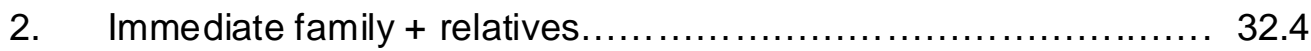

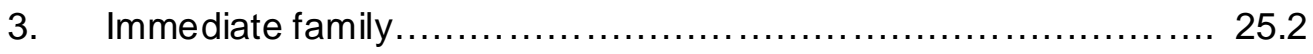

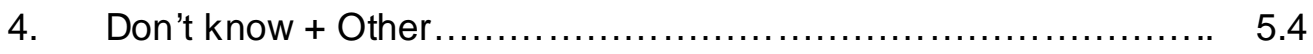

Note. $n=111$.

\subsubsection{Family transitions}

The participants were asked a number of vignette questions in section $\mathrm{C}$ which focused on family structure changes. Four of these vignettes, (questions 26, 28, 30 and 31), focused on whether familial relationships existed between the individuals mentioned in the vignette scenarios.

These questions were not included in the chi-square analyses. The reason for this omission was that the step-relationships were not openly identified in any of the four vignettes; the situations were left open to interpretation. As a result of this ambiguity the participants' 'yes' and 'no' answers were disregarded, and instead the reasoning for their answers was analysed.

The participants' reasoning was coded into one of six possible criteria: affective step-relationship, non-biological step-relationship, legal steprelationship, non-biological relationship, adding parent response, and 
cohabitation step-relationship. All participants mentioned just one criterion in their response. For each of the four questions the inter-rater reliability of the criteria was tested. For question 26 there was $90 \%$ agreement between the two raters, question 28 achieved $94 \%$ agreement, question 30 resulted in $97 \%$ agreement, and finally for question 31 there was $94 \%$ agreement of the coding of participants' responses. The responses that were not agreed upon were discussed by the two raters and resolved via joint consensus.

The first criterion, affective step-relationship, included any responses that identified the step-relationship and recognised an affective/nurturing component to their relationship. The non-biological step-relationship criterion incorporated responses that identified the step-relationship and referred to the fact that they were not biologically related. The legal step-relationship category included any responses that identified a step-relationship and also a legal connection. The non-biological relationship criterion included responses that mentioned the absence of a biological connection and, therefore, the absence of a familial relationship. The fifth criterion, adding parent, was applicable to questions 26,30 and 31 . The adding parent response referred to the presence of two parental figures: a non-resident biological parent and a co-resident stepparent. The final criterion, cohabitation step-relationship, included responses that focused on the step and co-residence connection. Refer to Table 6.13 for an overview of the criteria mentioned for each of the four family transition vignettes.

In question 26 the participants were questioned whether Mr Ngati was the father of Sam in the context of a newly blended family. Out of the sample, $40 \%$ referred to him as a stepfather, but specified that they were not biologically related. For example, "He is Sam's stepfather; they are not genetically the same." (New Zealand European male, aged 12). In comparison, $25 \%$ did not mention the step-relationship, but identified the absence of a biological connection and, therefore, the lack of a familial relationship. For example, “No he is not Sam's father because he didn't help make him." (New Zealand European male, aged 11). The affective stepfather connection was referred to by $16 \%$ of the children. For example, "He is Sam's 
stepfather, but he may love him and he may act more like a real father." (Korean female, aged 11). The adding parent criterion was alluded to by $11 \%$ of the sample; for example, "Mr Stephens is Sam's father, but Mr Ngati is a father to Sam while Mr Stephens is not there." (Māori female, aged 12). Finally, only $8 \%$ of the sample mentioned the legal step connection. A typical response was, "Mrs Stephens is Sam's mother and she married Mr Ngati, so he is now Sam's stepfather." (New Zealand European male, aged 10).

In question 30 the participants were again questioned whether Mr Ngati was the father of Sam, but this time in the context of a blended family of ten years. The percentage of children that endorsed the situation as representative of an affective stepfather relationship doubled compared to question 26 . It is also apparent that only half the number of children referred to the fact that they were not biologically related compared to question 26 . Interestingly, the cohabiting step-relationship was not referred to by any of the participants for both questions 26 and 30 . Similar results were found for question 31 .

Question 28 enquired whether the two children in the newly blended family were brother and sister. The findings indicated that $44 \%$ of the subjects classified them as stepsiblings, but specified that they were not biologically connected. A typical response was, "They have different parents so they are stepbrother and sister." (New Zealand European male, aged 10). Similarly, $23 \%$ of the sample identified them as stepsiblings, but referred to an affective connection instead of a biological one. For example, "Yes they are stepbrother and sister. They love each other and they act like brother and sister." (Māori female, aged 12).

Fewer participants referred to the step legal relationship, the step cohabitation connection, and the fact that they were not biologically connected. There were only 108 responses included in Table 6.13 for this question. The remaining participants, $3 \%$ of the sample, provided uncertain responses which were classed in the 'I don't know' category and were omitted from the table. 
Table 6.13

Family Change - Stepfamily Relationship Questions: Percentages of Criteria Mentioned in Reasoning

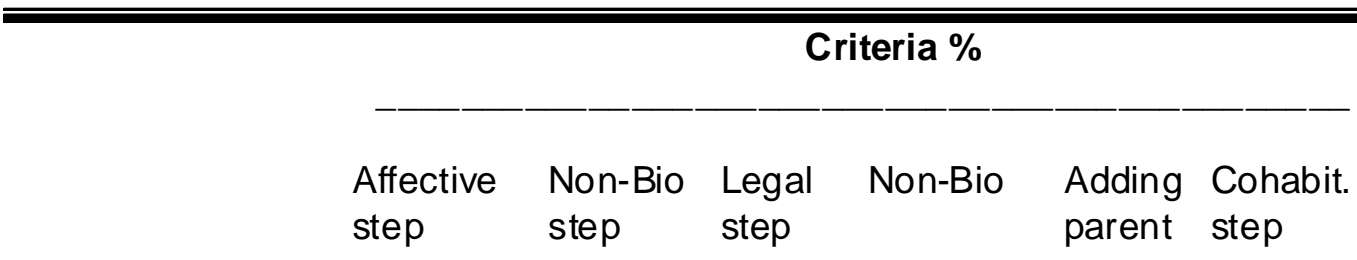

Situations

Q.26

Is he his father?

$16.2 \quad 39.6$

8.1

25.2

10.8

0.0

(New blended family)

Q.28 $(n=108)$

Are they brother and sister?

22.5

44.1

12.6

9.9

$\mathrm{N} / \mathrm{A}$

8.1

(New blended family)

Q.30

Is he his father?

(10 years have

$$
34.2
$$

38.7

$4.5 \quad 13.5$

$9.0 \quad 0.0$

passed).

Q.31

Is she her mother?

(10 years have passed).

32.4

39.6

$8.1 \quad 12.6$

$\begin{array}{ll}7.2 & 0.0\end{array}$

Note. $n=111$, unless otherwise specified.

\subsubsection{Overall inter-rater reliability}

As previously mentioned the participants' answers to seven of the interview questions, (questions 1, 2, 3, 26, 28, 30, and 31), were coded by a second individual. The extent to which the coding for these questions was repeated with similar results is an important factor in assuming reliability of the qualitative results. Overall, it was found that out of a total of 777 answers the two raters independently agreed on 738 of the coded responses. Therefore, for all seven questions there was an overall inter-rater reliability of $95 \%$. 


\section{Chapter Seven \\ Discussion}

The $21^{\text {st }}$ century family is clearly not a static global structure. Families will continue to become more diverse and children will experience family transitions. It is important to understand how young people conceptualise families before investigating their experiences of family structure change. By understanding what 'family' means to young people, we are better equipped to understand the experiences of a young person confronted with family change.

Study One aimed to investigate children's perceptions of family groupings and definitions of family. Children's perceptions were compared across family structures and cultural backgrounds. Furthermore, differences were explored by gender, between child age groups and by the number of family transitions experienced. Developmental comparisons were additionally carried out with an adolescent sample, and are reported and discussed below.

\subsection{The Endorsement of Family Groupings}

\subsubsection{Children versus adolescents}

In general, the children in Study One accepted a large number of the groupings as families. It is informative to compare these findings with previous research. In particular, comparisons with Anyan and Pryor's (2002) findings, from adolescents in New Zealand, are informative in order to ascertain whether development sequences exist. Table 7.1 shows a comparison of responses from the two studies.

The children in this study voiced their opinions about families with ease, as did Anyan and Pryor's (2002) adolescent sample. The one scenario that was endorsed as family by 100 percent of the children was the traditional image of a married couple with a child. Anyan and Pryor also reported that high numbers of their adolescent participants endorsed the married couple with 
child scenario. Similarly in Gilby and Pederson's (1982) study, the child participants (with a mean age of 9 years 11 months) and the young adult participants unanimously endorsed the married couple with child scenario as a family. In terms of the two groups of younger participants (aged between five and nine years), 90 to 95 percent perceived the scenario to be a family. Irrespective of children's age, the original two-parent family is consistently interpreted to be a family.

In this study, however, the traditional married couple with children family was not the only image they had of families. Between 85 percent and 99 percent of participants endorsed various groupings, such as: extended family, blended families, one-parent families, married couples, cohabiting couples with children, non-resident parents, and non-resident family members. The children, therefore, endorsed a wide array of scenarios as examples of families.

Of particular interest is comparing how scenarios involving married, cohabiting (de facto), and same-sex couples were perceived. Recently in New Zealand legislation was enacted to allow de facto couples in heterosexual or homosexual relationships the right to have their partnerships legally recognised through a civil union. At least four in 20 partnered men and women over 15 years of age were living in de facto relationships in 2006 (Statistics New Zealand, 2008). No differences were found between cohabiting and married parents when Pryor and Roberts (2005) examined aspects of commitment, commitment behaviour and relationship satisfaction. Pryor's findings indicate that there are more similarities between cohabiting and married couples than there are differences. It is, therefore, pertinent to provide some insight into how young people view these relationships.

The children tended to view childless couples who are married and childless couples who are cohabiting differently. Married couples constituted family for 88 percent of participants compared with cohabiting couples who were identified as family by 50 percent of participants. However, once these scenarios included children the importance of marriage diminished. The 
married couple with children vignette may have been unanimously supported as a family, but the cohabiting couple with children scenario was also highly endorsed (88\%). Parallels exist with Morrow's (1998) study, where the older children generally endorsed the married couple without children vignette and both the married and cohabiting couples with children vignettes as families.

Similar percentages were also found for the adolescent sample in Anyan and Pryor's (2002) study. Although, the adolescents were less likely to endorse the married couple without children vignette; just 62 percent interpreted the scenario as a family. This suggests that children were an important family component for these adolescents. With regard to the cohabiting couple without children vignette, Anyan and Pryor (2002) did not include an equivalent vignette.

In summary, the findings discussed above in relation to married and cohabiting couples show that a couple have to either have children or be married in order to be classified as a family. This is in contrast to the younger children in O'Brien, Alldred and Jones's (1996) study who commented that cohabiting couples with children should be married. Indeed just 33 percent of seven to 10 year olds interpreted the de facto couple with child scenario to be a family, compared to 74 percent of their older counterparts. The time lag between these studies and differences in social context may explain the variation in findings. Interestingly, for the majority of the participants in the present study and Anyan and Pryor's study, marriage was not viewed as essential in order to form a family. It is therefore likely that if marriage is not seen as necessary then civil unions may be viewed as an acceptable alternative by these young people.

Clearly, cohabiting couples were perceived to be representing a family if they intended to raise children, but what about cohabiting same-sex couples? It is important to note that the vignettes did not openly identify the homosexual relationships to the children. The vignettes were left open to interpretation, for example, "Anita and Rachel are two women aged 30. They live together. Neither of them have a child. Are they a family?" The ambiguous nature of the 
questions was decided upon because of the age of participants. From the responses received it is clear that the majority of the children interviewed were aware of the homosexual nature of the relationships.

Table 7.1

Percentages of Scenarios Endorsed as Families: Children vs. Adolescents

\begin{tabular}{|c|c|c|}
\hline 1. & $\begin{array}{c}\begin{array}{c}\text { Children } \\
(n=111) \\
\text { percent } \\
\ldots \ldots 100.0\end{array}\end{array}$ & $\begin{array}{c}\text { Adolescents } \\
(n=232) \\
\text { t } \\
\text { percent } \\
0 \\
99.6\end{array}$ \\
\hline 2. & Non-residential biological father (Q. 23) & 62.8 \\
\hline 3. & Non-residential immediate family member (Q. 4) & - \\
\hline 4. & Blended family of 10 years (Q. 29) . . . . . . & - \\
\hline 5. & Grandparents (Q. 11) . . . . . . . & 86.0 \\
\hline 6. & Grandparents, no contact (Q. 12) & - \\
\hline 7. & Aunt, uncle and cousins (extended family) (Q. 13) & 83.0 \\
\hline 8. & Lone mother + her child + partner (recently married) (Q. 25) . 92.8 & - \\
\hline 9. & 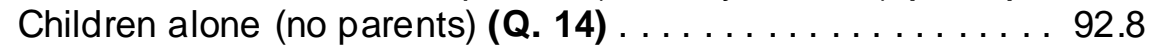 & - \\
\hline 10 & Lone mother + children (Q. 22) . & 92.6 \\
\hline 11 & Cohabiting couple + child (Q. 20) & 88.4 \\
\hline 12 & Married couple, no children (Q. 9) & 62.1 \\
\hline 13 & Lone father + children (Q. 7) . . . & 86.6 \\
\hline 14 & New blended family (Q. 27). & - \\
\hline 15 & Residential unrelated person (friend) (Q. 10) & 49.3 \\
\hline 16 & Family with out love (Q. 15) . . & 64.3 \\
\hline 17 & Cohabiting couple, no children (Q. 8) . & \\
\hline 18 & Cohabiting same-sex couple (female) + child (Q.19) . & 80.0 \\
\hline 19 & Cohabiting same-sex couple (male) + child (Q. 17) . & - \\
\hline 20 & Cohabiting same-sex couple (female), no children (Q. 18) . & 19.0 \\
\hline 21 & Cohabiting same-sex couple (male), no children (Q. 16) . & 17.7 \\
\hline 22 & Lone mother + her child + non-residential partner (Q. 24) . . . 19.8 & \\
\hline
\end{tabular}

Note. (-) indicates that no similar question was asked in Anyan and Pryor's (2002) study.

Only 36 percent of participants endorsed a cohabiting female couple without children as a family, compared to the 50 percent that endorsed a cohabiting heterosexual couple. However, in Anyan and Pryor's (2002) adolescent sample only 19 percent endorsed a cohabiting female couple without children as a family. There appears to be a pattern of the adolescents being less likely than the children to endorse couple scenarios as family if there are no children in the relationship. This is in contrast to Morrow's (1998) point that 
younger children are more likely to see children as an essential element of families. Overall, the children were divided about whether a cohabiting samesex couple with children constituted a family. In comparison, the adolescent participants highly endorsed the female couple with children scenario as a family (Anyan \& Pryor, 2002). This difference might be explained by the adolescent sample having a more advanced level of comprehension of samesex relationships.

In New Zealand just over one in three marriages are remarriages (Statistics New Zealand, 2006). Hence, step/blended families are becoming more prevalent as increasing numbers of couples are divorcing and repartnering. When presented with the newly established blended family scenario, 85 percent of the children supported it as a family grouping. This rose to 95 percent when the blended family had been together for 10 years. When presented with a scenario involving a lone mother and her child and her partner, whom she recently married, 93 percent believed the situation constituted a family. Therefore, the children displayed a very accepting attitude towards step and blended families. This may reflect the prevalence of stepfamilies in New Zealand society. It is not possible to compare these findings with Anyan and Pryor's adolescent sample due to the absence of blended family related questions. The closest stepfamily scenario involved a lone mother, her child and her cohabiting partner, which received lower levels of support with just over half of participants endorsing it as a family. It would be interesting to see if information about the length of time that they had been together as a couple would have influenced the adolescents' responses to this scenario. An equivalent scenario was not included in this study.

The children were asked additional questions about stepfamily relationships which were analysed as qualitative data. When a new stepfather and stepson relationship was portrayed, 25 percent did not identify a step-relationship and instead solely referred to the fact they were not biological connected. However, when they were portrayed as a stepfamily of 10 years only 13 percent referred to the absence of a biological connection. Also of note, only 16 percent mentioned a step-relationship and an affective connection 
between the stepfather and stepson, but when portrayed as a stepfather and stepson of 10 years, 34 percent identified the step-relationship as well as an affective connection. In the early stages of the stepfamily relationships the children's references to the fact they were not biologically connected were more frequent. However, as time passed the children perceived there to be a greater affective connection between the stepparent and stepchild. Time appears to be an important factor when it comes to these children's perceptions of stepfamily relationships. The increased emphasis placed on affective factors suggests that over time the relationship was interpreted to be more in line with their definitions of families.

Previous research has shown an increasing acceptance of one-parent families with age (Gilby \& Pederson, 1982; O’Brien et al., 1996).

Nevertheless, lone mother and lone father families were highly endorsed by both the children and adolescents in the New Zealand studies. Anyan and Pryor (2002) referred to this as a finding which mirrors social reality in New Zealand, where 29 percent of families with children are one-parent families (Statistics New Zealand, 2002b).

A non-resident biological parent was thought to be part of the family for almost all of the child participants in this study, which suggests that co-residence is less important. In comparison, only 63 percent of Anyan and Pryor's (2002) adolescent sample endorsed non-resident parents as family, and less than half of O'Brien et al.'s (1996) seven to 14 years olds were found to include non-resident parents. This large difference in endorsement between the present study and the other two studies could be attributed to a slight variation in question wording; for example, 'Is (non-resident dad) in (son's) family?' versus 'Are (son) and (non-resident dad) a family?' Still, the non-resident parent vignette for the present study and for Gilby and Pederson's (1982) study was worded in the same way (e.g. 'Is (non-resident dad) in (son's) family?'), but only 35 percent of the children with a mean age of eight and 50 percent of the children with a mean age of nine years 11 months responded that they were family. Thus, the differences between these two studies are not 
related to the wording of the question but are instead more likely to be related to the 20-plus year gap between the studies.

Grandparents are a vital component of families, especially when transitions are occurring (Cherlin \& Furstenberg, 1986). They can play an integral part in supporting grandchildren when parents separate and family structures change. Both the child and adolescent samples endorsed grandparents as family, with the children endorsing at a slightly higher rate. This may be explained by the large number of children in the sample who had experienced family transitions and who may have experienced increased interactions with their own grandparents. This is not always the case, however, as some grandchild-grandparent relationships wane after separation (Pryor \& Rodgers, 2001). Nonetheless, the children endorsed grandparents that have no contact with their grandchildren at the same rate as grandparents and grandchildren in contact, suggesting that biological connections override contact. In contrast, Gilby and Pederson (1982) found that only 35 percent of their eight year old participants included grandparents that lived in a different city as family. However, their nine year old participants were more likely to include grandparents as family, irrespective of whether they lived close.

The children in this study also endorsed extended family at the same rate as grandparents. In comparison, many of Anyan and Pryor's (2002) adolescents included the same aunt, uncle and cousin vignette as family, although at slightly lower rates than their younger counterparts. Very few of Gilby and Pederson's (1982) eight year old group endorsed the extended family scenario (55\%). However, the young adult participants were more open to including the aunt, uncle and cousin as family. All three of these studies also included a vignette depicting a family without love. The young adults in Gilby and Pederson's study were more likely to perceive a mother, father and son without love as family (70\%), compared to the younger participants. In comparison, the children in this study and the adolescents in Anyan and Pryor's (2002) study endorsed the family without love at similar rates. When comparing the research over the years there has tended to be a clear developmental sequence in the acceptance of situations as families (Diez- 
Martinez Day \& Remigy, 1999; Gilby \& Pederson 1982; Morrow, 1998;

O'Brien et al., 1996; Watson \& Amgott-Kwan, 1984). However, clear cut developmental sequences were not found when comparing New Zealand children's and adolescents' endorsements of families. Researchers, such as Fu, Goodwin, Sporakowki and Hinkle (1986) have reported differences between their younger and older participants but also many similarities across the age groups. However, the small number of scenarios in their study and the confounding of time make it difficult to accurately compare results.

In summary, both the child and adolescent samples from this study and Anyan and Pryor's (2002) study were largely open-minded in their acceptance of situations as families. The children appeared to be more idealistic than their adolescent counterparts, but this could be attributed to the more developed opinions, prejudices and abstract cognitive abilities of the adolescent sample. Overall there were more similarities between the children and adolescents than there were differences. The responses of these young people appear to be a reflection of the social context of the time, not just a reflection of their developmental stage. Their perceptions have possibly been shaped by the increased prevalence, awareness and acceptance of family diversity in New Zealand.

\subsubsection{Family structure comparisons}

Overall, very few differences were found in the children's endorsement of vignettes across the various family groupings they lived in. However, there were some significant findings and a number of interesting trends.

Of note, the original two-parent family sample unanimously endorsed ten out of the 24 situations as families. In comparison only two of the situations were unanimously endorsed by the lone/step/shared care group and three situations by the extended family sample. The adolescents from original families in Anyan and Pryor's (2002) study were also more likely to interpret the situations they were presented with as families. Thus, the original twoparent family participants appear to have a realistic image of family. These 
findings are in contrast to Brannen et al. (2000) who reported that children of separation were more open-minded than their original family counterparts.

The original family sample may have been more likely to endorse diverse structures as family but the extended family sample was least likely to. In fact out of the 24 situations the subjects were presented with the extended family sample had the highest percentages of 'no' responses for 12 of the situations. Many of the subjects in the extended family group were from 'other' ethnic groups; therefore, this diversity of ethnicities may have contributed to the large number of negative responses.

The participants from all three family structure groupings responded that the married couple with a child vignette constituted a family. Of particular interest is comparing the importance placed on marriage versus the presence of children. There were significant differences between the responses of the family structure groups for all three of the couple scenarios: a cohabiting couple with a child, a cohabiting couple without children, and a married couple without children. The extended family group participants were least likely to endorse the cohabiting couple without children and the cohabiting couple with children scenarios compared to the other two family groupings. The lone/step/shared care family grouping was less likely to endorse the married couple without children scenario, compared to the original and extended family groups.

Of the original family participants, 100 percent endorsed the married couple without children scenario and the cohabiting couple with children scenario as families. For approximately half of the original family group, marriage or children were necessary in order for the situation to be referred to as family. The other half of the group endorsed the childless cohabiting couple as a family. Consequently, neither marriage nor children were required for a situation to be referred to as family.

For the lone/step/shared care family grouping there was a preference for children over marriage when it came to endorsing a scenario as family. 
However, for 62 percent of the group neither marriage nor children were required for a situation to be referred to as a family. Finally for the extended family sample if the situation involved either marriage or children then it was endorsed as family. There was not a strong preference for marriage over children or vice versa. For over a quarter of the extended family sample neither marriage nor children were required for a situation to be endorsed as 'family'. These findings demonstrate that the family groupings that had experienced the most family transitions were least likely to perceive the scenarios as families, compared to their original family counterparts. For some children in the midst of tumultuous family transitions the uncertainty in their lives may contribute to their uncertainty of what is or is not a family. Even so, it is apparent that there were generally high levels of endorsement overall.

Funder (1996) found that some of the children in her study from separated families were restricted in the scenarios they included as families. Similarly, O'Brien et al. (1996) reported that non-resident fathers and children were less likely to be endorsed by participants from separated families. In contrast, the participants in this study that had experienced the most transitions - the lone/step/shared care grouping - all endorsed the non-resident biological father as part of the family. In fact, the lone/step/shared care grouping endorsed most of the vignettes at similar rates to the other two family groupings.

Overall, the findings suggest that there is not a strong relationship between the family structure of the children and the scenarios they endorse as families. Similarly, Anyan and Pryor (2002) also found few differences between them, as have a number of previous studies (Powell, Wiltcher, Wedemeyer \& Claypool, 1981; Wedemeyer, Bickhard \& Cooper, 1989; Horm-Wingerd, Groves \& Nekovei, 1992; Newman, Roberts \& Syre, 1993). It appears that family context has little or no effect on children or adolescents' perceptions of families. 


\subsubsection{Cultural comparisons}

The results indicate that there is not a strong relationship between the ethnic group of the children and the situations they endorse as family. There are, however, some significant findings to discuss and some notable trends. The Māori participants, the Pacific peoples, and 'other' ethnic groups sample unanimously endorsed 11 out of the 24 situations as family. The European New Zealand children were less likely to endorse the scenarios as families, with just two unanimously endorsed scenarios. Thus, the children belonging to the Māori, Pacific peoples and 'other' ethnic groups appear to have a broader definition of what constitutes a family. Anyan and Pryor (2002) also found a high rate of endorsement amongst their Māori participants, but a much lower rate from their Pacific peoples, Asian and European participants. This could be attributed to variations in cultural understandings of family, for example the wide definition of family (whānau) that is held by Māori.

The only situation to be endorsed by 100 percent of the participants in all four ethnic groups was the married couple with child vignette. This finding highlights the universal nature of the intact two-parent family form. The present study and Anyan and Pryor's (2002) study found that Māori participants made no distinction between married couples with children and cohabiting couples with children. Both scenarios were endorsed by 100 percent of the Māori participants in the present study. This suggests that for Māori, children are an important component of a family structure, more so than marriage. The reason the Māori participants endorsed cohabiting and married parents equally may be explained by traditional Māori culture, where there is no formal sacrament of marriage (Anyan and Pryor, 2002). The Māori participants in this study did, however, make clear distinctions between childless married couples and childless cohabiting couples. This implies that marriage becomes more important in defining family for Māori when there are no children in the relationship.

Children were also interpreted to be an important ingredient in the same-sex couple vignettes. The Māori participants endorsed the childless same-sex couples at much lower levels than the same-sex couples with children. In fact, 
overall they were least likely to endorse same-sex couples as families. When the vignettes depicted the same-sex couples with children, the Māori sample were more likely to endorse the situation as family. In Māori culture children are regarded as valuable treasures that belong to the whānau or extended kin group (Coney, 1993). Children are, therefore, seen as central to families and the responses of the Māori participants reflected this. The opposite was found for the Pacific Island participants; a childless married couple was more likely to be interpreted as a family compared to a cohabiting couple with a child. This may be explained by the importance of religion in some Pacific cultures and in particular the importance of marriage as an institution. For both the European New Zealand group and the 'other' ethnic group, there was a similar level of importance placed on marriage and children.

Morrow (1998) found that the Pakistani participants in her study were less likely to perceive a single mother and a child as a family. Anyan and Pryor (2002) additionally found that Māori participants were more likely to endorse extended family members than one-parent families. This is in contrast to the Māori children that endorsed extended and one-parent families at equally high rates in this study. The Pacific peoples, however, unanimously endorsed all three extended family scenarios, compared to the 82 percent that endorsed both of the one-parent family vignettes. This may reflect the importance Pacific peoples place on the extended family as their main social structure.

Also of note were the perceptions the Pacific Island children had of blended families. When a recently formed blended family was portrayed, 70 percent responded that the scenario constituted a family; however, when the vignette portrayed a blended family that had been together for 10 years, 100 percent endorsed the scenario. Clearly for these Pacific Island participants, time spent together and commitment were influential factors when deciding whether a blended grouping depicted a family.

Like Morrow (1998), the present study found more similarities than differences in the children's perceptions of families. In comparison, Anyan and Pryor (2002) reported that their adolescent cultural groups displayed many 
differences in endorsements. Similarly, Diez-Martinez Day and Remigy (1999) supported the influence of cultural factors, concluding that they were as influential as cognitive levels. Diez-Martinez Day and Remigy's study is perhaps a stronger example of a cultural comparison, due to the inclusion of children from two different ethnic groups that were living in two separate countries.

Overall, it appears that cultural context has little or no effect on New Zealand children's perception of families, but has a significant impact on adolescents' perceptions. The inclusion of a Chinese ethnic group in Anyan and Pryor's study could account for this difference, as could the possible acculturation of the adolescents. It is important to recognise that not all Māori and Pacific peoples in New Zealand stay embedded in their traditional cultural identity (Anyan \& Pryor, 2002). Therefore, the lack of cultural variation amongst the child sample could be attributed to the European, Māori and Pacific Island participants being born and raised in New Zealand, where urbanisation and modern-day society may have impacted on their perspectives and cultural ideology.

\subsubsection{Other comparisons}

The young people's endorsement of the vignettes was also compared by gender, age and the number of family transitions they had endured. The age group comparisons were based on the child's age at the time of the interview and also their age at the time of the separation (for those that had experienced separation).

With regard to gender, there were only three significant differences found. The three scenarios were endorsed at higher rates by the females. Two of these were the cohabiting same-sex male and same-sex female couple with children vignettes. Differences in maturity and understanding of same-sex parenting may explain the disparity between the males' and females' responses. The absence of gender differences is consistent with Wedemeyer et al.'s (1989) findings that the child's sex was not strongly related to their family perceptions. 
There were only two significant differences in terms of age; in both questions the older children (11 to 13 years of age) were more likely to view the family without love and residential unrelated person vignettes as families. The acceptance of these two vignettes demonstrates a more developed understanding of the scope of the family concept. Similarly, the older children (based on age at the time of parental separation) were more likely to endorse the family without love vignette. This is consistent with Diez-Martinez Day \& Remigy's (1999) finding that for younger children the permanence of family membership may be tenuous.

In terms of family transitions, significant differences were found for three of the vignettes: non-resident family member, residential unrelated person, and a newly blended family. The participants that had experienced a greater number of changes to their family structure were less likely to endorse the situations as family. This is similar to the trend discussed in the family structure comparisons section, which could possibly be explained by the uncertainty some young people may feel in their own families during transitions.

Overall, there were very few differences in terms of gender, age and experience of family transitions. There were some trends of note, but in general these variables did not have a large impact on the children's understanding of families.

\subsection{Definitions of 'Family'}

\subsubsection{How do young people define the concept of family?}

When the children were asked "What do you think 'family' is?" over half them mentioned affective factors in their responses. Clearly, for many of these children being loved and being cared for were critical components of a family. Being connected through cohabitation or being biologically or legally connected was not as important as the emotional connection. In Table 7.2 the children's definitions are compared with the adolescents in Anyan and Pryor's (2002) study. Affective factors were referred to more frequently in the adolescents' definitions, followed by biological factors and cohabitation. The 
prominence of affective factors in their definitions is consistent with the children's responses. Clearly facets of love, care, support and nurturing were paramount in the family descriptions of these young people.

Table 7.2

Percentages of Criteria Mentioned in Definitions of Families: Children vs. Adolescents

\begin{tabular}{|c|c|c|c|}
\hline \multicolumn{2}{|c|}{ Criteria } & \multirow{2}{*}{$\begin{array}{c}\text { CHILDREN } \\
(n=111) \\
\% \text { that mentioned } \\
\text { the criteria }\end{array}$} & \multirow{2}{*}{$\begin{array}{c}\text { ADOLESCENTS } \\
(n=224) \\
\% \text { that mentioned } \\
\text { the criteria } \\
80.0\end{array}$} \\
\hline 1. & Affective factors .................... & & \\
\hline 2. & Family members.. & 25.2 & 29.9 \\
\hline 3. & Biological factors.................... & 24.3 & 41.5 \\
\hline 4. & Cohabitation.... & 19.8 & 35.3 \\
\hline 5. & Legal factors....................... & 1.8 & 12.1 \\
\hline 6. & Don't know + Other ................. & 5.4 & - \\
\hline
\end{tabular}

Note. (-) indicates that there was no matching criterion in Anyan and Pryor's (2002) study.

Other research has reported the prominence of affective factors but also developmental variations when defining family (Newman et al., 1993; Morrow, 1998; Diez-Martinez Day \& Remigy, 1999; Brannen et al., 2000). Piaget (1928) found that there were definite cognitive differences in the children's definitions of family, although affective factors did not feature. The seven to 12 years olds went through a developmental sequence of mentioning cohabitation in the preoperational stage, then biological connections of those cohabiting in the concrete operational stage, and finally all biological connections independent of cohabitation in the formal operational phase. In contrast, less than a quarter of the children in this study referred to biological factors and even fewer mentioned cohabitation as a defining feature of family. Other studies also found that biological factors were not included in children's 
definitions (Fu et al., 1986; Horm-Wingerd et al., 1992; Morrow, 1998). Morrow (1998) concluded that her participants' definitions did not focus on the traditional 'nuclear family' form. The majority of the children in Brannen et al.'s (2000) study also rejected the notion of a 'proper family'. Similarly, the children in this study and adolescents in Anyan and Pryor's (2002) study did not prescribe to the traditional stereotype of family.

Fu et al. (1986) reported that nurturance/socialisation and co-residence were mentioned across all three age groups, which supports Piaget's (1928) findings related to the importance of cohabitation. However, 60 percent of the Fu et al.'s older participants (aged approximately 10 years old) also mentioned affective factors in their descriptions. The affective factors category in this study included love, care, support and nurturing. Nurturance and affective factors were separate categories in Fu et al.'s study; hence the percentage of criteria mentioned is much higher when the two categories are considered together. One of the difficulties in comparing family definition findings is the variation between studies of the classification of the criteria referred to in young people's responses.

Interestingly, very few of the children in this study mentioned legal factors. Similarly, the adolescents' descriptions in Anyan and Pryor's (2002) study rarely included legal ties. Horm-Wingerd et al. (1992) also noted the absence of legal references in their participants' definitions. These findings may reflect the prevalence of cohabiting couples and unrelated family members in modern-day society.

Developmental differences were not found between the children and adolescents with regard to the criteria they referred to in their definitions. The criterion most commonly mentioned by both age groups was affective factors. However, there were differences in the complexity of their definitions. The adolescents were more likely to incorporate affective components into their responses. They mentioned on average two criteria, compared with the children's reference to an average of one criterion. These variations can be 
attributed to developmental differences between the two groupings, with the adolescents providing more in-depth abstract definitions than their younger counterparts. This is consistent with other studies that have reported that the older the child the more complex the definition (Morrow, 1998; Newman et al., 1993; Watson \& Amgott-Kwan, 1984).

The children were additionally asked if family is important to them. They were unanimous about the importance of family. Their responses revealed the significance young people place on family and being loved. When asked who they think the members of a family are, most of the children referred to 'family' as anyone you consider to be family, or as immediate family and relatives. Therefore, the family form was not perceived to be a traditional small unit of relations. Most of the children referred to a broad range of possible family members, and some were even quite reluctant to put restrictions on who could or could not be part of a family. Unlike the children in Gilby and Pederson's (1982) study, the image the majority of these children had of family composition did not mirror the traditional nuclear family form.

It appears that there are a number of factors that may be influencing young people's perceptions. Some studies have found that developmental stages contribute significantly to participants' concepts of family. Family structure experiences and transitions, gender, and ethnic influences have also been implicated. However, it is difficult to pinpoint precisely what is influencing young people's perceptions. None of the variables examined in this study were found to be overwhelmingly connected to young people's views. It is likely that many factors are contributing to their inclusive perceptions of families. Factors such as religious beliefs, media influences, societal attitudes and policy and law, may all be playing a part in shaping young people's views. The difficulty, of course, lies in measuring these influences.

\subsection{In Summary}

Families can and do change, as can perceptions of families. A multitude of factors can shape and alter our opinions over time. Past research has shown distinct developmental sequences in young people's concepts of 'family', and 
in some studies cultural and social facets have also been linked to young people's perceptions.

The children's perspectives in the present study reflected contemporary society; they were less conservative than many of the children in previous research. Many similarities were found when the family concepts of New Zealand children and adolescents were compared. The family definitions of both age groups focused on aspects of love, care and support as essential features of a family, although the more concrete nature of the children's responses signalled some developmental differences in perception. In general, both samples of the children and adolescents were open-minded in their endorsement of situations as families. In this study there were few differences in the concepts of family across family structures and cultural groups. In comparison cultural differences were apparent in the adolescents' endorsements of families. Social and cultural facets, then, appeared to have more of an impact with age.

Overall, the traditional 'nuclear family' did not dominate these young people's perceptions of families. New Zealand children and adolescents have quite an inclusive and realistic view of what constitutes a family. Similar conclusions about young people's family concepts are also being reached in other countries at this time. The traditional family form of two heterosexual married parents with children may be viewed as the ideal by some, but in general young people have a very accepting and pragmatic view of family structures. Quite simply, these young people's family concepts depict the existing family diversity in society.

The children and adolescents in these studies were willing and able to voice their opinions regarding families in an open and articulate manner. Understanding what 'family' means to children and adolescents has important implications for how families reorganise themselves after separation and during stepfamily formation. Similarly, giving a voice to children's perspectives is paramount if we want to understand how best to nurture them through family transitions. Being listened to and involved in family life should be a 
fundamental right for all young people. Given the dynamic nature of families and the way 'the family' has evolved over time, it is important to continue to focus on children and adolescents' perceptions of families and in particular their understandings of family structure change. 


\section{STUDY TWO: \\ YOUNG PEOPLE'S EXPERIENCES OF FAMILY \\ STRUCTURE CHANGE}

\section{Chapter Eight}

\section{Method}

\subsection{The Research Questions}

In Study Two there are 20 research questions which investigate young people's perceptions and experiences of family structure change, both qualitatively and quantitatively.

\subsubsection{Qualitative questions}

The first two questions examine young people's concept of family, in particular their definitions of family and parental separation. The following four questions focus on the experiences of young people early on in the separation, which is referred to as Time 1. The remaining four questions focus on young people's experiences of parental separation 18 months following Interview 1 , which is referred to as Time 2. More specifically the young people's experiences at Time 2 are compared to their experiences at Time 1.

\section{The family concept:}

1. What are young people's definitions of family and family importance?

2. What are young people's definitions of separation?

\section{Time 1: Young people's experiences of parental separation}

3. What are young people's views and reactions in relation to parental separation?

4. What are young people's perspectives in relation to support and coping during parental separation?

5. What are young people's perspectives in relation to communication during parental separation?

6. What are young people's perspectives in relation to the future? 
These central questions focus on four areas of separation experiences. The 'views and reactions' question explores a variety of themes, including finding out about the separation, reactions, feelings, outlook for the separation, blame, reason for the break-up, relationship problems, living arrangements, contact arrangements, negative and positive aspects of the separation, challenges faced, and reminiscing. The 'support and coping' question focuses on what children say they need, formal and informal sources of support, coping strategies, availability of support, finding support, accessing resources, and ideas on coping. The 'communication' based question explores being informed, involvement in decision making, and advice about parental separation. The final question focuses on 'the future', in particular how young people view the future for their family and their views in relation to marriage and children.

\section{Time 1 vs. Time 2: Young people's experiences of separation over time}

7. How do young people's views and reactions to parental separation at Time 1 compare to their views and reactions at Time 2?

8. How do young people's perspectives regarding support and coping at Time 1 compare to their perspectives at Time 2?

9. How do young people's perspectives regarding communication at Time 1 compare to their perspectives at Time 2?

10. How do young people's perspectives regarding the future at Time 1 compare to their perspectives at Time 2 ?

These four research questions allow for comparisons between the young people's responses in the initial interview at Time 1 and in the follow up interview at Time 2.The interview questions that the participants were asked at Time 2 were similar to the interview questions at Time 1; however, they were adapted to suit the context at Time 2. The 'views and reactions' question focuses on a number of topics including feelings, outlook for the separation, blame, current feelings about living arrangements and contact arrangements, negative and positive aspects, and challenges faced. Questions six, seven and eight which cover 'support and coping', 'communication', and 'the future' are re-examined using the same topics for the Time 1 interview. 
Where applicable, the qualitative data were also analysed in terms of the response differences in the child and adolescent age groups and the earlystage and later-stage separation groups.

\subsubsection{Quantitative questions}

The ten quantitative research questions listed below focus on young people's adjustment to parental separation over an 18 month time frame. The first two questions are centred on the main effect by comparing the 'individual wellbeing' and 'family dynamics' from Time 1 to Time 2 . The following four questions investigate the interaction effect by comparing the 'individual wellbeing' and 'family dynamics' of the early-stage separation and later-stage separation participants at Time 1 and Time 2 , and the child participants and adolescent participants at Time 1 and Time 2. The final four questions concern the main effect for the groups by comparing the 'individual wellbeing' and 'family dynamics' for the early-stage and later-stage separation groups at Time 1 and then again at Time 2.

Main effect: Individual wellbeing and family dynamics at Time 1 vs. Time 2

11. Is there a significant difference in the individual wellbeing of the young people from Time 1 (post-parental separation) to Time 2 (18 months later)?

12. Is there a significant difference in the family dynamics from Time 1 to Time 2 ?

Interaction effect: Individual wellbeing and family dynamics at Time $1 \mathrm{vs.} \mathrm{Time}$ 2 for the separation groups and the age groups

13. Is there a significant difference in the individual wellbeing from Time 1 to Time 2 for the early-stage separation participants (1-10 months since separation) and the later-stage separation participants (14-24 months since separation)?

14. Is there a significant difference in the family dynamics from Time 1 to Time 2 for the early-stage separation participants and the laterstage separation participants? 
15. Is there a significant difference in the individual wellbeing from Time 1 to Time 2 for the child participants ( $9-13$ year olds) and the adolescent participants (14 -18 year olds)?

16. Is there a significant difference in the family dynamics from Time 1 to Time 2 for the child participants and the adolescent participants? Main effect for groups: Individual wellbeing and family dynamics for separation groups at Time 1 and at Time 2

17. Is there a significant difference in the individual wellbeing of the early-stage separation participants and the later-stage separation participants at Time 1 ?

18. Is there a significant difference in the family dynamics of the earlystage separation participants and the later-stage separation participants at Time 1 ?

19. Is there a significant difference in the individual wellbeing of the early-stage separation participants and the later-stage separation participants at Time 2?

20. Is there a significant difference in the family dynamics of the earlystage separation participants and the later-stage separation participants at Time 2?

\subsection{Participants}

A total of 52 young people were recruited for this study, 28 (54\%) of whom were females. All participants ranged in age from nine years to 18.5 years and were enrolled in primary, intermediate, secondary or tertiary education. The ethnic makeup of the sample was: 28 (54\%) European New Zealanders, 13 (25\%) Māori, eight (15\%) Samoan, and three (6\%) that were described as children from 'other' cultural backgrounds.

At the time of the first interview the parents of these young people had been separated for between one month and 24 months. To be involved in this study it was important that the separation had occurred within the previous 24 months. This prerequisite was imposed because past research has shown that after approximately two years young people's degree of distress and difficulties with behaviour have returned to the level that they were prior to the 
break-up (Pryor \& Rodgers, 2001). Therefore, the focus of the initial interview was young people's experiences during the most critical stages of the family transition.

All 52 participants contributed to the research at Time 1 and Time 2 . Three participants were unable to participate in a face-to-face interview at Time 2 because they had moved from the region. These young people were still interested in being involved in the second phase of the research; therefore the necessary forms were mailed to them. Instead of being interviewed face-toface, the interviews were carried out via telephone for two of the adolescent participants. The remaining participant was in the child age group. He was not interviewed; hence there is no Time 2 qualitative data from his perspective.

\subsection{Measures}

A number of measures were employed. A demographic questionnaire was used to gather information about the participant and their family. Two semistructured interviews over an 18 month period provided qualitative and quantitative data. Eight quantitative instruments also provided data over time.

\subsubsection{Demographic form}

A demographic form was developed for the caregivers of participants under 16 years of age to complete prior to Interview 1 (refer to Appendix I). There was also a similar demographic form for participants aged 16 years or older to complete before they were interviewed (refer to Appendix M). The form enabled a variety of background information to be compiled on each participant. The questions focused on participant related information, such as gender, age, and ethnicity. There were also a number of questions about the participants' family structure, including the current situation, and any past changes to the family structure. Further questions focused on details of the separation; for instance, age of the child at the time of the separation, the amount of contact between participant and non-resident parent, whether any information was received at the time of the separation, as well as the amount and type of information and usefulness of it. The information on this form was 
updated by caregivers and participants aged 16 or older at the time of Interview 1 if their circumstances had changed since Interview 2.

\subsubsection{Interview questions}

The interview questions were developed by the author to investigate the perceptions of young people experiencing parental separation at Time 1 and Time 2. The questionnaire administered at Time 1 consisted of six sections of questions (refer to Appendix 0 ). The first section focused on the participants' definitions of the 'family concept', and included the same two definition questions that were asked of participants in Study One. These questions were included in order to establish how the young people defined family. Achieving this level of understanding is paramount, due to the importance of understanding what family means to young people before attempting to understand their experience of changes to their family structures.

Furthermore, these questions provided responses that could be compared to the content analysis findings in Study One.

The second section enquired about 'family structure', in particular the composition of the family, the living arrangements, and the contact arrangements with the non-resident parent. The young people's 'views and reactions' in relation to the separation were of prime importance in the third section. These questions examined the definition of separation, finding out about the separation, initial reactions, feelings, reasons for the break-up, cognisance of relationship problems, outlook for the separation, blame, negative and positive aspects of the break-up, challenges encountered, and reminiscing about the past.

The fourth section focused on young people's experiences of 'support and coping', including what young people feel they need, formal and informal sources of support, strategies for coping, availability of support, access to resources, and ideas regarding coping. 'Communication' was the major theme of section five, which included questions about being informed, being involved in decision making, and what children want others to know about parental separation. The final section focused on 'the future', more specifically the 
young people's views about their family's future and their views on marriage and children. A number of the Time 1 interview questions were adapted to suit the follow up interview 18 months later. The questionnaire that was employed at Time 2 contained five sections of questions: family structure, views and reactions, support and coping, communication and the future (refer to Appendix P).

\subsubsection{Instruments}

Eight instruments were administered during the interviews of the young people at Time 1 and at Time 2. The scales provided information on two main areas of the young people's lives: their family dynamics and their individual wellbeing. The scales that provided data on family dynamics were the Family Environment Scale, the Perceptions of Parents Scale, and the Marital Conflict Scale. Information relating to individual wellbeing was collated via the Perception of Strengths Scale, Children's Feelings Scale, Strengths and Difficulties Questionnaire, and Children's Depression Inventory. An additional instrument known as the Locus of Control scale measured children's perceptions of control. The eight scales are described in more depth below and can be viewed in Appendix Q.

The Family Environment Scale (FES). This scale was devised by Moos and Moos (1981) to measure social and environmental characteristics of a wide range of families. The scale was included to examine the young people's perceptions of their family environment with a particular focus on the relationship dimensions. The original scale consists of 10 subscales profiling the family environment, two of which were used in this study. The first subscale consists of nine items that measure family cohesion and the second subscale uses nine items to examine family expressiveness (or communication). The 18 items were measured with true or false responses; for example, 'Family members help and support each other' (cohesion), 'We tell each other about our personal problems' (communication). After being totalled each subscale ranged from a minimum of zero to a maximum of nine. Moos and Moos (1981) reported Cronbach alpha coefficients of .78 for the cohesion subscale and .69 for the communication subscale. 
Perceptions of Parents Scale (POP). Phares and Renk's (1998) Perceptions of Parents Scale (POP) focuses on the child's thoughts and emotions in relation to his or her parents. The participants' positive and negative perceptions of their mother, and the positive and negative perceptions of their father, were examined using this scale. The advantage of using this measure over other measures of the parent-child relationship is that it applies to children who have contact with their parents and also to children who do not have regular contact. A slightly altered version of the scale was to be utilised for the purpose of this study as a measure of the young people's perceptions of their stepparent/s (POSP). However, due to the small number of participants with stepparents it was deemed unreliable to analyse the data from the POSP (the adapted scale can be found in Appendix $Q$ ).

The positive affect subscales (positive affect towards mother/positive affect towards father) each contained ten items, whereas both of the negative affect subscales (negative affect towards mother/negative affect towards father) consisted of five items. Each question was scored on a Likert scale from ' 1 ' (Not at all or Never) to '6' (Extremely or Always). For example, 'How much do you feel respect towards your mother?' (positive affect towards mother), 'How much do you feel anger toward your mother?' (negative affect towards mother). The positive affect subscale totals ranged from a minimum of ten to a maximum of 60 , whereas the negative affect subscales ranged from five to 30 when totalled. Phares and Renk (1998) reported strong internal consistency with .96 for positive perceptions of mother, .97 for positive perceptions of father, .81 for negative perceptions of mother, and .84 for negative perceptions of father.

Marital Conflict Scale. The first stage of the Conflict Scale was developed by Crawford (2002) to assess the levels of inter-parental conflict from the young person's perspective. More specifically the levels of emotional and physical conflict were measured. Pryor (2003) further developed the scale by incorporating a verbal conflict component. Pryor's adapted version of the Conflict Scale consists of 18 statements that are rated on a Likert scale from '1' (Never) to '4' (Very often). For example, 'When they argue, one parent 
makes the other one feel ashamed' (emotional conflict), 'My parents raise their voices when they argue' (verbal conflict), 'One of my parents hits the other when they are having an argument' (physical conflict). The total conflict scores were used in this study and ranged from a minimum of 18 to a maximum of 72. Pryor (2003) has reported strong internal consistency with Cronbach alpha coefficients of .89 or better for total score.

Perceptions of Strengths Scale (POS). The young people's perceptions of their own strengths were measured by Williams and McGee's (1991) Perceptions of Strengths (POS) questionnaire, which was developed with New Zealand young people in mind. The scale contains a list of 22 positive descriptive words that children choose from in order to identify their strengths. The total score is achieved by adding up the number of words selected.

Children's Feelings Scale (CFS). The Children's Feelings Scale (CFS) was developed by the author for the purpose of this study. The 20 item scale measures the intensity of ten negative and ten positive feelings that young people may be experiencing. The feelings are rated on a Likert scale from '1' (Not at all true) to '4' (Very true); for example, 'I feel hopeful' (positive feeling), 'I feel scared' (negative feeling). The total score for each subscale ranges from a minimum of ten to a maximum of 40 .

Strengths and Difficulties Questionnaire (SDQ). Goodman's (1997) Strengths and Difficulties (SDQ) questionnaire was incorporated in this study to measure the participants' pro-social behaviour, hyperactivity, internalising (or anxiety symptoms), externalising (or behaviour problems), and peer relationships problems. The SDQ assesses positive behaviour via the prosocial behaviour subscale and negative symptoms via the remaining four subscales. The questionnaire is made up of 25 items ( 5 items on each subscale) that are measured on a Likert scale that ranges from ' 1 ' (Not true) to ' 3 ' (Certainly true). For example, 'I am helpful if someone is hurt, upset, feeling ill' (pro-social), 'I am constantly fidgeting or squirming' (hyperactivity), 'I worry a lot' (internalising), 'I fight a lot. I can make other people do what I want' (externalising), 'I am usually on my own, and play alone' (peer 
problems). The total score for each subscale ranges from a minimum of five to a maximum of 15 . The five subscales of the SDQ have shown good internal and test-retest reliability. Goodman and Scott (1999) analysed the properties of the SDQ and the Child Behaviour Checklist (CBCL) in order to compare the two instruments. The authors attributed the reliability of the questionnaire to the high correlations between the CBCL and the SDQ, as well as the strong psychometric properties of the CBCL.

Children's Depression Inventory (CDI). Kovac's (1985) Children's Depression Inventory (CDI) measures key symptoms of depression, with an emphasis on behavioural, affective, and cognitive wellbeing. In particular, the scale measures negative mood, negative self esteem, loss of life enjoyment, unsociability, dissatisfaction with school, problems with sleeping and eating. The scale is recommended for use on children six to 17 years of age; however, it was used on participants up to 20 years of age in this study.

It is important to recognise that much criticism has been levelled at the CDI, specifically the soundness of the measure. Kovac's (1985) has reported Cronbach alpha levels of .80 or better which indicates acceptable reliability. However, in light of the well publicised dissonance surrounding the inventory and its psychometric properties, the scale has not been utilised as a measure of depression in this study. As suggested by Harold, Fincham, Osborne and Conger (1997) the scale has instead been employed and interpreted as a broad measure of dysphoria. Dysphoria is defined here as a state of feeling unwell or unhappy, which could include anxiety, depressive symptoms or unease.

This measure is made up of 27 items; although, Harold et al. (1997) excluded one CDI question about suicide in their study. Similarly, this question was omitted from the current study due to the focus of the measure being shifted away from clinical depression per se. Therefore, the adapted measure contains 26 items which are each made up of three statements, one of which is selected by the young person as the best description of his or her feelings over the previous two weeks. For example, '0' (I am sad once in a while), '1' (I 
am sad many times), '2' (I am sad all the time). The total score for the 26 item version can range between zero and 52. Kovac's (1985) reported that a score equal to or greater than 11 is associated with depressive disorder.

Locus of Control Scale (LOC). The Locus of Control scale by Connell (1985) is a three dimensional scale used to assess children's perceptions of control, specifically unknown locus of control, external locus of control, and internal locus of control. Locus of control can be described as the amount of perceived control people believe they do (or do not) have over events. Connell purports that perceived control is essential when it comes to understanding the motivational and cognitive reasons behind behaviour. Unknown locus of control can be defined as events that happen by chance. External locus of control refers to powerful others having control over what happens, and internal locus of control is described as individuals having control over events. The 12 items that make up this measure are rated on a Likert scale that ranges from '1' (Very true) to '4' (Not at all true). For example, 'When good things happen to me, many times there doesn't seem to be a good reason why' (unknown locus of control), 'To get what I want I have to please people who are in charge' (external locus of control), 'I can pretty much control what will happen in my life' (internal locus of control). These three subscales each contain four items and the total score for each subscale ranges from a minimum of four to a maximum of 16 . Connell (1985) reported Cronbach alpha values of .65 for unknown control, .57 for powerful others control, and .43 for internal control. These Cronbach alpha values are particularly low.

\subsection{Procedure}

The questionnaire was pilot tested on 12 young people (four males, seven females) between eight and 16 years of age who had experienced parental separation. These interviewees were recruited via Seasons for Growth in Wellington. Seasons for Growth are a secular education programme available in many New Zealand primary and secondary schools. The programme is targeted at young people who have experienced family structure change by way of separation, divorce, bereavement, or some other significant life event and loss (Seasons for Growth, 1996). 
Research information packs containing a letter, a consent form, a demographic form, and a contact details form were sent home with young people at a number of Wellington schools who were enrolled to participate in the Seasons for Growth programme. Some of the information packs were tailored specifically for the children's parents/caregivers. Examples of the parents/caregivers letter, consent form, demographic form, and contact details form can be found in Appendix $\mathrm{G}, \mathrm{H}, \mathrm{I}$, and J. Written consent to participate and demographic and contact information were provided by the caregiver of all interviewees under the age of consent. Research information packs were also designed for young people that were 16 years of age or older. To view examples of the letter, consent form, demographic form, and contact details form, refer to Appendix K, L, M, and N. All participants aged 16 or older provided written consent and completed the necessary forms. All completed forms were returned to Seasons for Growth via the school office.

The interview questions and scales were trialled on each young person at school at a convenient time approved by the school principal. Any problems relating to the young people's understanding of the questions or wording were noted and necessary changes made. Additional questions were also included as a result of the pilot interviews. Flash cards were introduced after the initial pilot interviews to increase the efficiency and accuracy of responses. The 12 young people took on average 55 minutes to complete the interview, including the scales.

After the pilot study the Chief Executive of a support service called Skylight was approached to assist with the recruitment of young people for this research. Skylight is a national not-for-profit charitable trust that provides information, resources, counselling, support and advocacy, as well as training and professional development. Research information packs were distributed by Skylight counsellors to caregivers and young people who accessed their services, and had experienced separation within the previous two years. The caregivers and young people who were happy to be involved in the study returned the completed forms by mail. The interested families were then contacted and a convenient time was arranged for the first interview. 
Interviews were carried out at a location convenient to the family. A support person was arranged to be available if an interviewee became upset at any stage during or after the interview process; however, this back up support was not required.

Participant recruitment via Seasons for Growth and Skylight proved to be an arduous and protracted process. Some parents displayed a lack of willingness to allow their children to talk about their experiences. A number of factors may have contributed to their reluctance. For instance, the intricacy of the circumstances, the recency of the separation, the need for discretion, concerns surrounding a child's wellbeing, and focusing on the family dynamics and current state of affairs, may have all played some role in discouraging families from becoming involved. Other researchers have also noted the difficulty of recruiting children to participate in research relating to separation and divorce (Hogan et al., 2002; Fawcett, 1998). Fawcett (1998) attributed the prolonged and difficult task of locating participants to the complex nature of the relationships of separating families. Hogan et al. (2002) highlighted privacy as a paramount issue when it came to parents' reluctance to allow their children to participate. They also recognised the potential obstacle of targeting families through support agencies, due to the likelihood that they were experiencing a high level of stress and were consumed with their current circumstances.

In this study additional avenues of recruitment were decided upon for two reasons. First, the extensive time it was taking to identify enough children to participate resulted in the need to cast the net wider than just support groups and schools. Second, by recruiting participants via other avenues a wider range of families were likely to be included, not just families seeking support. In 2003 the public affairs officer at Victoria University sent out a media release detailing the aims of the study and the need for participants. This resulted in articles published in a regional newspaper and a community newspaper. A local radio station aired a news bulletin about the study, and a pre-recorded interview and a live interview were broadcast nationally on two separate radio stations. Following on from this publicity, flyers advertising the need for 
research participants were posted at relevant support services. Word-ofmouth also led to the involvement of participants. Collectively, these methods resulted in the recruitment of the desired number of young people.

Each interviewee was provided with verbal information about the research project by the researcher. They were also informed of their right to withdraw from the study at any time, that there were no right or wrong answers, and they did not have to answer any questions they did not want to. Furthermore, they were informed that their answers were confidential and that they would be assigned a participant number to ensure they remained anonymous throughout the study. Verbal assent to participate was obtained for each interviewee under 16 years of age.

Before the interview commenced the interviewer engaged the participant in general conversation; for example, conversing about school or their favourite past times. This helped to reassure and build rapport with the interviewee. The young people were then asked a number of interview questions about family and family change (see Appendix $O$ ), which were taped on a recording device and later transcribed. Once the interview questions were completed the recording device was turned off and the quantitative scales were carried out (see Appendix Q). All scales were administered by the interviewer. A flipfile of flash cards displaying the range of answers for each scale was placed in front of the interviewee. The flash cards were included to assist children to recall the list of potential responses read aloud by the interviewer. The young people took on average one hour and eight minutes to complete the interview process.

Interview 2 was carried out approximately 18 months following Interview 1 . Letters were sent out to all caregivers and participants advising them of the opportunity to be involved in the second interview. The letters were followed up with a phone call to ascertain whether participants were happy to be involved in the final interview. Convenient interview times and locations were arranged for the second interview. The demographic form information was updated, if applicable. The interview was similar to Interview 1, but included a 
shortened version of the original interview questions (see Appendix $P$ ). The young people took on average 58 minutes to complete the interview, including the scales.

\subsection{Data Analysis}

The data that were analysed came from demographic information, interview transcripts and a number of scales which measured various aspects of the young people's environment, relationships, feelings, strengths, and wellbeing. Data from the scales and the demographic information was entered into the SPSS 10 (10.1) database, where quantitative analyses were performed.

The children's interviews were transcribed and were analysed using Content Analysis. More specifically, category analyses and quantitative descriptive analyses of the text were carried out. The data were analysed in keeping with the qualitative research questions identified in section 8.1.1.

The analysis approach drew on Glaser's (1992) Grounded Theory, whereby the research theory is emergent and discovered in the data. In effect the approach adopted in Study Two was grounded in learning from participants and their experiences. This fits with the research being in essence exploratory. The analysis also drew from Bryman's (2001) emphasis on mixed methods research; in particular a concurrent study whereby qualitative and quantitative data is converged to see whether they corroborate one another. Adopting a concurrent strategy in Study Two meant that the data was quantified by creating codes and categories qualitatively and then counting the number of times they occurred. The quantification of qualitative data enables the comparison of quantitative results with qualitative data (Creswell, 2003). 


\section{Chapter Nine}

\section{Results}

\subsection{Participant Characteristics (Time 1 and Time 2)}

The young people that participated in the two interviews ranged in age from nine years to 18.5 years at the time of Interview 1 (Time 1), and from 10.58 years to 20 years at the time of Interview 2 (Time 2).

Interview 1 was carried out between one month and 24 months (2 years) following parental separation. At the time of the second interview the participants' parents had been separated for between 19 months (1.58 years) and 43 months (3.58 years). Interview 2 was undertaken 18 to 20 months following Interview 1. The mean amount of time between Interview 1 and Interview 2 was 18.56 months. A thorough outline of the descriptive statistics for the participants in this sample can be found in Table 9.1 and Table 9.2.

Table 9.1

Descriptive Statistics for Participant Characteristics

\begin{tabular}{lccccc}
\hline & N & Minimum & Maximum & Mean & $\begin{array}{c}\text { Standard } \\
\text { Deviation }\end{array}$ \\
\hline $\begin{array}{l}\text { Age } \\
\text { (Time 1) }\end{array}$ & 52 & 9.00 & 18.50 & 13.80 & 2.97 \\
$\begin{array}{l}\text { Age } \\
(\text { Time 2) }\end{array}$ & 52 & 10.58 & 20.00 & 15.35 & 2.96 \\
$\begin{array}{l}\text { Time since separation } \\
\text { (Time 1) }\end{array}$ & 52 & 0.08 & 2.00 & 1.10 & 0.68 \\
$\begin{array}{l}\text { Time since separation } \\
\text { (Time 2) }\end{array}$ & 52 & 1.58 & 3.58 & 2.64 & 0.69 \\
\hline
\end{tabular}

\subsubsection{Age groups}

At the time of the first interview $52 \%$ of participants were between nine and 13 years of age (mean age $=11.3$ ) and were classified as part of the 'child age group'. The remaining 48\% were between 14 and 18 years of age (mean age $=16.5)$ and were labelled as the 'adolescent age group'. At the time of the second interview $37 \%$ of participants were between 10 and 13 years of age and $63 \%$ were between 14 and 20 years of age. However, it is important to 
emphasise that participants remained in their original child or adolescent groupings for the data analysis phases involving both Interview 1 and Interview 2.

Table 9.2

Frequency Statistics for Participant Characteristics

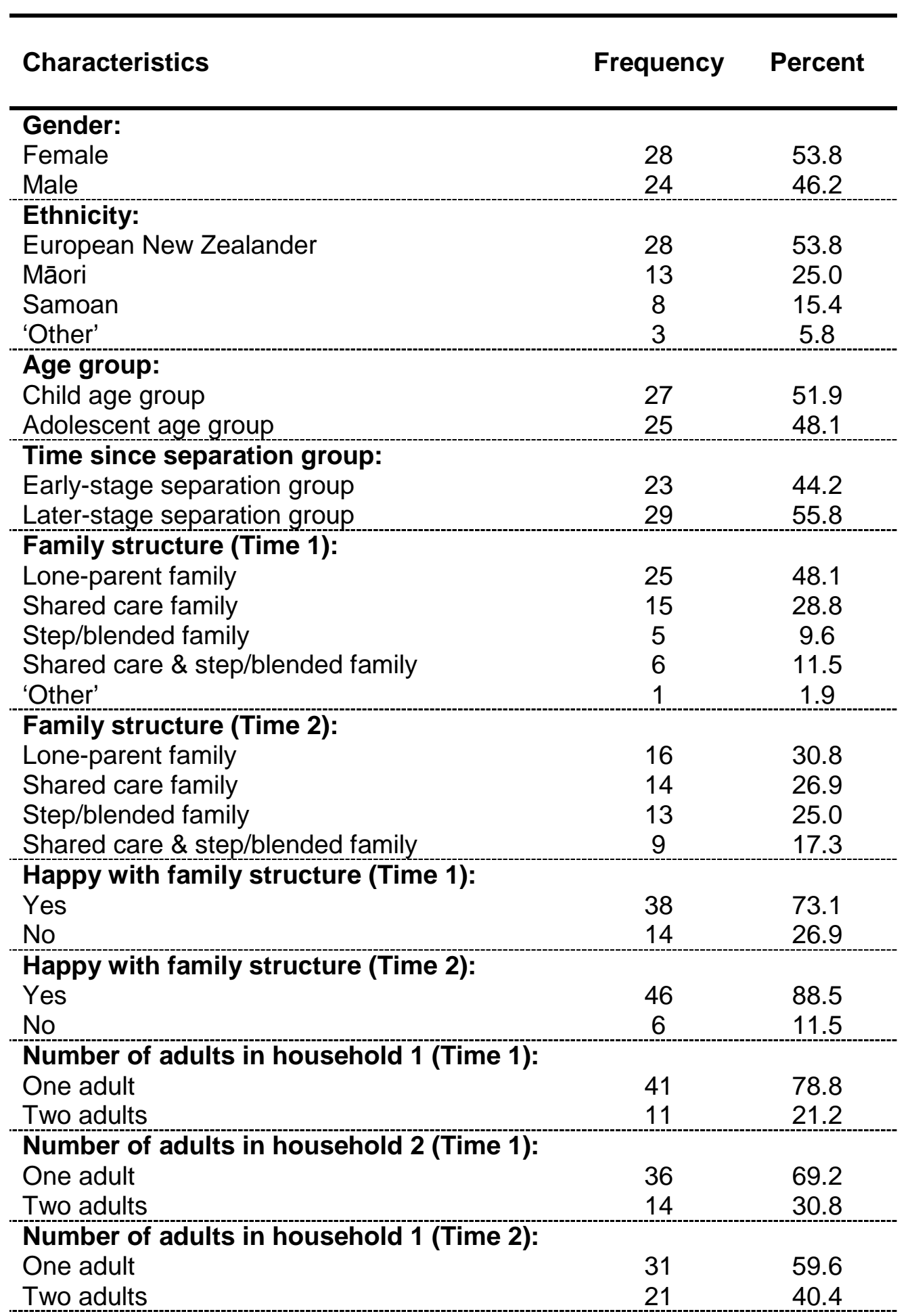

Number of adults in household 2 (Time 2): 


\begin{tabular}{|c|c|c|}
\hline $\begin{array}{l}\text { One adult } \\
\text { Two adults }\end{array}$ & $\begin{array}{l}29 \\
23 \\
\end{array}$ & $\begin{array}{r}55.8 \\
44.2 \\
\end{array}$ \\
\hline \multicolumn{3}{|c|}{ Number of transitions experienced (Time 1): } \\
\hline One transition & 23 & 44.2 \\
\hline Two transitions & 16 & 30.8 \\
\hline Three transitions & 9 & 17.3 \\
\hline Four transitions & 3 & 5.8 \\
\hline Five transitions & 1 & 1.9 \\
\hline \multicolumn{3}{|c|}{ Number of transitions experienced (Time 2): } \\
\hline One transition & 16 & 30.8 \\
\hline Two transitions & 19 & 36.5 \\
\hline Three transitions & 10 & 19.2 \\
\hline Four transitions & 4 & 7.7 \\
\hline Five transitions & 2 & 3.9 \\
\hline Six transitions & 1 & 1.9 \\
\hline \multicolumn{3}{|c|}{ Contact with non-resident parent (Time 1): } \\
\hline Shared care (joint custody) & 17 & 32.7 \\
\hline Weekly & 8 & 15.4 \\
\hline Fortnightly & 13 & 25.0 \\
\hline Once every three months & 6 & 11.5 \\
\hline Once every 6 months & 3 & 5.8 \\
\hline Once a year & 4 & 7.7 \\
\hline Never & 1 & 1.9 \\
\hline \multicolumn{3}{|c|}{ Contact with non-resident parent (Time 2): } \\
\hline Shared care (joint custody) & 25 & 51.9 \\
\hline Weekly & 12 & 23.1 \\
\hline Fortnightly & 2 & 3.8 \\
\hline Once every three months & 5 & 9.6 \\
\hline Once every 6 months & 4 & 7.7 \\
\hline Once a year & 1 & 1.9 \\
\hline Never & 1 & 1.9 \\
\hline \multicolumn{3}{|c|}{ Happy with amount of contact (Time 1): } \\
\hline Yes & 30 & 57.7 \\
\hline No & 10 & 19.2 \\
\hline 'Sort of' & 12 & 23.1 \\
\hline \multicolumn{3}{|c|}{ Happy with amount of contact (Time 2): } \\
\hline Yes & 37 & 71.2 \\
\hline No & 6 & 11.5 \\
\hline 'Sort of' & 9 & 17.3 \\
\hline
\end{tabular}

\subsubsection{Separation groups}

When Interview 1 was undertaken 44\% of participants' parents had separated between one month (.08) and 10 months (.83) earlier; with a mean of four months and three weeks (.39) since the separation. These participants were classified as the 'early-stage separation group' (ESG) since it had been less than one year since the separation. The remaining $56 \%$ of participants' parents had separated between 14 months (1.33 years) and 24 months ( 2 years) earlier. For these participants there was a mean of 20 months (1.66 
years) since the separation. These participants were referred to as the 'laterstage separation group' (LSG) since it had been between one year and two years since the separation.

\subsubsection{Cultural groups}

The cultural composition of the sample was 54\% European New Zealanders, $25 \%$ Māori, 15\% Samoan, and 6\% that were classified as belonging to other ethnic groups. The participants in the 'other' category were Chinese, Korean, and South African. For statistical and interpretation purposes the four cultural groups were recoded into three family structure groupings; European New Zealanders, Māori, and Samoan. The participants from other ethnic groups were not included in the ethnic comparisons.

\subsubsection{Family structure}

At the time of the first interview almost half of the participants were living in a lone-parent family. The remainder of the participants were residing in a shared care (or joint custody) family, a step/blended family, or a shared care and a step/blended family arrangement. A small number of young people were living in a situation which did not fit the aforementioned categories (i.e. a foster family). The number of participants residing in a shared care family was larger than expected, as was the case in Study One.

For statistical purposes these family structures were recoded into three categories; a lone-parent family category, a shared care family category and a stepfamily grouping. The category previously referred to as the shared care and step/ blended family arrangement was recoded as a step/blended family grouping. The reason behind the integration of these two groups is that the step/blended family situation was interpreted to be the principal household. After the recoding $48 \%$ of participants were in a lone-parent family structure, $29 \%$ were in a shared care family, and $21 \%$ were in a step/blended family. In the step/blended family grouping over half of the young people (12\%) also spent equal time in a second household. One participant's foster family structure did not fit the three previously mentioned categories and was, therefore, treated as missing data. The participants were asked if they were 
happy with their living arrangements during Interview 1. The responses were either 'yes' or 'no', with 73\% responding 'yes' and 27\% answering 'no'.

At the time of the second interview fewer participants were living in a loneparent family, compared to Time 1. A similar number were residing in a shared care family or in a shared care/stepfamily arrangement at Time 2. A larger number of young people were residing in a step/blended family during the second interview. The step/blended family percentage was recoded from the $25 \%$ identified as being in a step/blended family and the $17 \%$ that were in a shared care family and a step/blended family arrangement. The participant in the foster family scenario was living with one parent at the time of the second interview and was, therefore, categorised in the lone-parent family grouping. The participants were once again asked if they were happy with their family structure at Time 2. The majority of participants answered 'yes' (89\%).

All participants had two parents and two households. Household one was referred to as the household they spent the majority of the time in, except in the case of shared care family structures; the parent filling out the form was described as the caregiver in household one. There was one caregiving adult in household one at the time of the first interview for the majority of participants, and there was one adult in household two for $69 \%$ of participants. By the second interview there were fewer participants living in a household with one caregiving adult and more participants living with two caregiving adults.

\subsubsection{Transitions experienced}

The number of family transitions the participants had experienced prior to the first interview ranged from one to five transitions. Almost half of the participants had experienced one change to their family structure. For statistical and interpretation purposes the transitions experienced were recoded into three categories: 'one transition', 'two transitions' and 'three or more transitions'. One quarter of the sample had experienced three or more transitions at Time 1. By Time 2 the participants had experienced between 
one and six transitions; with 33\% undergoing three or more changes to their family structure.

\subsubsection{Contact arrangements}

The participants at Time 1 that had more frequent contact with their nonresident parent were those that described shared care (joint custody), weekly contact or fortnightly contact. The participants that experienced less frequent contact were those that saw their non-resident parent approximately once every three months, once every six months, had contact once yearly, or never had contact with their non-resident parent. During Interview 1, the participants were asked if they were happy with the amount of contact they were having with their non-resident parent. The responses were 'yes', 'no' or 'sort of' with just over half of the sample responding 'yes' and just under a quarter replying 'sort of'. The majority of young people that responded 'yes' were having more frequent contact with their non-resident parent.

In comparison to Time 1, a larger number of young people had shared care or weekly contact arrangements at Time 2 , and fewer participants had fortnightly contact arrangements. The participants were once again asked if they were happy with the amount of contact they were having with their non-resident parent. The majority of participants responded 'yes' at Time 2.

\subsubsection{Information about separation}

On the demographic form that was completed by each child's caregiver and by all adolescents aged 16 or older, there were three questions regarding information about parental separation. The parents and adolescents were asked if they received any information following the separation. No information was received by $62 \%$ (32) of participants and parents, while $36 \%$ (19) received information, and $2 \%$ (1) responded that the question was not applicable to them.

The $36 \%$ of parents and adolescents that did receive information were then asked how much information they received. Their answers were marked on a three-point Likert scale which ranged from 'not enough' (1.0) to 'too much' 
(3.0). Out of these parents and adolescents $21 \%$ felt that the information they had received was 'not enough' (1.0), while the answers of $42 \%$ fell somewhere between 'not enough' and 'about right' (between 1.25 and 1.75 on the Likert scale). The amount of information received was described as 'about right' (2.0) by $32 \%$ of these parents and adolescents. Only $5 \%$ rated the amount of information received as being better than 'about right' (2.25). No one rated the amount of information they had received as 'too much' (3.0); none of the responses were higher than 2.25 on the Likert scale.

These parents and adolescents ( $36 \%$ of the sample) were also asked how useful the information they had received was. Again, their responses were marked on a three-point Likert scale. The information was rated as 'not at all useful' (1.0) by $11 \%$ of these respondents. The information was seen to be in between 'not at all useful' and 'moderately useful' (between 1.25 and 1.75 on the Likert scale) by $58 \%$ of parents and adolescents. The information was rated as 'moderately useful' (2.0) by $10 \%$ of respondents, while the same percentage rated it as in between 'moderately useful' and 'extremely useful' (2.5). Only $11 \%$ rated the information they received as 'extremely useful' (3.0).

\subsection{The Concept of Family}

This section focuses on the first two research questions: 'What are young people's definitions of family and family importance?' and 'What are young people's definitions of separation?' The young people's descriptions and views are described in-depth below.

The participants that have been quoted in the next two sections are identified by their age, gender and time since separation, which are in parenthesis following each quotation. The age and separation timeframe are the participant's details as reported at Time 1. If the time since separation at Time 1 is between one month and 10 months then the participant is part of the early-stage separation group (ESG). If the participant's time since separation is between 14 months and 24 months then they are part of the later-stage separation group (LSG). 


\subsubsection{Definitions of 'family'}

At the start of the first interview the young people were asked, "What do you think 'family' is?" Their answers were analysed as they were in Study One; all responses were coded in terms of the criteria mentioned in their answers. The following categories became apparent: affective/nurturing factors, family members/individual choice, cohabitation, biological factors, legal factors, 'I don't know' and 'other' responses. A description of each of these criteria can be found in section 6.3. The title of the family members/individual choice criterion was varied slightly to include the individual choice element. The reason for this is that a number of the participants' responses referred to people who were members of a family, but they then went on to say that family could be any one that an individual identifies as family.

The participants' answers were independently coded by two individuals in order to establish the inter-rater reliability. The two individuals that analysed the responses agreed upon $96 \%$ of the coded responses in Question 1. The remaining $4 \%$ of responses were discussed and the coding differences were resolved by mutual agreement. The criteria mentioned in the participants' definitions of family are displayed in Table 9.3.

Table 9.3

Percentages of Criteria Mentioned in Definitions of 'Family' (Q.1)

\section{Criteria}

Affective / nurturing factors

Family members / individual choice

Cohabitation

Biological factors

Legal factors

Don't know + Other

Note: $n=52$
Percentage that mentioned the criteria 
Just over half $(54 \%)$ of the participants mentioned one criterion in their response, $36 \%$ mentioned two criteria, and $10 \%$ mentioned three criteria. When defining family, $65 \%$ of the sample referred to affective/nurturing components. The other criteria often mentioned were family members/individual choice and cohabitation. Many of the participants that defined family by its members did not solely refer to specific people in their descriptions. There were also frequent references to the concept of individual choice when it comes to defining family. For example, "Family is parents, kids, friends; whatever an individual thinks a family is" (16 year old female, 6 months since separation, ESG). The young people were less likely to include biological factors in their definitions and very rarely referred to legal elements.

\subsubsection{Family importance}

A question was also asked about the importance of family: 'Do you think 'family' is important? How come?' All of the young people replied 'yes' when asked if they thought family was important. The following categories summarise the reasons that they gave for their affirmative responses: affective/nurturing factors, biological factors, cohabitation and 'I don't know'. Most of the young people mentioned just one criterion in their responses (81\%), with only $19 \%$ mentioning two criteria. The participants' answers were also coded by a second individual to test the inter-rater reliability. The two individuals agreed upon $94 \%$ of the coded responses in question 2, and reached mutual agreement about the remaining $6 \%$ of responses. Refer to Table 9.4 for an outline of the criteria participants mentioned.

The majority of participants' responses included affective/nurturing related comments. For example, "Family are there to love you and protect you no matter what happens." (17 year old female, 14 months since separation, LSG). A quarter of the sample made references to biological factors, such as "Family are important because they are your blood and that means forever." (11 year old female, 20 months since separation, LSG). Close to a quarter of participants referred to cohabitation in their reasoning; for example, "It's important because they are the people who live with you." (9 year old male, 18 months since separation, LSG). 
Table 9.4

Percentages of Criteria Mentioned in Responses Relating to Family

Importance (Q.2)

\begin{tabular}{lc}
\hline \multicolumn{1}{c}{ Criteria } & Percentage that mentioned the criteria \\
\hline Affective/nurturing factors & 82.7 \\
Biological factors & 15.4 \\
Cohabitation & 13.4 \\
Don't know & 7.7 \\
\hline
\end{tabular}

Note: $n=52$

\subsubsection{Definitions of separation}

The young people were asked, "What does separation mean to you?" Their answers were coded in terms of all criteria derived from their responses. The following categories emerged: the parents' relationship, cohabitation, affective factors, time, legal factors, family change, and 'I don't know' or 'other' responses. Most of the young people mentioned either one criterion (44\%) or two criteria (40\%). A smaller number mentioned between three and four criteria (15\%). The participants' responses were coded by a second individual to test the inter-rater reliability. The two individuals agreed upon $91 \%$ of the coded responses in question 11 . The $9 \%$ of responses that they disagreed on were discussed and consensus was reached. For an outline of the criteria mentioned refer to Table 9.5.

The relationship criterion referred to parents breaking up and not wanting to be together. For example "I guess it's that parents don't want to be in the relationship anymore, and that they've grown apart." (16 year old female, 19 months since separation, LSG). The cohabitation criterion included responses about the parents not living together, such as, "It's when parents live in separate houses." (10 year old female, 8 months since separation, ESG). Affective factors were defined as the parents no longer being in love with each other or no longer being close or affectionate towards one another. For 
example, "Well, it means they don't love each other anymore and they move on." (9 year old male, 20 months since separation, LSG).

Table 9.5

Percentages of Criteria Mentioned in Definitions of Separation (Q.11)

Criteria

\begin{tabular}{ll}
\hline Relationship change & 29.3 \\
Cohabitation & 27.2 \\
Affective factors & 16.3 \\
Time & 14.1 \\
Legal factors & 5.4 \\
Family change & 4.3 \\
Don't know + Other & 3.3 \\
\hline
\end{tabular}

Note: $n=52$

Answers which referred to the parents no longer spending time together were classified as the time criterion. For example, "Parents not spending much time together and off doing their own thing." (10 year old male, 16 months since separation, LSG). The legal factors category included responses about divorce or about the marriage ending; for instance, "It means your parents' marriage is over." (14 year old male, 21 months since separation, LSG). Responses that focused on the family breaking up or changing were labelled as the family change category; for example, "It's kind of like families moving apart a bit more and not being around each other as much." (14 year old male, 19 months since separation, LSG). The final criterion included all 'I don't know' and other responses that did not fit into the previously mentioned categories. An example of a response classified in the 'other' category is: "I can't really explain it. It's not a bad word or a good word." (9 year old female, 24 months since separation, LSG). 
The young people were more likely to define separation in terms of parents rather than couples. Their definitions tended to focus on the relationship between two parents changing or on parents no longer cohabitating. Very few young people referred to separation in legal terms or in the context of the family breaking up or changing. The majority of definitions revolved around the parents not the family.

\subsection{Experiences of Separation (Time 1)}

The following section focuses on research questions three to six which enquire about young people's experiences of parental separation. Where applicable the (qualitative) data were analysed in terms of the response differences in the child and adolescent age groups and/or the early-stage and later-stage separation groups. The interview questions that address the following research questions can be found in Appendix $O$.

\subsubsection{Views and reactions}

Research question 3 enquired: 'What are young people's views and reactions in relation to parental separation?' In this section the young people's reactions, thoughts, and feelings are described in-depth.

Finding out about the separation. The young people were asked two questions in relation to being informed about their parents' separation. The first question explored the manner in which the participants found out that their parents were separating. The second question focused on who they would have wanted to tell them about the separation.

The main focus of the first question was how the young people learnt that their parents were separating. All participants responded by reliving the moment that they were verbally told about the break-up. However, it is fair to say that many of the participants were very aware of the situation and had in reality found out about the separation long before they were verbally informed. The young people's responses indicate that they were told about the break-up of their parents' marriage in a variety of ways. The majority of the young people were told by their mother (40), while very few participants were told by 
their father (2). Most of these young people were alone when they were informed of the situation. A small number were told at the same time as their siblings. Very few children were told about the separation by both parents simultaneously (3). Those that were informed in this manner were in the younger age group. In all of these cases the child was told at the same time as their siblings.

One child reported being told by their mother face-to-face and then being told by their father in a phone call that followed up the mother's explanation: "We'd just got back from shopping and mum told me that my dad wouldn't be living with us anymore. We talked about it for awhile, then dad rung to talk to me about things. I wanted to see him to talk face-to-face, but I guess I was just happy to talk to him. Silly me, I thought he was away on business but he was away for good." (13 year old female, 22 months since separation, LSG). A small number of children found out in other ways, including from siblings (2), or a family friend (3); for example, "Mum's best friend took me out to lunch and told me the news. Bought me a flash lunch, talking away, then dropped it in that my parents' marriage was finished. How rude's that?" (17 year old male, 3 months since the separation, ESG). One child reported being told by their mother and their grandparents together.

When asked who they would have wanted to tell them about the separation, all children stated that they would have liked their mother and father to tell them face-to-face and together about the break-up (52). They did not seem to have a preference about whether they were told on their own or with their siblings. One participant stated: "It would have been easier to have both mum and dad there telling me that they were splitting up. I didn't want to hear from just my mum. I wanted to see them together one last time and I wanted to hear what both of them had to say and ask them stuff. It would have reassured me that they could put the nastiness aside and come together to tell me to my face what was happening. That would have meant the world to me." (17 year old female, 14 months since the separation, LSG). 
Initial reactions to the separation. The young people reacted to the news of the separation in a number of ways, and some reported multiple reactions. Many of the participants cried and were visibly upset after they were told of the separation (27); one participant responded, "I just lost it. Cried and cried and cried." (11 year old female, 5 months since separation, ESG). Some participants were unresponsive (19); for example, "Mum said 'dad's leaving' and I didn't know what to say so I didn't react at all. I just sat there and stared at the TV." (15 year old male, 15 months since separation, LSG). Other participants that also depicted calm and collected responses were those who reacted in a supportive manner towards their parents (10). Some young people reported that they reacted by asking lots of questions (9); for example, "I kept asking her why, why, why. That's all I remember, asking what had happened and what was going to happen to us all; then I went to bed and got upset" (15 year old female, 23 months since separation, LSG). A small number acted out in anger (6); one boy described his reaction to the news, "I threw my plate, I yelled, I told them that I hated them." (12 year old male, 5 months since separation, ESG). Some participants even tried to sort things out and resorted to pleading with their parents (4). One participant recounted, "I couldn't believe what was happening, I told mum that I wanted her to make things all right, then I rang dad and told him that they had to stay together. I was on a mission." (17 year old female, 8 months since separation, ESG).

Of the 27 participants whose initial reactions were to cry, 19 were in the child age group, whereas 8 were in the adolescent grouping. The nine participants that reacting by asking questions were all in the older age group, whereas those who acted out in anger were all in the child age group. A number of the older participants reacted by staying stoic and taking on a supportive role for their parents (in most cases the mother), while also taking on a supportive role for their younger siblings. However, they all confessed to having private moments of being visibly upset or crying with their mother later on. A typical response from these participants was: “I couldn't cry I couldn't break mum's heart like that. She was a mess and I had to stay strong for her and my brothers. I didn't want her to have to worry about me, so I told her I was okay and that we'd be okay; but I was gutted." (17 year old male, 18 months since 
separation, LSG). Also typical from the older participants was the following reaction: "When mum told me I gave her a big hug and told her l'd look after her. Then we blubbered away for hours." (18 year old female, 5 months since separation, ESG).

Feelings about the separation at the time. The young people experienced a wide array of feelings when they were informed of their parents' separation. It was common for the participants to describe more than one feeling. Seven of the 12 feelings that the young people voiced about their parents' separation were negative feelings. The total number of times negative feelings were relayed was 152 , compared to the 53 that were positive and the two that were neutral. The feelings are displayed in Figure 9.1.

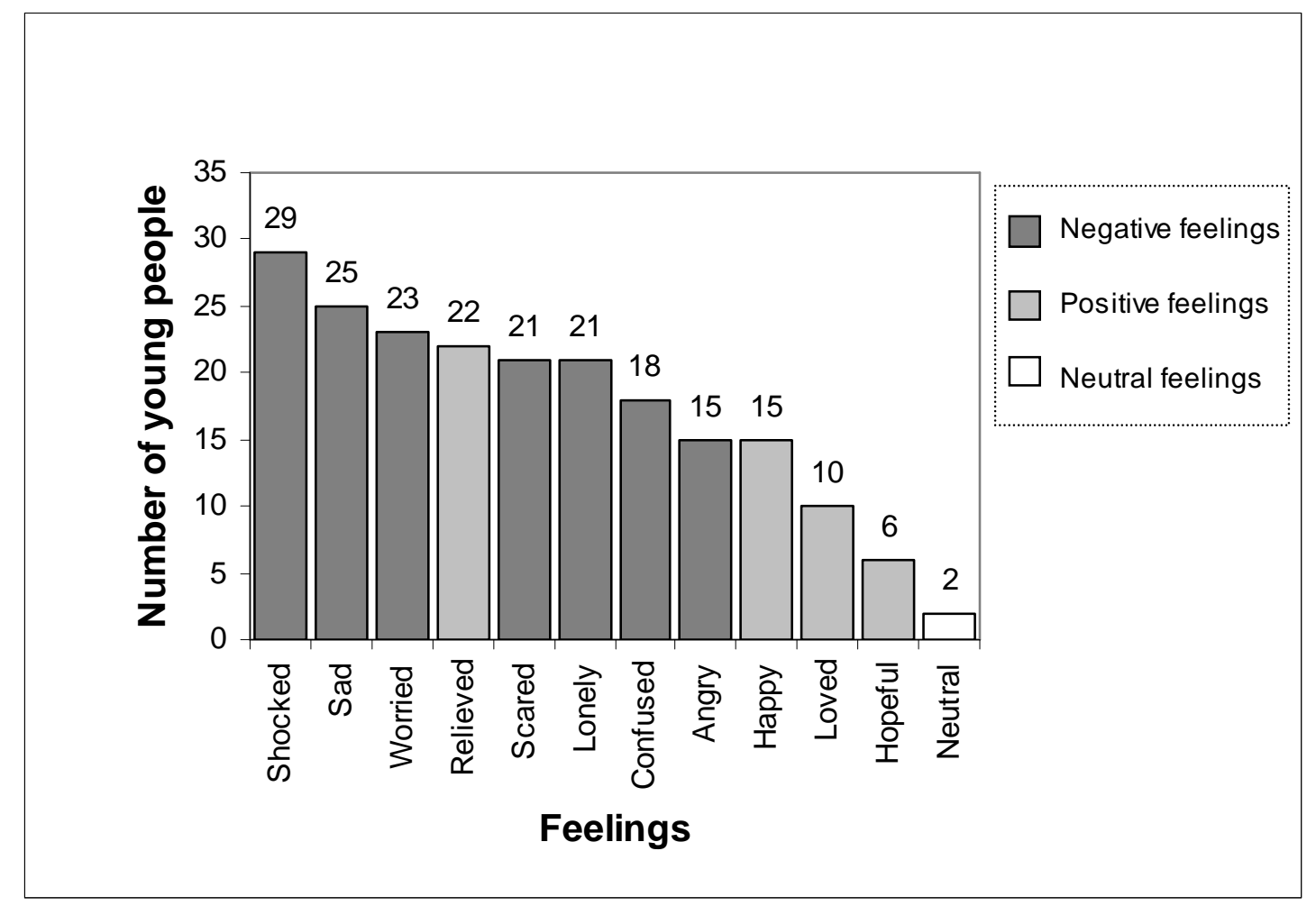

Figure 9.1. The young people's feelings about their parents' separation in retrospect (as reported at Time 1).

Interestingly, almost all of the children (50) reported that they were aware that something was going on prior to being told of the break-up. Because they were cognisant that the separation was looming, they were not necessarily surprised by the news; for example, "I had a feeling it was coming, so the 
news wasn't that new. I'm not at all surprised but I still feel weird, if you know what I mean. It still blows me away." (16 year old female, 2 months since separation, ESG). Despite conveying the lack of surprise many still described feelings of shock (29); for example, "I felt real shocked when I found out, but I sort of knew 'cause when I was little I used to always say 'mum, dad are you splitting up?", 'cause I knew. And then they told me so I was stunned, but not surprised." (11 year old female, 20 months since the separation, LSG).

A feeling of sadness was frequently reported (25): "I really felt sad for everything that was going on and everything that was going to happen. It was such a dark time, everyone was down and it was hard to not be sad." (15 year old female, 17 months since separation, LSG). Being worried and scared were common feelings amongst participants, with 23 conveying worry: "I was upset and worried about what was going to happen next." (12 year old male, 22 months since separation, LSG), and 21 expressing fear: "I felt scared, pit of my stomach scared, almost sick. I felt like someone had put a bomb under my family." (10 year old male, 16 months since separation, LSG). Many participants conveyed feelings of loneliness (21); a typical response was: "At that moment I was the only person in the world that was going through that. I felt so alone and so freaked out. I knew that heaps of kids had gone through the same thing, but I still felt strangely alone. It's hard to explain." (15 year old female, 1 month since separation, ESG). A number of participants stated that they felt confused (18); for example, “I didn't know how I felt. I couldn't get my head around it; I didn't understand what it meant for us all, I was pretty confused." (15 year old male, 6 months since separation, ESG). Fifteen young people conveyed anger; for example one young person said they felt "Angry. Pretty much felt scared and angry. Angry "cause everything was ruined." (10 year old male, 16 months since separation, LSG).

Negative feelings were not the only feelings expressed at the time of the separation; some participants conveyed feelings of a positive nature. An expression of relief was commonly referred to, with 22 of the young people recognising that the news made them feel liberated. One participant recounted how she felt: "This might sound wrong but I was like 'yeah, it's 
over'. The pressure was off, I felt free from all the fighting and angst. It was such a release."(16 year old female, 23 months since separation, LSG). Another young person referred to feelings of relief and hope after hearing about the separation: "It was like this huge weight had lifted; I didn't think I'd feel like that but the news was like 'phew' maybe things will be better now." (17 year old female, 8 months since separation, ESG). In fact six young people conveyed that they felt hopeful about the future.

Feelings of happiness were expressed by 15 young people; for example, "Well, I guess I felt happy. Happy that mum and dad were doing what they should have done a long time ago. l'd seen them unhappy for years, so even though it wasn't the best thing in the world to go through I still felt happy for them. I remember thinking 'finally!'." (18 year old male, 6 months since separation, ESG). Ten young people even mentioned feeling loved at that time; for instance, "I felt really upset and let down; but at the same time I felt extremely loved because even though mum and dad were giving us this bad news they made sure we knew how much we meant to them and that we were the priority." (17 year old female, 14 months since separation, LSG). Two participants reported feeling neutral, with one responding "I honestly didn't feel anything; I didn't feel sad, I didn't feel happy. I think I'm grown-up enough to realise it's their issue not mine and it doesn't really impact on me now." (18 year old male, 6 month since separation, ESG).

When comparing the young people at the early stages of separation and those at the later stages of separation there were no differences in the descriptions of the feelings they experienced when they were told about their parents' separation. To view the feelings of the ESG and LSG refer to Figure 9.2 . 


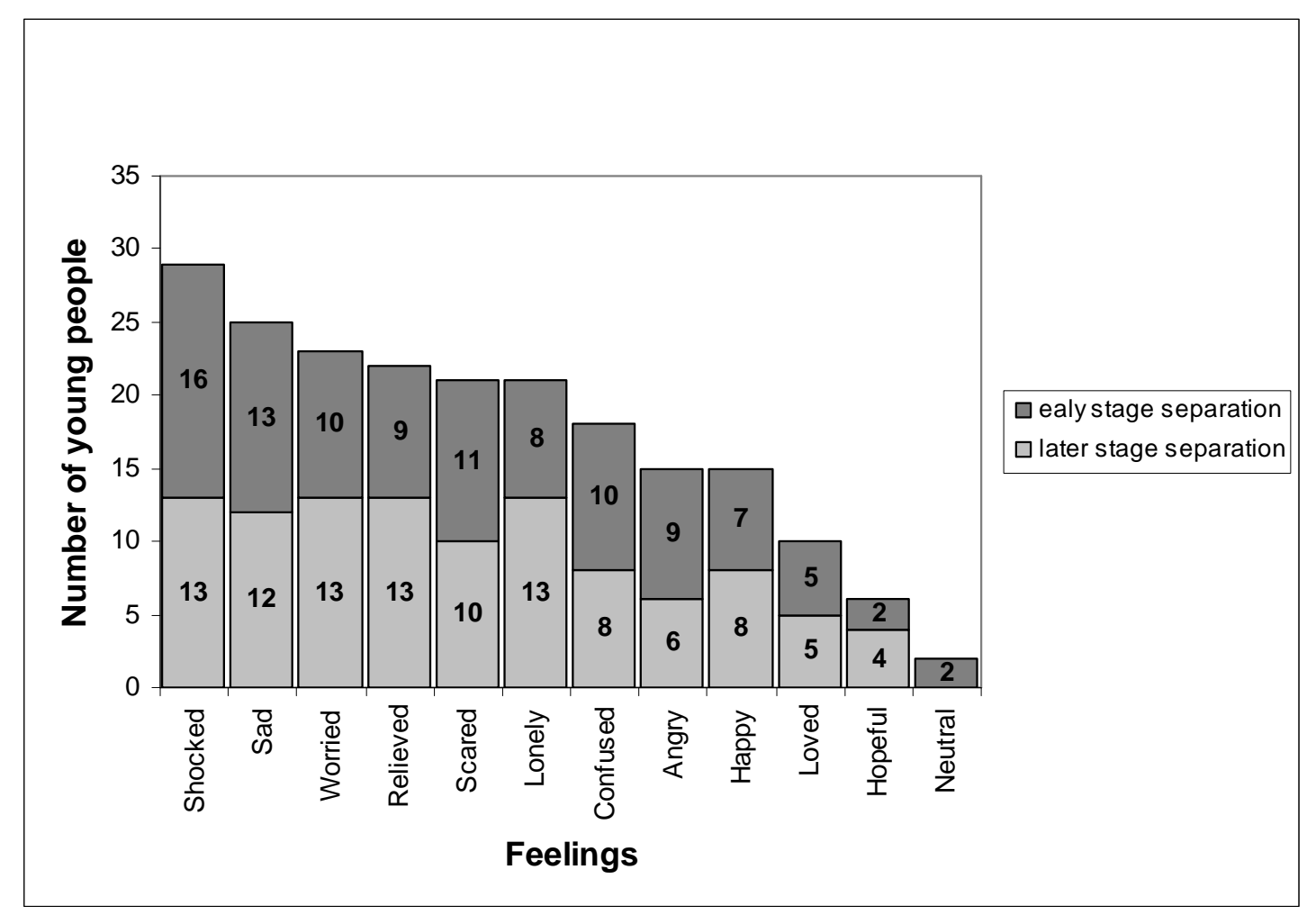

Figure 9.2. The early-stage separation participants and the later-stage separation participants' feelings about their parents' separation in retrospect (as reported at Time 1).

In terms of the age groups, the child participants were more likely than the adolescent participants to report feeling sad and scared. The younger age group were also more likely to convey feelings of confusion. A large number of the adolescents reported that they felt relieved and hopeful. The older participants were also more likely to report feeling worried, in comparison to their younger counterparts.

Feelings about the separation now. The young people's feelings about the separation at the time of the first interview (Time 1) included a range of negative and positive feelings. Participants tended to describe multiple feelings in their responses. An equal number of negative and positive feelings were expressed; although the total number of times positive feelings were relayed was 114 , compared to the 94 that were negative. The feelings that were expressed during the first interview are displayed in Figure 9.3. 


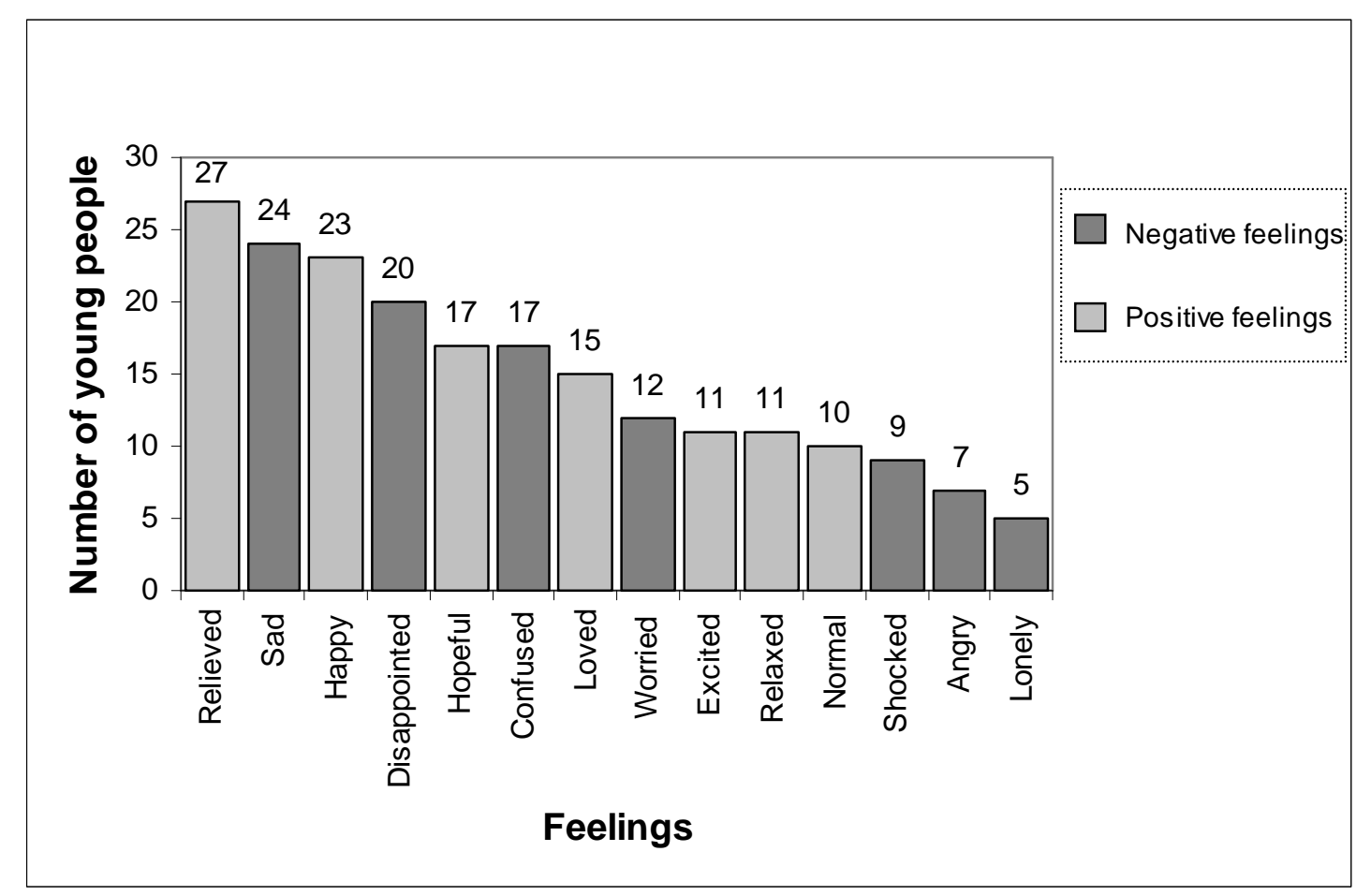

Figure 9.3. The young people's feelings about their parents' separation now (Time 1).

When the young people were asked how they felt about the separation now the feeling most frequently referred to was relief, with a total of 27 participants expressing a state of being at ease at the time of the first interview. A typical response is, "It was heartbreaking at the time, but I pretty much feel relieved now because things have worked out. And if I was being completely honest l'd probably say that things are better than they were before, just happier and more stable." (13 year old female, 22 months since separation, LSG). Also, commonly reported feelings at Time 1 were sadness (24) and happiness (23).

Twenty young people expressed disappointment: "I feel a bit let-down by mum and dad. They could try harder to make it work. But who knows. . I don't really understand what they're going through." (13 year old male, 1 month since separation, ESG). Seventeen participants conveyed feelings of hope for the future of their family; for example, "I feel pretty good about things now. I'm much more positive about what's going to happen; it's not so scary. I guess I just feel confident that we can still be a family and still have a good life." (16 year old female, 23 months since separation, LSG). The same number of 
young people responded that they felt confused; one participant stated: "I don't know. I feel pretty confused. I don't know what's gone wrong, I feel like everything's being done behind my back. And it sucks!" (16 year old female, 2 months since separation, ESG).

Fifteen young people stated that they felt loved; for example, "I think they're doing everything they can to make this tough time easier for us kids, so I feel really important and loved and ok." (17 year old female, 3 months since separation, ESG). Some young people reported being worried about their parents' separation and the future (12); a typical response was: "(I feel) concerned. It's hard not to worry when my dad's god knows where and my mum's losing it." (10 year old male, 1 month since separation, ESG). Feeling relaxed about their parents' separation was the response of 12 participants; for example, "I feel pretty relaxed about it now but I wasn't when it happened." (11 year old male, 17 months since separation, LSG). The same number of young people conveyed feelings of excitement; for example, "It's a weight off, you know? I'm pretty excited about our family. There's new people and new things to do and it's better than two people yelling at each other day and night." (15 year old male, 23 months since separation, LSG).

Ten young people stated that they felt normal: "I feel ok about it" (What do you mean by ok?). "I feel pretty normal really, things are ok and I don't feel anything but normal." (12 year old male, 5 months since separation, ESG). Another response was: "That's hard to answer. I had a lot of feelings going on when they first split, but now I feel normal. I'm just the same as all my other friends; we've all been there. Life has its ups and downs." (12 year old female, 16 months since separation, LSG). A smaller number of young people expressed feelings of shock, anger and loneliness.

In order to compare the feelings of the young people in the early stages of separation and those in the later stages of the break-up, refer to Figure 9.4. The feelings that tended to be reported equally by the early-stage and laterstage separation participants were relief, hopefulness, and confusion. The ESG was more likely than the LSG to report that they were feeling sad, 
worried, and angry. For example, "I'm a bit sad and I worry what's going to happen to us all." (10 year old male, 3 months since separation, ESG), and "I feel pretty worked up, it's hard not to be angry when your dad ups and leaves." (16 year old female, 2 months since separation, ESG). All of the participants that reported feeling shocked or lonely were from the ESG.

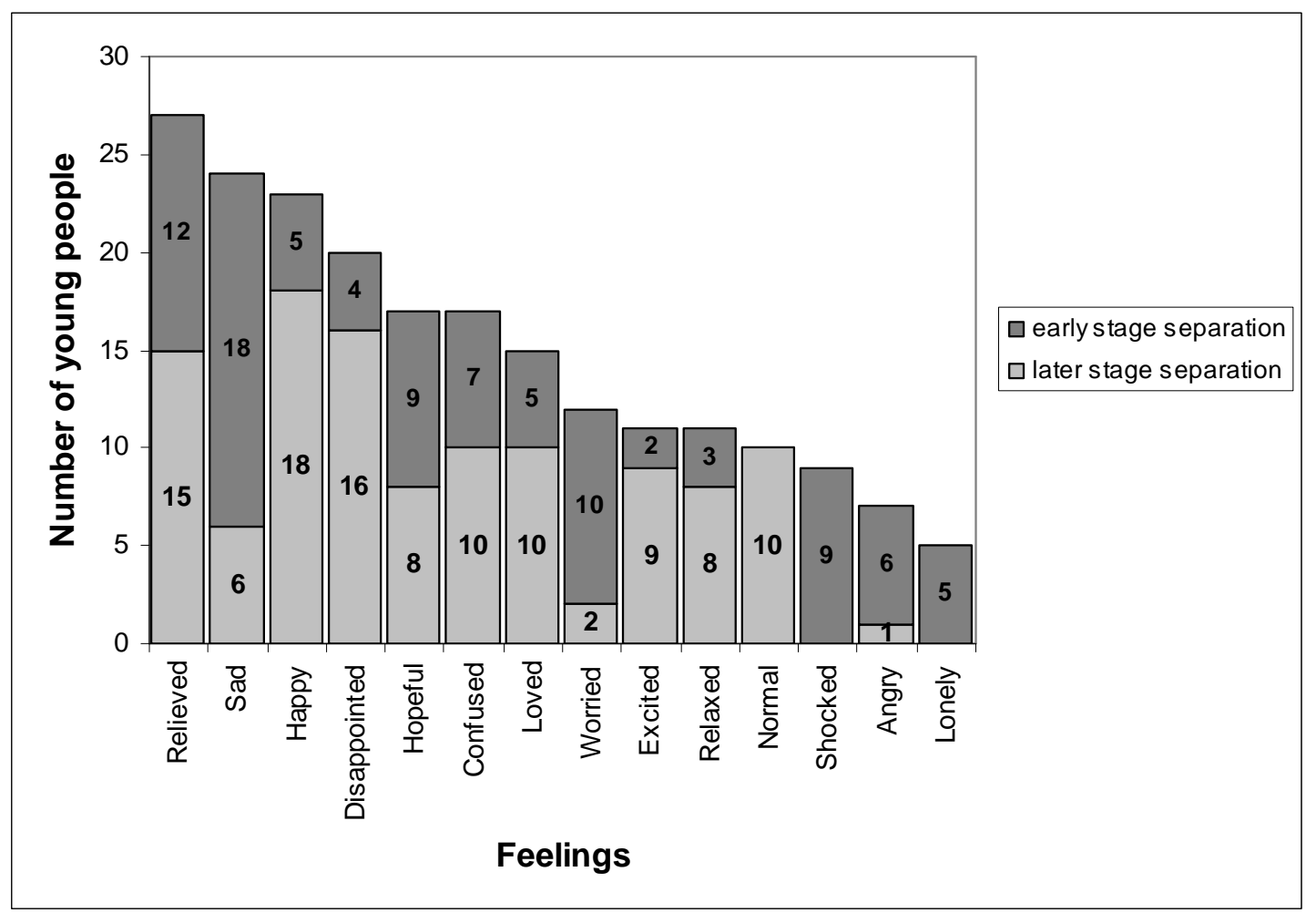

Figure 9.4. The early-stage separation participants and the later-stage separation participants' feelings about their parents' separation now (Time 1).

The participants in the LSG were more likely to report feeling happy, loved, relaxed, and excited, in comparison to the early-stage separation participants. For example, "It's kind of awkward still and weird, but I think I feel a lot happier now because it's better than them being together and fighting; because now they get along better and we're all looking forward to things." (13 year old female, 22 months since separation, LSG), and "It's pretty good now. I mean l'd so much rather that they were apart and happy than together and not happy. Mum's happy now, she's got a new partner, and dad seems really happy too. I know they both really care about me". (16 year old female, 23 months since separation, LSG). The later-stage separation participants 
were also more likely to express disappointment compared to the ESG: "(I feel) a bit let down; it would have been easier to grow up with both parents around. Sometimes I wonder if they tried hard enough." (12 year old male, 20 months since separation, LSG). All of the young people that stated that they felt normal were from the LSG.

Many in the later stages of separation stated that they were used to it now, that it has become easier and that they no longer felt as sad (12). For example, "Life is back to normal now, well a different normal but normal. I'm used to it and I'm not sad about what's gone on. I still get to see my parents and we are happier now because there's not so much fighting." (16 year old female, 18 months since the separation, LSG). Some of these children also stated that they did not mind that their parents had separated and didn't feel that it had affected them (6). Five children reported that they felt better about life now than they did before the break up. For example, "It was quite sad and disappointing but l'm over it now. Life's better." (14 year old male, 20 months since the separation, LSG), and "I don't really mind because we get to see dad still, and it's cool 'cause we get lots of presents, separate presents. And it's cool "cause sometimes dad comes over when I have a big assignment to do or something. I'm all right. It has worked out pretty well." (10 year old female, 24 months since the separation, LSG).

Four of the older participants in the ESG also felt at ease with the break-up. One participant commented: "I haven't really got a problem with it. I'm quite a bit older than my sister so it didn't really affect me as much. I was pretty much already independent and I still got to see them both and everything, so it's okay." (18 year old male, 6 months since the separation, ESG).

Outlook for the separation. The participants were asked if they thought their mum and dad would reunite and also whether they wished they would live together again. The majority of the young people were realistic about their parents' separation (41); they believed that it was a permanent decision. The remainder of the participants were unsure whether their parents would reunite 
(11). Interestingly, none of the participants responded that they thought their parents would get back together.

Of the 41 participants that believed their parents' decision to separate was permanent, 19 of them stated that they did not want their parents to reunite, because life was better and they were happier. A typical response was, "No I don't think they will, but I don't want them to either. Things are good now, we are happy. I wouldn't want them to go back to the way they were, that wouldn't be good for any of us." (14 year old male, 20 months since separation, LSG). Fourteen of these young people responded that they did not know if they wanted their parents to reunite and eight replied that they wanted their parents to reunite. For example, "I really don't know if l'd want that. I wouldn't want the fights to happen like they did before. It would be hard to choose if I had to make a choice between them being together and a home with no fighting." (16 year old female, 6 months since separation, ESG). A response that was typical of the participants that wanted their parents to reunite was: "Yes, l'd like them to get back together so that things could be the way they were. But I know it's not that simple, it could never be that easy." (13 year old male, 10 months since separation, ESG).

Of the 11 participants that were unsure whether their parents would get back together, all of them wished that they would. More specifically eight of these participants wished that their parents would get back together, but specified certain conditions that would have to be met if the relationship resumed. They all specified that the family environment could not be the way it was, in terms of the level of conflict and general unhappiness. One young person stated: "Of course! l'd love them to be a couple again. But in saying that I wouldn't want them together if it was going to be the same old shenanigans. I couldn't cope with that!" (16 year old female, 6 months since separation, ESG). The remaining three participants were hopeful that their parents would reunite. For example, "I don't know if they will (get back together). I still think that they might make up. I hope they will." (9 year old female, 1 month since separation, ESG). All of the participants that were unsure whether their parents would reunite were from the ESG. 
Blame for the separation. The children were asked whether anyone was to blame for their parents' separation. The majority of the young people stated that no one was to blame (42). A typical response was: "No. No one's to blame. It's just one of those things." (9 year old female, 19 months since separation, LSG). A few children identified one parent as the person responsible for the break-up (4); in three of the situations the father was blamed for the separation. For example, "Yeah I kind of blame my dad; he's the one that did it." (10 year old male, 3 months since separation, ESG). Three young people laid equal blame on both parents for the separation. One participant stated, "Yes I blame mum and dad; they both yelled and screamed at each other, they both said nasty things." (13 year old male, 10 months since separation, ESG). The same number of young people blamed a third party (primarily the adulterer or new partner). For example, "Yip. I don't really know what happened, but I think dad met someone at work. I think she's to blame for breaking them up." (16 year old female, 6 months since separation, ESG). Notably, none of the children blamed themselves for their parents' separation.

Reason for the separation. The participants were asked why their mum and dad separated. If they did not know the cause they were asked if they wished the reason had been explained to them. Only three young people knew emphatically why their parents separated; one stated, "They're not together because mum fell in love with someone else. She likes dad but doesn't love him, so she had to leave him so the family scene wouldn't get unstable for everyone." (13 year old female, 22 months since separation, LSG). Most of the young people were uncertain why their parents separated (49), and just over half of these participants speculated about the basis for the separation. For example, “I don't know. But I think it's because dad was spending too much time at work." (18 year old male, 6 months since separation, ESG), and "I've never been told. I've asked lots. I think it's because mum didn't want to be around us anymore. I think we made her angry and stressed." (10 year old male, 16 months since separation, LSG). The other half simply responded that they did not know; for example, "I have no idea. But l'd really like to know." (11 year old female, 5 months since separation, ESG). Interestingly, all 
of the participants who were unsure about the reason for their parents' separation stated that they wished their parents had explained to them why they had parted ways.

Cognisance of problems with parents' relationship. The young people were asked if they were aware that their parents were having relationship problems prior to the separation. All of the participants were cognisant of the relationship difficulties between their parents. The young people referred to a variety of factors that made them aware of the relationship problems. These included an increasing number of arguments or 'fighting' (48), parents no longer sleeping in the same room (19), parents no longer talking to each other (37), one or both parents being visibly upset (14), a lack of affection between parents (10), parents going out to places by themselves (10), and parents participating in fewer activities as a family (9).

The most frequently reported sign that there were problems in the relationship was the 'fighting' between parents. When the young people were questioned further about what they meant by the term 'fighting', it was clear that their descriptions were more in line with the concepts of both verbal conflict and emotional conflict. Reports of the verbal conflict included, "There was lots more yelling and it was almost every night after dinner, lots of shouting and cruel things being said." (11 year old female, 20 months since separation, LSG). "I knew something was up with all the arguing, they couldn't talk to each other without shouting." (15 year old male, 6 months since separation, ESG). The emotional conflict was also extremely prominent in the young people's descriptions, with many of them referring to their parents in terms of the general coldness between them, the avoidance, the stonewalling, the belittling and the animosity. For example, “They weren't even talking near the end; they couldn't even be in the same room . . . just really cold and bitter to each other." (17 year old female, 8 months since separation, ESG), and "Mum tried to pretend like nothing was going on but it was so obvious. (Mum and dad were) Ignoring each other, taking cheap shots, making the other one look bad. Did they really think they were playing happy families?" (17 year old male, 18 months, LSG). 
A smaller number of participants mentioned physical conflict, such as breaking things, pushing each other, and hitting or slapping. For example, "They were fighting all the time, mum would throw things, dad would slap her, and it would go quiet and then happen all over again." (15 year old female, 1 month since separation, ESG), and "One day dad got really angry and punched mum. I knew it (their marriage) was over then." (18 year old male, 21 months since separation, LSG).

Feelings about living arrangements. When asked about their current living arrangements and if they were happy with the arrangements the young people provided 'yes', 'no', and 'sort of' responses, and the reason for their responses. A total of 29 participants answered 'yes' they were happy, 11 answered 'no', and 12 responded that they were 'sort of' happy. The young people that responded 'yes' were asked what makes them happy and those that answered 'no' were asked what makes them unhappy. The participants that responded that they were 'sort of' happy were asked what makes them 'sort of' happy/unhappy,

The young people often identified the absence of conflict (28), and the increased level of happiness amongst members of the family (24), as reasons for their happiness with their living arrangements. A typical response was: "Yeah I'm happy with how things are because mum and dad don't argue like they did when we all lived together and so everyone's much happier." (12 year old female, 16 months since separation, LSG). Some young people stated that they were happy because they still got to see both parents (12), and some identified that they liked having two houses to go to (10). For example, one participant responded: "I'm happy because I still get to see my mum and my dad every week, and spend time with my cat and dog." (10 year old female, 5 months since separation, ESG), and another stated: "It's good because I have this home and my other home and I like spending time at both." (15 year old male, 15 months since separation, LSG). One participant was unable to describe what made them happy and responded 'I don't know'. 
Those that were unhappy with their living arrangements consistently identified the lack of contact with their non-resident parent as the main reason for their unhappiness (18). One participant stated: "I'd be happier if I got to see more of my dad. I talk to him on the phone, but I want to see him, not just on my birthday." (9 year old female, 19 months since separation, LSG). Other participants referred to financial difficulties such as the downsizing of the family home and a decrease in disposable income as reasons for their unhappiness (6). For example, "I liked where we lived before, the house we are in now is too small, there's not enough room." (16 year old female, 2 months since separation, ESG), and "There's not enough money now. I know dad has a hard time finding the money to look after us all. We were richer when we all lived together." (9 year old male, 18 months since separation, LSG). A small number identified a particular person or people as the reason for their unhappiness (3); for example, "I don't like it . . mum's boyfriend is living with us and he's annoying." (18 year old female, 9 months since separation, ESG). In all cases the person or people described were a parent's new partner which sometimes included his or her children.

Those in the earlier stages of separation were more likely to be unhappy with their living arrangements (9) compared to those in the later stages (2). Many of the children in the earlier stages stated that they were still getting used to their situation and, therefore, avoided saying 'yes' they were happy or 'no' they were not. Instead, they commonly used the terminology 'sort of' to refer to their level of happiness (11). The young people in the later stages of separation were more likely to say they were happy with their living arrangements (26), compared to those in the earlier stages (3). The young people in the later stages of separation that were unhappy with their living arrangements (2) or 'sort of' happy (1) were more likely to refer to new members of the family as the reason for their unhappiness.

Feelings about contact arrangements. The young people were asked about their current contact arrangements. In particular if they were happy with the amount of contact they had with their non-resident parent. If the participant was living in a shared care setup they were asked if they were happy with the 
amount of contact they had with both parents. The participants replied in one of three ways: 'yes', 'no', and 'sort of'. Just over half of the participants (27) responded 'yes' they were happy, 13 replied 'no', and 12 answered that they were 'sort of' happy. The reasons for these responses were explored.

The young people that were happy with the amount of contact tended to focus on the fact that they were able to see their parent/s regularly and spend quality time together (14). One young person stated "I get to see dad whenever I want. Sometimes it doesn't work out, but most times I get to stay over and we cook dinner, or play games, or he helps me with my homework." (9 year old female, 24 months since separation, LSG). Another young person commented that she was happy because: “. . I get to spend as much time as I want with mum and dad. Both of my houses are quite close so I get to see my parents as much as I did when we all lived in one house. But these days we all make more of an effort when we have time together." (10 year old female, 5 months since separation, ESG). These young people frequently referred to spending 'quality time' together doing 'things', not just being around each other. For example, "I like how we do stuff together. We plan things to do; we don't just hang around while mum or dad does their work or housework." (14 year old male, 19 months since separation, LSG).

Ten participants responded that they were happy because they were able to have regular contact with the aid of technology. For example, "I get to talk to dad whenever I want, and he texts me every morning and every night. We also send emails and photos all the time. So I get to see him and talk to him whenever I want." (16 year old female, 6 months since separation, ESG). Also of importance was that their parent/s were involved in activities that were significant to them, such as extracurricular activities, school events, and community outings (3). One young person commented, "It works out good. Dad still comes to watch me play soccer and sometimes we go to watch games and stuff. He came on my school camp too." (9 year old male, 20 months since separation, LSG). 
The majority of young people who were unhappy with their contact arrangements stated that they unhappy because they did not get to see their non-resident parent enough (10). Some of the reasons for the lack of contact were: distance, one parent preventing contact, work commitments, and financial difficulties. For example, "I don't get to see dad much, he works really long hours and so I can only stay over once every couple of months ..." (9 year old male, 18 months since separation, LSG), and "I like seeing mum, but dad tells me I can't 'cause she's a bad influence and 'cause her boyfriend could be mean to us." (14 year old male, 20 months since separation, LSG). Two participants stated that they were unhappy because they were spending more time at their non-resident parent's place than they wanted. One participant stated: "l'd like to spend more time at mums because that's where all my stuff is and it's hard taking stuff from house to house each week. l'd be happier if it was only once every couple of weeks not every week." (17 year old female, 8 months since separation, ESG).

All of the young people that were in the 'sort of' happy faction expressed that they were only partially happy with their current contact arrangements because they would like to see more of their non-resident parent. One young person stated: "It would be better if I got to see mum more often, I'd love to spend more time at her place" (12 year old male, 22 months since separation, LSG). Another young person commented, "I guess l'd prefer it if dad wasn't just a dad at Christmas. I know he lives in the South Island and that it costs to travel, but ideally l'd like to see him or at least talk to him more often." (12 year old female, 21 months since separation, LSG).

There were no differences in the responses of the early-stage and later-stage separation participants. However, a finding of interest is that all of the young people that had a shared care contact arrangement with their parents reported that they were happy with the amount of contact they had with their parents (15).

Negative aspects of the separation. The participants were asked four questions which focused on the negative aspects of their parents' separation. 
The first question investigated the bad things about their parents' break-up and the second question explored what they miss the most. The third question focused on what they dislike about living in their household/s; whilst the fourth was a follow-up question that delved into any ideas they had on how to improve life in their household/s.

When the participants were asked 'what are some of the bad things about the separation' the most common response was not being able to see their nonresident parent as much as they would like to (37). A typical response was, "I don't like it that I don't get to see dad." (9 year old female, 1 month since separation, ESG). Many young people also recognised travel and the distance between themselves and their non-resident parent as a negative factor (34). For example, “Dad lives ages away, so I can't just go down the road and visit him after school or on weekends. I have to wait until holidays and there's not many of them in a year." (14 year old male, 21 months since separation, LSG). Moving between houses and moving possessions was a problem frequently reported by the young people (34). One participant protested, "I hate having to pack up and move every week. I always forget something; it's so frustrating!" (13 year old male, 10 months since separation, ESG).

Some young people recognised parents arguing as a confusing and negative aspect of the separation (18). One young person said: "We were quite young and it was really hard hearing them argue. There were times when I just completely blanked out and would go all emotional and stuff. And it was confusing as well. It must have been completely over my little brother's head 'cause if I was nine he was only six or seven or something. I mean he would have just been so confused..." (11 year old female, 22 months since separation, LSG). Another participant perceived the following elements to be negative: "That we had to move. The arguments. Money being tighter." (16 year old female, 23 months since separation, LSG). As highlighted in the previous quotation, an added negative feature was the change in financial circumstances (25). This included the decrease in family income and having to go without things that were affordable before the break-up. Also, many participants reported that their family home was sold and they had to resort to 
moving to a smaller house. Therefore, missing the 'family home', having less space, and sharing rooms with siblings were some of the negative factors reported by the participants.

A number of the young people also conveyed disappointment when it came to family holidays and the fact that they were unable to be together as a whole family. In particular 21 participants commented that they did not like it that they did not spend 'quality time' all together, and more specifically that family occasions were not spent together as a family. A typical response was: "I don't like how we spend half of Christmas day with mum and then half with dad. It would be special if we could spend the whole day together." (16 year old female, 23 months since separation, LSG). Another negative factor the participants alluded to was moving out of their community, in particular moving further away from friends, family or their school (16). For example, "Because they separated we had to move out of the area and that means it now takes me half an hour on the bus to get to my friend's house." (10 year old female, 5 months since separation, ESG). One participant mentioned relocating to a new town as a negative outcome of the separation.

A few participants reported that they were dissatisfied with the contact arrangements with their non-resident parent (12). For example, one young person specified that a negative aspect of the separation was: "The schedule mum's worked out. l'd like to have an extra night with dad, or more flexibility." (12 year old male, 5 months since separation, ESG). Parents entering into new relationships and having new people in their lives was described as a negative aspect of separation by nine of the participants. One participant voiced her disapproval: "The worst thing is dad seeing other people. It's horrible to think that he could have a girlfriend." (13 year old female, 22 months since separation, LSG).

Six young people commented on their feelings about the relationship problems they were having with one parent. For instance, "How I can't talk to my dad and how I get lonely and stuff." (10 year old male, 1 month since separation, ESG). Five young people referred to less contact with some 
extended family members as a negative aspect: "I don't get to see grandma much anymore. It's like I lost dad and I lost grandma at the same time." (11 year old female, 5 months since separation, ESG). Pets were referred to in the answers of five participants. Four participants responded that there were no 'bad things' about their parents' separation.

The participants were also asked a question about what they miss the most since the separation. Again, the most frequently mentioned response involved the non-resident parent; a number of participants conveyed that they missed not having their non-resident parent around all the time (26). A typical response was: "I miss dad. Like, I miss that he isn't there for all the little things ... tucking me in, reading to me, tickling me." (9 year old female, 1 month since separation, ESG). A similar number of participants mentioned that they missed not having everyone together as 'one big family' and doing activities and going on holiday together (24). For example, "We used to all jump into mum and dad's bed in the weekend and I wish we could still do that. I miss not doing stuff together with mum and dad." (11 year old female, 20 months since separation, LSG). A smaller number of young people referred to pets that they missed (10), others missed the way their non-resident parent kept the house (5), some also missed one parent's cooking (4), and others missed friends (3). One young person missed their old school and another missed her home town.

The young people were also asked what they dislike about living in their household/s (with the people they live with). The majority of participants answered this question by referring to specific features of the house or houses that they live in, or to the financial situation, rather than referring to aspects of the family grouping or people around them. Therefore, many of the responses described below were more superficial in nature due to the young people's interpretation of the world 'household'.

The majority of participants identified an aspect of their house or houses that they disliked, such as the small size of certain rooms, the limited size of the backyard, the lack of bedrooms, the lack of places to play, or the general 
condition of the house (31). For instance, a participant responded: "Our room's small and sometimes the house gets a little bit smelly 'cause the cats come inside." (10 year old female, 8 months since separation, ESG). In relation to the state of the house, some young people mentioned its untidy condition and the diverse capabilities of parents with regards to maintaining the house and undertaking household duties, such as cooking, cleaning and shopping (10). For example, "My dad isn't that great at keeping the house (tidy), doing the dishes and everything, no food that sort of thing. Mum was always responsible for the food and everything." (18 year old male, 40 months since separation, LSG).

A number of young people mentioned the impact of the separation on their household financially; in particular the lack of money since the separation and the inability to live like they used to (14). A smaller number of participants specified that they disliked arguing with their siblings and/or parents (10). However, this was often connected to the lack of space at home and inability to get away from one another, or as a result of sharing a bedroom. For example, "I don't like the fighting with my sister. We have to share a bedroom now and she keeps putting her stuff on my side and she brings her friends over and takes over the room." (11 year old female, 5 months since separation, ESG). Eighteen participants also commented on the arguments between their parents and nine stated that they disliked that they did not get to see their non-resident parent enough or that they missed him/her. One young person responded: "I hardly ever get to see dad and there's a lot of fights going on between them (mum and dad) sometimes." (9 year old female, 1 month since separation).

Twelve young people commented that they disliked a parent's partner or stepparent. When asked what he disliked about both households one young man responded: "Nothing much really. I guess when dad's girlfriend comes over it can be a bit uncomfortable because I don't know her as well as I know mum's partner. l've known him for quite awhile now and he's an old friend of ours." (16 year old male, 18 months since separation, LSG). Nine young people stated that they disliked how bored or lonely they were at home, 
because there was nothing to do and their mum or dad worked long hours. One young person stated: "I often come home to an empty house. Mum works long hours and sometimes I don't want to have dinner by myself." (16 year old female, 23 months since separation, LSG). Some of these young people also mentioned that living in their household was not as 'fun' as their previous living arrangement. Five young people replied that they did not get to spend time as a family with both of their parents. For example, "It's pretty good, but I don't get to hang around with mum and dad at home. It's never all of us together at once under the same roof." (14 year old male, 21 months since separation, LSG).

Nine young people commented on the differences in rules between households as something they disliked; for instance, "That I sometimes can't use the phone at night at dad's (house)." (11 year old male, 17 months since separation, LSG). A similar number of participants identified the increased responsibility as an aspect that they disliked (8); in particular, caring for siblings, cooking meals and carrying out more chores since the separation. One young person protested, "I'm always babysitting my brother, and I have to help out around the house morning and night. Life was much easier before dad left." (17 year old female, 14 months since separation, LSG). Six young people commented on the fact that they did not have a good relationship with one parent: "(I dislike) the fact that I really don't get along with my dad very well, and I find it really hard to talk to him and stuff, whereas my mum is a lot easier to talk to." (16 year old female, 18 months since separation, LSG).

Five participants provided responses that differed to those above: two referred to moving between households as something they disliked, another participant said they missed their kitten, one young boy referred to the number of people in his household, and another young person mentioned the pressure associated with 'juggling everything'. One participant did not answer the question. Eight young people stated that there was nothing that they disliked about living in their household/s. A typical response was: "I don't know. I don't dislike anything really." (12 year old female, 21 months since separation, LSG). 
When asked if they have any ideas on how to improve life in their household, there were a variety of answers. The majority of participants replied that they would like more time with their parents (29), even though only 14 participants in the previous question mentioned the lack of time spent with both of their parents or with their non-resident parent as one of the aspects they disliked about living in their household. One young person commented: "I can't believe I'm saying this 'cause sometimes I really don't want this, but more time with mum and dad would be good. I think that would help make things better at both my homes if we talked more and argued less and just spent more time together." (16 year old female, 6 months since separation, ESG). Some participants expressed a desire for their parents to spend less time working so they could see more of them. Also spending time all together 'having fun like old times' was frequently mentioned.

The idea that parents stop arguing and maintain a civil relationship was an important solution for 27 young people. One young person stated: "Well this is like a miracle to me, but it would be mum and dad coming back together and not fighting and just agreeing about things and talking it over quietly." (9 year old female, 4 months since separation, ESG). Connected to this young girl's comment is the suggestion that her parents resume their relationship. Fourteen participants commented that the solution to their household issues would be if their parents reconciled. As was the case in the quotation above, the majority of the young people stipulated that their parents' relationship would need to be free of conflict.

A large number of participants commented that life would be better if they had a bigger or improved house, in particular their own bedroom and more space (25). A similar number specified that more money would improve life in their household (23), with almost half of the young people suggesting that they could find after school or weekend employment to help their mother or father pay the bills, or to be self-sufficient. Ten participants stated that if more attention went into the upkeep of their house then that would improve life in their household. For instance, one participant stated: "The running of the 
household. Cleaning and making sure things are done that need doing." (15 year old male, 15 months since separation, LSG).

A number of young people mentioned that increased levels of communication and affection would improve the household environment (20); in particular, being able to tell each other their problems, being able to express how they felt, and being affectionate. One young man's suggestion was to "Keep being open about things. Like mum and dad always talk to me, like when they first started seeing other people they would check with me to make sure if it was okay for them to stay over or go out and do stuff. They would check that I was okay with it. More of that is good." (16 year old male, 19 months since separation, LSG).

Ten young people responded that if they had extra help and support with their babysitting duties and chores then life would be better in their household. A similar number of participants said life would improve if they refrained from arguing with their siblings or their parents (9). A number of suggestions were made, including spending more time together doing fun activities, getting more sleep and being less stressed, making the effort not to annoy each other, and being more considerate. A few participants believed that life would be better if their parents trusted them and gave them more freedom (5).

Four participants said that life would improve in their household if their parent stopped smoking and/or drinking. Living in closer proximity to their nonresident parent was the solution for two participants. Four young people believed that if they could make more of an effort with their relationships then that would be a significant improvement: "Just being a bit nicer and patient and not giving them (mum and stepfather) such a hard time." (16 year old female, 23 months since separation, LSG). One young girl stated that if she gave her mother space and time to relax then that would improve the household environment. Eight participants believed that 'nothing' would improve life in their household because improvements were not required. A similar number replied that they did not have any ideas that would improve life 
in their household (7). Two participants gave answers that did not fit into any of the categories and did not actually relate to the question.

Positive aspects of the separation. The participants were asked two questions about their parents' separation which had a positive focus. The first question explored the positive aspects associated with parental separation, and the second question investigated what the young people like about living in their household/s.

The young people were asked to discuss the good things about their parents' separation. All of the participants acknowledged the decreased level of conflict in the family environment as the most positive outcome of the separation (52). A typical response was: "Mum and dad don't fight anymore. I hated the fighting; it scared the shit out of me." (16 year old male, 6 months since separation, ESG). A large number of participants also mentioned being happier as a positive outcome of the separation (34); for example, "It was pretty hard at the start but it's, like, everyone is happier now, and so I guess we're better off being split and happy. Better than being chaotic and sad." (17 year old female, 14 months since separation, LSG). Another positive aspect frequently mentioned was having two houses to go to (22); one participant commented, ". . . when you get sick of one parent or place you can go to the other one." (13 year old male, 10 months since separation, ESG).

A number of children stated that they spent more quality time with their parent/s and participated in more fun activities since the separation (21). Just under half of these participants specifically highlighted the new experiences they had shared due to their non-resident parent living at a distance. This included travelling around New Zealand and overseas, visiting new places and engaging in activities that they had not previously experienced. One participant stated: "Dad rings up and says 'Let's do this or that together when you fly down', we get to do some real cool stuff and I'm really happy when I get to hang out with him." (9 year old male, 18 months since separation, LSG). Another young person said, "Mum really makes the effort with the time she has with us these days. She's so busy with work that when she is home 
we sit 'round chatting and doing crafts and laughing more than we ever did before." (13 year old female, 20 months since separation, LSG). A similar number of participants remarked that they had seen more of their extended family since the separation (20). In all cases the extended family that were referred to were either the maternal or paternal grandparents; although it was more common for maternal grandparents to be mentioned. The young people that referred to their paternal grandparents were mostly from families where both parents shared their care. A typical response was: "Since mum and dad broke we've seen more of 'gran', she comes over every day to see us and sometimes we stay with her and 'gramps'." (9 year old female, 4 months since separation, ESG).

A few participants mentioned the new people they had met as a positive outcome of the separation (13). This included a parent's new partner, the partner's children and family members, and new friends they have made since moving house. For example, "I really like Kate (dad's new partner). I guess I wouldn't have met Kate if mum and dad didn't split." (12 year old female, 16 months since separation, LSG). Ten participants specified that the pets that have joined their family since the separation are a positive factor; one young person stated, “I love our new kitten. We couldn't have a cat before because dad would sneeze." (10 year old female, 8 months since separation, ESG). Five participants perceived their new house to be a positive outcome of the separation; for example "We live in a nicer house now, it's new and there's lots of room to run around." (10 year old male, 16 months since separation, LSG). The same number of participants mentioned that they now had closer relations with siblings and/or parents; one young person stated: "We looked after each other when mum left; so I'm closer to my brother and sister now." (18 year old male, 9 months since separation, ESG).

The young people were additionally asked what they like about living in their household. The majority of participants responded 'the people' (42). A large number also answered that they enjoyed the 'fun times' they had together (37). Eleven participants stated that they liked their house or their bedroom, 
and five young people responded that they were fond of the area that they lived in. Two participants did not answer the question.

Challenges encountered. The young people were asked two questions about the problems they have experienced. The first question focused on the problems the young people may have faced since the separation, while the second question explored their suggestions about what could assist them to better deal with the challenges.

The problems experienced by the young people since the separation tended to revolve around coming to terms with the break-up and the subsequent transitions that transpired. Managing relationships was particularly difficult for these young people. More specifically a number of young people mentioned the challenge of juggling a relationship with both parents and worrying about the equality of their time and affection (35). One participant expressed her concern: "I worry that one parent might feel left out or less loved than the other". (18 year old female, 9 months since separation, ESG). A similar number of participants discussed the challenge of coming to terms with one parent no longer living with them (31). When asked what problems they have faced one young person stated, "Wanting dad back. It's so hard getting up and having breakfast and coming home and he's not here." (13 year old male, 1 month since separation, ESG).

Maintaining relationships with extended family, family friends, and school friends proved problematic for 21 young people. In most cases the people that were mentioned were on the non-resident parent's side of the family. For example, "I find it hard not seeing my aunt and uncle and dad's mate Rob. I used to spend lots of time with them." (9 year old male, 18 months since separation, LSG). Three participants commented on the difficulties they were having with stepsiblings; for instance, "I fight all the time with Mia (stepsister); we don't get on." (12 year old female, 16 months since separation, LSG).

Informing people about their parents' separation was a major challenge for a number of young people (18). A typical response was, "I have trouble telling 
people. I kind of feel embarrassed and don't know what to say." (10 year old male, 3 months since separation, ESG). Other participants referred to the difficulties surrounding their confusion and lack of understanding about the situation (28). For example, "I've been walking around in a daze. I feel like I'm spending all my time trying to figure out what went wrong. I listen to mum when she's on the phone and I'm snooping around trying to find answers. I'm pretty obsessed about it." (16 year old female, 2 months since separation, ESG).

Financial problems were described as problematic by 15 young people, especially the older children who felt they needed to find work to either supplement their parent's income or to earn their allowance because their lone-parent could not afford it. For example, "Mum says she finds it hard to make ends meet. I know money's tight right now but it's hard not having money when your friends have it." (17 year old female, 8 months since separation, ESG). Two participants commented that they were having difficulty keeping up with their school work and extracurricular commitments, with one boy saying: "I'm struggling to keep up with my homework at the moment. And l've got sport on all weekend ... not enough time to deal with everything." (18 year old male, 6 months since separation, ESG). Ten young people stated that they have not had any problems since their parents decided to separate.

The participants were also asked what would help them better deal with the challenges they faced. Many of the young people struggled for ideas to resolve their problems; in fact 19 participants were unable to provide any solutions. The majority of the remaining participants referred to their parents in their answers. In particular, making the effort to understand what their children were experiencing was seen as the best solution (22). A typical response was, "If mum understood what I was going through then I think she could help with my problems." (13 year old female, 20 months since separation, LSG). A similar number of participants also said that if their parents were more civil with each other and refrained from bad-mouthing the other parent then that would help immensely (21). One young person 
commented, "Like, if mum and dad stopped putting each other down in front of us and didn't put us in the middle then I think I could deal with things so much better." (16 year old female, 6 months since separation, ESG). Some participants stated that if their parents talked to them and helped them understand what was going on then that would help with their confusion and acceptance of the situation (17). For example, "I keep saying 'Mum what's going on?" and she keeps ignoring me. I just want some answers so I can move on." (16 year old female, 2 months since separation, ESG). Another participant suggested that he would feel better about telling people if he understood what had happened: "I find it hard to tell people because I don't get it. I mean if mum and dad could tell me why then I might find it easier to tell my friends that they've split-up." (10 year old male, 3 months since separation, ESG).

Twelve young people mentioned that it would help them face the challenges in their lives if they had more contact with their non-resident parent. One young person commented, "Dad says mum's gone and I should get used to it, but I need her as much as him. I'd find it easier to get used to things if I could see her now and then. So my answer is seeing mum more often would help heaps." (14 year old male, 20 months since separation, LSG). Some of the participants believed that if they found employment then they would have more money and be less reliant on their parent/s for an allowance (8). A typical answer was, "If I got a job after school then mum wouldn't be so strapped for cash." (18 year old male, 6 months since separation, ESG). Two participants commented that moving would fix their problems because they would be closer to friends and relatives; for example, "If we moved back to the area we used to live in then I could keep seeing nana and poppa." (10 year old female, 2 years since separation, LSG).

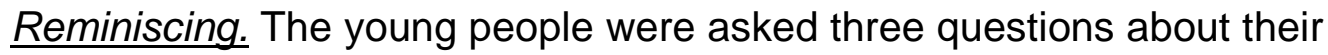
recollections. The first question focused on the participants' thoughts about life before the separation, whereas the last two questions explored the young people's memories about life before and after the separation. These two questions were broader in scope than the first question. 
The young people were asked if they think about life before their family structure changed, and if so, what do they think about. Sixteen participants responded that they reminisced about the happy times prior to the separation, but only occasionally and usually at times that were traditionally 'family times', such as public holidays, school events, and family holidays. For example one participant recounted, "I always think about Christmas. We'd go to the beach, swimming and camping and toasting marshmallows and bread. We haven't done it since." (10 year old male, 16 months since separation, LSG). A number of young people also said that they often looked at photos or video footage (15). The majority of these participants commented that looking at the photos made them sad, but also happy thinking about the occasion in the photo. A typical response was, "Yeah I think about our old family. I've got all our photos in an album. Sometimes I get sad looking at them, but if I'm not feeling down then I like going though them." (15 year old female, 23 months since separation, LSG).

A large number of young people responded that they thought about life before the break-up, but that their memories were of the more tumultuous times (25). In particular, the participants mentioned the build-up to their parents' separation which included increased levels of conflict and angst within the family. One participant recounted her memories: "I sometimes think about all the horrible fighting. Mum and dad screaming at each other. It still makes the hairs on the back of my neck stand up." (13 year old female, 20 months since separation, LSG). Some of the participants replied that they did not reminisce about life before the break-up, because they were keen to get on with life and put the past behind them (19). A typical response was, "No, I don't really think about it. That's the way it used to be and l've moved on." (14 year old male, 19 months since separation, LSG).

Furthermore, participants were asked which three memories stand out about family life before the separation. The majority of participants struggled to come up with three memories. Those that answered were inclined to relive family holidays or other regular family occasions such as Christmas (29). A number of young people mentioned family outings, for instance a bike ride or 
a bush walk (22). Five participants recounted the death of a much loved family pet. One participant mentioned the birth of a sibling, while another described the wedding of a relative. A number of young people described memories of conflict and unrest (19); for example, "I remember when mum threw dad's dinner on the floor after we'd spent the day at my cousins birthday party. There was food and glass everywhere." (9 year old female, 24 months since separation, LSG). Fifteen participants were unable to provide any memories.

The participants were also asked for three memories about their family life now. Once again the young people struggled to provide three examples. Family holidays and events were frequently mentioned (32), although they were referred to as holidays or events that involved only one parent. Many of the participants referred to new places they had visited. Furthermore, memories of family outings were frequently mentioned (29). In the examples the young people provided, it was clear that it was either the mother or the father that they spent time with, never both parents simultaneously. For example, "We'd go to watch the planes with dad every second weekend, and sometimes we'd go inside the airport." (9 year old male, 20 months since separation, LSG). Noticeably, many of the participants referred to new experiences or activities that they had undertaken during their outings. For instance, "We went to see the seals with mum; we'd never seen seals before. And then another time we went on the ferry across to the island in the harbour." (10 year old female, 8 months since separation, ESG).

A small number of young people mentioned the day that their stepparent, and in some cases their stepsiblings, moved in. They expressed memories of nervousness and anticipation (4); for example "I remember when (stepfather) and (stepbrother) started living with us. They brought all their belongings to our house and it was just a really weird scenario. No one knew what to do; we were all on edge trying to figure out where we fitted in the new arrangement." (17 year old female, 18 months since separation, LSG). Nineteen young people had difficulty coming up with memories about life since their parents separated. 


\subsubsection{Support and coping}

Research question 4 enquired: 'What are young people's perspectives in relation to support and coping during parental separation?' In this section the young people's needs, sources of help, ability to cope, support accessibility, and views on coping are described in-depth.

What young people say they need. The young people were asked what they needed most during the separation. The majority of children replied that they needed both their mum and their dad to support them (40). A typical response was, "I've needed my parents. Not just mum, not just dad, but both of them to be there for me." (15 year old female, 1 month since separation, ESG). A similar number of participants specified that they needed time to understand what was happening before their environment started changing (38). For example, "Everything changed too quickly. I needed time to take it all in before mum started packing dad's things up and making all those big changes." (14 year old male, 19 months since separation, LSG). They also needed to know what was currently happening and what was going to happen (34). More specifically, a number of young people said they wanted reassurance that they were going to have contact with both parents. One young person commented, "All I needed was to know that dad wasn't going away forever. It felt like I was never going to see him again, I really thought that was the end of our family. It would've helped to know that he was still going to be in our lives." (15 year old female, 23 months since separation, LSG).

A large number of young people also commented that they needed to know what had caused the separation in order to understand and accept the changes (30). When one participant was asked what she needed during the separation, she responded: "That's easy. I needed answers! It's so hard to have all these changes around you, that affect you, but you don't know why they're happening. How can you be expected to deal with something that you know nothing about?" (16 year old female, 2 months since separation, ESG). The same number of young people said that they wanted someone to listen to 
them. More often than not both parents were referred to as the people they wanted to listen to them.

A small number of young people stated that they needed to be left alone (12). Some young people commented that because they were worried about their parents they needed reassurance that they were 'all right' (10). For example, "Mum was pretty gutted. I was pretty worried about her. I needed to know that she was going to be ok. I didn't know how dad was either. It's pretty scary because you don't really know what people will do in those states. So, that played on my mind a bit." (18 year old male, 21 months since separation, LSG). Five young people commented that they needed to stay with a relative or family friend when one parent moved out of the family home.

Formal sources of support. The children were asked who formally helped and supported them during the separation. Very few participants received formal sources of support. Four young people were helped via a support group, and the same number participated in an education programme. Five young people underwent community based counselling and one young person received school counselling. Interestingly, all of the participants that received community based counselling commented that the counselling was not helpful. A typical response was, "I went to a therapist, but I didn't find it useful. Talking to some stranger didn't help me one iota." (17 year old female, 14 months since separation, LSG). The overwhelming majority of young people did not have any sources of formal support during the break-up (41).

Informal sources of support. The children were more likely to refer to informal sources of support than formal sources. In general, one or both parents were identified as providers of support (44), as were older siblings (30). Friends were frequently identified as providers of support (28), irrespective of whether or not they had personally experienced parental separation. Grandparents were also commonly called upon to offer support (27), as were other extended family members (18), and family friends (14). Some children mentioned pets as sources of support (9). Six young people reported that they had no help or support during their parents' separation. Some of these participants 
commented that at the time of the separation their parents were upset and preoccupied and therefore support was not initially sort.

Coping strategies. The young people provided a number of strategies when they were asked how they personally coped during the break-up. Many participants relied on the internet as a way of coping; more specifically, chat rooms and emailing were used to discuss parental separation with other young people in similar circumstances (25). For example, "I get on the web and chat to people that know what l'm going through." (13 year old male, 10 months since separation, ESG). A number of the participants commented that they found fun things to do to keep themselves occupied and to prevent them from thinking about the break-up (21). Similarly, a number of young people relied on time spent with friends as a distraction from their family issues (17). Another form of distraction, which was reported by 15 participants, was to immerse oneself into school work or school extracurricular activities.

Other participants spent time alone, usually in their bedroom (12). The same number used their cell phone to communicate (via text messaging) with friends whenever they felt upset. One young person stated: "I text my friends when I'm feeling sad about dad leaving. I get it all out and feel better." (11 year old female, 5 months since separation, ESG). Talking to people about their situation was the coping strategy employed by 10 participants. In comparison, eight young people wrote about their experiences in a diary or in an online diary (also known as a blog); for example, "I write about it in my diary, I guess that helps me to think and contemplate our family." (16 year old female, 6 months since separation, ESG).

Five young people stated that they did not know what would make things better and, therefore, did not employ any strategies to cope. Two participants used escapism to cope. One of these young people described how she mentally escaped: "I remember doing this thing, usually at night times. I would imagine myself going into this little trap door in the base of my wall under my bed. It was the most amazing space, it was this little room set up like a home and I would spend time there. I even went there before they separated 
because they would always fight at night. I started doing it when I was really young because I would sometimes be frozen with fear. The secret hole in the wall helped me so much. I know I was imagining it but at the time it felt so real. I haven't thought about it (in awhile); talking about it now still makes me feel happy and safe; (it was) my idea of heaven." (16 year old female, 23 months since separation, LSG).

Availability of support. The participants were questioned whether the support they received was sufficient. Most of the young people believed that they were receiving enough support (39). A quarter of the sample felt they needed more support (13). These young people were then asked who they would want to assist them. Ten young people named their non-resident parent as the person that they wanted to give them more support. Two participants wanted more support from both of their parents. One participant did not know who they wanted to help and support them.

Finding support. The young people were asked if they knew where to find support if they needed it. All of the young people said that they knew where to find assistance (52). The majority of participants identified immediate family members, in particular parents (28) and siblings (22), as the people they would approach for support. Many also identified friends (15), extended family members (12) or family friends (12), as possible sources of support. Sixteen young people said they would use the internet, in particular 'web chatting' and online information, for support; for instance one participant commented, "l'd go online and chat to people if I felt I needed a shoulder to cry on." (15 year old female, 1 month since separation, ESG). One young person referred to a stepparent as someone she would go to for assistance. Two participants said that they would seek support from a teacher at school. One participant said that she would talk to someone on the 'What's up?' child helpline. No one identified counsellors, therapists, education programmes, support groups, or other professional or community services as sources of support.

The young people were additionally asked if they would be open to assistance via a support group or education programme. The majority of the children 
were open to this scenario (44). In comparison, six of the older participants said that they did not need these services and two of the younger participants stated that they would not feel comfortable accessing either of these forms of support. The participants were also asked if they would be happy to receive support via a community counsellor, therapist or psychologist. Almost all of the young people replied that they would not want support from any of these sources (47). Five young people stated that they would feel comfortable receiving counselling.

The prospect of accessing support via a school counsellor was also put to the young people. Thirty participants stated that they would not utilise this source of support. In comparison, 22 participants conveyed that they would feel comfortable talking to a school counsellor. It was evident from the participants' responses that they had an extremely negative impression of counsellors, therapists, and psychologists; but had a slightly more favourable view of school counsellors.

Access to resources. Two questions about resources were put to the young people. The first question enquired whether they have been given any information to help them understand their parents' separation and, if not, what information would they find helpful. The second question focused on the amount of information received. The majority of the young people were not given any information to help them understand the separation (47). The five participants that received information were from the younger age group, and the source of information was books. None of the participants were supplied with information via pamphlets, video or DVD recordings, CD-ROMS or websites. However, as reporter earlier, some participants did access internet resources (websites and chat rooms) of their own volition.

The first question referred to the 'information' that they may have received as books, pamphlets and technological resources. Irrespective of this, a number of participants answered the question by stating that they wanted information about why their parents separated and what was going to happen. When this response occurred the question was repeated by specifically asking which 
information, in the form of a resource, would they find most helpful. The participants identified specific information resources that would help them to cope with the break-up. The overwhelming majority of young people preferred resources that were in an electronic form (41). Seven participants preferred pamphlets for their brevity and four young people did not express a preference.

A number of young people also provided information in relation to the content of the resources. Participants frequently replied that they knew what separation was, but they did not know what separation meant. Thus, they did not know what the consequences of separation were; in particular, what it meant for families, relationships, and their lives in general. Accordingly a number of participants suggested that information about the consequences of separation would be helpful (33). More specifically they conveyed the importance of knowing what to expect, or at least being familiar with the possible scenarios, in order to avoid as many 'surprises' as they could. For example, one young person stated: "When they told me they were splitting up I didn't know what that would do to us as a family. I wanted to know what the possibilities were so that I knew what we could be facing." (15 year old male, 15 months since separation, LSG). A similar number of young people suggested that descriptions of young people's experiences would help then understand parental separation and give them some idea of what to expect (31). Of note, many of the older participants requested age specific information because they did not want to be 'babied'. Six participants did not provide responses to the question.

The participants were questioned further about information resources. Of particular importance was whether they felt they had been given enough information, and if not, what kind of information they needed. Only two participants responded that they were happy with the amount of information they had received. Almost all of the young people replied 'no' they had not received enough information (50). 
Ideas on coping. The young people were asked if there was anything else that would make their parents' separation easier for them to cope with. The overwhelming majority of participants replied that if their parents talked to them, and were honest with them, then that would have helped them to cope (48). In particular, keeping them informed about what was going on was of utmost importance to the young people. Some participants conveyed that their ability to cope was poor, because they did not understand what was going on, and were busy speculating about the basis for the break-up. One young person aptly commented: "My mind's working overtime. I wish mum would open up and tell me what went on. Then l'd know what I was trying to cope with." (18 year old female, 5 months since separation, ESG).

A number of young people also suggested that the separation would be more bearable if they had improved contact with their non-resident parent (20). Some participants implied that if they had access to a support group or education programme early on in the separation, then the transitions would have been easier to deal with (11). A few participants commented on their parents' behaviour following the separation; in particular that it would be easier to cope if they stopped arguing and remained friends (10). Ten young people commented that nothing would make the separation easier to manage; that they needed time to become accustomed to the situation.

\subsubsection{Communication}

Research question 5 enquired: 'What are young people's perspectives in relation to communication during parental separation?' In this section the young people's views on being advised and consulted are discussed in detail.

Being informed. The young people were asked two questions about being kept up-to-date during their parents' separation. The first question enquired whether their parents had kept them informed of any decisions made about the family situation. The second question focused on their views about being informed. 
The majority of participants felt that their parents had not kept them informed of decisions that were made about the family situation during the separation (46). A typical response was: "No, not at all. I have no idea what's happening." (15 year old female, 1 month since separation, ESG). A much smaller number of participants felt that their parents were keeping them up-todate (6); for example, "Yeah, they're always talking to us about what's going to happen next." (17 year old male, 5 months since separation, ESG). The participants were unanimous when asked if they liked the notion of their parents keeping them informed of any decisions made about the family situation; all participants responded 'yes' (52).

Being involved in decision making. Three questions about decision making were included in the questionnaire. First, the participants were asked if their parents had sought their input into any decisions being made about the family situation; while the second question enquired if they liked the idea of their parents asking them for their opinion. The objective of the final question was to find out whether they would feel comfortable telling their parents what they were feeling and what they wanted.

The first question enquired whether the participants had been asked to have their say about decisions that related to the family situation. There were more young people that had not been asked for their input than there were young people that had been asked; in fact, the large majority of participants had not been consulted (43). Only nine participants stated that their parents had conferred with them about the decisions they were making following the separation. Eight of these participants were from the adolescent age group.

In terms of the second question, almost all of the young people liked the idea of their parents asking for their opinion about any decisions being made (48). In fact, the participants strongly conveyed a desire to be asked what they thought, so that they felt involved and informed. However, their responses tended to suggest that they were not in favour of adult-like decision making responsibilities. For example, one young person commented: "Yes, it'd be great to be asked and to feel listened to. It's not that they have to do exactly 
what I say, but if they take the time to run it past me then I might feel better about the decisions they make." (17 year old female, 18 months since separation, LSG). Another participant said, "Yeah, l'd liked to be asked, but I don't want to decide what happens for everyone." (12 year old male, 5 months since separation, ESG). Only four young people opposed the idea of voicing their opinions about their family circumstances. For example, "No, I wouldn't want to say what I thought. Mum and dad should decide." (10 year old male, 3 months since separation, ESG). Of note, all of the young people that did not want to contribute to the decision making were in the child age group.

In the third question the participants were asked if they would feel comfortable telling their parents how they were feeling and what they wanted.

Approximately half of the participants responded that they would feel comfortable talking to their parents (28), while the remainder replied that they would not feel comfortable (24). Those that were comfortable were asked what makes them feel comfortable talking to their parents about their views. There were a variety of responses. Most of the young people replied that it was easy to talk because their parents listened and encouraged them to say what they felt, even if it was not what they wanted to hear (21). For example, "Mum and dad take the time to listen to my point of view, which is often way different to theirs, but they still encourage it." (17 year old male, 18 months since separation, LSG). Also, some participants responded that they felt comfortable because their parents were easy-going or very open people (11). One participant commented: "My parents are very approachable so talking about my feelings and what I need is not unusual for me." (12 year old female, 16 months since separation, LSG). A similar number responded that their parents loved them and were caring and wanted to know how they felt (10). Four participants did not know what made it easy for them to talk to their parents.

The participants that were uncomfortable voicing their perspectives were asked what would make it easier for them to talk to their parents. Many of the young people stated that if their parents wanted to know what they thought, and made the effort to ask them and listen to them, then they would feel more 
comfortable relaying their feelings (16). For instance, one participant commented: "If they showed me that they were capable of listening to me, and not just talking over me, then I might consider it." (13 year old male, 1 month since separation, ESG). The need for open lines of communication was expressed by a number of young people who recognised that if their parents were able to talk to them then they may find it easier to communicate with their parents (12). For example, "If my mum and dad were comfortable talking to me then I might be comfortable talking to them. They act awkward when it comes to personal stuff so that makes me feel awkward. l'd never even seen them kiss each other, I feel more embarrassed about that than I would if I'd seen them kissing. l'll never feel comfortable showing my emotions and telling them what I think, 'cause they can't do it" (18 year old female, 5 months since separation, ESG).

Four children decided that they would feel more comfortable if they could write on paper what they were thinking, because they were unable to discuss their thoughts and feelings face-to-face with their parents. For instance, "I could probably do it if I wrote down everything I wanted to say and then they could read it while I was away." (10 year old female, 5 months since separation, ESG). Similarly, it could easily be construed that mediation would be fitting, in light of the comments some participants made about feeling comfortable telling a third party what they felt, so that the third party could inform their parents (4). For example, one young person commented: "It would be easier if I could tell Lucy (mum's friend) what I wanted, and then she could talk to mum about it." (11 year old male, 17 months since separation, LSG). Three participants did not have any ideas about what would make it easier for them to talk to their parents.

What young people want others to know about separation. The young people were asked two questions in relation to the advice that they would give about parental separation. The first question concentrated on the advice that they would give to a child who was about to experience his or her parents' separation. The second question focused on the advice that they would give to parents that were about to separate. 
There were a fairly small range of responses when the young people were asked what advice they would give to a child experiencing separation. The majority of participants simply advised that 'things would get better' with time (37); for example, "I would say to him that it may seem really bad when your parents break-up, but things change for the better and before you know it life is normal again." (13 year old male, 10 months since separation, ESG). One young person answered the question by saying: "I'd tell them not to lose sight of what's important. It may seem like your life is over; but in reality you still have your parents and family, it's only the way that you live together that changes." (17 year old female, 14 months since separation, LSG).

Ten participants said that they would inform the child that they would still get to see both parents after the separation. They believed that it was essential to let other children know that parental separation does not necessarily mean losing a parent. Nine young people gave advice about talking to their parents or other adults; in particular, telling them how they felt and what they wanted, and asking for their help and support when they required it. A typical response was: "l'd tell them to talk, talk and talk. Your parents can't help you if they don't know how you feel, so it's important to say what you think ... instead of keeping it all inside." (15 year old female, 1 month since separation, ESG). A number of participants replied that there was nothing that they would want a child in their situation to know (11). These participants were mainly from the ESG.

There was a wide range of responses when it came to the advice that they would give to parents who were about to separate. The overwhelming majority commented that they would tell parents to talk to their children about the separation and to ask them for their opinions (44). Twenty participants said that they would tell parents to be kinder to each other during the separation, because they risked hurting their children by being 'mean and nasty'. For example, one young person commented: "l'd say, look, don't be horrible, don't be mean to each other, just do what you have to do in a civil way so that your children don't get more upset than they already are." (15 year old female, 2 months since separation, ESG). Fifteen young people commented that they 
would tell the parents to make arrangements for their children to have contact with both parents.

Ten participants referred to the changes that occur after separation in their answers. They recommended that parents make small changes over time, rather than subjecting their children to multiple transitions immediately after the decision is made to separate. One young person suggested: "Parents should wait before they change their children's environment. They shouldn't start packing up the house, or seeing other people, or moving in new people, until the children have time to understand what's happening." (15 year old female, 23 months since separation, LSG). Five participants said that they would tell parents that they should avoid pretending to their children that everything is 'all right', because their children sense that there are problems. Two young people said that they did not have any advice for separating parents. Interestingly, none of the participants responded that they would tell the parents not to separate.

\subsubsection{The future}

Research question 6 enquired: 'What are young people's perspectives in relation to the future?' In this section the young people's perceptions on the future of their family are addressed, as are their perspectives when it comes to their individual future, more specifically the prospect of marrying and having children.

Family. Each participant was asked how they felt about their family's future. The largest number of participants responded that they felt 'okay' about the future state of their family, and were generally optimistic in their responses (22). For example, "I guess I feel all right. I'm pretty sure everything will work out okay in the end. It's hard now, but I don't think our family is doomed or anything." (13 year old male, 1 month since separation, ESG). A smaller number commented that they felt 'okay' about the years ahead, but alluded to being slightly uncertain about what the future held for their family (11). For instance, one participant commented: "I feel pretty good about the future, but I 
don't really know how things will work out." (10 year old male, 3 months since separation, ESG).

Eleven young people felt very positive about their family's future; for example, one participant commented that she felt: "Great! I don't have any worries about my family in years to come. We're a pretty solid family and I'm confident that we can deal with any problems that pop up in the future. This (the separation) hasn't ruined us." (16 year old female, 23 months since separation, LSG). Five participants expressed worry and anxiety about the future; a typical response was, "I don't really know. I don't feel that great about it, because I'm concerned about how their break-up will change our family." (11 year old female, 5 months since separation, ESG). Two participants responded in a pessimistic manner; for example, "I don't think the future's that bright for our family. It's pretty messy right now, and I can see things getting worse. So yeah I guess you could say l'm quite cynical about it." (18 year old male, 6 months since separation, ESG). One participant did not answer the question.

Marriage. The young people's views of marriage were assessed in two questions. Each participant was initially asked if they anticipated getting married one day. In the second question each participant was asked about marriage and its importance.

A number of the participants were not sure if they would get married sometime in the future; in fact, they were fairly nonchalant about the prospect of marriage (24). A typical response was: "I don't know. I haven't really thought about it. I don't have strong feelings either way." (14 year old male, 19 months since separation, LSG). A similar number of participants replied that they felt they would get married one day because they either liked the idea of it, or it was a natural step to take (23). For example, one young person commented: "Yes. I like the idea of finding someone and having the big wedding and being happy. All a bit dreamy, I know, but there's no harm in giving it a go." (15 year old female, 1 month since separation, ESG). Three participants stated that they would probably consider a civil union rather than 
a traditional marriage; for example, "Yes, but it would have to be less conservative than marriage, something like a civil union." (16 year old female, 18 months since separation, LSG). Only two participants responded that they did not envision themselves getting married.

The participants were additionally asked if marriage is important to them. The majority of the young people replied 'not really' (25) or 'no' (18). The reasoning for these responses included the following: it is 'only a piece of paper'; it is a religious notion; it is a tradition; marriage is outdated; it is not necessary to marry in this day and age; you do not have to marry in order to be happy; you can have children outside of marriage; it is acceptable to live in a de facto relationship; it is an individual's choice and people have the right to choose how they want to live; and finally that marriage is an excuse for a good party. Four participants were unable to provide reasoning for their initial responses.

A small number of young people stated that marriage means a lot to them (9). Almost all of these participants commented that it was important to them because it meant spending their lives with someone and raising children together. One participant stated that it was important because marriage was a cultural experience.

Children. Two questions about having children were put to the participants. Each young person was initially asked if they anticipate that they will have children one day. In the second question each participant was asked if having children means a lot to them. The majority of participants either responded that they 'don't know' if they will have children (21) or that they will 'maybe' have children some day (19). Twelve participants answered 'yes' they think they will have children in the future. None of the participants stated that they do not think that they will have children.

The last question assessed whether having children means a lot to the participants. The large majority of young people responded that having children is important (44). The reasons that the participants came up with fell 
into the following categories: the importance of building a family grouping; the importance of having people around you that love you and support you; children provide happiness; raising children is an important job; the family name can be carried on; having a family provides security in old age; information and knowledge can be passed on; and that having children is a life-long responsibility. The remaining eight participants replied that they 'don't know' if having children is important to them.

\subsection{Experiences of Separation (Time 1 vs. Time 2)}

The following section focuses on research questions seven to ten, which enquire about young people's subjective experiences of parental separation over time. The participants' responses at Time 2 are compared to their responses at Time 1 (approximately 18 months prior to Time 2). The interview questions that address the following research questions can be found in Appendix P.

The participants that have been quoted in this section are identified by their age, gender and time since separation, which are in parenthesis following each quotation. The age and separation timeframe are the participant's details as reported at Time 2. If the time since separation at Time 2 is between 19 months and 28 months then the participant is part of the original early-stage separation group (ESG). If the participant's time since separation is between 33 months and 43 months then they are part of the original later-stage separation group (LSG). Similarly, if the participant's age at Time 2 is between 10.58 years and 15.50 years then they are part of the original child age group. If their age is between 15.58 years and 20 years then they are part of the original adolescent age group.

\subsubsection{Views and reactions}

Research question 7 enquired: 'How do young people's views and reactions to parental separation at Time 1 compare to their views and reactions at Time $2 ?$ 
Feelings about the separation at the time. During Interview 2, approximately 18 months following the first interview, the young people were asked for a second time to recall the feelings that they had when they were informed that their parents were separating. As was the case at Time 1, the young people expressed a range of feelings about the separation, which are displayed in Figure 9.5. At the time of the second interview eight of the 13 feelings that the young people voiced about their parents' separation were negative feelings. In comparison, at Time 1 seven of the 12 feelings that were expressed were negative feelings. At Time 2 the total number of times negative feelings were relayed was 189 times, positive feelings were mentioned 43 times and four were neutral feelings. Compare this to Time 1 where negative feelings were mentioned 152 times, positive feelings were expressed 53 times and two of the feelings were neutral (refer back to Figure 9.1). Thus, at Time 2 there were more negative feelings and fewer positive feelings reported retrospectively than there were at Time 1.

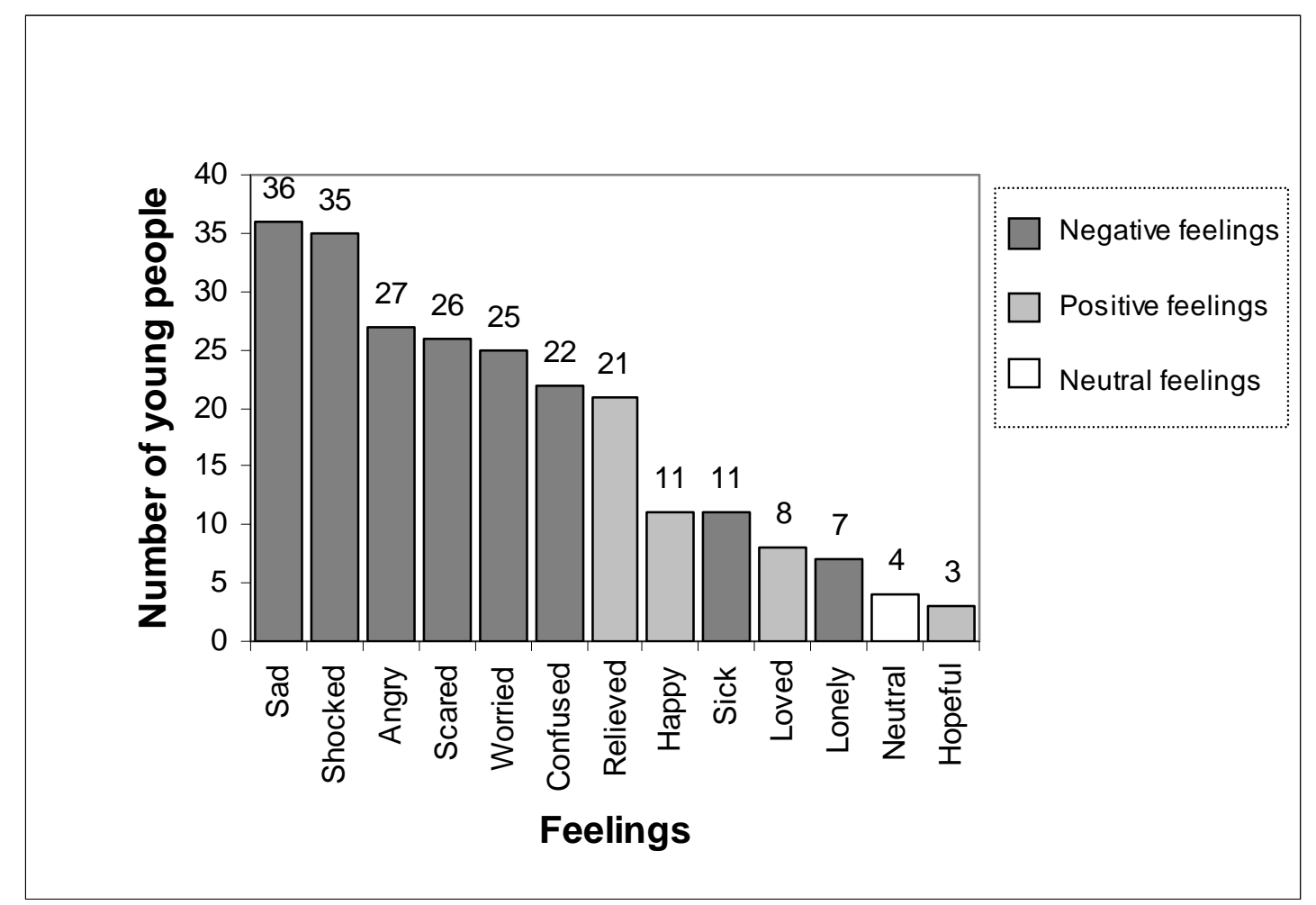

Figure 9.5. The young people's feelings about their parents' separation in retrospect (as reported at Time 2). 
When comparing the young people in the early-stage separation group and those in the later-stage separation group there were no differences in the descriptions of the feelings the young people experienced when they were told about their parents separation (refer to Figure 9.6). This was also the finding when this question was asked at Time 1 (refer back to Figure 9.2). There were fewer age group differences than there were at Time 1. The child participants were more likely to report feeling scared, in comparison to their older counterparts.

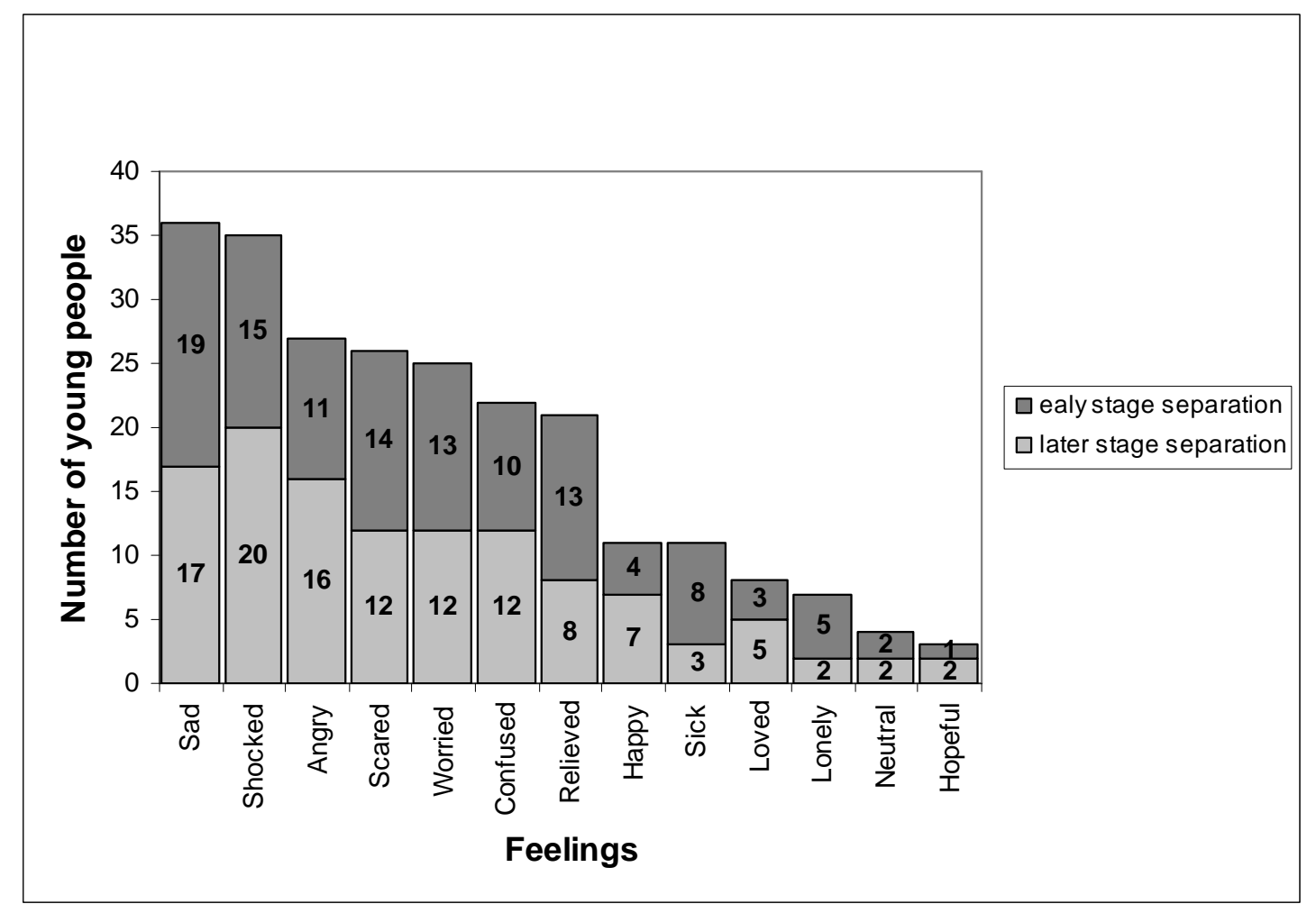

Figure 9.6. The early-stage separation participants and the later-stage separation participants' feelings about their parents' separation in retrospect (as reported at Time 2).

Feelings about the separation now (Time 2). The young people's feelings about the separation were re-examined at Time 2 . The majority of participants referred to multiple feelings in their responses. There were more positive feelings (7) than there were negative feelings (5) mentioned at Time 2, compared to Time 1 where an equal number of positive and negative feelings were expressed ( 7 of each). At Time 2 there was a much larger number of positive feelings relayed than there was negative feelings, with 178 positive 
feelings mentioned compared to the 76 that were negative. In comparison, at Time 1 the total number of times positive feelings were expressed was 114 , while negative feelings were expressed 94 times (refer back to Figure 9.3). Thus, at Time 2 there were more positive feelings and fewer negative feelings reported than there were at Time 1. The feelings that were expressed during the second interview are displayed in Figure 9.7.

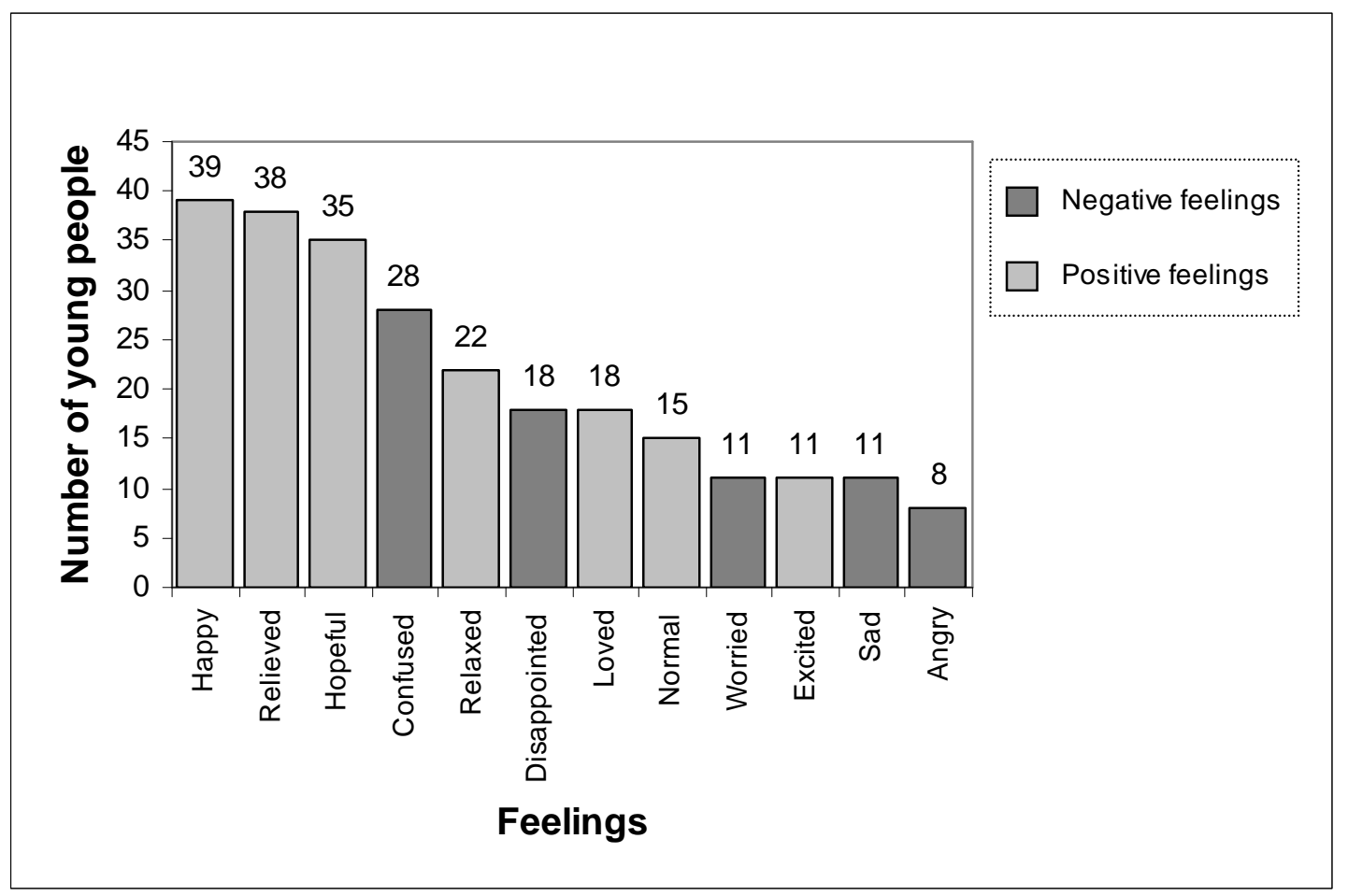

Figure 9.7. The young people's feelings about their parents' separation now (Time 2).

A similar number of young people mentioned feelings of happiness (39) and relief (38) when they were interviewed at Time 2. For example, one young person stated: "I feel relieved that that's all in the past and that our family is still together - well together in the sense that the separation wasn't the end of us. You think the worst when it happens. We're still a family unit and I'm happy with the way we are." (16 year old male, 39 months since separation, LSG).

Also commonly reported feelings at Time 2 were hopefulness (35) and confusion (28). For example, "I feel that things have worked out (for the) best and will continue that way. I'm no longer worried about it; it's not the end of 
our family. I'm looking forward to the future with my 'multi-fam'. That's what I like to think of us as, a multi family with many parts that make up a whole. Our situation's not unique but sometimes I think we're better - one of a kind." (16 year old female, 19 months since separation, ESG).

More participants reported feeling happy, relieved and hopeful at Time 2 than they did at Time 1. Interestingly, a larger number of participants also mentioned feeling confused at Time 2 than they did at Time 1. For example: "I still don't get it; I don't understand why this had to happen. They (mum and dad) are both so covert about the break-up that l've got less answers and more confused as time's gone on." (17 year old female, 20 months since separation, ESG).

More young people reported feeling loved, relaxed, and normal at Time 2, than they did at Time 1. For example, one participant responded: "(I feel) Pretty normal really. Yeah it's happened but they still love me. The fact that they don't love each other isn't really an issue for me. Would I prefer it if they pretended to be in love? Hell no!" (18 year old female, 42 months since separation, LSG). Compared to Time 1 fewer young people mentioned feelings of sadness at Time 2. A similar number of young people reported feelings of disappointment, worry, excitement and anger at the Time 1 and the Time 2 interviews. No participants mentioned feelings of shock or loneliness at Time 2.

In order to compare the feelings of the young people in the early stages of separation and those in the later stages, refer to Figure 9.8. There were no differences in the feelings reported by the ESG and the LSG at Time 2. In comparison there were clear differences between the two separation groups and the feelings that they reported during the interview at Time 1 (refer back to Figure 9.4).

Outlook for the separation. The participants were once again asked if they believed that their parents would reunite and if they wished they would. The large majority of participants responded that they did not believe that their 
parents would live together again (45); that their separation was a permanent decision. Out of the remaining participants six were unsure whether their parents would reunite and one participant believed that his parents would get back together: "I think they will. I have a feeling they'll work it out." (11 year old male, 22 months since separation, ESG). Similar responses were given at Time 1, with 41 participants stating that they did not think their parents would reunite and 11 that were unsure whether their parents would get back together. At Time 1 none of the participants responded with the belief that their parents would reunite.

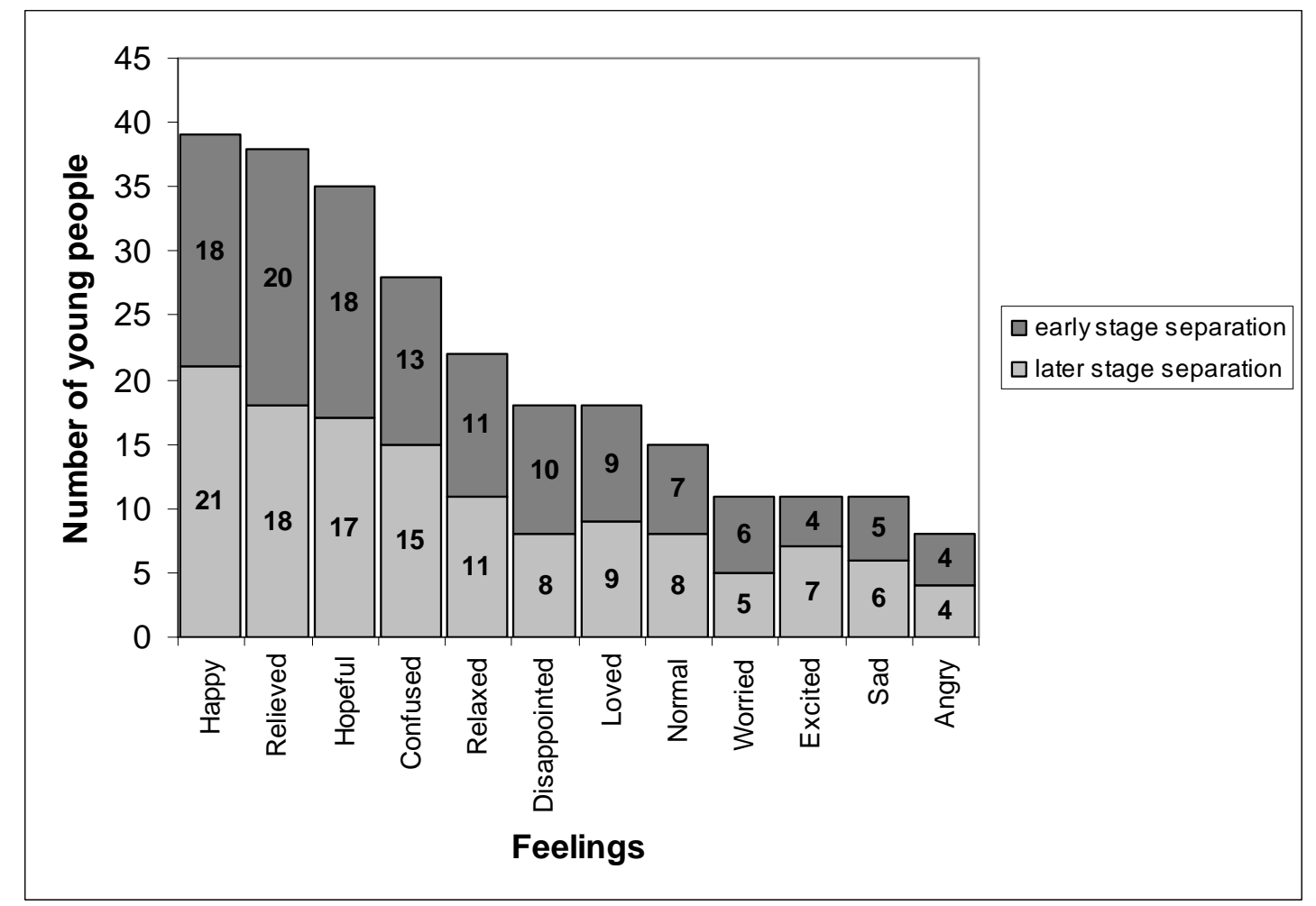

Figure 9.8. The early-stage separation participants and the later-stage separation participants' feelings about their parents' separation now (Time 2).

Of the 45 participants that stated that they did not think their parents would reunite, 32 of them specified that they did not want their parents to get back together because everyone was happier or because life was better. For example, one young person stated: “No, I can't see them being together again. No, I wouldn't want things to be the way they were; they are happy now. They weren't happy before, and neither were we (the children)." (12 year 
old female, 28 months since separation, ESG). Ten participants were unsure whether they would want their parents to reunite; for example, "That's a hard one. I can see good things and bad things about them being back together. I don't know." (14 year old male, 20 months since separation, ESG). Three young people wanted their parents to reunite, but they all placed conditions on their reunion. A typical response was: "l'd like them to get back together, if they promised they wouldn't fight anymore." (10 year old male, 36 months since separation, LSG). In fact, these young people all referred to the absence of conflict as the main condition that they would impose if their parents were to resume their relationship.

Of the six participants that were unsure whether their parents would reunite, four did not know whether they did or did not want them to get back together and two participants wished they would reunite. For example, "I couldn't say whether I wish for them to get back together or not. I don't think I know." (18 year old female, 26 months since separation, ESG), and "Yeah, I really wish they would. It would make me so happy if they did." (14 year old male, 27 months since separation, ESG).

It is apparent that a number of the young people changed their wishes over time. At Time 1, when they were first interviewed, 19 participants did not want their parents to reunite. However, at Time 2 (approximately 18 months later) 32 participants did not want their parents' relationship to recommence. At Time 1 eight young people wanted their parents to reunite, compared to just three young people that wanted their parents' relationship to resume at Time 2.

Blame for the separation. At Time 2 the young people were asked if anyone was to blame for their parents' separation. As was the case at Time 1 the majority of participants replied that no one was to blame for the break-up. None of the children blamed themselves for the separation. They were extremely confident that they were not responsible for the difficulties in their parents' relationship. It was common for the participants to report that their 
parents had reassured them frequently that they were not responsible for the break-down of their marriage.

Feelings about living arrangements. The participants were asked who they are currently living with and whether they were happy with their living arrangements. The majority of participants responded that they were happy were their living arrangements at Time 2 (40). Eight participants replied that they were unhappy, while five participants said that they were 'sort of' happy. In comparison, at Time 1 fewer participants replied that they were happy (29), a similar number reported that they were unhappy (11), and a larger number responded by saying that they felt 'sort of' happy (12). The reasons behind the participants' responses at Time 2 were further explored.

Of the 40 young people that were happy with their current living arrangements all of them referred to the absence of conflict as one of the reasons for their happiness, which was similarly the case at Time 1. At Time 2 a large number of young people also referred to the fact that they felt settled in their current family structure (28); for example one participant commented, "I'm happy because l'm used to it now. I feel comfortable with my situation. I guess time really does heal in some ways." (16 year old male, 25 months since separation, ESG). A similar number of young people mentioned the improved level of happiness amongst family members as a reason for their happiness (27). A typical response was: "Everyone in my family is in a better way now. Life's better than before the divorce because we're happier; we've got it sorted now." (15 year old female, 39 months since separation, LSG).

Another common reason for their happiness involved being able to spend time with both parents (20); for instance, "I get to visit both my mum and my dad so that makes me happy. It's also good because we seem to get on better, I mean just happier around each other." (12 year old male, 35 months since separation, LSG). Fourteen young people mentioned having two houses as an aspect of their living arrangements that makes them happy. Others specified that they were happy living with their stepsiblings (9). For example, one participant responded: "I like spending time with both parents, at both 
houses, and I enjoy hanging out with my stepsister. Contrary to what people think we actually get on really well, she's not the evil stepsister or anything." (19 year old female, 27 months since separation, ESG). Two participants were unable to answer the question and responded 'I don't know'.

All of the young people that were not happy with their living arrangements stated that their unhappiness was due to the lack of contact with their nonresident parent (9). A typical response was: "It's 'cause I don't get to see dad as much as l'd like. I find it hard to be close to him when I see him a couple times a year." (15 year old male, 38 months, LSG). Similarly, at Time 1 all of participants that were unhappy with their living arrangements referred to insufficient contact as a factor that impacted on their level of happiness.

A number of young people also expressed frustration about the lack of control over their own living arrangements (6); for example, "We barely get to see him (dad). We have no say when it comes to organising our own lives. I think I'm old enough to figure out if and when I want to see my own father." (14 year old male, 27 months since separation, ESG). Four participants mentioned that a specific person contributed to their level of unhappiness; in all cases the person referred to was a parent's new partner. One young person stated: "I'd be happier if dad's girlfriend wasn't around so much. We never see him by himself. I hate how we don't get to see much of dad and when we do she's tagging along." (18 year old female, 25 months since separation, ESG).

At Time 1 the young people in the ESG were more likely to express unhappiness with their living arrangements than the participants in the LSG. The later-stage separation participants were more likely to express happiness with their current circumstances than their early-stage separation counterparts. In comparison, at Time 2 there were no such differences between the participants in the early-stage and later-stage separation groups.

Feelings about contact arrangements. During the second interview the participants were again questioned about how they felt about their contact arrangements. The majority of the young people responded that they were 
happy (37). Only six participants stated that they were unhappy and nine responded that they were 'sort of' happy. In comparison, at Time 1 fewer participants replied that they were happy (27); more participants reported that they were unhappy (13) and a similar number stated that they were 'sort of' happy. The reasons behind the participants' responses at Time 2 were further explored.

The participants that were happy with their contact arrangements were inclined to refer to the time they spent together as the reason for their level of happiness (31). These participants preferred to see their parents regularly but were primarily focused on the quality of the time that they spent interacting with their parents as opposed to spending time around their parents. One young person commented: "I'm happy seeing dad every second weekend. I mean, I wouldn't say no to seeing more of him, but I wonder if we'd spend less time mucking around if we saw each other every week. It's kind of special when we have our weekend. We spend the whole weekend together doing stuff. I don't think other kids with 'together parents' spend that much time with their dads in the weekend." (12 year old female, 39 months since separation, LSG).

Scheduled visits with parents were also important to the large majority of these young people. They were eager to know the date of their visits so that they did not have to speculate when they would next see their parent. For example, "Yeah (I'm happy). It's a lot better 'cause he used to come over one time a week on weekdays but now we do a bit more with him. But it's also not that good because I don't know when he is going to come over to our house or when we are going to his house because he's at work most of the time, and when I ring he's in a meeting or something." (12 year old male, 19 months since separation, ESG). Another young person commented: "I like it when I get to spend time with mum. I'm happy with the plan we have now because I know when I'm going to see her each time. I put it on the calendar with a big happy face; I look forward to it." (11 year old female, 21 months since separation, ESG). 
It is vital, however, to recognise that the children were also in favour of having some leeway with their arrangements. A number of young people mentioned the importance of flexibility in terms of contact arrangements. In fact they expressed happiness with the contact arrangement because they had an element of control over their contact schedule; for example, "Yes, I'm happy with the contact. I see dad every week which is good because we do lots of things together.... But I like it too that I can change my plans. If something comes up then we can make other arrangements." (16 year old female, 43 months since separation, LSG). It was more common for the participants in the older age group to highlight the importance of flexibility and individual control over their contact arrangements with their non-resident parent.

A number of young people also expressed happiness about the amount of contact that they had with their parent/s through the use of technology (18). A typical response was: "Yeah, I'm happy with the amount of contact. We spend a lot of time together, really. But it's not like we can only see each other that weekend, we also talk whenever we want. He sends me emails and texts me. Sometimes we talk over the internet. So there's lot of contact when you think about it." (10 year old male, 40 months since separation, LSG). This type of response highlights the important role that communication via home telephone, cell phone and computer all play in maintaining relationships with non-resident parents. It is clear that communicating with the aid of technology constitutes contact for these participants and contributes to their level of happiness with their contact arrangements.

Six young people commented that they were happy with their contact schedule because the arrangements suited them better than the previous contact arrangements that they had experienced. One boy that spends over a month at a time with each parent commented: "Yeah it's good because it's quite a hassle moving every week and I usually see them sometime during the week anyway." (10 year old male, 36 months since separation, LSG). One young person commented that she was happy with the contact arrangements with her dad although she felt as though she should spend more time with him but was too busy to do so. 
A finding of interest at Time 1 was that all of the participants with shared care contact stated that they were happy with their contact arrangements (15). This finding was repeated at Time 2 when the fourteen participants that resided in shared care family structures commented that they were happy with their contact arrangements.

Most of the young people that expressed unhappiness about their contact arrangements commented that their dissatisfaction was due to the lack of contact with their non-resident parent (5). More specifically these participants commented that they did not have enough contact with their non-resident parent because: s/he lived at a distance; financial difficulties made it difficult to spend more time together; the parent was busy or had work commitments; the parent was spending a lot of time with their new partner. For instance, one young person commented: "No, I'm not that happy with the arrangements we have. I only see dad in the holidays. He lives too far away and he works a lot. Plus he's got other family now so he finds it hard to juggle his time." (14 year old female, 39 months since separation, LSG).

Four young people also commented that they were not happy with their contact arrangements because they disliked the conflict between their parents during the change-over from one parent to the other. One child who had contact with her dad most weekends stated: "I guess I'm not happy. I'd like to see more of dad but he's pretty busy. It'd be better if mum and dad didn't act the way they did when mum drops me off. They're quite mean to each other and it ruins my visit." (14 year old female, 28 months since separation, ESG). Three participants also mentioned cancelled visits as something they were unhappy about; for example, "No, sometimes it sucks. Dad lives out of town, I see him some weekends but that's not much. Then he rings and says he can't make it and changes my plans on me. I find that hard." (14 year old male, 20 months since separation, ESG). One young person commented that he was unhappy with his contact arrangements because he did not have a good relationship with his father; for that reason he preferred to live with his mother. 
The unanimous reason for the 'I'm sort of happy' responses was that they would like to spend more time with their non-resident parent (9), a finding also reported at Time 1. The reasons the participants presented for the lack of contact were similar to those reported above by the young people who were unhappy with their contact arrangements (i.e. distance, financial difficulties, work commitments and divided time).

Negative aspects of the separation. The young people's negative experiences of separation were revisited in the second interview. The range of negative factors referred to at Time 2 was very similar to those mentioned at Time 1 . The absence of a parent, being unable to see their non-resident parent as often as they wanted and missing them was the most frequent response (29), as it was at Time 1 (37). For example, one young person responded: "Not getting to see dad much, that and not getting to see Pup (family pet) much." (13 year old male, 28 months since separation, ESG). Another participant commented: "I hardly ever get to see my dad and I always miss him. Also when I go to dad's sometimes for a weekend I miss mum 'cause I am so used to being with her." (11 year old female, 19 months since separation, ESG).

The number of participants that referred to travel and the distance between themselves and their non-resident parent as a negative outcome of the separation in the second interview (27) was similar to the number that responded in this manner in the first interview (34). Similarities were also apparent between the number of young people that mentioned the change in financial circumstances and 'going without' as a negative aspect at Time 2 (26) and at Time 1 (25). For instance, "I don't get as much good presents. I don't spend much quality time with them together. After they've been together mum always says these stink things about dad." (11 year old female, 19 months since separation, ESG). Four participants referred to one parent making unkind remarks or 'badmouthing' the other parent as a negative factor. Arguments between parents were mentioned by five participants at Time 2, thirteen fewer than at Time 1. 
Fewer participants commented on the difficulty of moving possessions between houses at Time 2 (19) compared to Time 1 (34). Those that responded in this manner frequently used the 'living out of a suitcase' sentiment. A smaller number of participants mentioned their non-resident parent and their dissatisfaction with the contact arrangements (5), compared to Time 1 when 12 participants voiced their discontent. During the first interview a total of 17 young people specified moving to a new area or a new town as a negative outcome. In the second interview seven participants responded in this manner; for example, "We had to move. I liked living in that area. I don't get to see Gran as much". (12 year old female, 40 months since separation, LSG). A larger number of young people referred to the loss of contact with extended family as a negative outcome of the separation at Time 2 (13), compared to Time 1 (5). For example, "I haven't seen much of our wider family lately. We seem to see them less and less." (16 year old female, 21 months since separation, ESG).

Spending family holidays and other family events apart, as well as no longer spending quality time all together were mentioned by 21 young people in the first interview, and by 19 young people in the second interview. When asked about the bad things about his parents' separation, one young person succinctly commented: "That I can't see them together!" (12 year old male, 19 months since separation, ESG). A few participants talked about their relationship with one parent as a negative outcome of the separation and their feelings about their relationship at Time 2 (7), six young people mentioned this at Time 1. One young person listed the negatives as, "Stepparents. Having two houses, like, having to equalise your stuff. Also I don't get on well with my dad but I still miss him. Like, being there in the morning and stuff." (18 year old female, 42 months since separation, LSG).

At Time 2 seven participants perceived missing their pets as a bad outcome, as was the case for five participants at Time 1. One young person described missing her non-resident parent and pets, and the quandary she felt in saying what she wanted or how she felt. She outlined the negative aspects of separation as: "Having to move. I miss my cats a lot and of course the other 
parent. I don't really like saying stuff, 'cause there's a whole bunch of guilt going around. If I say 'I don't really want to move back to dads', mum will say I feel so terrible about it. So mum sort of blames herself and dad sort of blames himself. Whereas me and 'Johnny' (brother) don't really see it like that, it's what they both wanted and so it's just the way it is, and we are just complaining about the way it is not the way it could have been." (17 year old female, 37 months since separation, LSG).

In the second interview four young people commented that their parent/s expected them to help out more. For instance, "mum wants me to do this and that, (she is) always asking me to do something." (18 year old male, 21 months since separation, ESG). These young people clearly felt that the extra demands placed on them were a negative aspect of the separation. One young person made a comment in reference to her mother's health and the pressure the separation had caused which she viewed as a negative outcome: "It makes people sick, all that stress I guess. That's been the worst thing, how mum's coped. Well, actually I mean how she hasn't coped." (19 year old female, 25 months since separation, ESG).

One of the most visible changes over time was the number of participants that referred to the new people in their lives, such as a parent's new partner or his/her family members, as a negative aspect of the separation. At Time 1 only nine participants voiced their disapproval; in contrast 20 participants viewed it as a negative factor at Time 2. One young person commented, "Not being able to see dad that much sucks. Then (there are) all the new people in our home now. It's just new people to get on with." (14 year old male, 25 months since separation, ESG). Another young person was divided in relation to how she felt about the new people in her life, namely her mum's new partner and his children: 'I guess l'd say that 'Josh' and 'Sam' and 'Dave' aren't a positive for me. But then on the other hand I love having 'Katie' around. So it's half negative and half positive." (14 year old female, 35 months since separation, LSG). Six participants commented that there was nothing negative about the separation during the second interview, and four felt this way during the first interview. 
Overall fewer negative aspects of parental separation were mentioned by the participants at Time 2 compared to Time 1. In the first interview the young people mentioned a total of 223 negative aspects that were connected to the separation. In the second interview the young people referred to 193 negative facets of their parents' break-up.

When the young people were asked at Time 2 what they miss the most since their parents' break-up, the majority referred to their non-resident parent (21), as was the case at Time 1 (26). A large number also commented that they missed spending time together as a family with both parents present and participating in holidays and family outings (20). During the first interview 24 participants missed this aspect of their lives. A number of young people referred to members of their extended family when reflecting on what they missed (9). For example, "I miss seeing my cousins on dad's side. We used to have dinner with them on Sundays. We don't go any more." (12 year old female, 25 months since separation, ESG). At Time 1 none of the participants referred to extended family, however three young people did mention friends.

Pets were mentioned by seven participants during the second interview and by 10 participants at the time of the first interview. A total of nine young people missed their parent's cooking or the way they ran the house at Time 1, which was reiterated by 12 young people at Time 2. A typical response was: "I miss mum's cooking, and the lunches, and she organised everything for us." (15 year old male, 38 months since separation, LSG). One young person missed the neighbourhood they had previously lived in. Two participants referred to their family's diminished finances. For example, when asked what he missed one young person responded: "Having lots of money and buying heaps of stuff. The money between my mum and dad is not even. Mum only gets a bit, and it seems like my dad is robbing us. And I miss dad's cooking." (12 year old male, 19 months since separation, ESG). Five participants, all from the later-stage separation group, could not think of anything that they missed. In comparing Time 1 and Time 2, the participants referred to a similar range of factors that they grieved post-separation. During the first interview 74 elements were mentioned compared to the 72 at Time 2. 
For a second time the young people were also asked what they did not like about living in their household/s. When this question was initially asked most of the young people interpreted it to mean: 'what do you dislike about your house?' At Time 2 the interviewer was careful to put more emphasis on their household and the people they cohabited with when asking the question. Once again some of the young people made a point of referring to the inadequacies of their house, such as small rooms, location, not enough bedrooms, limited outdoor space and the state of the house (18). For instance, "I don't like our house, it's too small (and) we can't get away from each other. That's why us kids end up fighting, (there is a lack of) space. I don't want to fight." (10 year old male, 36 months since separation, LSG). In comparison, during the first interview 31 young people disliked aspects of their houses. As mentioned in the previous quotation, arguing with siblings and/or parents was referred to by some participants (10). The same number of young people disliked this aspect of their household/s at Time 1. A large number of participants referred to the conflict between their parents as something they despised (20). Parental conflict was also mentioned by 18 young people during the first interview.

At Time 1 five young people made reference to the family not being all together. Double the number of participant responded in this way at Time 2 (10); for example, "We don't have as much fun as we would if it was all of us." (12 year old female, 25 months since separation, ESG). Twelve young people commented on their parent's partner or a stepparent at Time 1; a similar number also did so at Time 2 (15). For instance, when one participant was asked what she disliked about her household she responded: "Probably having my stepdad around because he's quite hard to get on with." (15 year old female, 40 months since separation, LSG). The increased responsibility around the house and in particular the pressure to help out with the care of siblings and household chores was intolerable for 12 participants. One participant quite simply stated: "I have to do more chores. I hate that." (20 year old male, 24 months since separation, ESG). Eight young people voiced similar opinions at Time 1. 
Some young people disliked a parent's cooking and/or housekeeping abilities during the first interview (10), compared to the 16 participants that responded in this manner at Time 2. Five participants made comments in reference to the number of people living in their household: for example, "There's not much (I dislike). It's really crowded and small (the house). There are a lot of people around in such a small house. There (are) six people here, sometimes five if nana has to go into hospital." (12 year old male, 35 months since separation, LSG). Only one participant mentioned the number of people living with them during the first interview. Eight young people disliked that they did not have a good relationship with a parent, as did six young people at Time 1. The different rules between parents were a problem for 13 participants. A typical response was: "Mum says one thing, dad says another. Talk about confusing!" (14 year old female, 39 months since separation, LSG). During the first interview a similar number of participants responded in that manner (9).

The household finances were an issue for seven young people, compared to the 14 young people that felt that way at Time 1. One young person stated that they disliked having just the one parent in their household: "It's harder with only one parent. If one parent is busy the other one is not there." (16 year old male, 38 months since separation, LSG). In comparison, at Time 1 nine young people more specifically stated that they did not have enough contact with their non-resident parent and that they missed him/her. One participant responded that he was often bored and did not have as much fun in his new household; nine young people expressed comparable views at Time 1. During the first interview eight participants stated that there was nothing that they disliked about their household. Approximately double the number of participants responded in the same way during the second interview (15). It is apparent that at Time 1 and Time 2 the participants revealed a large range of factors that they disliked about living in their households. During the first interview 146 factors were mentioned compared to the 136 that were mentioned at Time 2. It is, however, difficult to compare the participants' responses at Time 1 and Time 2 because, as mentioned above, the question was asked differently at Time 2 . 
Once again the young people provided a variety of ideas about how they could improve life in their household/s. Spending more time with both parents was the most common suggestion to their household concerns (22). A number of these participants emphasised their desire to spend more time with their non-resident parent. During the first interview 29 participants mentioned spending extra time with their parents. A large number of young people at Time 2 commented that if their parents refrained from arguing and became friends then life would improve in their household/s (18). At the time of the first interview 27 young people expressed similar views. A bigger and better house, moving rooms or fixing their house were some of the solutions put forth by 15 participants. For instance, when asked if anything would help improve life in her household one young person replied: "Yip. When we get a puppy, and cleaning the house would help, and if we swapped rooms with dad." (10 year old female, 43 months since separation, LSG). In the first interview 25 participants mentioned improvements to their house.

Greater communication between household members was an important solution to their household difficulties for 14 participants. In comparison 20 young people mentioned communication at Time 1. A number of young people stated that having their non-resident parent (most often their father) living in the same town or closer would improve life in their household (8). Two young people expressed similar views at Time 1. During the first and the second interviews 10 young people believed their households would improve if their parents put more effort into running them. This included cooking, cleaning, shopping and other household chores. At Time 2 nine young people stipulated that money was the key to improving their household. For example, one young person unequivocally stated: "More time with dad. More money." (15 year old male, 19 months since separation, ESG). In comparison, during the first interview 23 young people declared that being in a stronger financial position was the answer to their household issues.

Eleven young people believed that life would be better in their household if they personally made a concerted effort to improve their relationships. Some of these young people commented that they could be more open, accepting, 
patient and respectful. One young person commented: "I'd like for me to respect my stepdad more and actually make an effort to get along with him. Because sometimes I just flip out and yell at him and tell him he's not my dad and can't tell me what to do and stuff, but then afterwards I always feel real bad but I can't apologise." (15 year old female, 40 months since separation, LSG). At Time 1 four young people believed that they could put more emphasis on developing and maintaining their household relationships. Connected to this were the suggestions four young people put forth about reducing the conflict between themselves and their siblings and parents. In particular, making the effort to not argue with family members and consequently improve their household environment. At Time 1 nine young people also recommended this as a solution to their household problems.

A few participants stated that life would improve if they, and the members of their household/s, could better manage their time (5). For example, "If we figured out our schedules so that we could all work better together. Time is a big issue for me." (19 year old female, 27 months since separation, LSG). Extra help with their chores was a solution for six participants at Time 2 and for 10 participants at Time 1. One young person commented that getting a pet would help. Another stated that if her father stopped smoking life would be better in her household; four young people made similar comments with regards to tobacco and/or alcohol at Time 1 . One young person believed that life in his household would improve if his mum and dad's relationship resumed. In comparison, 14 young people suggested that their parents reunite at Time 1. A number of participants stated that nothing would improve life in their household/s because improvements were not necessary (13); eight young people responded similarly during the first interview. A few participants did not offer any suggestions to improve life in their household/s (3).

Positive aspects of the separation. During the second interview the participants were also asked about their positive experiences of separation. As was the case at Time 1, the overwhelming majority of young people at Time 2 stated that there was less parental and family conflict since the separation. At the time of the first interview all of the participants mentioned 
this as a positive aspect of the separation; during the second interview 46 participants referred to the decrease in the level of conflict in the family environment. A number of participants remarked that their parents 'get on better now'. Another positive aspect that the participants revealed at Time 1 and Time 2 was that they were happier now. At Time 2 a large number of young people mentioned happiness (40); a similarly large number also did so at Time 1 (34). Participants were inclined to refer to themselves and their family as happier, and often commented that they were less stressed. For instance one participant replied: "It's a lot calmer and easier to get on with your life and do stuff like studying. They don't fight like they used to. We don't stress so much. It's just easier." (16 year old male, 33 months since separation, LSG).

A number of participants commented on the new people in their lives as a positive outcome of the separation (26). One young person talked about the good things that came from his parents' separation: "The new people that we live with. The new relations (I have met) and equally building strong relationships with them as well." (14 year old male, 27 months since separation, ESG). During the first interview 13 participants referred to the new people in their lives as a positive outcome of the separation. Connected to this outcome is the idea of carrying on with life. A few participants made reference to 'moving on' with their lives (14); in particular that their parents have also progressed since the separation. For instance, one young person viewed the following outcomes as positive: "That they have moved on and found new people. Plus I get two bedrooms to cram full of stuff." (17 year old female, 35 months since separation, LSG). At Time 1 none of the participants referred to proceeding with life as a positive aspect of the separation. As mentioned in the previous quotation, the benefits associated with living in two houses were commented on by 17 young people at Time 2 and 22 young people at Time 1 .

Quality time with parent/s and siblings was frequently mentioned at Time 1 (21) and Time 2 (25). The young people felt that they spent more quality time with their parents and engaged in a greater number of new and fun activities than they did prior to the separation. It is clear that the majority of the 
participants that mentioned this factor were not experiencing quality time with both parents simultaneously. A number of young people felt that they were closer to their parents and/or siblings as a result of the separation (18). Five young people expressed similar feelings at Time 1. During the second interview some of the young people referred to the presents they received, mostly from their non-resident parent, as a positive outcome of the break-up (7). One young girl said: You get to know one of your parents more. And you get stuff from the other parent." (10 year old female, 43 months since separation, LSG). Spending more time with extended family members was a positive outcome for 20 young people in the first interview and seven young people in the second interview. Pets were an important feature of their postseparation lives for 12 participants. A similar number of young people felt this way at Time 1 (10).

Being closer to school was a good outcome of the separation for one young girl and making new friends at school was a positive outcome for two participants. One older participant believed that there were no good outcomes from his parents' separation; he responded, “I can't really say there's anything that's made life better." (20 year old male, 24 months since separation, ESG). In summary, a larger number of positive aspects of parental separation were mentioned by the participants at Time 2. In the first interview the young people mentioned a total of 182 positive elements connected to their parents' separation. In comparison, during the second interview the young people referred to 215 positive features.

The young people also outlined what they liked about life in their household/s. The most frequent response involved the people that they resided with and spending time with them (39), which was also the finding at Time 1 (42). One young girl commented: "I like seeing my nana and granddad every day and I like seeing my mum every day. I also like talking to dad and talking to James he's mum's boyfriend - about science and stuff." (10 year old girl, 38 months since separation, LSG). Fun was a feature of many of the young people's households, with 29 young people referring to the fun they enjoyed in their household/s. This response was often made in relation to the people they 
were living with. During the first interview 37 participants also mentioned their fun experiences. At Time 2 some participants stated that happiness was something that they like about their household (11) and nine mentioned the decrease in parental conflict.

Particular aspects of their houses were mentioned by 10 young people; for instance the size, the bedrooms and the outdoor space. At Time 1 features of their houses were also mentioned by 11 young people. At Time 2 six participants also referred to the household environment; for example, "The closest thing I have had to having a real home feeling since we left out first house, is mum's place she's got now. It's just nice and cosy and just feels like a family home. It's all pretty settled now and feels like home." (17 year old female, 35 months since separation, LSG). Five participants mentioned household pets at Time 2 and one older participant stated that he liked that he did not have to pay rent or board. Another participant enjoyed having less people living in her new household because it made it quiet and easy to relax. One older male stated that there was nothing that he liked: "I don't particularly like anything about living in this (dad's) house at all. It came out of something I didn't really want to happen." (17 year old male, 37 months since separation, LSG). At Time 1 the young people mentioned 95 aspects that they liked about life in their household. In comparison, at Time 2 the participants referred to 112 factors.

Challenges encountered. The young people were asked for a second time if they had experienced any problems since their parents' separation. The most frequently reported problem was the relationship between their parents (21), in particular the animosity and bad mouthing that their parents engaged in. Many of these young people found it difficult to hear what one parent would say about the other parent or to have one parent ask questions about the other parent's new life. Some participants also stated that they observed the hostility between their parents; for example, "I don't like how mum and dad act when they drop us off. They're cold and angry and say stuff that we don't need to hear." (15 year old male, 28 months since separation, ESG). Some young people commented that it was problematic that they were not seeing 
enough of their parents (13). In particular, many participants commented that they did not get to see their non-resident parent as often as they would like to. A challenge for a number of young people post-separation was maintaining their relationships with their extended family and friends (13). During the first interview 21 young people also referred to this as a problem. Some participants mentioned that they found it difficult to equally divide their time between their parents (12), and were concerned that they were not being fair with their time and affection. This was the most frequent response at Time 1 (35). At Time 2 ten participants stated that they found it challenging to learn to live in their household without their second parent. In comparison, during the first interview 31 young people cited this as a problem they were experiencing.

A similar number of participants mentioned financial problems at Time 1 (15) and Time 2 (12). Keeping on top of school/university work and extracurricular commitments proved problematic for six participants at Time 2 and two participants at Time 1. Eight young people stated that they had not had any problems since their parents' separated. In comparison, during the first interview 10 young people responded similarly. Of particular note, at Time 1 eighteen participants commented that informing people about their parents' separation was a challenge for them. At Time 2 none of the participants referred to this as a challenge. The total number of problems mentioned at Time 1 was 122, while 87 were mentioned during the second interview.

The young people came up with a number of solutions to address the problems they were experiencing. The solution for most of the young people was for their parents to become friends and refrain from arguing and talking negatively about the other parent (31). For example one young boy stated: "The best thing would be if they got back together and didn't fight, but I doubt that's going to happen. If they had a truce and made up and decided not to fight again that would be good. They wouldn't have to get back together, but just make up." (12 year old male, 19 months since separation). During the first interview 21 participants also commented that this was the answer to their problems. Increased contact with their non-resident parent was important to 
nine young people, as it was to 12 young people at Time 1 . Spending more time with their parents was the answer for 16 participants and eight participants suggested spending more time with their extended family and friends.

As was the case at Time 1, a number of the participants' solutions involved communication and a sense of understanding. A number of young people commented that if their parents talked to them, to help them to understand the separation and clear up any confusion, then that would assist them to deal with challenges they faced (28). During the first interview 17 young people felt the same way. Some participants also stated that if their parents understood them better and understood their perspectives then that would significantly help them (10). A large number of participants mentioned this solution at Time 1 (22). A few participants gave financial solutions to their problems (4), namely finding employment to help their parents, and one young person said winning 'lotto' would help. At Time 1 eight participants came up with solutions to improve their financial state. A few participants did not answer the question because they had already stated on the previous question that they had not experienced any challenges (8). At Time 2 six young people were unable to come up with any ideas to help them deal with the challenges they faced; in comparison, at Time 1 a large number of participants were unable to provide solutions for their problems (19).

Reminiscing. For a second time the young people were asked whether they think about life before their family structure changed. A number of participants replied that they did think about their 'old life', in particular the happy times they had experienced (13). These young people tended to recall times spent together as a family, holidays and family outings or other family oriented events prior to the separation. One young person answered by saying: "Yeah. Just memories of stuff we did together, just good times and family stuff. It doesn't make me sad really. I think they're things l'd think about whether they'd divorced or not." (18 year old female, 32 months since separation, LSG). At Time 1 a similar number of young people reminisced about the happy times they experienced prior to the break-up (16). 
A large number of participants also thought about their 'old life', but their memories were centred on their turbulent experiences (30). This included the conflict between their parents, the general unrest within the family and the way their parents treated each other. One young person recounted his memories of life before his family structure changed: "Mostly them fighting because that's permanently in your head. It's sort of like that thing where you only remember bad times." (12 year old male, 19 months since separation, ESG). During the first interview 25 participants described unhappy memories.

Other participants responded that they thought about the past when they looked at photos or video footage of their lives before the separation (8). At Time 1 almost double the number of young people reminisced in a similar way (15). A few young people recounted memories of their childhood that involved spending time with friends (4); for instance, one participant commented: "I think about the times we'd go and play with my friends. We'd go on all kinds of adventures." (11 year old female, 42 months since separation, LSG). It was not uncommon for participants to refer to both happy and unhappy times in their responses.

A few participants commented that they did not reminisce about the life they had before their family structure changed (11). These young people often mentioned that they had moved on with their lives and were happy now, and therefore did not need to focus on the past. Also, one participant did not want to dwell on the past because it made him sad. During the first interview 19 young people did not think about life before the break-up.

\subsubsection{Support and coping}

Research question 8 enquired: 'How do young people's perspectives regarding support and coping at Time 1 compare to their perspectives at time 2?'

What young people say they need. The young people were asked for a second time what they needed most during the separation. Almost all of the participants mentioned their parents when answering this question (46). In 
particular they needed to be in touch with both parents so that they felt supported and understood. Forty young people responded similarly at Time 1. Also frequently mentioned at Time 2 was the need to know what caused their parents to separate (37). At Time 1 thirty young people wanted to know what had happened. Many participants still felt confused and ill-informed about the motivation for their parents' break-up. For these young people knowing what went wrong was an important part of accepting the changes they were experiencing.

During the second interview a number of participants stated that they needed their parents to listen to them (23). Being listened to was also cited by 30 young people at Time 1. Some participants voiced a need to know what the current plans were for their family (11). A large number of participants responded in this manner during the first interview (34). In fact, it was more common at Time 1 for the participants to also want to know what was going to happen in the months to come. Very few participants mentioned this feeling of uncertainty at Time 2. At both Time 1 and Time 2 the young people wanted reassurance that they would have sustained contact with each of their parents in the future.

The need for time to understand what happened before their environment changed was an important factor for 38 participants during the first interview. In comparison at Time 2 only five young people mentioned this need. However, a number of participants did refer to time in the sense of 'getting on with life' and coming to terms with the changes they were experiencing (14). Five participants said they needed to be left alone at Time 2 and 12 felt the same at Time 1. Five young people also needed reassurance that their parents were 'all right', as did 10 young people at Time 1. Two young people replied that they did not need anything.

Formal sources of support. At Time 1 very few of the participants had received formal support for the separation (only 14 sources of support had been utilised). Approximately 18 months later 19 young people had been formally helped and supported during their parents' break-up. Five young 
people had participated in a support group, eight had taken part in an education programme, and the remaining participants had accessed community or school based counselling. The majority of participants had not received any formal support at Time 1 (41) and Time 2 (37).

Informal sources of support. During the first and second interviews informal sources of support were more likely to be employed than the formal sources. At Time 2 support was mostly provided by siblings (42) and friends (36). One or both parents were mentioned as important sources of support at Time 2 (35). Family friends (23) and grandparents (11) also played an important role. Four young people named other extended family members as their support, and the same number of participants stated that pets had helped them. In comparison, at Time 1 one or both parents was the most common response (44), followed by: older siblings (30); friends (28); grandparents (27); other extended family (18); family friends (14); and pets (9).

During the second interview 11 young people named a parent's partner as their source of support. None of the participants named a parent's partner during the first interview. At Time 2 all participants said that they had at least one source of informal support, whereas at Time 1 six young people stated that they had not had any informal support.

Coping strategies. The participants' coping strategies were similar at Time 1 and Time 2. The most obvious difference was the number of young people that used the internet or their cell phone as a form of coping. During the first interview 25 young people emailed and/or used internet chat rooms to 'talk' about their parents' separation, and 12 used their cell phone to text message their friends. At Time 2 even more young people relied on the internet (34) and text messaging (21) as a form a coping. At Time 1 and Time 2 a similar number of young people spent time with friends, found fun things to do, spent time alone, or concentrated on school, university or work commitments to help them to cope. 
Availability of support. During the second interview the young people were asked if the support they had received was sufficient. The majority of participants felt that they had received adequate support during the separation (44). Eight participants felt that they had not received enough support. Out of these eight participants, five wanted more support from their non-resident parent and three wanted both parents to be more supportive. Similar results were reported at Time 1.

Finding support. All participants stated that they knew where to find support if they needed it, as was the case at Time 1. The range of people the participants identified as support sources were similar the sources during the first interview. Most of the young people stated that immediate family members, namely parents (38) and siblings (29), were the people they would approach for help. Friends (24), extended family members (19), the internet (19), family friends (5) and the 'What's up?' child helpline (5) were also mentioned. At Time 2 none of the participants stated that they would consider seeking support from a school teacher. As was the case at Time 1, none of the participants referred to counsellors, therapists, support groups, education programmes or other support services in their responses. Importantly, at the time of the second interview 17 young people stated that they would approach a stepparent or parent's partner for support. One participant at Time 1 mentioned their stepparent as a source of support.

Ideas on coping. The young people were asked for a second time if there was anything that would make the separation easier for them to cope with. The most common response was if their parents were friends and refrained from arguing and badmouthing each other (31). In comparison during the first interview 10 young people referred to their parents' relationship and interactions post-separation. Some young people also commented that the changes they were experiencing would be easier to cope with if their parents talked openly with them about the break-up so that they knew what was happening around them (30). Being listened to and involved was also important to many of these young people. At Time 1 communication and honesty were mentioned by 48 participants. 
Some young people commented that they would cope better if they were able to have more contact with their non-resident parent (27). During the first interview 20 young people made a similar response. At Time 2 nine participants stated that spending time with both parents would help them to cope. Five young people referred to an education programme as a source of coping at Time 2, whereas during the first interview 11 young people mentioned an education programme or support group post-separation. Two young people stated that nothing would make the separation easier for them, as did 10 young people at Time 1 .

\subsubsection{Communication}

Research question 9 enquired: 'How do young people's perspectives regarding communication at Time 1 compare to their perspectives at Time 2?'

Being informed. At Time 2 the participants were again asked if their parents had kept them informed of any decisions made regarding the family situation, as well as their views about being kept up-to-date. There were no differences between the participants' Time 1 and Time 2 responses in relation to being informed. The majority of participants felt that their parents were not keeping them up-to-date about matters pertaining to the separation at Time 2 (48), compared to Time 1 (46). Also, all of the participants preferred that their parents kept them informed with regard to any decisions that affected the family (52).

Being involved in decision making. The participants were asked if they felt their parents had conferred with them about any decisions concerning the family situation. Their views were also explored regarding being asked for their opinion and telling their parents what they felt and wanted. The responses that the participants provided at Time 2 were similar to the responses given at Time 1. At Time 2 the majority of participants reported that they had not been asked for their input in relation to any decisions that their parents were making that affected the family (47). Only five participants described being consulted about decisions concerning the family. In 
comparison during the first interview 43 participants stated that they had not been consulted.

When the young people were asked if they liked the idea of their parents asking for their opinion 45 of them responded 'yes'. Three young people did not like the idea of their opinions being sought and four participants were unsure if they actually wanted to be asked. The four participants that were unsure were from the child age group, as were two of the participants that did not want their opinions asked. In comparison, during the first interview 48 young people wanted their parents to ask their opinion and four were opposed to the idea. The third question focused on whether the participants felt comfortable telling their parents what they wanted and how they felt at Time 2 . Similar results were found at Time 1 and Time 2. During the first interview 28 young people were comfortable talking to their parents and 24 felt uncomfortable. During the second interview 34 participants were comfortable, 17 were uncomfortable and one did not know how she felt.

What young people want others to know about separation. The participants gave similar responses at Time 1 and Time 2 when they were asked what advice they would give to a child who is about to experience a separation and to a parent that is about to separate. The advice that was most frequently given to children during both interviews was that in time the situation would improve (37 at Time 1, 45 at Time 2). The old adage that 'time heals' and that 'life must go on' were standard comments. During both interviews the most common response for parents in the process of separating was to talk to their children, to ask for their opinion and to listen to them (44 at Time 1, 50 at Time 2). Advice also revolved around the parents' relationship and the importance of being kinder to each other and refraining from arguing. This point was made more frequently at Time 2 (20 at Time 1, 33 at Time 2). Many young people also commented that they would make sure the parents knew how important it was that their children maintained contact with their mother and their father (15 at Time 1, 22 at Time 2). During the first interview none of the participants responded that they would tell the parents not to separate, 
this was also the case at Time 2. Also of note is that the participants offered more advice at Time 2 than they did at Time 1.

\subsubsection{The future}

Research question 10 enquired: 'How do young people's perspectives regarding the future at Time 1 compare to their perspectives at Time 2?'

Family. The young people were asked at Time 2 how they felt about the future prospects for their family. Over half of the sample expressed extremely positive feelings about their family's future (27); one participant commented, "I feel excited. There's so much to look forward to. I don't have any concerns about the future. Not that I think it's all roses or anything, I'm just not worried about what may or may not happen." (17 year old female, 37 months since separation, LSG). In comparison, at Time 1 only 11 young people conveyed extremely positive feelings. At Time 2 a number of the participants stated that they felt 'okay' about the future and were reasonably optimistic (17); for example, "I'm okay about it. I think we'll get through all of this and we'll always be a family." (12 year old female, 25 months since separation, ESG). At Time 1 the majority of young people that replied in either of these ways (i.e. felt okay about their family's future but expressed some uncertainty; expressed worry and anxiety about their family's future; did not know how they felt) were from the LSG; whereas, at Time 2 there was no difference between the responses of the participants in the early-stage and the later-stage separation groups.

Four young people felt 'okay', but expressed some uncertainty about what the future held for their family. For instance, one participant stated: "I feel okay. Not that I know what'll happen. It could all change and dad and (his dad's girlfriend) could break-up. Anything could happen." (18 year old male, 23 months since separation, ESG). A similar number of young people conveyed feelings of worry and anxiety about the future (3). For example, "I think about that a bit. I probably worry about our family changing again. l'd hate for it to blow-up again. Mum can't promise me that things won't change." (11 year old female, 19 months since separation, ESG). One participant replied that he did 
not know how he felt about his family's future: “I don't know. I don't know what to think. I really don't know how I feel about our future. It's unpredictable" (19 year old male, 36 months since separation, LSG). At Time 1 most of the young people that replied in one of these three ways were from the earlystage separation group. In comparison, at Time 2 there were no such differences between the responses of the early-stage and later-stage separation group participants.

Marriage. The young people were once again asked about their views on the topic of marriage. In particular, whether they believed they would marry one day and the importance of marriage. There were no differences between the participants' Time 1 and Time 2 responses regarding marriage and their future.

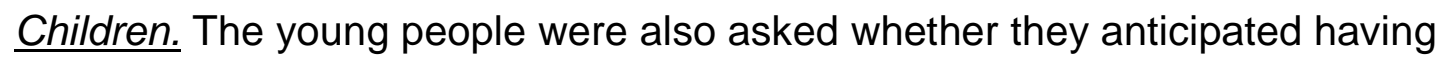
children in the future and if having children was important to them. Their replies were compared to the responses that were given at Time 1. There were no differences between the participants' Time 1 and Time 2 responses regarding children and their future.

\subsection{Reliability Analyses and Descriptive Statistics (Time 1 and Time 2)}

\subsubsection{Individual wellbeing: The variables}

The means and standard deviations for all of the individual variables at Time 1 and Time 2, as well as the Cronbach alpha coefficients for each of the subscales can be found in Table 9.6. All of the individual variables (with the exception of some of the SDQ subscales) obtained Cronbach alpha values that were above .70 and were, therefore, high enough to confirm the reliability of the measures at Time 1 and Time 2.

Perceptions of Strengths Scale. It was not possible to carry out a reliability analysis on this scale because of its elementary design. The mean number of strengths chosen at Time 2 was higher than the mean number chosen at Time 1. 
Table 9.6

Descriptive Statistics for Individual Wellbeing Variables at Time 1 and Time 2

\begin{tabular}{|c|c|c|c|c|c|c|}
\hline Individual Variables & $n$ & Min. & Max. & Mean & $\begin{array}{l}\text { Std. } \\
\text { Dev. }\end{array}$ & $\begin{array}{l}\text { Cron. } \\
\text { Alpha }\end{array}$ \\
\hline \multirow{2}{*}{$\begin{array}{l}\text { Perception of strengths } \mathbf{1} \\
\text { (POS) } \\
\text { Perception of strengths } 2 \\
\text { (POS) }\end{array}$} & 52 & 7.00 & 22.00 & 16.02 & 4.13 & $\mathrm{n} / \mathrm{a}$ \\
\hline & 52 & 11.00 & 22.00 & 17.46 & 2.95 & $\mathrm{n} / \mathrm{a}$ \\
\hline \multirow{2}{*}{$\begin{array}{l}\text { Positive feelings } 1 \\
\text { (CFS) } \\
\text { Positive feelings } 2 \\
\text { (CFS) }\end{array}$} & 52 & 15.00 & 40.00 & 32.56 & 5.54 & .91 \\
\hline & 52 & 29.00 & 39.00 & 35.10 & 2.37 & .87 \\
\hline \multirow{2}{*}{$\begin{array}{l}\text { Negative feelings } 1 \\
\text { (CFS) } \\
\text { Negative feelings } 2 \\
\text { (CFS) }\end{array}$} & 52 & 11.00 & 33.00 & 20.37 & 6.59 & .92 \\
\hline & 52 & 10.00 & 22.00 & 16.60 & 2.87 & .88 \\
\hline \multirow{2}{*}{$\begin{array}{l}\text { Prosocial behaviour } 1 \\
\text { (SDQ) } \\
\text { Prosocial behaviour } 2 \\
\text { (SDQ) }\end{array}$} & 52 & 8.00 & 12.00 & 10.94 & 1.07 & .69 \\
\hline & 52 & 10.00 & 15.00 & 13.62 & 1.16 & .73 \\
\hline \multirow{2}{*}{$\begin{array}{l}\text { Hyperactivity } 1 \\
\text { (SDQ) } \\
\text { Hyperactivity } 2\end{array}$} & 52 & 5.00 & 14.00 & 9.29 & 2.00 & .71 \\
\hline & 52 & 5.00 & 12.00 & 8.58 & 1.81 & .70 \\
\hline \multirow{2}{*}{$\begin{array}{l}\text { Internalising } 1 \\
\text { (SDQ) } \\
\text { Internalising } 2 \\
\text { (SDQ) }\end{array}$} & 52 & 5.00 & 15.00 & 8.15 & 2.59 & .85 \\
\hline & 52 & 5.00 & 12.00 & 7.21 & 1.81 & .84 \\
\hline \multirow{2}{*}{$\begin{array}{l}\text { Externalising } 1 \\
\text { (SDQ) } \\
\text { Externalising } 2 \\
\text { (SDO) }\end{array}$} & 52 & 5.00 & 12.00 & 7.62 & 1.83 & .76 \\
\hline & 52 & 5.00 & 11.00 & 7.31 & 1.57 & .70 \\
\hline \multirow{2}{*}{$\begin{array}{l}\text { Peer problems } 1 \\
\text { (SDQ) } \\
\text { Peer problems } 2 \\
\text { (SDQ) }\end{array}$} & 52 & 5.00 & 12.00 & 7.40 & 1.67 & .74 \\
\hline & 52 & 5.00 & 10.00 & 7.31 & 1.28 & .69 \\
\hline \multirow{2}{*}{$\begin{array}{l}\text { Dysphoria } 1 \\
\text { (CDI) } \\
\text { Dysphoria } 2 \\
\text { (CDI) }\end{array}$} & 52 & 0.00 & 32.00 & 11.13 & 8.70 & .93 \\
\hline & 52 & 1.00 & 17.00 & 8.10 & 4.11 & .92 \\
\hline
\end{tabular}

Children's Feelings Scale. The participants' positive feelings mean score was higher at Time 2 than it was at Time 1 ; whereas, the negative feelings mean score was higher at Time 1 than Time 2. The feelings scale was devised for this study; therefore, it was important to carry out a factor analysis in order to evaluate the scale and establish whether the components of the scale are 
reliably different from one another. A preliminary factor analysis showed that the variables loaded onto one factor.

Pallant (2005) specified that it is more reliable to carry out a factor analysis on larger samples for the reason that the correlation coefficients between the variables are less reliable for smaller samples. Statistics authors Tabachnick and Fidell (2001) have commented that a factor analysis can be carried out with a smaller sample if there are a number of marker variables above .80 . Recent debate has also concentrated on the ratio of subjects to items rather than solely the size of the sample (Pallant, 2005). Some authors have recommended 10 cases for each item in the scale; others have suggested as few as five cases for each item (Tabachnick \& Fidell, 2001). This scale consists of 20 items. If we were following the five cases to each item proposal then a total of 100 cases would be required to carry out a reliable factor analysis. In this study there are 52 cases, thus it would not be reliable to carry out an analysis.

Strengths and Difficulties Questionnaire. Out of the five subscales in the SDQ the pro-social behaviours subscale is the only one that is a positive variable. The mean score for pro-social behaviour at Time 2 was higher than the mean at Time 1. The remaining four subscales are all negative variables. The mean scores for both the hyperactivity and internalising subscales were slightly higher at Time 1 than they were at Time 2. In comparison, the mean scores were very similar at Time 1 and Time 2 for the externalising variable and for the peer problems variable.

Children's Depression Inventory. The young people's mean score at Time 1 was 11.13 , which is much higher than their mean score at Time 2 (8.10). Kovac (1985) described participants with scores equal to or greater than 11 as showing signs of a depressive disorder. According to Kovac's criteria the average participant at Time 1 was showing signs of depression. In this study the measure was interpreted as a broad measure of dysphoria, not depression. At Time 1 the proportion of participants that had a score equal to or greater than 11 was $40 \%$, which suggests that they were in a state of 
feeling unwell or unhappy and possibly experiencing anxiety, depressive symptoms or unease. The young people that had a score equal to or greater than 11 at Time 2 , was $21 \%$ of participants.

\subsubsection{Individual wellbeing: The groups}

The means for the individual wellbeing variables for the early-stage separation group and the later-stage separation group are displayed in Table 9.7. The ESG had a lower mean score at Time 1 for all of the positive variables: perception of strengths, positive feelings and pro-social behaviour. In comparison the ESG had a higher mean score at Time 1 for all the negative variables: negative feelings, hyperactivity, internalising, externalising, peer problems, and dysphoria. A similar pattern exists for the Time 2 variables; however, the differences between the mean scores of the ESG and the LSG are negligible.

Table 9.7

Means for Individual Wellbeing Variables for the Early-Stage Separation Group and the Later-Stage Separation Group

\begin{tabular}{|c|c|c|c|c|}
\hline Individual Variables & & $\begin{array}{c}\text { Total } \\
\text { Sample } \\
(n=52)\end{array}$ & $\begin{array}{c}\text { Early-Stage } \\
\text { Separation } \\
\text { Group } \\
(n=23)\end{array}$ & $\begin{array}{c}\text { Later-Stage } \\
\text { Separation } \\
\text { Group } \\
(n=29)\end{array}$ \\
\hline \multirow{2}{*}{$\begin{array}{l}\text { Perception of strengths } 1 \\
\text { (22 items) } \\
\text { Perception of strengths } 2 \\
(22 \text { items) }\end{array}$} & Mean & $16.02(4.13)$ & $12.70(3.34)$ & $18.66(2.45)$ \\
\hline & Mean & $17.46(2.95)$ & $16.70(3.17)$ & $18.07(2.66)$ \\
\hline $\begin{array}{l}\text { Positive feelings } \mathbf{1} \\
(10 \text { items, range } 10-40)\end{array}$ & Mean & $32.56(5.54)$ & $28.35(4.82)$ & $35.90(3.39)$ \\
\hline $\begin{array}{l}\text { Positive feelings } 2 \\
\text { (10 items, range } 10-40)\end{array}$ & Mean & $35.10(2.37)$ & $34.57(2.81)$ & $35.52(1.90)$ \\
\hline $\begin{array}{l}\text { Negative feelings } 1 \\
\text { (10 items, range } 10-40)\end{array}$ & Mean & $20.37(6.59)$ & $25.57(4.81)$ & $16.24(4.60)$ \\
\hline $\begin{array}{l}\text { Negative feelings } 2 \\
(10 \text { items, range } 10-40)\end{array}$ & Mean & $16.60(2.87)$ & $17.35(3.07)$ & $16.00(2.60)$ \\
\hline $\begin{array}{l}\text { Prosocial behaviour } 1 \\
\text { (5 items, range } 5-15 \text { ) }\end{array}$ & Mean & $10.94(1.07)$ & $10.87(1.06)$ & $11.00(1.10)$ \\
\hline $\begin{array}{l}\text { Prosocial behaviour } 2 \\
(5 \text { items, range } 5-15)\end{array}$ & Mean & $13.62(1.16)$ & $13.48(1.12)$ & $13.72(1.19)$ \\
\hline $\begin{array}{l}\text { Hyperactivity } 1 \\
(5 \text { items, range } 5-15)\end{array}$ & Mean & $9.29(2.00)$ & $9.48(1.86)$ & $9.14(2.13)$ \\
\hline $\begin{array}{l}\text { Hyperactivity } 2 \\
\text { (5 items, range 5-15) }\end{array}$ & Mean & $8.58(1.81)$ & $8.78(1.81)$ & $8.41(1.82)$ \\
\hline
\end{tabular}




\begin{tabular}{|c|c|c|c|c|}
\hline $\begin{array}{l}\text { Internalising } 1 \\
(5 \text { items, range } 5-15)\end{array}$ & Mean & $8.15(2.59)$ & $9.83(2.19)$ & $6.83(2.09)$ \\
\hline $\begin{array}{l}\text { Internalising } 2 \\
(5 \text { items, range } 5-15)\end{array}$ & Mean & $7.21(1.81)$ & $7.48(1.62)$ & $7.00(1.95)$ \\
\hline $\begin{array}{l}\text { Externalising } 1 \\
(5 \text { items, range } 5-15)\end{array}$ & Mean & 7.62 (1.83) & $8.61(1.47)$ & $6.83(1.71)$ \\
\hline $\begin{array}{l}\text { Externalising } 2 \\
(5 \text { items, range } 5-15)\end{array}$ & Mean & $7.31(1.57)$ & $7.48(1.41)$ & $7.17(1.69)$ \\
\hline $\begin{array}{l}\text { Peer problems } 1 \\
(5 \text { items, range } 5-15)\end{array}$ & Mean & 7.40 (1.67) & 7.65 (1.58) & $7.21(1.74)$ \\
\hline $\begin{array}{l}\text { Peer problems } 2 \\
\text { (5 items, range } 5-15 \text { ) }\end{array}$ & Mean & $7.31(1.28)$ & $7.30(1.40)$ & $7.31(1.20)$ \\
\hline $\begin{array}{l}\text { Dysphoria } 1 \\
\text { (26 items, range } 0-52 \text { ) }\end{array}$ & Mean & $11.13(8.70)$ & $16.00(8.08)$ & $7.28(7.55)$ \\
\hline $\begin{array}{l}\text { Dysphoria } 2 \\
\text { (26 items, range } 0-52 \text { ) }\end{array}$ & Mean & $8.10(4.11)$ & $9.78(4.11)$ & $6.76(3.64)$ \\
\hline
\end{tabular}

Note: $(\quad)$ = Standard deviation

\subsubsection{Family dynamics: The variables}

The means and standard deviations for all of the family dynamics variables at Time 1 and Time 2 can be found in Table 9.8, as can the Cronbach alpha values for each of the subscales. The family dynamic scales and subscales obtained Cronbach alpha coefficients that were high enough to confirm the reliability of the measures at both Time 1 and Time 2 .

Family Environment Scale. The cohesion and the communication subscales both achieved Cronbach alpha scores at Time 1 and Time 2 that were higher than the scores reported by Moos and Moos (1981). The mean score for the cohesion subscale was higher at Time 2 than it was at Time 1. Similarly, the mean score was higher at Time 2 for the communication subscale.

Perception of Parents Scale. The mean scores for the positive perceptions of mother and father subscales were both lower at Time 1 than at Time 2, while the mean scores for the negative perceptions of mother and father subscales were higher at Time 1.

Marital Conflict Scale. The young people rated their parents' total conflict with a higher mean score at Time 1 than at Time 2. The subscales of emotional conflict and verbal conflict ranged from six to 23 , with a mean of 13.08 (SD= 3.05) for emotional conflict and a mean of $13.50(S D=3.64)$ for verbal conflict. 
The subscale of physical conflict ranged from six to 12 and had a mean of $6.58(S D=1.26)$. It is important to highlight that only the total conflict scores were used in this study, the individual subscales were not analysed separately.

Table 9.8

Descriptive Statistics for Family Variables at Time 1 and Time 2

\begin{tabular}{lcccccc}
\hline Family Variables & $\boldsymbol{n}$ & Min. & Max. & Mean & $\begin{array}{l}\text { Std. } \\
\text { Dev. }\end{array}$ & $\begin{array}{c}\text { Cron. } \\
\text { Alpha }\end{array}$ \\
\hline $\begin{array}{l}\text { Cohesion 1 } \\
\text { (FES) }\end{array}$ & 52 & 0.00 & 9.00 & 6.96 & 2.50 & .85 \\
$\begin{array}{l}\text { Cohesion 2 } \\
\text { (FES) }\end{array}$ & 52 & 4.00 & 9.00 & 7.73 & 1.24 & .80 \\
\hline $\begin{array}{l}\text { Communication 1 } \\
\text { (FES) }\end{array}$ & 52 & 0.00 & 9.00 & 5.50 & 2.48 & .74 \\
$\begin{array}{l}\text { Communication 2 } \\
\text { (FES) }\end{array}$ & 52 & 1.00 & 9.00 & 6.60 & 1.91 & .78 \\
\hline $\begin{array}{l}\text { Positive perceptions of } \\
\text { mother 1 (POP) }\end{array}$ & 52 & 34.00 & 59.00 & 50.27 & 6.20 & .91 \\
$\begin{array}{l}\text { Positive perceptions of } \\
\text { mother 2 (POP) }\end{array}$ & 52 & 48.00 & 58.00 & 53.23 & 2.61 & .86 \\
\hline $\begin{array}{l}\text { Positive perceptions of } \\
\text { father 1 (POP) }\end{array}$ & 52 & 26.00 & 60.00 & 46.87 & 6.94 & .89 \\
$\begin{array}{l}\text { Positive perceptions of } \\
\text { father 2 (POP) }\end{array}$ & 52 & 35.00 & 58.00 & 52.23 & 4.01 & .89 \\
\hline $\begin{array}{l}\text { Negative perceptions of } \\
\text { mother 1 (POP) }\end{array}$ & 52 & 5.00 & 23.00 & 12.17 & 4.58 & .85 \\
$\begin{array}{l}\text { Negative perceptions of } \\
\text { mother 2 (POP) }\end{array}$ & 52 & 6.00 & 16.00 & 9.40 & 2.41 & .85 \\
\hline $\begin{array}{l}\text { Negative perceptions of } \\
\text { father 1 (POP) }\end{array}$ & 52 & 6.00 & 24.00 & 12.48 & 4.07 & .77 \\
$\begin{array}{l}\text { Negative perceptions of } \\
\text { father 2 (POP) }\end{array}$ & 52 & 6.00 & 19.00 & 9.77 & 6.62 & .80 \\
\hline $\begin{array}{l}\text { Total conflict 1 } \\
\text { (Marital Conflict) }\end{array}$ & 52 & 20.00 & 52.00 & 33.15 & 6.85 & .90 \\
$\begin{array}{l}\text { Total conflict 2 } \\
\text { (Marital Conflict) }\end{array}$ & 52 & 21.00 & 37.00 & 28.75 & 3.37 & .89 \\
\hline
\end{tabular}

\subsubsection{Family dynamics: The groups}

The means for the family dynamics variables for the ESG and the LSG are displayed in Table 9.9. The ESG had a lower mean score at Time 1 for all of the positive family variables: cohesion, communication, positive perceptions of mother and positive perceptions of father. The ESG also had a higher mean 
score at Time 1 for all the negative variables: negative perceptions of mother, negative perceptions of father, and total conflict. This pattern is also evident when comparing the Time 2 variables, although the difference between the mean scores of the ESG and the LSG is not so apparent.

Table 9.9

Means for Family Variables for the Early-Stage Separation Group and the Later-Stage Separation Group

\begin{tabular}{|c|c|c|c|c|}
\hline Family Variables & & $\begin{array}{c}\text { Total } \\
\text { Sample } \\
(n=52)\end{array}$ & $\begin{array}{c}\text { Early-Stage } \\
\text { Separation } \\
\text { Group } \\
(n=23)\end{array}$ & $\begin{array}{c}\text { Later-Stage } \\
\text { Separation } \\
\text { Group } \\
(n=29)\end{array}$ \\
\hline \multirow{2}{*}{$\begin{array}{l}\text { Cohesion } 1 \\
(9 \text { items, range 0-9) } \\
\text { Cohesion } 2 \\
(9 \text { items, range 0-9) }\end{array}$} & Mean & $6.96(2.50)$ & $5.65(2.93)$ & $8.00(1.44)$ \\
\hline & Mean & $7.73(1.24)$ & $7.43(1.20)$ & $7.97(1.24)$ \\
\hline \multirow{2}{*}{$\begin{array}{l}\text { Communication } 1 \\
(9 \text { items, range } 0-9) \\
\text { Communication } 2 \\
(9 \text { items, range } 0-9)\end{array}$} & Mean & $5.50(2.48)$ & $4.17(2.27)$ & $6.55(2.13)$ \\
\hline & Mean & $6.60(1.91)$ & $6.22(2.04)$ & $6.90(1.78)$ \\
\hline \multirow{2}{*}{$\begin{array}{l}\text { Positive mother } 1 \\
(10 \text { items, range } 10-60) \\
\text { Positive mother } 2 \\
(10 \text { items, range } 10-60)\end{array}$} & Mean & $50.27(6.20)$ & $46.17(5.69)$ & $53.52(4.46)$ \\
\hline & Mean & $53.23(2.61)$ & $52.70(3.02)$ & $53.66(2.19)$ \\
\hline \multirow{2}{*}{$\begin{array}{l}\text { Positive father } \mathbf{1} \\
\text { (10 items, range } 10-60) \\
\text { Positive father } \mathbf{2} \\
(10 \text { items, range } 10-60)\end{array}$} & Mean & $46.87(6.94)$ & $43.43(5.50)$ & $49.59(6.83)$ \\
\hline & Mean & $52.23(4.01)$ & $51.17(4.76)$ & $53.07(3.13)$ \\
\hline \multirow{2}{*}{$\begin{array}{l}\text { Negative mother } 1 \\
(5 \text { items, range } 5-30) \\
\text { Negative mother } 2 \\
(5 \text { items, range } 5-30)\end{array}$} & Mean & $12.17(4.58)$ & $15.30(3.87)$ & $9.69(3.47)$ \\
\hline & Mean & $9.40(2.41)$ & $9.91(2.79)$ & $9.00(2.02)$ \\
\hline \multirow{2}{*}{$\begin{array}{l}\text { Negative father } 1 \\
(5 \text { items, range } 5-30) \\
\text { Negative father } 2 \\
(5 \text { items, range } 5-30)\end{array}$} & Mean & $12.48(4.07)$ & 14.48 (3.89) & $10.90(3.51)$ \\
\hline & Mean & 9.77 (6.62) & $10.39(3.14)$ & $9.28(2.03)$ \\
\hline \multirow{2}{*}{$\begin{array}{l}\text { Total conflict } 1 \\
\text { (18 items, range 18-72) } \\
\text { Total conflict } 2 \\
\text { (18 items, range } 18-72)\end{array}$} & Mean & $33.15(6.85)$ & $37.70(6.30)$ & $29.55(4.90)$ \\
\hline & Mean & $28.75(3.37)$ & $29.65(3.38)$ & $28.03(3.23)$ \\
\hline
\end{tabular}

Note: $(\quad)$ = Standard deviation

\subsubsection{Perceptions of control: The variables}

Locus of Control Scale. In this study stronger Cronbach alpha coefficients were achieved for the three subscales at Time 1 and Time 2, compared to the 
values reported by Connell (1985). Refer to Table 9.10 for the descriptive statistics and reliability scores. The first Locus of Control subscale, unknown control over events, and the second subscale, external control over events, both had higher mean scores at Time 1. In comparison the internal control over events subscale had a lower mean score at Time 1.

Table 9.10

Descriptive Statistics for Locus of Control Variables at Time 1 and Time 2

\begin{tabular}{lcccccc}
\hline Variables & $\boldsymbol{n}$ & Min. & Max. & Mean & $\begin{array}{l}\text { Std. } \\
\text { Dev. }\end{array}$ & $\begin{array}{c}\text { Cron. } \\
\text { Alpha }\end{array}$ \\
\hline $\begin{array}{l}\text { Unknown control 1 } \\
\text { (LOC) }\end{array}$ & 52 & 5.00 & 16.00 & 10.21 & 3.43 & .91 \\
$\begin{array}{l}\text { Unknown control 2 } \\
\text { (LOC) }\end{array}$ & 52 & 4.00 & 13.00 & 8.67 & 2.21 & .87 \\
\hline $\begin{array}{l}\text { External control 1 } \\
\text { (LOC) }\end{array}$ & 52 & 6.00 & 16.00 & 10.60 & 3.09 & .89 \\
$\begin{array}{l}\text { External control 2 } \\
\text { (LOC) }\end{array}$ & 52 & 4.00 & 15.00 & 8.96 & 2.34 & .87 \\
\hline $\begin{array}{l}\text { Internal control 1 } \\
\text { (LOC) }\end{array}$ & 52 & 6.00 & 16.00 & 10.58 & 2.40 & .77 \\
$\begin{array}{l}\text { Internal control 2 } \\
\text { (LOC) }\end{array}$ & 52 & 8.00 & 15.00 & 11.88 & 1.97 & .76 \\
\hline
\end{tabular}

\subsubsection{Perceptions of control: The groups}

The means for the control variables for the ESG and the LSG are displayed in Table 9.11. Differences in Locus of Control scores are frequently reported amongst younger and older children (Duke \& Lancaster 1976; Kurdek \& Siesky, 1980; Connell, 1985). Therefore, the mean scores of the children and adolescents were also analysed and reported in Table 9.12.

The ESG had a higher mean score at Time 1 for the unknown control over events variable and the external control over events variable. For the internal control over events variable the ESG had a lower mean score at Time 1. A similar pattern exists for the Time 2 variables; however, the difference between the mean scores of the ESG and the LSG is comparatively small. 
Table 9.11

Means for Locus of Control Variables for the Early-Stage Separation Group and the Later-Stage Separation Group

\begin{tabular}{lcccc}
\hline Variables & & $\begin{array}{c}\text { Total } \\
\text { Sample } \\
(\boldsymbol{n}=\mathbf{5 2})\end{array}$ & $\begin{array}{c}\text { Early-Stage } \\
\text { Separation } \\
\text { Group } \\
(\boldsymbol{n}=\mathbf{2 3})\end{array}$ & $\begin{array}{c}\text { Later-Stage } \\
\text { Separation } \\
\text { Group } \\
(\boldsymbol{n}=\mathbf{2 9})\end{array}$ \\
\hline $\begin{array}{l}\text { Unknown control 1 } \\
\begin{array}{l}4 \text { items, range 4-16) } \\
\text { Unknown control 2 }\end{array}\end{array}$ & Mean & $10.21(3.43)$ & $12.91(2.35)$ & $8.07(2.51)$ \\
\begin{tabular}{l}
$(4$ items, range 4-16) \\
\hline $\begin{array}{l}\text { External control 1 } \\
(4 \text { items, range 4-16) }\end{array}$
\end{tabular} & Mean & $8.67(2.21)$ & $9.30(2.24)$ & $8.17(2.09)$ \\
$\begin{array}{l}\text { External control 2 } \\
(4 \text { items, range 4-16) }\end{array}$ & Mean & $10.60(3.09)$ & $12.70(2.08)$ & $8.93(2.74)$ \\
\hline $\begin{array}{l}\text { Internal control 1 } \\
(4 \text { items, range 4-16) }\end{array}$ & Mean & $10.58(2.40)$ & $9.43(1.50)$ & $8.59(2.81)$ \\
$\begin{array}{l}\text { Internal control 2 } \\
(4 \text { items, range 4-16) }\end{array}$ & Mean & $11.88(1.97)$ & $11.65(2.14)$ & $12.07(1.83)$ \\
\hline
\end{tabular}

Note: $(\quad)$ = Standard deviation

Table 9.12

Means for Locus of Control Variables for the Child Age Group and the Adolescent Age Group

\begin{tabular}{lcccc}
\hline Variables & & $\begin{array}{c}\text { Total } \\
\text { Sample } \\
(\boldsymbol{n}=52)\end{array}$ & $\begin{array}{c}\text { Child Age } \\
\text { Group } \\
(\boldsymbol{n}=\mathbf{2 7})\end{array}$ & $\begin{array}{c}\text { Adolescent } \\
\text { Age Group } \\
(\boldsymbol{n}=\mathbf{2 5})\end{array}$ \\
\hline $\begin{array}{l}\text { Unknown control 1 } \\
(4 \text { items, range 4-16) }\end{array}$ & Mean & $10.21(3.43)$ & $11.15(3.47)$ & $9.20(3.14)$ \\
$\begin{array}{l}\text { Unknown control 2 } \\
(4 \text { items, range 4-16) }\end{array}$ & Mean & $8.67(2.21)$ & $10.00(1.73)$ & $7.24(1.74)$ \\
\hline $\begin{array}{l}\text { External control 1 } \\
(4 \text { items, range 4-16) }\end{array}$ & Mean & $10.60(3.09)$ & $11.22(3.09)$ & $9.92(3.00)$ \\
$\begin{array}{l}\text { External control 2 } \\
(4 \text { items, range 4-16) }\end{array}$ & Mean & $8.96(2.34)$ & $10.11(2.21)$ & $7.72(1.81)$ \\
\hline $\begin{array}{l}\text { Internal control 1 } \\
(4 \text { items, range 4-16) }\end{array}$ & Mean & $10.58(2.40)$ & $9.89(2.44)$ & $11.32(2.15)$ \\
$\begin{array}{l}\text { Internal control 2 } \\
(4 \text { items, range 4-16) }\end{array}$ & Mean & $11.88(1.97)$ & $10.67(4.57)$ & $13.20(1.44)$ \\
\hline
\end{tabular}

Note: $(\quad)$ = Standard deviation 
The child age group participants had a higher mean score at Time 1 and Time 2 for the unknown control over events variable and the external control over events variable. In comparison the children's mean scores for the internal control over events variable at Time 1 and Time 2 were much lower than the adolescents' mean scores.

\subsection{Relationships Among Variables}

Pearson product-moment correlation analyses were carried out in order to explore the inter-relationships among variables that were in the individual outcomes category and/or the family outcomes category. Before the analyses were carried out the data were examined and found to meet the assumptions of normality, linearity and homoscedasticity. The Bonferroni correction was the approach used for multiple tests. Regression analyses are not reported here, because a number of assumptions about the data were violated. In particular the sample size in relation to the number of predictor variables made it difficult for the results to be repeated, and consequently offered limited scientific value.

\subsubsection{Correlations between family and individual variables}

A cross-lagged correlation design was employed to explore the interrelationships among the family dynamics variables and the individual wellbeing variables over the two time periods. Most importantly, the aim of these analyses was to provide insight into the individual outcomes and the family variables that were related to them. The inter-relationships that were examined were: perception of parents and dysphoria; perception of parents and behaviour; parental conflict and dysphoria; and family environment and feelings. The correlations between all the individual and family variables at Time 1 and Time 2 can be found in Table 9.13 and Table 9.14.

Perception of parents and dysphoria. The impact of the mother/child relationship and the father/child relationship on dysphoria was explored. The young people's positive perceptions of their mother at Time 1 were significantly correlated with dysphoria at Time $2, r=-.421, p<.05$; while dysphoria at Time 1 was significantly correlated with positive perceptions of 
Table 9.13

Pearson Product-Moment Correlations between Measures of Individual Wellbeing (Time 1) and Family Dynamics (Time 1 \& 2)

\begin{tabular}{|c|c|c|c|c|c|c|c|c|c|}
\hline $\begin{array}{l}\text { INDIV. VARIABLES } \\
\text { FAM. VARIABLES }\end{array}$ & POS 1 & Pos. feel 1 & Neg. feel 1 & Prosocial 1 & Hyper. 1 & Int. 1 & Ext.1 & Peer prob. 1 & Dysphoria 1 \\
\hline Cohesion 1 & $.487^{\star \star}$ & $.574^{\star \star}$ & $-.528^{\star \star}$ & .087 & -.182 & $-.556^{\star \star}$ & $-.300^{\star}$ & -.184 & -.259 \\
\hline Cohesion 2 & .162 & .222 & -.218 & -.115 & -.118 & -.237 & -.246 & .016 & -.018 \\
\hline Comm. 1 & $.448^{* *}$ & $.581^{* *}$ & $-.643^{\star \star}$ & .136 & -.215 & $-.540^{* *}$ & $-.403^{\star \star}$ & .021 & $-.332^{*}$ \\
\hline Comm. 2 & $.297^{*}$ & $.407^{\star \star}$ & $-.419^{\star \star}$ & .046 & -.153 & $-.375^{\star \star}$ & -.163 & .027 & -.261 \\
\hline Pos. mother 1 & $.705^{\star \star}$ & $.744^{\star \star}$ & $-.731^{\star *}$ & $.347^{*}$ & -.139 & $-.522^{\star \star}$ & $-.376^{\star \star}$ & -.196 & $-.621^{\star *}$ \\
\hline Pos. mother 2 & $.384^{*}$ & $.371^{\star *}$ & $-.410^{* \star}$ & .180 & -.066 & $-.339^{\star}$ & $-.363^{\star \star}$ & -.080 & $-.443^{\star *}$ \\
\hline Pos. father 1 & $.459^{\star *}$ & $.501^{\star \star}$ & $-.330^{\star}$ & .007 & .127 & $-.324^{*}$ & -.236 & -.110 & $-.411^{* *}$ \\
\hline Pos. father 2 & $.340^{*}$ & $.463^{\star *}$ & $-.347^{\star}$ & .158 & .101 & -.194 & -.138 & -.161 & $-.288^{\star}$ \\
\hline Neg. mother 1 & $-.629 * *$ & $-.574^{\star *}$ & $.723^{\star \star}$ & -.237 & .208 & $.538^{\star \star}$ & $.538^{\star *}$ & .139 & $.606^{\star *}$ \\
\hline Neg. mother 2 & $-.430^{\star \star}$ & $-.298^{*}$ & $.396^{\star *}$ & -.195 & .085 & .272 & $.339^{*}$ & .153 & $.462^{\star \star}$ \\
\hline Neg. father 1 & $-.392^{* *}$ & $-.538^{\star *}$ & $.582^{\star \star}$ & -.088 & .199 & $.596^{\star \star}$ & $.416^{\star \star}$ & .158 & $.485^{\star \star}$ \\
\hline Neg. father 2 & -.223 & $-.421^{\star *}$ & $.407^{\star \star}$ & -.026 & .121 & $.396^{\star \star}$ & .133 & .179 & .265 \\
\hline Conflict 1 & $-.493^{\star \star}$ & $-.789^{\star *}$ & $.719^{\star *}$ & $-.326^{\star}$ & .147 & $.709^{\star \star}$ & $.529 * \star$ & .203 & $.414^{\star *}$ \\
\hline Conflict 2 & $-.369^{\star *}$ & $-.547^{\star \star}$ & $.440^{\star *}$ & -.270 & .028 & $.452^{\star \star}$ & $.322^{*}$ & .085 & .259 \\
\hline
\end{tabular}

Note: * $p<0.05 ;{ }^{* *} p<0.01$, (two tailed tests) 
Table 9.14

Pearson Product-Moment Correlations between Measures of Individual Wellbeing (Time 2) and Family Dynamics (Time 1 \& 2)

\begin{tabular}{|c|c|c|c|c|c|c|c|c|c|}
\hline INDIV. VARIABLES & POS 2 & Pos. feel 2 & Neg. feel 2 & Prosocial 2 & Hyper. 2 & Int. 2 & Ext. 2 & Peer prob. 2 & Dysphoria 2 \\
\hline FAM. VARIABLES & & & & & & & & & \\
\hline Cohesion 1 & .245 & $.448^{\star *}$ & $-.360^{\star \star}$ & .076 & -.043 & $-.298^{*}$ & -.198 & -.058 & -.160 \\
\hline Cohesion 2 & .072 & .183 & -.246 & .063 & -.017 & -.272 & -.229 & -.133 & -.037 \\
\hline Comm. 1 & .078 & $.412^{* *}$ & $-.387^{\star *}$ & .130 & -.039 & $-.322^{*}$ & -.207 & .186 & -.234 \\
\hline Comm. 2 & .169 & $.459^{\star *}$ & -.270 & $.274^{*}$ & -.118 & -.139 & -.200 & .060 & -.237 \\
\hline Pos. mother 1 & $.441^{\star \star}$ & $.417^{\star \star}$ & $-.390^{\star *}$ & .239 & -.164 & -.170 & -.227 & -.058 & $-.421^{*}$ \\
\hline Pos. mother 2 & $.325^{\star}$ & $.326^{*}$ & $-.424^{\star \star}$ & .264 & -.141 & -.156 & $-.406^{\star *}$ & -.104 & $-.357^{*}$ \\
\hline Pos. father 1 & .169 & .172 & .101 & .098 & .167 & .026 & -.095 & -.237 & -.269 \\
\hline Pos. father 2 & .117 & $.483^{\star \star}$ & -.152 & .062 & .054 & -.037 & -.049 & -.240 & -.170 \\
\hline Neg. mother 1 & $-.281^{*}$ & -.227 & $.353^{*}$ & $-.346^{*}$ & .198 & .204 & .266 & .108 & $.540^{\star \star}$ \\
\hline Neg. mother 2 & -.181 & -.110 & $.304^{*}$ & $-.295^{\star}$ & .112 & .029 & $.304^{*}$ & .048 & $.455^{\star \star}$ \\
\hline Neg. father 1 & -.039 & $-.290 *$ & .084 & -.239 & .042 & .266 & .115 & $.281^{*}$ & $.491^{\star *}$ \\
\hline Neg. father 2 & .047 & $-.442^{* *}$ & .152 & .022 & .037 & .238 & -.025 & $.292^{*}$ & $.283^{*}$ \\
\hline Conflict 1 & -.192 & $-.459^{* *}$ & $.447^{\star \star}$ & $-.279^{*}$ & -.041 & $.415^{\star \star}$ & .222 & .095 & $.320^{\star}$ \\
\hline Conflict 2 & -.170 & $-.227^{*}$ & $.448^{* *}$ & $-.317^{*}$ & -.047 & .244 & .223 & .146 & .178 \\
\hline
\end{tabular}

Note: * $p<0.05 ;{ }^{* *} p<0.01$, (two tailed tests) 
mother at Time 2, $r=-.443, p<.01$. These correlations were similar in strength. Thus, the mother/child relationship was impacting on the young people's dysphoria across time, and their dysphoria was impacting on the mother/child relationship. In comparison the young people's positive perceptions of their father at Time 1 was not significantly correlated with dysphoria at Time 2, but their dysphoria at Time 1 was significantly correlated with positive perceptions of father at Time 2, $r=-.288, p<.05$. This suggests that the young people's dysphoria was having an impact on their positive father/child relationship across time; their positive father/child relationship at Time 1 was not impacting on their dysphoria at Time 2.

Also of interest was the participants negative perceptions of their parents. The young people's negative perceptions of their mother at Time 1 was significantly correlated with their dysphoria at Time $2, r=.540, p<.01$; while their state of dysphoria at Time 1 was significantly correlated with the negative perceptions of their mother at Time 2, $r=.462,(p<.01)$. Therefore, both Time 1 variables were having an impact at Time 2. In comparison, the young people's negative perceptions of their father at Time 1 was significantly correlated with the young people's dysphoria at Time $2, r=.491, p<.01$; but their dysphoria at Time 1 was not significantly correlated with their negative perceptions of their father at Time 2. This suggests that the negative father/child relationship was impacting on the young people's dysphoria over time, but not vice versa.

\section{Perception of parents and behaviour. The impact of the mother/child} relationship and the father/child relationship on the young people's behaviour was examined using the five subscales of the Strengths and Difficulties scale. The young people's positive perceptions of their mother at Time 1 were not significantly correlated with their pro-social behaviour at Time 2; neither was their pro-social behaviour at Time 1 and their positive perceptions of their mother at Time 2 correlated. This was similarly the case for the positive perceptions of father variable and the negative perceptions of father variable. However, the negative perceptions of mother at Time 1 variable was significantly correlated with the young people's pro-social behaviour at Time $2, r=-.346, p<.05$; while their pro-social behaviour at Time 1 was not 
significantly correlated with their negative perceptions of mother at Time 2 . This suggests that the negative mother/child relationship was impacting on the young people's pro-social behaviour over time.

The participants' positive perceptions of their mother at Time 1 was not significantly correlated with their internalising behaviour at Time 2; although their internalising behaviour at Time 1 was significantly correlated with their positive perceptions of their mother at Time 2, $r=-.339, p<.05$. Another finding of interest was that the young people's internalising behaviour at Time 1 was significantly correlated with their negative perceptions of father at Time 2, $r=$ .396, $p<.01$. This suggests that the young people's internalising behaviour was impacting on their positive mother/child relationship and on their negative father/child relationship across time.

The young people's positive perceptions of their mother at Time 1 was not significantly correlated with their externalising behaviour at Time 2 , but their externalising behaviour at Time 1 was correlated with their positive perceptions of mother at Time $2, r=-.363, p<.01$. Similarly the young people's externalising behaviour at Time 1 was significantly correlated with their negative perceptions of mother at Time $2, r=.339, p<.05$. There were no significant cross lag correlations between externalising behaviour and positive and negative perceptions of father. It appears that the young people's externalising behaviour was impacting on the positive and negative mother/child relationship, but not the father/child relationship.

The only perception of parents and peer relationship problems cross-lag comparisons that were significant were the negative perceptions of father at Time 1 and the peer relationship problems at Time 2 correlation, $r=.281$, $p<.05$. This suggests that the negative father/child relationship was impacting on the young people's peer relationship problems over time. There were no significant cross-lagged correlations between the Strengths and Difficulties hyperactivity subscale and the perceptions of mother variables or the perception of father variables. 
Parental conflict and dysphoria. The impact of parental conflict on young people's dysphoria was explored. Parental conflict at Time 1 was significantly correlated with participants' dysphoria at Time 2, $r=.320, p<.05$; but participants' dysphoria at Time 1 was not significantly correlated with parental conflict at Time 2. This suggests that conflict between parents has an impact on young people's state of dysphoria over time.

Family environment and feelings. The impact of the family environment on young people's feelings was examined. Family cohesion at Time 1 was significantly correlated with participants' positive feelings at Time $2, r=.448$, $p<.01$, and with participants' negative feelings at Time $2, r=-.360, p<.01$. Both participants' positive feelings at Time 1 and participants' negative feelings at Time 1 were not significantly correlated with family cohesion at Time 2 . These correlations imply that family cohesion has an impact on young people's negative and positive feelings across time.

With regard to the second family environment subscale, there was a significant correlation between family communication at Time 1 and participants' positive feelings at Time $2, r=.412, p<.01$; but there was no relationship between participants' positive feelings at Time 1 and their family communication at Time 2. This suggests that family communication was impacting on the young people's positive feelings across time. In terms of the young people's negative feelings, there was a significant correlation between family communication at Time 1 and negative feelings at Time $2, r=-.387$, $p<.01$, and between negative feelings at Time 1 and family communication at Time $2, r=-.419, p<.01$. Therefore, across time family communication was impacting on the young people's negative feelings and their negative feelings were impacting on their family communication.

\subsubsection{Correlations between family variables}

A cross-lagged correlation design was also employed to investigate the interrelationships among the family dynamic variables over the two time periods. The family inter-relationships that were examined were: parental conflict and perception of parents; parental conflict and family environment; and family 
environment and perceptions of parents. The correlations between all the family variables at Time 1 and Time 2 are displayed in Table 9.15.

Parental conflict and perception of parents. The association between parental conflict and the mother/child relationship was investigated, as was parental conflict and the father/child relationship. Parental conflict at Time 1 was significantly correlated with the young people's positive perceptions of their mother at Time 2, $r=-.346, p<.05$; while their positive perceptions of their mother at Time 1 were significantly correlated with parental conflict at Time 2, $r=-.541, p<.01$. Similarly, there was a significant bi-directional correlation between parental conflict and positive perceptions of father. This suggests that parental conflict was impacting on the positive mother/child relationship and on the positive father/child relationship over time, and that these positive relationships were also impacting on parental conflict across time.

There was no significant correlation between parental conflict at Time 1 and negative perceptions of mother at Time 2, but young people's negative perceptions of mother at Time 1 were significantly correlated with parental conflict at Time 2, $r=.388, p<.01$. This implies that the negative mother/child relationship was impacting on parental conflict across time. There was a significant correlation between parental conflict at Time 1 and negative perceptions of father at Time $2, r=.308, p<.05$, and between the negative perceptions of father at Time 1 and parental conflict at Time 2, $r=.356, p<.01$. This implies that parental conflict was impacting on the negative father/child relationship across time and vice versa.

Parental conflict and family environment. The relationship between parental conflict and the family cohesion and communication was investigated. Parental conflict at Time 1 was not significantly correlated with family cohesion at Time 2; however family cohesion at Time 1 was significantly correlated with parental conflict at Time $2, r=-.484, p<.01$. Similarly, parental conflict at Time 1 was not significantly correlated with family communication at Time 2, but family communication at Time 1 was significantly correlated with parental conflict at Time $2, r=-.408, p<.01$. This suggests that family cohesion 
Table 9.15

Pearson Product-Moment Correlations between Family Variables at Time 1 and Time 2

\begin{tabular}{|l|c|c|c|c|c|c|c|}
\hline FAMILY T2 & Cohesion 2 & Comm. 2 & Pos. mother 2 & Pos. father 2 & Neg. mother 2 & Neg. father 2 & Conflict 2 \\
\hline FAMILY T1 & $.478^{* *}$ & $.424^{* *}$ & $.363^{* *}$ & $.342^{*}$ & $-.339^{*}$ & $-.395^{* *}$ & $-.484^{* *}$ \\
\hline Cohesion 1 & $.339^{*}$ & $.499^{* *}$ & $.349^{*}$ & $.381^{* *}$ & $-.356^{* *}$ & $-.354^{*}$ & $-.408^{* *}$ \\
\hline Pos. mother 1 & .132 & $.406^{* *}$ & $.558^{* *}$ & $.470^{* *}$ & $-.432^{* *}$ & -.221 & $-.541^{* *}$ \\
\hline Pos. father 1 & -.011 & .228 & .230 & $.608^{* *}$ & -.067 & $-.463^{* *}$ & $-.353^{*}$ \\
\hline Neg. mother 1 & -.216 & -.265 & $-.384^{* *}$ & $-.311^{*}$ & $.731^{* *}$ & .205 & $.388^{* *}$ \\
\hline Neg. father 1 & -.204 & $-.307^{*}$ & -.225 & $-.511^{* *}$ & $.416^{* *}$ & $.683^{* *}$ & $.356^{* *}$ \\
\hline Conflict 1 & -.261 & -.255 & $-.346^{*}$ & $-.325^{*}$ & .257 & $.308^{*}$ & $.738^{* *}$ \\
\hline
\end{tabular}

Note: ${ }^{*} p<0.05 ;{ }^{* *} p<0.01$, (two tailed tests) 
and family communication were both having an impact on parental conflict over time.

Family environment and perception of parents. The association between family cohesion and communication and the mother/child and father/child relationships was examined. The young people's family cohesion at Time 1 was significantly correlated with their positive perceptions of their mother at Time 2, $r=.363, p<.01$, and their positive perceptions of their father at Time 2, $r=.342, p<05$. Family cohesion at Time 1 was also significantly correlated with their negative perceptions of their mother at Time 2, $r=-.339, p<.05$, and their negative perceptions of their father at Time 2, $r=-.395, p<.01$. The young people's positive and negative perceptions of their mother and their father at Time 1 were not significantly correlated with family cohesion at Time 2 . This suggests that family cohesion was impacting on the young people's positive and negative perceptions of both their mother and their father across time.

In terms of family expressiveness it was found that family communication at Time 1 was significantly correlated with the young people's positive perceptions of their mother at Time $2, r=.349, p<.05$; but their positive perceptions of their mother at Time 1 were also significantly correlated with family communication at Time $2, r=.406, p<.01$. This implies that family communication was impacting on the positive mother/child relationship and the mother/child relationship was impacting on family communication across time. In terms of the father/child relationship, family communication at Time 1 was significantly correlated with the participants positive perceptions of their father at Time 2, $r=.381, p<.01$, but positive perceptions of their father at Time 1 was not significantly correlated with family communication at Time 2. Thus, family communication was impacting on the positive father/child relationship across time, but not vice versa.

Family communication at Time 1 was significantly correlated with the young people's negative perceptions of mother at Time 2, $r=-.356, p<.01$; their negative perceptions of their mother at Time 1 were not significantly correlated with family communication at Time 2 . Thus, family communication 
was impacting on the negative mother/child relationship across time, but not the other way around. Communication at Time 1 was significantly correlated with participants' negative perceptions of their father at Time $2, r=-.354, p<.5$, and negative perceptions of their father at Time 1 was significantly correlated with family communication at Time $2, r=-.307, p<.05$. This suggests that family communication was impacting on the negative father/child relationship over time, and vice versa.

\subsubsection{Correlations between individual variables}

A cross-lagged correlation design was employed to explore the interrelationships among the individual wellbeing variables over the two time periods. The individual inter-relationships that were examined were: dysphoria and feelings; and dysphoria and behaviours. The correlations between all the individual outcomes at Time 1 and Time 2 are displayed in Table 9.16.

Dysphoria and feelings. The relationship between young people's dysphoria and their positive and negative feelings was examined. Young people's dysphoria at Time 1 was not significantly correlated with their positive feelings at Time 2; although their positive feelings at Time 1 were significantly correlated with their dysphoria at Time $2, r=-.448, p<.01$. This suggests that young people's positive feelings were impacting on their state of dysphoria across time, but not vice versa. Similarly, young people's dysphoria at Time 1 was not significantly correlated with their negative feelings at Time 2 , but their negative feelings at Time 1 were significantly correlated with their dysphoria at Time 2, $r=.472, p<.01$. This implies that across time the young people's negative feelings were having an impact on their state of dysphoria, but their state of dysphoria was not impacting on their negative feelings.

Dysphoria and behaviours. The relationship between young people's dysphoria and their pro-social behaviour, hyperactivity, internalising behaviour, externalising, and peer relationship problems was examined. Young people's dysphoria at Time 1 was not significantly correlated with their internalising behaviour or their externalising behaviour at Time 2. However, young people's internalising behaviour at Time 1 was significantly correlated 
Table 9.16

Pearson Product-Moment Correlations between Individual Wellbeing Variables at Time 1 and Time 2

\begin{tabular}{|c|c|c|c|c|c|c|c|c|c|}
\hline INDIVIDUAL T2 & POS 2 & Pos. feel 2 & Neq. feel 2 & Prosocial 2 & Hvper. 2 & Int. 2 & Ext. 2 & Peer prob. 2 & Dysphoria 2 \\
\hline INDIVIDUAL T1 & & & & & & & & & \\
\hline POS 1 & $.659^{* *}$ & .254 & -.191 & .121 & -.130 & -.111 & -.122 & -.113 & $-.471^{* *}$ \\
\hline Pos. feel 1 & $.273^{*}$ & $.580^{* *}$ & $-.350^{*}$ & .202 & -.064 & $-.353^{*}$ & -.242 & -.113 & $-.448^{\star \star}$ \\
\hline Neg. feel 1 & $-.288^{*}$ & $-.513^{* *}$ & $.538^{\star *}$ & $-.323^{*}$ & .186 & $.459^{* *}$ & .200 & .033 & $.472^{* *}$ \\
\hline Prosocial 1 & .132 & .133 & .005 & $.345^{\star}$ & $-.285^{*}$ & -.064 & -.199 & .013 & -.128 \\
\hline Hyper. 1 & .017 & -.006 & -.024 & -.239 & $.711^{* *}$ & .237 & .090 & -.104 & .187 \\
\hline Int. 1 & -.179 & $-.443^{\star *}$ & $.475^{\star \star}$ & $-.333^{*}$ & $.274^{*}$ & $.683^{\star \star}$ & .263 & .051 & $.406^{\star *}$ \\
\hline Ext. 1 & -.006 & -.136 & .269 & $-.285^{*}$ & .217 & $.322^{*}$ & $.563^{* *}$ & .043 & $.326^{*}$ \\
\hline Peer prob. 1 & $-.281^{*}$ & -.252 & .092 & .051 & .084 & .211 & .169 & $.538^{\star \star}$ & .194 \\
\hline Dysphoria 1 & $-.332^{*}$ & -.159 & .155 & -.220 & -.018 & .097 & .221 & .109 & $.809^{* *}$ \\
\hline
\end{tabular}

Note: ${ }^{*} p<0.05 ;{ }^{* *} p<0.01$, (two tailed tests) 
with their dysphoria at Time $2, r=.406, p<.01$, and their externalising behaviour at Time 1 was significantly correlated with their dysphoria at Time $2, r=.326, p<.05$. This suggests that the young people's internalising and externalising behaviour was impacting on their dysphoria over time. There were no significant correlations between the young people's state of dysphoria and their pro-social behaviour, hyperactivity or peer relationship problems.

\subsection{Young People's Adjustment to Parental Separation: Multivariate Analyses}

The multivariate analysis of variance (MANOVA) technique was employed to analyse young people's adjustment to parental separation. More specifically, the young people's individual wellbeing and their family dynamics were analysed. MANOVA was chosen due to its ability to protect against the Type I error that arises by chance as a result of multiple tests being carried out on individual variables (Field, 2005).

The individual wellbeing category was made up of the following dependent variables: perceptions of strength, positive feelings, negative feelings, prosocial behaviours, hyperactivity, internalising, externalising, peer problems, and dysphoria. The dependent variables that formed the family dynamics category were: family cohesion, family communication, positive perceptions of mother, positive perceptions of father, negative perceptions of mother, negative perceptions of father, and parental conflict. Some comparisons were made between the early-stage separation group (ESG) and the later-stage separation group (LSG), and the child participants and the adolescent participants. Where relevant, univariate analyses provided insight into which variables contributed to the significance. It was not necessary to carry out post hoc tests because only two groups were involved in each comparison (Hair, Black, Babin, Anderson \& Tatham, 2006).

Ten research questions were devised, two of which explored the main effects for time, four of the research questions focused on interaction effects for time and the groups, and the final four questions investigated the main effects for 
the groups. If there is a significant interaction then the interaction should be reported before the main effects, for the reason that the interaction influences how the effect of each independent variable is interpreted (Tabachnick \& Fidell, 2007; Hair et al., 2006). Thus, the interaction effects are reported first, followed by the main effects for time and then the main effects for the group. The interaction and main effects questions and results can be found in sections 9.7.1, 9.7.2 and 9.7.3.

Before the MANOVA analyses were carried out the individual wellbeing data were examined and found to meet the assumptions of normality, linearity and multicollinearity. The data were also examined for univariate and multivariate outliers $(p<.001)$ and homogeneity of variance-covariance matrices. There were no violations of these assumptions. The groups were comparable in size and there was no missing data.

The family dynamics data were also assessed for its ability to meet the assumptions for MANOVA. There were some violations of the assumptions, including breaches of normality and the homogeneity of variance-covariance matrices. Two of the assumptions that were met were the no missing data criterion and the groups being similar in size criterion. Tabachnick and Fidell (2007) commented that if there are relatively equal sample sizes in groups and at least 20 degrees of freedom for error, the $F$ test is more robust to violations of normality of variables. This is because, irrespective of the distributions of variables, the sampling distributions of means are normally distributed on account of the Central Limit Theorem. In this moderately sized sample there were more cases in each cell than the number of dependent variables, making it more robust to violations of normality. Also, there were no major concerns with the distributions for the majority of the family dynamics variables.

The few variables that were deemed to be not normally distributed included: family cohesion at Time 1 and Time 2 (both LSG), positive perceptions of mother at Time 1 (LSG), which were all moderately negatively skewed and peaked. Also violating the assumption of normality were the negative 
perceptions of mother at Time 1 and Time 2 (both LSG), which were moderately positively skewed and peaked.

The homogeneity of variance-covariance matrices assumption was examined using Box's M Test of Equality of Covariance Matrices for the family dynamics variables that were repeatedly measured (the interaction effect and the main effect for time). The assumption was violated $(p=.000)$. Levene's Test of Equality of Error Variances tested the assumption of equality of variance for each variable. The following variables violated this assumption: family cohesion at Time $1(p=.000)$, positive perceptions of mother at Time $1(p=$ $.039)$, and negative perceptions of mother at Time $2(p=.013)$.

The homogeneity of variance-covariance matrices assumption was also violated for the family dynamics variables that were measured at the two separate time points and compared across the groups (main effect for the groups). The Box's M for the family dynamics variables at Time 1 for the ESG versus the LSG was $p=.008$. Family cohesion at Time 1 and positive perceptions of mother at Time 1 both violated the assumption of Levene's Test of Equality of Error Variances ( $p=.000 \& p=.039$, respectively). The Box's $M$ for the family dynamics variables at Time 2 for the ESG versus the LSG was $p=.004$. The negative perceptions of mother at Time 2 variable violated Levene's assumption of equality of variance $(p=.013)$.

Even though Tabachnick and Fidell (2007) identified that the assumption of normality is evaluated with respect to the sampling distribution of means and that in adequately sized samples the Central Limit Theorem predicts normality, they also recognised that transformations may improve the analysis and should therefore be carried out. Accordingly, the decision was made to transform the offending variables at Time 1 and Time 2 in order to improve normality.

The positive and negative perceptions of mother and father variables, from the POP scale, were measured on a 6-point Likert scale. Scales that are sums of items measured on a Likert scale are approximately normally 
distributed because of the Central Limit Theorem. The family cohesion variable, from the Family Environment Scale (FES), comprises subscales that are sums of true/false responses. Scales of this type are generally binomially distributed and may be close to normally distributed, depending on their mean. These scales do not have equal variances in groups that have different means. It is this exact situation that a transformation called the arsine square root variance stabilising transformation was designed for (C. Kelly, personal communication, August 2, 2006). Thus, an arcsine transformation was applied to the cohesion Time 1 and Time 2 variables because of its variance stabilising abilities. This transformation was designed to correct the differences in variances rather than make the data normally distributed.

Because the statistical tests that were used on this data were more robust to the normality assumption, the main concern was the homogeneity of variances.

The positive and negative perceptions of mother variables were measured on a Likert scale, but the descriptive statistics revealed that they were behaving like a sum of true/false items. In particular, for the LSG the positive perception of mother at Time 1 mean was very close to the maximum value and the standard deviation was smaller than it was for the ESG, which had a smaller mean. The opposite scenario was found for the negative perceptions of mother at Time 1 variable. The LSG had a negative perception of mother at Time 1 mean approaching the minimum, and a smaller standard deviation compared to the ESG. Thus, even though it was not a sum of yes/no items the arsine square root transformation was also applied to this variable. Before the transformation was carried out the minimum score was subtracted and then divided by the maximum score to ensure all scores were between 0 and 1. The transformation was applied to both the Time 1 and the Time 2 variables.

The arsine square root transformations did not improve the normality of the family cohesion variables or the positive and negative perception of mother variables. Further transformations were carried out. The square root, reflect and square root, logarithm, and reflect and logarithm transformations were 
utilised. The results revealed that there was no advantage of using data transformations on these variables, given that the distributions did not improve.

The decision was made to conduct the analyses with the variables in their original state. Tabachnick and Fidell (2007) recommended that untransformed variables should have a more stringent alpha level of .025 if there is a moderate violation. Furthermore, the decision was made to follow up the parametric test results with non parametric tests in order to confirm the reliability of the analyses. The non parametric test results are reported in section 9.8 .

The interaction effects, main effects for time and the group effects are reported below. A significant interaction was found; therefore, the interaction results are reported first because these results influence how the effect of each independent variable is interpreted (Tabachnick \& Fidell, 2007).

\subsubsection{Interaction effects}

A doubly-multivariate analysis of variance repeated measures design was used to analyse the interaction of groups over time on the individual and family outcomes. The within-subjects factor referred to as the time effect (Time 1 and Time 2) was analysed multivariately to avoid the assumption of sphericity. The repeatedly measured noncommensurate dependent variables that made up the individual wellbeing variable and the family dynamics variable were also analysed in a multivariate manner. In comparison, the between subjects factor referred to as the group effect (e.g. early-stage separation group and the later-stage separation group) was analysed in a singly multivariate manner. Thus, the within-subjects effects and the interactions were "doubly multivariate"; whereas, the group effect was "singly multivariate" (Tabachnick \& Fidell, 2007).

Four research questions were employed to investigate whether there were differences between the early-stage separation participants' (1-10 months since separation) and the later-stage separation participants' (14-24 months 
since separation) individual wellbeing from Time 1 (between one month and 24 months following parental separation) to Time 2 (approximately 18 months later) and their family dynamics from Time 1 to Time 2. Comparisons were also made between the child participants' (9-13 year olds) and the adolescent participants' (14-18 year olds) individual wellbeing and family dynamics from Time 1 to Time 2 . The interaction effects for the separation groups and the age groups are reported in Table 9.17.

Table 9.17

The Doubly Repeated Measures MANOVA results for the effect of stage of separation, age and time on individual wellbeing and family dynamics from Time 1 to Time 2.

\begin{tabular}{|l|l|c|c|c|c|c|c|}
\hline \multicolumn{1}{|c|}{ Effect } & \multicolumn{1}{|c|}{$\begin{array}{c}\text { Dependent } \\
\text { Variables }\end{array}$} & $\boldsymbol{\Lambda}$ & $\boldsymbol{F}$ & $\boldsymbol{d} \boldsymbol{f}$ & $\begin{array}{c}\text { Error } \\
\boldsymbol{d f}\end{array}$ & $\boldsymbol{p}$ & $\boldsymbol{\eta}^{\mathbf{2}}$ \\
\hline $\begin{array}{l}\text { Interaction effect: } \\
\text { Time x Separation } \\
\text { Groups }\end{array}$ & Individual 1\&2 & .254 & 13.703 & 9 & 42 & .000 & .746 \\
\hline $\begin{array}{l}\text { Interaction effect: } \\
\text { Time x Age Groups }\end{array}$ & Individual 1\&2 & .930 & .349 & 9 & 42 & .953 & .070 \\
\hline $\begin{array}{l}\text { Mamily 1\&2 } \\
\text { Time }\end{array}$ & .282 & 16.022 & 7 & 44 & .000 & .718 \\
\hline
\end{tabular}

Individual wellbeing at Time 1 vs. Time 2 for early-stage group and later-stage group. Research question 11 enquired: "Is there a significant difference in the individual wellbeing from Time 1 to Time 2 for the early-stage separation participants and the later-stage separation participants?" A doubly-multivariate analysis of variance was carried out to establish whether there were differences in individual wellbeing over time for the two groups. A significant 
and strong group by time interaction was found $[F(9,42)=13.70, p=.000$; Wilks' Lambda $=.25$; partial eta squared $=.75]$.

The univariate results for the individual wellbeing variables were also analysed. There were no significant differences between the ESG and LSG pro-social behaviour, hyperactivity and peer relationship mean scores from Time 1 to Time 2 . The variables that were found to be statistically significant, using a Bonferroni adjusted level of .006, were: perception of strengths, positive feelings, negative feelings, internalising, externalising, and dysphoria (as reported in Table 9.18). For all of these significant results the ESG mean scores either increased or decreased in a manner that indicated an improved level of individual wellbeing from Time 1 to Time 2. In comparison the LSG mean scores were comparatively stable from Time 1 to Time 2 (refer to Appendix R).

Table 9.18

The univariate results for the interaction effect of time and stage of separation on individual wellbeing.

\begin{tabular}{|l|c|c|c|c|}
\hline $\begin{array}{c}\text { Dependent Variables: } \\
\text { Individual Wellbeing }\end{array}$ & $\boldsymbol{F}$ & $\boldsymbol{d f}$ & $\boldsymbol{p}$ & $\boldsymbol{\eta}^{2}$ \\
\hline Perception of Strengths 1 \& 2 & 59.945 & 1 & .000 & .545 \\
\hline Positive Feelings 1 \& 2 & 54.010 & 1 & .000 & .519 \\
\hline Negative Feelings 1 \& 2 & 52.226 & 1 & .000 & .511 \\
\hline Pro-social Behaviour 1 \& 2 & .103 & 1 & .750 & .002 \\
\hline Hyperactivity 1 \& 2 & .005 & 1 & .945 & .000 \\
\hline Internalising 1 \& 2 & 40.191 & 1 & .000 & .446 \\
\hline
\end{tabular}




\begin{tabular}{|l|c|c|c|c|}
\hline Externalising 1\&2 & 13.531 & 1 & .001 & .213 \\
\hline Peer Relationship Problems 1\&2 & 1.233 & 1 & .272 & .024 \\
\hline Dysphoria 1 \& 2 & 14.360 & 1 & .000 & .223 \\
\hline
\end{tabular}

Family dynamics at Time $1 \mathrm{vs}$. Time 2 for early-stage group and later-stage group. Research question 12 enquired: "Is there a significant difference in the family dynamics from Time 1 to Time 2 for the early-stage separation participants and the later-stage separation participants?" A doubly-multivariate analysis of variance was carried out to determine whether there were differences in family dynamics over time for the separation groups. A significant and strong group by time interaction was found $[F(7,44)=16.02, p$ $=.000 ;$ Wilks' Lambda $=.28$; partial eta squared $=.72$ ] .

The results for the individual family variables were analysed separately, and are reported in Table 9.19. All seven of the family variables were found to be statistically significant using a Bonferroni adjusted alpha level of .007. For all of these results the ESG mean scores either increased or decreased in a manner that indicated an improved level of family dynamics from Time 1 to Time 2. In comparison the LSG mean scores were comparatively stable over time. Refer to Appendix S.

\section{Individual wellbeing at Time $1 \mathrm{vs}$. Time 2 for child group and adolescent} group. Research question 13 enquired: "Is there a significant difference in the individual wellbeing from Time 1 to Time 2 for the child participants and the adolescent participants?" A doubly-multivariate analysis of variance was performed to establish whether there were differences in individual wellbeing over time for the two age groups. There was no group by time interaction [ $F$ $(9,42)=.35, p=.95 ;$ Wilks' Lambda $=.93 ;$ partial eta squared $=.07]$. 
Family dynamics at Time $1 \mathrm{vs.} \mathrm{Time} 2$ for child group and adolescent group. Research question 14 enquired: "Is there a significant difference in the family dynamics from Time 1 to Time 2 for the child participants and the adolescent participants?" A doubly-multivariate analysis of variance was carried out to ascertain whether there were differences in family dynamics over time for the age groups. There was no group by time interaction $[F(7,44)=1.30, p=.28$; Wilks' Lambda $=.83$; partial eta squared $=.17]$.

Table 9.19

The univariate results for the interaction effect of time and stage of separation on family dynamics.

\begin{tabular}{|l|c|c|c|c|}
\hline $\begin{array}{c}\text { Dependent Variables: } \\
\text { Family Dynamics }\end{array}$ & $\boldsymbol{F}$ & $\boldsymbol{d f}$ & $\boldsymbol{p}$ & $\boldsymbol{\eta}^{2}$ \\
\hline Family Cohesion 1 \& 2 & 10.438 & 1 & .002 & .173 \\
\hline Family Communication 1 \& & 8.354 & 1 & .006 & .143 \\
\hline Positive Perceptions of Mother 1 \& 2 & 30.209 & 1 & .000 & .377 \\
\hline Positive Perceptions of Father 1 \& 2 & 8.818 & 1 & .005 & .150 \\
\hline Negative Perceptions of Mother 1 \& 2 & 54.594 & 1 & .000 & .522 \\
\hline Negative Perceptions of Father 1 \& 2 & 40.191 & 1 & .000 & .446 \\
\hline Parental Conflict 1 \& 2 & 10.468 & 1 & .002 & .173 \\
\hline
\end{tabular}

\subsubsection{Main effects for time}

A doubly-multivariate analysis of variance repeated measures design was used to analyse the main effect of time on the individual and family outcomes. 
The within-subjects factor referred to as the time effect (Time 1 and Time 2) was analysed multivariately to avoid the assumption of sphericity. The repeatedly measured noncommensurate dependent variables that made up the individual wellbeing variable, and the family dynamics variable, were also analysed in a multivariate manner. Thus, the within-subjects effects and the multiple dependent variables resulted in a "doubly multivariate" design (Tabachnick \& Fidell, 2007). Two research questions were employed to investigate whether there were differences in the young people's individual wellbeing and their family dynamics from Time 1 to Time 2 . The main effects for time are reported in Table 9.17.

Individual wellbeing at Time 1 vs. Time 2. Research question 15 enquired: 'Is there a significant difference in the individual wellbeing of the young people from Time 1 to Time 2?' A doubly-multivariate analysis of variance was undertaken in order to investigate whether there were differences in individual outcomes over time. For the combined dependent variables of individual wellbeing, a significant and extremely strong effect for time was found $[F(9$, $42)=45.24, p=.000 ;$ Wilks' Lambda $=.09 ;$ partial eta squared $=.91]$.

The results for the individual wellbeing variables were analysed separately. The variables that were found to be statistically significant, using a Bonferroni adjusted alpha level of .006, were: perceptions of strength, positive feelings, negative feelings, pro-social behaviour, hyperactivity, internalising, and dysphoria (as reported in Table 9.20).

After taking the mean scores into account it is apparent that the participants at Time 2 had higher levels of perception of strengths, positive feelings, and prosocial behaviour than they did earlier in the separation (at Time 1). The participants at Time 2 also had lower levels of negative feelings, hyperactivity, internalising, and dysphoria than they did at Time 1. These results show an improved level of wellbeing over time. The non significant externalising and peer problems variables both stayed relatively stable from Time 1 to Time 2. Refer to Appendix T. 
Table 9.20

The univariate results for the main effect of time on individual wellbeing.

\begin{tabular}{|l|c|c|c|c|}
\hline $\begin{array}{c}\text { Dependent Variables: } \\
\text { Individual Wellbeing }\end{array}$ & $\boldsymbol{F}$ & $\boldsymbol{d f}$ & $\boldsymbol{p}$ & $\boldsymbol{\eta}^{2}$ \\
\hline Perception of Strengths 1 \& 2 & 33.214 & 1 & .000 & .399 \\
\hline Positive Feelings 1 \& 2 & 42.302 & 1 & .000 & .458 \\
\hline Negative Feelings 1 \& 2 & 58.740 & 1 & .000 & .540 \\
\hline Pro-social Behaviour 1\&2 & 219.035 & 1 & .000 & .814 \\
\hline Hyperactivity 1 \& 2 & 11.898 & 1 & .001 & .192 \\
\hline Internalising 1 \& 2 & 29.945 & 1 & .000 & .375 \\
\hline Externalising 1 \& 2 & 3.837 & 1 & .056 & .071 \\
\hline Deer Relationship Problems 1 \& 2 & .362 & 1 & .550 & .007 \\
\hline
\end{tabular}

Family dynamics at Time 1 vs. Time 2. Research question 16 enquired: 'Is there a significant difference in the young people's family dynamics from Time 1 to Time 2?' A doubly-multivariate analysis of variance was performed to establish whether there were differences in family dynamics over time. For the combined dependent variables of family dynamics, a significant and strong effect for time was found $[F(7,44)=35.66, p=.000$; Wilks' Lambda = .15; partial eta squared $=.85]$. 
The results for the family dynamics variables were also analysed separately. All of the family variables were found to be statistically significant using a Bonferroni adjusted alpha level of .007, and are reported in Table 9.21. After taking the mean scores into account it is apparent that the participants at Time 2 had higher levels of family cohesion, family communication, and positive perceptions of mother and father, than they did at Time 1. The young people at Time 2 also had lower levels of parental conflict, negative perceptions of mother and negative perceptions of father, than they did at Time 1. These results demonstrate an improved level of family interactions and relations over time (refer to Appendix U).

Table 9.21

The univariate results for the main effect of time on the family dynamics.

\begin{tabular}{|l|c|c|c|c|}
\hline \multicolumn{1}{|c|}{$\begin{array}{c}\text { Dependent Variables: } \\
\text { Family Dynamics }\end{array}$} & $\boldsymbol{F}$ & $\boldsymbol{d f}$ & $\boldsymbol{p}$ & $\boldsymbol{\eta}^{2}$ \\
\hline Family Cohesion 1 \& 2 & 9.661 & 1 & .003 & .162 \\
\hline Family Communication 1 \& 2 & 16.515 & 1 & .000 & .248 \\
\hline Positive Perceptions of Mother 1 \& 2 & 32.877 & 1 & .000 & .397 \\
\hline Positive Perceptions of Father 1 \& 2 & 61.294 & 1 & .000 & .551 \\
\hline Negative Perceptions of Mother 1 \& 2 & 91.325 & 1 & .000 & .646 \\
\hline Negative Perceptions of Father 1 \& 2 & 56.066 & 1 & .000 & .529 \\
\hline Parental Conflict 1 \& 2 & 84.938 & 1 & .000 & .629 \\
\hline
\end{tabular}




\subsubsection{Main effects for the early-stage and later-stage separation}

groups

A multivariate analysis of variance design was used to investigate the main effect of the two groups on the individual and family outcomes. The noncommensurate dependent variables that made up the individual wellbeing variable, and the family dynamics variable, were analysed in a multivariate manner. The between-subjects factor was the early-stage separation group and the later-stage separation group.

Four research questions were employed to establish whether there were differences between the ESGs' and the LSGs' individual wellbeing at Time 1, and also their family dynamics a Time 1 . Similarly, any differences between the two groups' individual wellbeing and family dynamics at Time 2 were explored. The main effects for the separation groups are reported in Table 9.22 .

Table 9.22

The MANOVA results for effect of stage of separation on individual wellbeing and family dynamics at Time 1 and at Time 2.

\begin{tabular}{|l|l|c|c|c|c|c|c|}
\hline \multicolumn{1}{|c|}{ Effect } & $\begin{array}{l}\text { Dependent } \\
\text { Variables }\end{array}$ & $\boldsymbol{\Lambda}$ & $\boldsymbol{F}$ & $\boldsymbol{d f}$ & $\begin{array}{c}\text { Error } \\
\boldsymbol{d f}\end{array}$ & $\boldsymbol{p}$ & $\boldsymbol{\eta}^{2}$ \\
\hline $\begin{array}{l}\text { Main effect: } \\
\text { Separation Groups }\end{array}$ & Individual 1 & .296 & 11.112 & 9 & 42 & .000 & .704 \\
\hline $\begin{array}{l}\text { Mamily 1 } \\
\text { Separation Groups }\end{array}$ & $\begin{array}{l}.432 \\
\text { Individual 2 }\end{array}$ & .787 & .1 .263 & 7 & 44 & .000 & .568 \\
\hline
\end{tabular}

Individual wellbeing for early-stage group vs. later-stage group at Time 1. Research question 17 enquired: "Is there a significant difference in the individual wellbeing of the early-stage separation participants and the later- 
stage separation participants at Time 1?" A multivariate analysis of variance was carried out in order to determine whether there were any differences in the individual outcomes of the ESG and LSG at Time 1. For the combined dependent variables of individual wellbeing, a significant and strong effect for the groups was found $[F(9,42)=11.11, p=.000$; Wilks' Lambda $=.30$; partial eta squared $=.70]$.

The univariate results for the individual wellbeing variables were also analysed. The variables that were found to be statistically significant, using a Bonferroni adjusted alpha level of .006, were: perception of strengths, positive feelings, negative feelings, internalising behaviour, externalising behaviour, and dysphoria (refer to Table 9.23). For perception of strengths and positive feelings the LSG had higher mean scores than the ESG. For negative feelings, internalising, externalising, and dysphoria, the ESG had higher mean scores than the LSG. These results show that the LSG had a higher level of individual wellbeing at Time 1 than the ESG. There were no significant differences between the groups in relation to pro-social behaviour, peer relationship problems and hyperactivity. These findings are summarised in Appendix V.

Table 9.23

The univariate results for the main effect of the stage of separation on individual wellbeing at Time 1.

\begin{tabular}{|l|c|c|c|c|}
\hline $\begin{array}{c}\text { Dependent Variables: } \\
\text { Individual Wellbeing }\end{array}$ & $\boldsymbol{F}$ & $\boldsymbol{d f}$ & $\boldsymbol{p}$ & $\boldsymbol{\eta}^{\mathbf{2}}$ \\
\hline Perception of Strengths 1 & 55.096 & 1 & .000 & .524 \\
\hline Positive Feelings 1 & 43.825 & 1 & .000 & .467 \\
\hline Negative Feelings 1 & 50.642 & 1 & .000 & .503 \\
\hline
\end{tabular}




\begin{tabular}{|l|c|c|c|c|}
\hline Pro-social Behaviour 1 & .186 & 1 & .668 & .004 \\
\hline Hyperactivity 1 & .366 & 1 & .548 & .007 \\
\hline Internalising 1 & 25.353 & 1 & .000 & .336 \\
\hline Externalising 1 & 15.697 & 1 & .000 & .239 \\
\hline Peer Relationship Problems 1 & .908 & 1 & .345 & .018 \\
\hline Dysphoria 1 & 16.079 & 1 & .000 & .243 \\
\hline
\end{tabular}

Family dynamics for early-stage group vs. later-stage group at Time 1.

Research question 18 enquired: "Is there a significant difference in the family dynamics of the early-stage separation participants and the later-stage separation participants at Time 1?" A multivariate analysis of variance was carried out to ascertain whether there were any differences in the family outcomes of the ESG and LSG at Time 1. For the combined dependent variables of family dynamics, a significant and strong effect for the groups was found $[F(7,44)=8.25, p=.000$; Wilks' Lambda $=.43$; partial eta squared $=$ .57].

The results for the family dynamics variables were also analysed separately, and are reported in Table 9.24. All of the family variables were found to be statistically significant using a Bonferroni adjusted alpha level of .007. For family cohesion, family communication, positive perceptions of mother, and positive perceptions of father, the LSG had higher mean scores than the ESG. For negative perceptions of mother, negative perceptions of father and parental conflict the ESG had higher mean scores than the LSG. These results (as reported in Appendix W) illustrate that the LSG had a higher level of family wellbeing at Time 1 than the ESG. 
Table 9.24

The univariate results for the main effect of the stage of separation on family dynamics at Time 1.

\begin{tabular}{|l|c|c|c|c|}
\hline \multicolumn{1}{|c|}{$\begin{array}{c}\text { Dependent Variables: } \\
\text { Family Dynamics }\end{array}$} & $\boldsymbol{F}$ & $\boldsymbol{d f}$ & $\boldsymbol{p}$ & $\boldsymbol{\eta}^{2}$ \\
\hline Family Cohesion 1 & 14.300 & 1 & .000 & .222 \\
\hline Family Communication 1 & 15.079 & 1 & .000 & .232 \\
\hline Positive Perceptions of Mother 1 & 27.220 & 1 & .000 & .352 \\
\hline Positive Perceptions of Father 1 & 12.315 & 1 & .001 & .198 \\
\hline Negative Perceptions of Mother 1 & 30.400 & 1 & .000 & .378 \\
\hline Negative Perceptions of Father 1 & 12.127 & 1 & .001 & .195 \\
\hline Parental Conflict 1 & 27.513 & 1 & .000 & .355 \\
\hline
\end{tabular}

Individual wellbeing for early-stage group vs. later-stage group at Time 2.

Research question 19 enquired: "Is there a significant difference in the individual wellbeing of the early-stage separation participants and the laterstage separation participants at Time 2?" A multivariate analysis of variance was undertaken to establish whether there were any differences in the combined individual outcome variables of the ESG and LSG at Time 2. There were no significant differences between the two groups $[F(9,42)=1.27, p=$ .28 ; Wilks' Lambda $=.79$; partial eta squared $=.21]$. When the univariate results were analysed the ESG and LSG were found to have similar mean scores for the majority of the individual outcome variables. The one variable that the groups differed on was dysphoria $[F(1,50)=7.89, p=.007$; partial 
eta squared = .14]; the ESG had higher mean scores than the LSG. However, using a Bonferroni adjusted alpha level of .006, this result was assessed as non significant. On the whole these results reveal that there was no difference in the wellbeing of the two groups at Time 2 . These results are reported in Table 9.25 and Appendix X.

Table 9.25

The univariate results for the main effect of the stage of separation on individual wellbeing at Time 2.

\begin{tabular}{|l|c|c|c|c|}
\hline \multicolumn{1}{|c|}{$\begin{array}{c}\text { Dependent Variables: } \\
\text { Individual Wellbeing }\end{array}$} & $\boldsymbol{F}$ & $\boldsymbol{d f}$ & $\boldsymbol{p}$ & $\boldsymbol{\eta}^{2}$ \\
\hline Perception of Strengths 2 & 2.889 & 1 & .095 & .055 \\
\hline Positive Feelings 2 & 2.115 & 1 & .152 & .041 \\
\hline Negative Feelings 2 & 2.933 & 1 & .093 & .055 \\
\hline Pro-social Behaviour 2 & .574 & 1 & .452 & .011 \\
\hline Hyperactivity 2 & .529 & 1 & .470 & .010 \\
\hline Internalising 2 & .896 & 1 & .348 & .018 \\
\hline Externalising 2 & .484 & 1 & .490 & .010 \\
\hline Peer Relationship Problems 2 & .000 & 1 & .987 & .000 \\
\hline Dysphoria 2 & 7.891 & 1 & .007 & .136 \\
\hline
\end{tabular}

Family dynamics for early-stage group vs. later-stage group at Time 2.

Research question 20 enquired: "Is there a significant difference in the family 
dynamics of the early-stage separation participants and the later-stage separation participants at Time 2?" A multivariate analysis of variance was carried out to ascertain whether there were any differences in the combined family outcome variables of the ESG and LSG at Time 2. There were no significant differences between the two groups $[F(7,44)=.81, p=.59$; Wilks' Lambda $=.89$; partial eta squared $=.11]$. The ESG and LSG had similar mean scores for all of the family outcome variables. These results illustrate that there was no difference in the family dynamics of the two groups at Time 2 (refer to Table 9.26 and Appendix Y).

Table 9.26

The univariate results for the main effect of the stage of separation on family dynamics at Time 2.

\begin{tabular}{|l|c|c|c|c|}
\hline \multicolumn{1}{|c|}{$\begin{array}{c}\text { Dependent Variables: } \\
\text { Family Dynamics }\end{array}$} & $\boldsymbol{F}$ & $\boldsymbol{d f}$ & $\boldsymbol{p}$ & $\boldsymbol{\eta}^{2}$ \\
\hline Family Cohesion 2 & 2.421 & 1 & .126 & .046 \\
\hline Family Communication 2 & 1.638 & 1 & .207 & .032 \\
\hline Positive Perceptions of Mother 2 & 1.760 & 1 & .191 & .034 \\
\hline Positive Perceptions of Father 2 & 2.979 & 1 & .091 & .056 \\
\hline Negative Perceptions of Mother 2 & 1.871 & 1 & .178 & .036 \\
\hline Negative Perceptions of Father 2 & 2.394 & 1 & .128 & .046 \\
\hline Parental Conflict 2 & 3.084 & 1 & .085 & .058 \\
\hline
\end{tabular}




\subsection{Non Parametric Results}

In section 9.7 it was noted that some of the variables violated the assumption of normality. A number of transformations were applied to the offending data, but due to a lack of improvement in the distributions the MANOVA analyses were carried out using the original dataset. In order to establish the reliability of the untransformed data and results, non parametric tests were also carried out. This enabled comparisons to be made between the parametric test results and the non parametric results. If the comparisons presented inconsistent findings this would indicate that the violations were affecting the results. Alternatively, if the results were analogous this would dispel concerns regarding the non-normal variables. The non parametric results are reported in Appendix Z.

\subsubsection{In summary: Non parametric results vs. parametric results}

The non parametric results confirm all of the parametric results reported in section 9.7; thereby adding weight to the parametric analyses. In light of these results, it can be concluded that the transformations were not required on the moderately skewed data. Furthermore, because the parametric and non parametric test results are comparable, this implies that there is no concern surrounding the loss in power that is often attributed to non parametric tests. Accordingly, the parametric and non parametric results can both be viewed as valid and reliable. 


\section{Chapter Ten \\ Discussion}

Families are increasingly experiencing changes to their composition, and consequently a rising number of young people are faced with familial transformations. Children are often the family members least likely to have initiated the transition, but they are, nonetheless, intensely involved in the process (Pryor \& Rodgers, 2001). In New Zealand one in three marriages will end in divorce, and approximately half of these will involve young people. Unfortunately official statistics on the number of de facto couples that have separated are not available. An increasingly large number of young people are obviously experiencing family transitions; however, little research has been carried out on New Zealand children's perspectives in relation to families and family change.

Study Two aimed to investigate young people's concept of family and parental separation and their experiences of parental separation. Their adjustment to the separation was also explored with regard to their individual wellbeing and family dynamics. Of particular importance was the investigation of the young people's experiences and adjustment over time. Even more imperative was that the experiences and adjustment were directly from the children's own point-of-view.

\subsection{Definitions of 'Family' and Separation}

The young people's definitions of family were also explored in Study Two, as were their definitions of parental separation. The definition questions were included on the premise that it is necessary to comprehend how children view families before understanding their experiences of family changes.

With regard to the young people's concept of 'family', there were many similarities with the responses provided by the children in Study One and the adolescents in Anyan and Pryor's (2002) study. Affective factors was the criterion 
most frequently mentioned by the young people (65\%), as it was in Study One (55\%) and in Anyan and Pryor's study (80\%). The 'family members' criterion (listed individuals or relationships) was the second most mentioned criterion in Study Two, as it was with Anyan and Pryor's adolescents and the children in Study One. Cohabitation was referred to by 29 percent of the young people, compared to 20 percent in Study One and 35 percent of the adolescent sample. Thus, the percentages from this study of children and adolescents seem to be consistently placed between the percentages reported for the children in Study One and the adolescents in Anyan and Pryor's study, which suggests developmental trends in their conceptualising. As was the case in the other two studies, very few participants mentioned biological factors or legal ties in their descriptions. These findings are consistent with research that describes young people's definitions as emotionally based rather than structural.

In Study Two the young people were also asked if family is important to them. The findings repeated those in Study One; 100 percent of the young people replied that family is important to them. This is especially important when one considers that all of the participants had experienced parental separation; whereas more than half of the children in Study One were from intact two-parent families. Thus, the experience of separation did not impact on their perceptions of the importance of family. The majority of young people stated that families were important because of affective factors (83\%), as was reported in Study One $(78 \%)$.

The young people were also asked what separation means to them. Their definitions of separation referred to two main criteria. First, a change in the relationship was mentioned in 29 percent of young people's definitions. Second, a similar number referred to cohabitation or parents no longer living together. Just over a quarter of the participants mentioned affective factors (no longer being close or in love with each other), and just under a quarter referred to parents no longer spending time together. As was the case with the young 
people's family definitions, legal factors were barely mentioned in their separation descriptions. Only 4 percent of participants defined separation in terms of the impact on the family, such as the family breaking up or changing. For these young people the definition of separation focused on the adult relationship and not the family unit.

In contrast, when Kurdek and Siesky (1980) asked their participants what it means when two people divorce, just under half of the children mentioned affective factors in their descriptions. The second and third most frequently referred to criteria were physical separation (cohabitation) and the marriage ending (relationship change). The same percentage of Kurdek and Siesky's participants referred to the legal aspects of the separation. Any differences in findings may be explained by the variation in the separation question wording, time differences between the two studies, and differences between New Zealand and the United States in the use of litigation following family transitions.

In summary, these young people's definitions of separation were centred on the structural aspects of the relationship; that is, the relationship breaking up and coresidence. More specifically the parents were predominantly implicated in the separation, rather than the family as a whole. These aspects of the separation were more salient than the emotions involved in parental separation or the decrease in time spent together. These young people's responses suggest that 'separation' is viewed as an event that has a limited life span, compared to 'family' which is perceived as more of an emotional and enduring concept.

\subsection{Young People's Experiences of Separation}

The young people in this study described a myriad of experiences and views regarding their parents' separation. In the following section, the young people's experiences, as reported at Time 1, will be discussed alongside the research to date. In section 10.2.2, the young people's experiences and opinions at Time 1 are compared with their experiences and views at Time 2. 


\subsubsection{Time 1}

Views and reactions. The first set of questions focused on young people's views and reactions regarding their parents' separation. First, in terms of finding out about the separation, most of the participants were told by their mother. This is consistent with Hogan, Halpenny and Greene's (2002) findings that mothers alone often deliver the news of the separation. It was rare for the participants to be informed by their father or by both parents at the same time. Dunn and Deater-Deckard (2001) found that just under a quarter of participants were not told about the separation. Similarly, some studies have shown that a number of children first find out about the separation when one parent leaves the family home (Wallerstein \& Kelly, 1980; Brannen, Heptinstall \& Bhopal., 1999). Of note, all of the young people in this study wanted their mother and their father to inform them of the separation together. It appears particularly important to children that parents show a united front despite the break-down in their relationship.

Importantly, all of the children were aware of the problems in their parents' relationship well before they learned of the separation. This is consistent with the research findings of Amato (1987) and Hogan et al. (2002). Some of the examples given by the young people in this study were overt examples, for instance an increase in verbal conflict, parents that are visibly upset and parents that are sleeping in separate rooms. Other examples were more concealed, and included forms of emotional conflict and a decline in parent-to-parent affection. This finding echoes Pryor and Pattison's (2007) observation that the young people in their study were aware of the 'silent conflict' between their parents, which included changes in parental interactions and behaviour. This has important implications for how and when parents should broach the separation with their children. Parents can wrongly assume that because the conflict between them is nonverbal their children are protected and unaware of the relationship problems. Separating parents need to appreciate that children are adept at recognising problems in parental relationships; which in turn emphasises the importance of keeping lines of communication open. 
The young people were questioned about their reactions to the news of the separation. Some of the participants' responses were overt: crying and being visibly upset, or acting out in anger. Some reacted by asking lots of questions or pleading with their parents. The more covert responses included being unresponsive, or being calm and supportive for their parents. Age differences were evident in the participants' responses. The majority of participants that responded overtly were in the child age group, whereas those that asked questions or were supportive were mostly in the adolescent age group. The young people's attributions of control may help to explain these differences. The children in this study had a higher external locus of control and unknown locus of control. In comparison, the adolescents were higher in terms of their internal locus of control. Kurdek, Blisk and Siesky (1981) reported that children experience higher levels of distress if they attribute the control over events to external sources. The younger participants in this study were more likely to respond as though they had little control over the situation, whereas the older participants that took a supportive stance demonstrated higher internal control.

The young people's feelings about the separation were of particular interest. They were first asked for their feelings in retrospect; specifically, how they first felt when they were informed of their parents' separation. The sentiments most often conveyed about the separation at the time were feelings of shock, sadness, worry, relief, fear, loneliness, confusion, anger, and happiness. Smaller numbers of participants mentioned that they felt loved, hopeful, or expressed neutral feelings at the time. The feeling most frequently mentioned was shock. This is despite all children being aware of their parents' relationship problems prior to the separation. Feelings of shock have been widely reported in the literature (Walczak \& Burns, 1984; Neugebauer, 1989; Amato, 1987; Smith et al., 1997; Pritchard, 1988; Burns \& Dunlop, 1999).

Butler, Scanlan, Robinson, Douglas and Murch (2002) found that many participants expressed anger at the news of the break-up, as did Wallerstein and 
Kelly (1980). This is in contrast to the young people's reports in this study, only 15 participants mentioned feeling angry at the time. Interestingly, 22 young people stated that they felt relieved. Consistent with this finding is the relief reported by a similar number of children in Hogan et al.'s (2002) study. Younger participants were more likely to express feelings of sadness and fear, which is consistent with Wallerstein and Kelly's (1980) finding that younger children are more likely to fear that they will not see one or both parents again. Thus, children's conflicted feelings at learning of their parents' separation can generate a range of mixed emotions, reinforcing the view that informing children about separation needs to be handled carefully.

The younger participants in this study were also more likely to convey feelings of confusion, which may relate to their cognitive abilities to understand and process adult relationships. In contrast the adolescents were more likely to express relief, worry and hopefulness. The adolescents may have experienced the relationship breakdown over a longer period, and may have also had more information and a greater understanding of the issues surrounding the relationship breakdown; hence the increased likelihood of feeling relieved and hopeful about the future. They may also be more likely to understand the implications of parental separation, which may result in greater worry about the future than their younger counterparts. Added to this is the increased likelihood that the adolescents had been supporting their parent/s, which may explain the worry they felt for one or both parents. Hogan et al. (2002) reported that both their younger and older participants expressed worry about their parents and were mindful of causing them further distress. Thus, young people clearly show concern for the wellbeing of their parents; the parent-child relationship is one based on mutual care and concern (Smart, Wade \& Neale, 1999).

The young people were also asked about their feelings in relation to the separation now (at Time 1). An equal number of negative and positive feelings were expressed. The most frequently articulated feeling at Time 1 was relief. 
Other studies have also reported that separation can result in feelings of relief, especially when the young person has endured parental conflict (Amato, 1987; Neugebauer, 1989; Pritchard, 1998). Evidently, the family circumstances prior to the separation can have a large impact on young people's feelings postseparation. Burns and Dunlop (1999) commented that feelings of relief can continue long after parents have separated.

The large majority of young people considered their parents' decision to be a permanent one. Other studies have also reported that the children did not envisage their parents reuniting (Hogan et al., 2002). The young people in this study were realistic about their parents' decision. They appeared to comprehend the enormity and permanency of the situation. Only a few participants wanted their parents to resume their relationship. In contrast, Plunkett and Kalter (1984) found that almost 100 percent of their participants wanted their parents to reunite. The Plunkett and Kalter study was undertaken nearly 25 years ago. It is possible that as parental separation has become more common in Western countries, children whose parents separate no longer feel that their situation is unusual and are therefore less consumed with the idea of their parents reuniting.

Most of the young people responded that no one was to blame for their parents' separation. Just four young people blamed one parent for the separation, and a further four participants blamed a third party. Crucially, none of the children blamed themselves for the break-up. Burns and Dunlop (1999) found that reports of self-blame were rare, and Kurdek and Siesky (1980) reported that only five percent of participants believed that the blame for parental separation lay with children. In contrast, Wallerstein and Kelly (1980) and Kalter and Plunkett (1984) both found that approximately a third of their participants felt some responsibility for the separation. Clearly, the studies are mixed regarding self-blame, although the more recent research has shown that children are pragmatic enough to realise that adult issues are driving the separation. Wallerstein and Kelly (1980) noted that self-blame was more prevalent in children less than eight years of age. 
Children younger than eight were not included in this study; therefore it is difficult to compare the findings.

The reasons for their parents' separation were explored from the young people's perspectives. In particular, they were asked why their parents separated, and if they wished the reason had been explained to them. Almost all of the young people were uncertain why the separation had occurred. Only three participants understood the reason why their parents had parted. Notably, all of the participants that were uncertain about the cause wished that their parents had explained their reasoning to them. Over half of these young people speculated about the cause of it. These findings help explain the large number of young people that reported feeling confused when they were asked for their feelings about their parents' break-up at Time 1. Similarly, Hogan et al. (2002) commented that the children who did not understand what was happening and had unanswered questions were more likely to feel worried and confused. Thus, the young people in this study expressed a strong desire for more information about the cause of the separation. It is clear that they did not see themselves as the cause of the break-up, but they were plainly left to wrestle with the reasons why it occurred. As Wallerstein and Kelly (1980) noted, from a parent's perspective it can be difficult to know how much information to divulge. Evidently, these young people felt they were entitled to some information. However, age and stage appropriate information is paramount.

Young people's perspectives regarding their living arrangements were also addressed. Of the 52 participants, 29 responded that they were happy with their current living arrangements, 12 were 'sort of' happy, and 11 were not happy. The main reason given for their happiness was the absence of conflict in their new set-up. Likewise, the elimination of parental conflict was an important aspect for the young people in Kurdek and Siesky's (1984) study. The young people in this study also referred to the happiness amongst family members in contrast to before the separation, and maintaining contact with both parents. Having two 
houses to go to was another reason attributed to their approval of their living arrangements. In Dunn and Deater-Deckard's (2001) study over half of the participants referred to living in two households as a positive outcome of the separation. Thus, contrary to the view that children are necessarily disadvantaged by living in two households, children may find aspects of it enjoyable and beneficial. The main reason given for being unhappy with living arrangements was the lack of contact with their non-resident parent. Similar findings have been widely reported concerning the loss of contact with one parent (Kurdek \& Siesky, 1980; Lamb, Sternberg \& Thompson, 1997; Sviggum, 2000; Gollop, Taylor \& Smith, 2000; Pryor, 2004; Parkinson, Cashmore \& Single, 2005).

There were differences among the early-stage and later-stage separation groups. The ESG were more likely to be unhappy with their living arrangements, compared to the LSG. Many of the early-stage participants commented that they were still getting used to their new living arrangements, and their responses clearly reflected a settling-in period. Children can start to feel their circumstances are close to normal once routines are in place (Smart, Wade \& Neale, 2000).

Feelings about current contact arrangements were also explored. Just over half of the young people were happy with the amount of contact they had with their non-resident parent. The primary reason for their happiness was that they were able to regularly see their parent/s and spend quality time with them. Kurdek and Siesky (1980) identified that quality time spent with non-resident parents can increase post-separation. Contact arrangements for some participants were easier to adjust to given that they had technological aids to ensure regular contact with their parents. A finding of interest is that all of the participants that were in shared care contact arrangements were happy with the amount of contact they had with each parent. It is not surprising that children prefer to have regular contact with both parents; it would be interesting to see if this finding was 
replicated with a larger sample of young people from varying family structures, including shared care arrangements.

A major aim of this study was to focus on both negative and positive aspects of parental separation. The majority of participants stated that not being able to see their non-resident parent as much as they liked was a negative factor, while similar numbers mentioned the inconvenience of moving between two houses. Smart et al. (2000) likewise reported some practical problems associated with living in two households. When the participants were asked what they dislike about their household/s they gave a wide range of responses; including, an aspect of their house (e.g. their small bedroom), arguing between parents, the untidiness of the house, the financial restrictions, insufficient time spent with their non-resident parent, a parent's partner or stepparent, arguing with siblings and/or parents, being bored or lonely, and differences in rules between parents. A confounding issue with this question was the use of the word 'household/s'. Instead of interpreting it in terms of the people they live with, many of the young people focused on specific features of their house that they disliked. Therefore, the responses to this question may not be entirely accurate.

Even though only 14 young people referred to the lack of time they spent with both of their parents or with their non-resident parent as an aspect they disliked about their household, 29 replied that the answer to their household problems was to spend more time with their parents. It appears that in the children's eyes some of the things they disliked would improve if they were able to spend more time with their parents. While in reality increased time with a parent may not have solved some of their practical problems, these results reinforce the point that children place a high value on spending time with parents. They feel that time with parents can make life's challenges easier to deal with.

All of the young people considered that there were positive outcomes from the separation, primarily the decline in parental conflict. Other participants 
recognised that being happier, having two houses to spend time at, increased quality time spent with their parents, more time with extended family, the new people they had met post-separation, and new pets as some positive benefits that had arisen out of the separation. Despite the change in their family unit the participants mentioned positive outcomes that were predominantly related to the people they classified as family, which included spending time together and the importance of improving and maintaining their many relationships.

In short, the young people were competent at articulating what they did and did not like about the separation. They were capable of recognising that there were both negative and positive outcomes from the separation. Many of the things they identified were pertinent to their everyday lives; they were less likely to refer to frivolous aspects that they liked or disliked. These findings demonstrate young people's ability to reflect on their experiences and to make critical judgements (Wade \& Smart, 2002). As can be expected, the cognitive complexity of their responses varied across the child and adolescent age groups, with the adolescents consistently providing more in-depth responses. Nevertheless, the children's social agency was evident across both age groups. They did not passively endure events that transpired around them, but rather interpreted information given to them, valued positive experiences, interacted with others, recognised problems, and proposed solutions. In other words, they were active participants in the process.

Young people's memories of life before the separation were a mix of happy and unhappy recollections. Some participants expressed memories of happy family times, holidays and events. Other participants reminisced by looking at photos or video footage, which made them sad and happy at the same time. Most young people commented that their memories of life before the separation were of the more tumultuous times in their family. A similar number also commented that they did not reminisce about life prior to the separation because the past was behind them. Thus, their memories of life prior to the separation did not describe 
the idyllic family life. Both happy and unhappy memories were revealed about their pre-separation lives. Likewise, their memories following the separation were not all unhappy memories. In fact, there were far more happy memories expressed than negative ones.

Support and coping. In order to assist young people to better adapt to their new family structure it is essential to ascertain what they need and their ideas on support and coping. It should be acknowledged that differences in participants' responses may be partly explained by the time-lag between the separation and the interviews. For example, some young people may not have accurately recalled who supported them immediately following the separation. Nevertheless, the findings from this study suggest four factors are especially important. First, most of the participants stated that they needed both their mother and their father to support them post-separation. As others have noted, because separation is a difficult time for parents, many mothers and fathers may feel emotionally unavailable to act in a supporting capacity (Wallerstein \& Kelly, 1980; Pryor \& Rodgers, 2001). Second, young people want to be reassured that they will have ongoing contact with both parents. Many of the children in Hogan et al.'s (2002) study also required reassurance from their non-resident parent that they would remain in their lives. Third, young people want information to help them cope. This includes being told what caused the separation, being kept informed about current events, and what would happen later in the separation process. The young people in this study wanted to understand the situation so that they could comprehend what they had to cope with. Fourth, young people generally wanted someone to listen to them, specifically both parents.

The participants were queried on their formal and informal sources of support. The majority of participants did not receive formal support. Only 14 participants were formally supported through an education programme, a support group or via counselling. There are some support and education programmes in New Zealand that are designed for young people experiencing family transitions, such 
as Seasons for Growth and Skylight. However, the low numbers that have received support suggests that programmes such as these are not reaching the children that are affected by separation. Thus, it may be beneficial for a nationwide support programme to be devised to support children and adolescents. A pilot parent education programme entitled 'Children in the Middle' (CiM) was created for New Zealand parents experiencing separation. The programme was initiated by the Auckland Family Courts Association and was piloted at Auckland's North Shore. CiM was found to be a successful method of educating and supporting parents to take the best interests of their children into account during the separation process (Gillard \& Seymour, 2005). An equivalent programme designed for young people may prove more accessible and more widely employed than the support and education programmes currently available.

With regard to the young people's informal sources of support, one or both parents were predominantly identified as the main providers of support. This is in contrast to Dunn and Deater-Deckard's (2001) finding that extended family and friends were more likely to provide support than mothers, who were ranked as the third source of support following the separation. Gollop et al. (2000) commented that their participants often felt their parents were preoccupied with their own issues. It seems that the parents of the young people in this study were both willing and able to act in a supporting capacity for their children. The second most frequently mentioned form of support was older siblings. Similarly, Hogan et al. (2002) found that their younger participants viewed their siblings as an essential source of support. In contrast, Gorell Barnes, Thompson, Daniel and Burchardt (1998) and Butler et al. (2002) found that mutual support between siblings was rare. These differences may reflect closer relationships between siblings in this study, which may be due to them being similar in age. It may also mean that the young people's siblings had similar views and reactions to the separation. Siblings that have different separation experiences may be less likely to act as a source of support for one another (Butler et al., 2002). 
The next most frequently mentioned source of support was friends. Again the findings are mixed when it comes to the supportive role of friends. Dunn and Deater-Deckard (2001) found that friends were a source of support for the young people in their study, as have other researchers (Butler et al., 2002; Hogan et al., 2002). In contrast, a number of other studies have found that children are not willing to talk to their peers about their parents' separation (Kurdek \& Siesky, 1980; Wallerstein \& Kelly, 1980; Gollop et al., 2000). This suggests that the young people in this study benefited from having supportive friends. It may also indicate that their school and social environments were such that parental separation did not mark children out as being unusual or different, meaning that they mostly felt comfortable talking about their parents' separation with their peers. The emphasis these young people placed on consulting their peers was evident in their desire to discuss their experiences in internet chat rooms, which can often be separate chat rooms that discuss specific topics and are designed for young people that are similar in age.

Grandparents proved to be an important source of support, and were ranked fourth behind the young people's friends. Many grandparents take on a caregiving role during times of family transition (Cherlin \& Furstenberg, 1986; Brannen et al., 1999; Pryor \& Rodgers, 2001; Butler et al., 2002). Furthermore, extended family was referred to as the fifth source of support. Hogan et al. (2002) likewise reported that grandparents and other extended family members provided care and support on an ongoing basis. In contrast, Wallerstein and Kelly (1980) reported that three quarters of their participants were not supported by grandparents or other extended family members, mainly due to distance. The ability of some young people to draw on relatives as sources of support underscores the importance of wider family networks in helping children cope with changes in their family structures. This may vary between ethnic groups because the importance placed on extended family can differ according to cultural norms and values. 
The young people's coping strategies were also examined. A number of participants commented that they kept themselves busy to avoid dwelling on the separation, which usually involved fun activities. Time spent with friends, school work or extracurricular commitments, time spent alone, text messaging, talking to people, and writing about their experiences were all strategies the young people used to help them cope. This assortment of strategies illustrates that the children and adolescents were capable of developing their own ideas to cope.

An emerging trend amongst young people in this study was the use of the internet, web-based chat rooms, and emailing as their way of coping. This is a new trend that has come about as a result of recent technological advances and has therefore received comparatively little attention in the research to date. On the basis of these results, it seems that digital technologies will play an increasingly important role in delivering support for young people dealing with parental separation. Partly this is because of ease of availability. The internet is an integral part of many young people's daily lives. Thus, when asked what information about parental separation would help, the majority of young people referred to electronic resources, such as internet websites and chat rooms. Likewise, Lyon, Surrey and Timms (1998) found that their participants preferred information about separation to be in readily available and accessible forms, such as the internet.

Young people's perceptions of sources of support may also be relevant. None of the children suggested counsellors, education programmes, support groups or other community initiatives as support services they would seek out. Similarly, when they were asked about their willingness to receive support from a community counsellor, therapist or psychologist, almost all of the young people were reluctant, although they did express a more open attitude to being supported by school counsellors. The overwhelming reluctance to consult counsellors is consistent with Dunn and Deater-Deckard's (2001) finding that very few children in their study confided in counsellors. It is possible that as a 
source of information and support, using the internet does not suffer from the same negative connotations than can be associated with seeing a therapist or psychologist. While mental health professionals may be able to provide a supportive clinical environment, young people may nevertheless prefer the individual choice and anonymity that the internet provides when coming to terms with parental separation. It is also possible that they do not need the clinical intervention, as is the case with most young people whose parents separate.

When questioned about the content of the resources, many wanted information about the consequences of separation. These young people understood what separation was but did not appear to understand its implications, hence the desire for information that discussed the consequences of separation for their families, in terms of their relationships and the affect on their lives. They specified a strong desire to know what to expect in the future, and to be prepared for possible scenarios. In a further sign of the growing importance of digital resources, a number of young people wanted to read about other young people's experiences online, where they could share their experiences and hear about other young people's experiences. Additionally, age-appropriate information was important to the older participants; they did not want to read information designed for children. Almost all of the young people responded that it would help if their parents talked to them and kept them informed about what was happening. Also a number of young people felt that improved contact with their non-resident parent would help them to cope. Similar views were found by Hogan et al. (2002).

Communication. A recurring theme within the literature is young people's frustration at the lack of information parents provide about the separation, and the few opportunities, if any, they have to contribute to decisions that affect them (Mitchell, 1985; Brannen et al., 1999; Smart et al., 1999; Smith \& Gollop, 2001). This study has found similar results. All of the participants stated that they wanted to be kept up-to-date with decisions their parents made. Yet almost all of 
them felt that their parents had not done so. Furthermore, almost all of the participants liked the idea of their parents asking them their views on key family decisions. However, most reported that they were not asked for their opinions when those decisions were made. It appears, therefore, that the findings of earlier research have not yet translated into separating parents informing and consulting their children to the extent that young people would like. In saying this, open discussions with children may be challenging, and parents may themselves be uncertain as to what the future holds (Wallerstein \& Kelly, 1980; Butler et al., 2002). However, studies such as this one continue to show that most young people dislike being kept in the dark and much prefer information and open discussion. In addition, as discussed above, how young people cope with their parents' separation many be influenced by the level of communication between parents and their children.

Two further points should be made about the level of communication. First, while nearly all young people in this study strongly conveyed that they wanted to be consulted, they also stated that they did not necessarily want the full responsibility of making decisions for the entire family. Other studies have reiterated the importance of asking children for their point-of-view but not placing them in the position of sole decision-maker (Morrow, 1998; Smart \& Neale, 2000; Pryor \& Rodgers, 2001). Second, of the four participants who did not like the idea of voicing their opinions in this study, all were from the child age group, which may explain their unwillingness to voice their point-of-view. This echoes Smart and Neale's (2000) findings that younger children were happy for their parents to make decisions without consulting them first. It is essential, therefore, to find a balance between giving children information and encouraging their participation without applying unreasonable pressure.

Communication is a two-way street. This study revealed some interesting findings in terms of information flow from young people to parents. Just over half of the participants commented that they would feel comfortable telling their 
parents what they wanted and how they felt about the family situation, while the remainder said that they would not feel comfortable doing so. What factors are likely to encourage openness from children? For those participants that were willing to discuss their views and opinions with parents, it was important that their parents were open to listening to what they had to say and even encouraged them to do so, irrespective of what was actually said. Having 'easy-going' parents was another reason given, as was having parents that love them and wanted to know how they felt. Those children who were reluctant to talk were asked what might help them open up to their parents. Many replied that they would be more comfortable if their parents made the effort to ask them for their thoughts and to listen to them. Open-lines of communication were also frequently mentioned. These findings have implications for the way in which parents interact with their children. They suggest that children will be more open with parents if parents take the time to encourage children to tell them how they are feeling, to listen to what children have to say, and to provide as much information as possible in return.

Children who have experienced parental separation can provide valuable insights into factors that can help make the separation process easier for children to deal with. The young people in this study were asked what advice they would give to a child who was about to experience their parents' separation. The majority simply advised that with time the situation would improve. These participants clearly felt that their own circumstances had improved over time. Other comments included advice to talk to their parents or other adults, and reassuring the child that they would still get to see both parents. Eleven young people stated that there was nothing that they would want a child in their situation to know. This may reflect the recency of their own separation as most of these young people were earlystage separation participants. Similar to the Smith and Gollop (2001) study, children in this study advised separating parents to talk with their children and listen to their opinions. Other participants advised parents to be kinder to each other, to make arrangements for their children to have contact with both parents, 
to make small changes over time, and to not pretend to their children that everything is 'all right'. Of particular interest is that none of the participants replied that they would advise the parents not to separate. All of the young people were pragmatic about the impending separation and very aware that it was an adult decision. Reinhard (1977) also recognised that young people are able to comprehend that the decision to separate may be sensible in light of the circumstances. Again this demonstrates children's social agency. Children in this study were quite capable of putting their own interests aside and objectively weighing up the circumstance of their parents relationships.

The future. Children in this study were asked how they felt about the future state of their family. Responses were mixed but overall tended to be more optimistic than pessimistic. Some participants were very positive about the future, many were optimistic, while some were uncertain. Seven young people expressed worry and anxiety or were pessimistic about their family's future. A variety of answers was not unexpected. Family structure change is typically a major upheaval in a child's life and can be distressing (Pryor \& Rodgers, 2001). For some young people, routines and roles may become established relatively quickly, and this may contribute to a more stable and positive outlook. For others, particularly those whose parents have not adjusted to post-separation life, or who experience multiple transitions, short-term life may be more unpredictable, resulting in a more uncertain view of how family life will pan out in time.

The issue of what effect, if any, parental separation has on how children view their future life path, including the possibility of marriage and the desire to have children, has been of considerable interest to researchers (Kurdek \& Siesky, 1980; Mazur, 1993). The results from this study give further weight to the view that parental separation is an unreliable guide to future familial intentions. Most of the young people either did not know if they would have children, or thought that they might one day have children. When asked about their future in terms of marriage the participants were split, with just under half being fairly certain that 
they would get married and a similar number being unsure if they would marry. Just two young people responded that they did not think they would get married. Interestingly, when asked if marriage was important to them just under half of the participants responded 'not really' and slightly fewer replied 'no'. Only nine young people stated that marriage was important to them.

The difficulty with interpreting these results, however, is that to some degree the participants' views are a product of the social contexts in which they live. For example, rates of marriage are lower now than in previous decades. Alternative forms of relationships, in particular de facto relationships, are more socially acceptable than they used to be. Three young people in the study, for example, suggested that they would enter into a civil union rather than a marriage. Thus, it is difficult to isolate the possible effect of parental separation on children's view about marriage from the impact of changes in societal views as to the importance of marriage.

\subsubsection{Time 1 vs. Time 2}

There is little research comparing children and adolescents subjective experiences of parental separation over time. Hence in this section the focus is on comparing the young people's responses at Time 1 with their responses approximately 18 months later at Time 2 .

Views and reactions. The young people's retrospective feelings about the separation, as reported at Time 1 and Time 2, were compared. There are several trends of note as shown in Appendix AA. There was a higher rate of negative feelings reported at Time 2 compared to Time 1. More specifically, the young people reported that they were more shocked, sad, scared, confused, angry, and 'sick' at the time of the separation, as reported at Time 2, compared to their reports at Time 1. Burns and Dunlop (1999) reported that ten years post-divorce the participants in their study overestimated their original distress. In particular they exaggerated their feelings of shock and upset. Interestingly, in this study 
many of the young people's retrospective feelings of distress increased from Time 1 to Time 2, a period of just 18 months. It appears that these young people also overestimated their feelings; although there is a large time difference between the Burns and Dunlop study and the present study, making it difficult to reliably compare findings.

The young people were slightly less likely to recall positive feelings in retrospect at Time 2 compared to Time 1. For instance, slightly fewer young people reported feeling happy and hopeful at Time 2 . Similar numbers of young people reported feeling relieved, loved or neutral feelings at Time 1 and Time 2. Burns and Dunlop (1999) also found that their participants' retrospective reports of relief were similar to their initial reports. However, in contrast they did not find a difference in the participants' initial and retrospective reports of happiness. In short, the young people's retrospective reports in this study were more negative over time and generally less positive. The participants appear to have overestimated their negative feelings at the time of the separation and underestimated their initial positive feelings. One explanation for this may lie in participants' own feelings that they have improved over time. Since they feel better now, as a matter of logic they may consider that they must have been worse before, thus producing a tendency to recall feelings and emotions as being worse than they actually were (Woodruff \& Birren, 1972; Burns \& Dunlop, 1999).

The young people's negative and positive feelings about the separation at Time 2 were also compared with their feelings about it at Time 1, as displayed in Appendix BB. There were more positive feelings reported at Time 2, compared to Time 1 where there were an equal number of positive and negative feelings reported. The participants were more likely to feel relieved, happy, hopeful, relaxed, loved, and normal at Time 2 than they were at Time 1 . This suggests that over the 18 months these young people were feeling markedly better about the separation. In fact the only positive feeling that was not reported at a higher rate at Time 2 was excitement, which was equally reported at Time 1 and Time 2. 
Burns and Dunlop (1999) also reported that their participants' feelings of gladness increased over time, and that their feelings of relief increased sharply from Time 1 to Time 2. It is possible that the young people are more content with their circumstances over time, and subsequently their positive feelings are more salient at Time 2.

In terms of their negative feelings about the separation, there were a number of differences between the two time points. Fewer participants mentioned feeling sad at Time 2 compared to Time 1. In fact at Time 2 none of the participants reported feeling shocked or lonely. Again, this supports the notion that over time young people can come to terms with the trauma of parents separating, and feel that they have loving and supportive relationships with others. Amato (1987) found that the negative feelings the children reported about the separation at the time of the break-up were higher than how they felt about the separation at the time of the study. Burns and Dunlop (1999) similarly found that the participants' negative feelings of sadness decreased over time, as did their feelings of disbelief and shock.

Similar numbers of participants reported feeling disappointed, worried and angry during both interviews. Notably, more participants felt confused at Time 2 compared to Time 1. It is possible that their feelings of disappointment, worry and anger were connected to their confusion surrounding the separation. From the young people's responses regarding communication, it is apparent that as time progressed their questions were not answered and they felt less informed and more confused then earlier in the separation. These results again highlight the point that communicating with young people, keeping them up-to-date, asking for their opinions, and answering any questions can help them feel less bewildered and anxious about the changes they are facing.

It is interesting to note the differences in positive and negative feelings between the ESG and the LSG over time. At Time 1 there were clear differences between 
the two groups. The ESG were more likely to report feeling sad, worried, shocked, and lonely. The LSG were more likely to mention feeling happy, loved, excited, relaxed, and normal. They were also more likely to report feeling disappointed, which again may reflect the ongoing lack of answers and understanding, or lack of contact with their non-resident parent. In comparison, at Time 2 there were no differences in the feelings reported by the ESG and LSG. This is further demonstrated in Appendix CC. The ESG's positive feelings have consistently increased from Time 1 to Time 2 and most of their negative feelings decreased from Time 1 to Time 2. Their feelings of confusion and disappointment did, however, increase over time. In comparison, in Appendix DD the LSG's positive feelings were relatively stable across time, although they were slightly happier, more relieved, more relaxed, and a great deal more hopeful. Their negative feelings were similar to their Time 1 feelings of sadness, worry and anger. They were less disappointed at Time 2 and more confused.

Clearly over time most of the LSG's feelings remained relatively stable, whereas the ESG's positive feelings increased and their negative feelings mainly decreased. Both groups showed an increase in their level of confusion. Becoming more confused with time suggests a lack of information and communication between children and parents. Therefore, time since separation has resulted in an improvement in feelings for the early-stage separation participants, while the later-stage participants have remained comparatively stable. Pryor and Rodgers (2001) noted that young people's emotional reactions can stabilise over time.

In summary, the ESG participants, whose parents had separated between one month and 10 months earlier, reported similar rates of feelings as the more stable LSG just 18 months later. Thus, the early-stage participants had improved to the level of the LSG at between 19 and 28 months following the separation. This is well within the two to three year timeframe that is often reported as the time it takes young people to adjust to separation (Hetherington, 1989). It is 
important to consider these findings in relation to the quantitative analyses discussed later.

The young people were again asked if they believed their parents would reunite. Similar responses were given at Time 2 . The young people still believed that their parents would not reconcile. However, when they were asked whether they wanted their parents to reunite there were differences between their Time 1 and Time 2 responses. At Time 2 a larger number of participants replied that they did not want their parents to resume their relationship. This implies that over time the young people were happier with their circumstances and believed their parents were better off living apart. This clearly demonstrates their cognitive maturity and ability to understand the situation from their parents' point-of-view.

At Time 2 most of the participants stated that they were happy with their living arrangements, compared to Time 1 when fewer participants reported being happy. During the second interview the young people were more likely to report feeling settled in their current family structure. The ESG were less likely to express happiness with their living circumstances at Time 1 compared to the LSG. These differences were not found in the second interview. Thus, time appears to have impacted on many participants feelings about their living arrangements and the new routines and relationships they had established.

Similarly more participants reported feeling happier with their contact arrangements at Time 2 compared to Time 1. It seems that as time progressed the young people became more accustomed to their schedule or possibly reached a contact plan that they were happier with. A finding of interest that was replicated at Time 2 was that all of the young people with a shared care arrangement reported that they were happy with their contact arrangements. Compared to the other contact arrangements the young people with shared contact with their parents were more satisfied with the arrangement. This once again illustrates children's preference to spend time with both parents. 
The differences between the young people's reports of negative and positive aspects of separation over time are particularly important. The range of aspects mentioned were similar, however the rates of reporting revealed an interesting trend. The young people reported fewer negative aspects of parental separation at Time 2 compared to Time 1. They also reported fewer elements they disliked about living in their household at Time 2. However, in terms of the things that they missed post-separation, the participants referred to a similar range of elements and reported them at comparable rates. Thus, the young people were less likely to refer to negative components or aspects they disliked about the separation at Time 2, but equally reported similar elements of their preseparation life that they missed at Time 1 and Time 2. This shows that over time the young people were having fewer negative experiences of separation but were still yearning for certain aspects of their old life that they missed.

These findings were strengthened in the assessment of young people's positive perceptions of separation. The participants reported more positive elements in relation to their parents' separation at Time 2, than they did at Time 1 . They also reported more features that they liked about their household at Time 2. Thus, over time the young people reported more positive experiences and aspects that they liked. It is possible that the young people became more accustomed to the transitions and subsequently reported more positive experiences. Similarly, their wellbeing and environment may have improved from Time 1 to Time 2 and this may have been reflected in their increased positive and decreased negative experiences. The quantitative results later in this chapter provide further insight into the young people's wellbeing and family environment over time.

When questioned about the challenges they had faced since their parents separation, the young people reported fewer challenges at Time 2. Also, at Time 2 the participants were more capable of coming up with solutions for their problems than they were at Time 1 . This may be explained by the increased age 
of the participants and their own experiences in navigating the challenges associated with family transitions.

Support and coping. Some of the young people's needs at Time 2 were similar to their needs at Time 1. For instance, first and foremost was the availability of both parents to act in a supporting capacity. There were some differences over time though. It was more common for the young people at Time 1 to respond that they needed to know what was happening in the months to come. There was less uncertainty expressed at Time 2. Fewer participants at Time 2 commented that they needed time to come to terms with what had happened compared to Time 1. Time was more likely to be referred to at Time 2, in the sense of 'getting on with life'. These differences can largely be attributed to the uncertainty associated with the initial phase of the separation. A further point of note is that an increased number of participants wanted to know what had caused their parents to separate at Time 2. This indicates that their confusion surrounding their parents break-up had not diminished over time. Time, it seems, had not resulted in parents being more forthcoming with their children about the separation. In support of this point is the increase in young people that reported feelings of confusion at Time 2.

At Time 2 the majority of young people had not received any formal support. In fact only five young people had received support in the 18 months following the first interview. As will be discussed in the following chapter, this suggests that uptake for formal support programmes for children remains low in New Zealand. There were some differences in the young people's reports of informal sources of support over time. At Time 1 one or both parents were the most frequent source of support, but at Time 2 siblings and friends were mentioned more often than parents, although parents were ranked in third place. This may reflect the increased number of friends that become aware of a young person's changed circumstances, which in turn increased the pool of potential sources of support amongst their peer group. 
The young people reported similar coping strategies at Time 1 and Time 2, although there were a larger number of participants that reported using technology at Time 2 to cope. This finding is consistent with the rapid uptake of digital technologies amongst young people. As will be discussed, this trend has important policy implications. As was the case at Time 1, most of the young people felt they had received enough support, and they all knew where to find it if needed. A similar range of people were mentioned. However, they were more likely to name a parent's partner as someone they would approach for support at Time 2. This once again reflects the impact time has on the young people's ability to adapt to their new family arrangement and to build new relationships within it.

Communication. There were similar responses at Time 1 and Time 2 regarding children being informed and involved in decision making. The majority of participants still felt they had not been kept up-to-date, and they all still wanted to be kept informed. The majority of participants also felt that they had not been asked for their opinions regarding decisions that had been made, and almost all participants wanted to be asked for their input. The advice the young people offered to children and parents experiencing separation was also similar over time, although more advice was offered at Time 2, which reflects the increased age and experience of the participants.

The future. The young people expressed more positive feelings about their family's future at Time 2. In contrast to Time 1, there were no differences between the responses of the early-stage and later-stage separation groups. In terms of the participants feelings about marriage and children, there were no decipherable differences between the two time points. Overall, the young people were more optimistic about their family's future at Time 2 , which may be explained by the increased stability in their family life since the separation. 


\subsubsection{In summary}

The comparison of the qualitative findings across time reveals an overwhelming trend of improved feelings, experiences and positive outlook for the future. Likewise, there are many examples of similarities between the early-stage separation participants and the later-stage separation participants, compared to Time 1 where group differences were commonly illustrated. This reflects the improved experiences of the ESG over time. Overall, there were some similarities between the young people's responses at Time 1 and Time 2; however, the large number of differences provides a strong indication that these young people have adjusted better to their circumstances by Time 2 .

As mentioned in chapter eight, the content analysis of the data drew on Glaser's (1992) Grounded Theory. Glaser's approach suggests that the research theory is emergent and discovered during analysis of the data. It is possible to describe Amato's (2000) divorce-stress-adjustment theory as grounded in the data. For instance the 'crisis' model, which describes the separation process as a disturbance that most children will adjust to in time, was consistent with the qualitative findings across time. However, discussion of the quantitative data is necessary to further explore the connection with Amato's perspective on young people's adjustment to parental separation.

\subsection{Young People's Adjustment to Separation}

As Amato and Keith (1991) and Rodgers and Pryor (1998) found in their metaanalyses, children from separated families have a higher risk of adverse outcomes than children from intact two-parent families. Nonetheless, the extent of the differences in outcomes was reported to be relatively small. There is a large amount of research that compares the wellbeing of children from separated families and children from original families, and research that examines children's outcomes pre and post-separation. There has, however, been comparatively less research that has focused solely on the adjustment of young people postseparation. This component of the study provides much needed insight into 
children and adolescents' individual and family outcomes following parental separation. The previous discussion of the qualitative differences reveals that the young people's experiences have generally improved over time. The following section also focuses on time and provides further evidence in support of this finding.

\subsubsection{Effect of time on adjustment}

Effect of time. In terms of the young people's individual outcomes, there was an improvement from Time 1 to Time 2. More specifically, they reported more positive feelings, and had a higher perception of their own strengths and improved pro-social behaviour. They also reported fewer negative feelings, and had lower levels of dysphoria, internalising behaviour and hyperactivity. Therefore, individual wellbeing improved over time. There were also improvements over time for all of the young people's family dynamic variables. Thus, their family environment improved, as shown by the higher levels of family cohesion and communication. Their parent-child relationships improved, with increased positive perceptions of their mother and their father and fewer negative perceptions of both parents. Finally, the parental conflict they were exposed to decreased over time. Overall, from Time 1 to Time 2 there was an improved level of family interactions.

Stage of separation. During the first interview (Time 1) there was a difference in the individual wellbeing of the early-stage separation group and the later-stage separation group. The LSG had a higher perception of their strengths and expressed more positive feelings. In comparison, the ESG expressed more negative feelings, higher internalising and externalising behaviour and higher dysphoria scores. Overall, the LSG had a higher individual wellbeing at Time 1. Similarly, there was a difference between the family dynamics of the two groups. The LSG had higher family cohesion and communication, and higher positive perceptions of their mother and their father. In contrast, the ESG had higher negative perceptions of their mother and their father and higher parental conflict 
scores. The LSG clearly demonstrated a higher level of family wellbeing during the first interview.

By the time of the second interview (Time 2), however, there were no significant differences between the ESG and the LSG's individual outcomes or family dynamics. The LSG's individual wellbeing and family wellbeing scores were relatively stable across time. By comparison, the ESG's individual and family scores either increased or decreased in a manner indicating improved individual outcomes and family dynamics from Time 1 to Time 2 . Therefore the young people's stage of separation influenced their individual and family wellbeing. Those in the early stages were doing less well at Time 1, but by Time 2 were comparable with those in the later stages of separation.

Adjustment timeframe. These findings suggest that there is a specific period of adjustment in which most children adjust to their parents' separation; more specifically their individual and family wellbeing improves. This period is 19 to 28 months following parental separation. This calculation is premised on the ESG's parents having been separated for between one and 10 months at Time 1. After 18 months (Time 2), the ESG's individual and family wellbeing was at the level of the LSG, who had remained stable over the 18 month period. Thus, at the 18 month point (Time 2) it had been between 19 and 28 months since the ESG's parents separated. This is well within the two to three year timeframe that Hetherington (1989) has identified as the time it takes most children to adjust to their parents' separation. Moreover, it remains possible that some of the young people in the ESG adjusted to their parents' separation even earlier than the 19 to 28 month timeframe. However, in the absence of additional time points between Time 1 and Time 2, this cannot be tested.

An interesting question is whether the LSG's family dynamic and individual outcome scores are a suitable benchmark against which the ESG outcomes can be compared. In other words, were the LSG indicative of well adjusted 
individuals? There are no pre-separation scores to analyse; therefore, it is not possible to know if the LSG was worse off post-separation, better off or the same. The problems associated with recruiting participants prior to separation and then interviewing them post-separation, in addition to time constraints, meant that this was not a feasible option in this study. At this point an original twoparent family control group may have provided insight into how the LSG's level of individual and family wellbeing compared to young people that had not experienced separation. However, as discussed further below, there can be no guarantee that children from an original two-parent family are well adjusted, meaning that any such comparison would be of limited value.

Even without comparison or control groups, it is clear that the LSG were at a higher level of adjustment than the ESG at Time 1, and that the LSG's level of wellbeing was maintained over time. Furthermore, the LSG's mean scores for each significant individual and family wellbeing variable show that these participants were scoring toward the higher end of the maximum score for positive variables and toward the lower end of the minimum score for negative variables. This indicates that they were performing well above the median in terms of their individual wellbeing and family interactions. Thus, comparisons with an original two-parent family group would be interesting, but are not necessary to demonstrate the LSG's level of wellbeing in this study.

\subsubsection{Stressors, protective factors and outcomes}

The divorce-stress-adjustment perspective predicts that young people's adjustment will be determined by the balance of stressor and protective factors they are exposed to throughout the separation process (Amato, 2000). The fewer stressors that exist, and the greater the number of protective factors there are, the better their adjustment is likely to be. Applying this framework to the quantitative results from this study suggests that overall young people benefited from being exposed to a favourable combination of protective mediating and 
moderating variables. This is especially so given that the adjustment occurred within a comparatively short timeframe of 19 to 28 months.

Two points should be made about stressors and protective factors. First, a number of potential stressors and protective factors that are generated from within the family have been identified as being relevant to children's outcomes. These include the presence of conflict (Hawthorne, Jessop, Pryor \& Richards, 1999), the quality of parent-child relationships (Videon, 2002), and the levels of family cohesion and communication (Kurdek \& Sinclair, 1988). The results from this study add further weight to the findings of others who stress the importance of the family environment for children's adjustment. For example, the presence of parental conflict at Time 1 was positively correlated with children's dysphoria at Time 2. The state of the parent-child relationship also appeared to be an important variable. Thus, children's negative perceptions of their mother at Time 1 were negatively correlated with young people's pro-social behaviour at Time 2 . Also, negative perceptions of fathers at Time 1 were positively correlated with both children's dysphoria and peer relationship problems at Time 2. Similarly, the cohesion of the family at Time 1 was positively correlated with children's positive feelings at Time 2, and negatively correlated with children's negative feelings at Time 2. Family communication at Time 1 was also positively correlated with positive feelings at Time 2 . It is also possible that other family related variables not considered in this study impacted on the young people's adjustment, for example parents psychological wellbeing.

A second point of interest in the context of stressors and protective factors is that the presence of a particular stressor may indicate the likely presence of additional stressors across time. For example, a negative perception of mothers at Time 1 was positively correlated with the presence of parental conflict at Time 2. The significance of these findings is that they illustrate how stressors can compound; one stressor builds on another producing a 'snowball' effect. Kelly (1998) made a similar observation when she noted that high-conflict relationships 
were associated with poor parenting techniques. As Pryor and Rodgers (2001) noted, the accumulation of multiple risk factors can significantly increase the overall risk for children's poor outcomes.

The inverse position, however, is that the presence of a protective factor at Time 1 may indicate the presence of other protective factors at Time 2. Family cohesion at Time 1, for example, was positively correlated with positive perceptions of both parents at Time 2. In addition, communication within the family at Time 1 was positively correlated with positive perceptions of fathers, and negatively correlated with negative perceptions of mothers. Thus, one protective factor might provide a foothold from which other protective factors can develop across time. This suggests that the sooner that stressors can be minimised and protective factors established within families, the better a young person's prospects will be of adjusting to their parents' separation.

\subsection{3 'Crisis' vs. 'chronic strain' model}

As identified in chapter three, within the divorce-stress-adjustment perspective there are contrasting perspectives regarding children's adjustment. The 'crisis' model proposes that separation is a disturbance that most children will adjust to with the benefit of time. The 'chronic strain' model on the other hand argues that children's wellbeing will not return to pre-separation levels because the stressors carry on long after the separation occurs (Amato, 2000). The findings in this study support the 'crisis' model, for the reason that the young people's adjustment, in terms of their individual wellbeing and family dynamics, improves from Time 1 to Time 2. This suggests either that the stressors that did exist became less prevalent over time, or that the protective factors largely mitigated those risks, or a combination of both factors. This finding is consistent with those studies that have concluded that children's adjustment improves over time (Bussell, 1995; Frost \& Pakiz, 1990; Goldberg et al., 1992; Jekielek, 1998), and contrasts with the results of Cherlin, Chase-Lansdale and McRae (1998) which found that negative outcomes increased over time. 
Finally, one feature of the crisis model is that it assumes that young people whose parents separate will eventually return to pre-separation levels of wellbeing (Amato, 2000). No finding can be made on this point given the unavailability of pre-separation data for the participants in this study. Regardless, it should not be assumed that children prior to separation had a high level of individual or family wellbeing. Sun (2001) found that significant pre-separation academic, psychological and behavioural problems could be detected in children prior to their parents separating. This may be because children have already been exposed to stressors such as parental conflict for a sustained period (Amato \& Keith, 1991). Indeed, in this study the parental conflict score indicated that most children were exposed to less conflict in the period of time following the separation, while their qualitative responses indicated that they were exposed to less conflict post-separation. Thus, pre-separation levels of wellbeing may not be a useful guide against which to compare children's post-separation adjustment.

\subsubsection{In summary}

The quantitative results from this study showed an improvement across time for the participants' individual outcomes and family dynamic variables. While the ESG initially lagged behind the LSG in terms of their wellbeing at Time 1, by Time 2 there were no significant differences in individual and family wellbeing between the two groups. Based on the results for the ESG, it is possible to conclude that young people are capable of adjusting to parental separation between 19 to 28 months following the separation, if not sooner. This is earlier than the established guide of two to three years. These results reiterate the importance of the family environment in terms of the impact of potential stressors and protective factors. They also highlight the possibility of clusters of mediating and moderating factors forming within families across time. Overall, these results support the crisis model of the divorce-stress-adjustment perspective. 


\section{CONCLUSIONS}

\section{Chapter Eleven \\ Overall Summary and Implications}

\subsection{Young People's Perceptions of Families and Experiences of Family Structure Change: Study One and Study Two}

Families are dynamic and diverse structures. The relationships and experiences that occur within families impact significantly on young people's lives. As family diversity increases young people are more likely to experience one or more changes to their family structure. Of particular importance is the likelihood that young people's perceptions of what families are influences how they cope with family transitions. The two studies in this thesis provide first an understanding of how children and adolescents conceptualise families, and second an understanding of young people's experiences of family in the midst of change.

The significance of this research lies in the examination of children and adolescents' perceptions of families across family structures and ethnic groups, together with an investigation of young people's experiences of family structure change over time. No other research has considered these two areas in a single research project. Its importance also lies in its focus on young people postseparation. Much of the research that has been carried out has compared the family transition experiences of children from intact families with children from separated families. Other research has examined children's wellbeing prior to and following their parents' separation. Because this research focuses solely on young people's post-separation experiences, it provides information on their experiences and adjustment in their new family arrangement as well as their experiences over time. Furthermore, the inclusion of qualitative and quantitative data increases the scope of understanding of their experiences. Listening to 
young people's perspectives about their personal experiences and then measuring their adjustment over time provides a wealth of information that can be used to support children and family in practice and in policy.

The findings from Study One, since published as Rigg and Pryor (2007), illustrate that children are willing and able to articulate their views about families. The original two-parent family was most frequently endorsed as family; however, this was not the only image they had of families. These young people had a very accepting and pragmatic view of families and endorsed a wide array of scenarios as examples of families. The centrality of children to families was apparent, as married and cohabiting couples with children were endorsed at similarly high rates. When the children's family structures and ethnic groups were compared there were more similarities between the groups than differences. In comparing New Zealand children and adolescents, many similarities were found in their concepts of family. The young people's definitions primarily referred to affective factors over cohabitation, biological factors or legal ties. Love, care, support and nurturing are important defining features of families. Cleary, family composition is less important than the intrinsic qualities of family relationships. Overall, young people's concept of family is inclusive. It portrays a picture of diversity which depicts society today.

The young people in Study Two were similarly inclusive in their concept of families. Their experiences of family transitions included many collective experiences and many individual ones. For example, they expressed a need for increased communication and information, and to be consulted and listened to. Time with both parents was paramount and they especially wanted them to work together amicably in their parenting. They expressed a large range of negative and positive experiences, although their negative experiences decreased over time and their positive experiences increased with time. Clearly the young people were adjusting well; it is possible that they may have shown greater 
improvements or improved even faster if some of their concerns, such as a lack of communication and information from parents had been addressed.

Young people's individual wellbeing and family dynamics significantly improved from Time 1 to Time 2. The qualitative and quantitative components of Study Two provide complementary perspectives. In diverse ways both methods show the impact of time. For instance, some of the young people's subjective feelings and experiences improved from Time 1 to Time 2, as did their individual wellbeing and family dynamics over time. In particular, their stage of separation was important. The qualitative results show that the later-stage separation group's feelings remained relatively stable over time, whereas the earlyseparation group's positive feelings increased and their negative feelings decreased. Similarly, the quantitative results illustrate that those in the early stages of separation had lower levels of individual and family wellbeing at Time 1 than the later-stage separation group. At Time 2 the early-stage group and laterstage group had similar levels of individual and family wellbeing. Both sources of data indicate that the early-stage separation group had improved over time whereas the later-stage separation group had stayed relatively stable. Thus, components of the qualitative and quantitative results show that the adjustment time frame was between 19 and 28 months following parental separation, if not sooner. This time frame is earlier than the two to three years often mentioned in research examining children's adjustment to separation. Therefore, these findings suggest that young people may 'bounce back' quicker than previously thought.

It is clear that young people's experiences post-separation demonstrate three important elements: change, stability and variability. The change is represented in a number of ways and includes the increase in the early-stage separation participants' individual and family wellbeing from Time 1 to Time 2. Change is also evident in some of the young people's subjective reports over time, namely the increase in the early-stage separation group's positive feelings. In contrast 
the stability element can be seen in the later-stage participants' similar Time 1 and Time 2 individual and family wellbeing scores. Finally, variability is evident by the young people's diverse range of qualitative experiences. Specifically, some of their perspectives about their present circumstances and thoughts about their past did not show a clear pattern of stability or an increase or decrease from Time 1 to Time 2, but were more variable. In summary these young people's qualitative and quantitative experiences were multifaceted.

As illustrated in Study One and Study Two the young people were more than capable of expressing considered and balanced views. In Study Two the participants expressed a strong desire for relevant information, the opportunity to express their views, and for these views to be listened to. In this respect, this study has added further weight to the notion of children's social agency (Smart, Wade \& Neale, 1999). Some caution may nevertheless be appropriate. While some children may be astute capable communicators, other children may not know exactly how they feel or may be experiencing confused emotions. Some children may even prefer to keep their opinions to themselves. Thus, children should not be burdened with the expectation that they will express unequivocal views on aspects of family decision-making.

The findings from Study Two were consistent with Amato's (2000) divorce-stressadjustment perspective. Specifically, the findings supported the 'crisis' model that separation is a disturbance that most children will adjust to with the benefit of time. A caveat is required however. As discussed below, one limitation of Study Two is that the participants were not interviewed past the 18 month time point. Thus, no conclusions are possible as to the long-term adjustment of the participants. It is possible that some of the young people in this study that improved with time may go on to experience some adjustment problems later in their adolescent or adult years. It is also important to recognise that external validation of the young people's reports on their wellbeing and family dynamics 
was not sort. Individuals connected with the young people may have held very different views about their state of wellbeing and family dynamics.

As mentioned earlier, it is important to understand what family means to young people before understanding their perspectives in relation to family transitions. The young people were remarkably pragmatic in their acceptance of family diversity. Having such an open and accepting view of families is important for a child experiencing family structure change. During the transitional phases of parental separation, and in the subsequent years, young people's families and households can undergo multiple changes. Understanding what family means to young people can ensure a more thorough understanding of their experiences of family transitions. They may be less likely to see separation as an event that destroys the family if they have an inclusive concept of families. Thus, a realistic view of family diversity may help young people to navigate the transitions they experience in their family lives.

\subsection{Research Limitations and Recommendations}

There are some limitations in relation to Study One and Study Two. First, in Study One information on ethnic groups was collected in order to compare perceptions of families across cultural groups. There were few significant differences with regard to ethnicity. One of the difficulties in comparing groups by ethnicity is establishing whether the participants actually participate in their culture. For instance, New Zealand is a multicultural country; a number of the children interviewed were born and raised in New Zealand but identified themselves as belonging to an ethnic group that was not native to New Zealand. It is not surprising then that few differences were found given that these children had been raised in New Zealand. Stronger conclusions could have been drawn from the cultural comparisons in Study One if the extent of the children's cultural views and assimilation into New Zealand society was considered. Alternatively, studies that compare the perceptions of children from different countries, for 
example Diez-Martinez Day and Remigy (1999), may provide more reliable information regarding cross-cultural differences in perceptions of families.

Study Two was a longitudinal investigation of young people's experiences and adjustment; however, it could more accurately be referred to as a minilongitudinal study. The young people were interviewed at two time points over an 18 month period. The findings revealed a 19 to 28 month time frame for adjustment; however, as mentioned in chapter ten it was not possible to establish whether the young people had in reality improved earlier than the 19 to 28 month time frame suggests. Thus, future studies would benefit from an additional interview at the mid-way point of the 18 months in order to provide further information on their process of adjustment.

Furthermore, the Study Two participants were not interviewed past the 18 month time point. A question that arises from these findings is whether the improvements and stability of their individual and family wellbeing variables are evident long-term. An extended version of this study would be able to establish if their improved adjustment continued into adolescence and adulthood or whether their individual outcomes and family dynamics declined in time.

Control groups would have provided interesting comparative information in Study Two in terms of the extent of these young people's adjustment. However, as discussed previously the aim in this study was to provide information about young people post-separation and did not set out to replicate the findings of studies that have been carried out a number of times elsewhere. Study Two also may have benefited from information on income and socio-economic status as economic circumstances can potentially impact on young people's postseparation experiences.

Parents were reluctant to allow their children to participate in Study Two; therefore, it took considerable time to recruit the 52 young people. Some of the 
participants were recruited via a support group and an education programme in the initial stages of recruitment. Recruitment in this manner proved difficult as many of the young people's parents had been separated for longer than two years. This in itself provides valuable anecdotal evidence that young people may be provided with support and education programmes too late in the separation process. This is especially pertinent given the finding in this study that children can adjust earlier to parental separation than previously thought. It is important to emphasise that very few participants in this research were actually recruited via support groups or education programmes. Participants were later sought through other avenues, including newspaper articles and radio interviews, thus ensuring a wider range of participants. The initial aim in Study Two was to recruit approximately 70 young people; however it was not possible to reach that number. Future studies would benefit from larger samples, especially in order to undertake detailed family structure comparisons post-separation.

It was vital to retain all 52 participants over the course of the 18 months. Three participants had moved from the Wellington region by the time the second interviews were conducted. Two of these adolescent participants were interviewed by phone. The child participant was not interviewed by phone; therefore, there was no qualitative data for him. All three participants completed and returned their wellbeing scales by mail. This may have caused a variation in the data collection for a small number of the young people. However, every effort was made to ensure that the process was carried out as similar to a face-to-face interview as possible.

Finally, an important limitation to consider in Study Two involves the child participants that needed parental consent to participate. It is likely that the parents that were willing to allow their children to take part in Study Two were satisfied with the way they handled the separation and were therefore happy for their child to share their experiences. Thus, parents that were not happy with how they had dealt with the separation, or parents that were preoccupied with their 
own issues, may have been less likely to allow their children to take part. This scenario is difficult to avoid. Because the sample was self-selected and in fact selected by their parents, this may have biased the findings. However, it is clear from young people's responses in this study that not all parents were coping or dealing with the break-up optimally; there was a wide range of positive and negative experiences expressed.

\subsection{Research and Policy Implications}

The results of this study have a number of implications for policy and practice. These implications can be grouped under five headings, although there is significant overlap between them: children's perceptions of families; parental understanding of children's needs; support and coping; the importance of the family environment; and children's adjustment over time.

Children's perceptions of families. This research shows that children place a high value on families, while holding realistic and inclusive views of what constitutes a family. This suggests that children who experience new family structures as a result of parental separation will still consider themselves to be part of a family unit, particularly where positive affective factors are present. A similar conclusion was drawn by Anyan and Pryor (2002) in their study of adolescents' perceptions of families. The unanimous endorsement of the 'married couple with child' scenario in Study One shows that the original two-parent family remains the predominant family form in children's eyes. However, the inclusive nature of their definitions of family undermines any notion that this is the only structure children will accept as constituting a family. Transposing adult understandings of what constitutes a family on to children ignores their ability to think independently and to make reasoned value judgements.

Parental understanding of children's needs. Together the qualitative and quantitative results identify three key needs that young people have of their parents at the time of the separation. First, young people want both parents to tell 
them about the separation together. There is perhaps symbolic value for a child in parents acting together as a couple at this time. Second, children want to know that both parents will be available to support them throughout the process, and they will both continue to be involved in their lives. This underscores the importance of parents telling a child about the separation together. Not doing so might be interpreted by a child as a sign that one parent is no longer interested in them. Third, children want information about why the separation is happening, and what it will mean in practical terms. The young people in this study considered that they had not been kept properly informed during the separation, and that the flow of information had failed to improve over time. While they did not blame themselves for the separation, they were left to speculate as to the causes of it.

Given the range of mixed emotions children experience when their parents separate, this research suggests that separating parents should pay particular attention to these three areas. It is reassuring, therefore, to see that in New Zealand the Ministry of Justice funds a parent support programme called Parenting Through Separation (developed out of the Children in the Middle programme) that does address these issues with participating parents. Other government agencies, such as the Families Commission, might also take some responsibility for educating parents in these areas.

Support and coping. A key finding of Study Two is that few young people utilised formal sources of support, such as an education programme, a support group or counselling. This may indicate that the existing support programmes for children are not making their services widely known, or more likely that there are simply too few programmes available. These results might also be explained on the basis that parents and children simply do not wish to use formal support services. Indeed the young people in this study were reluctant to see counsellors, therapists or psychologists. If replicated across the wider population, this finding may raise an important question for potential support providers. It is often 
assumed that children should be offered formal support services to help them cope with parental separation. Yet the views expressed by young people in this study suggest that they may not want to use the services even if they are available.

One avenue that should be explored further is the development of an online resource that provides young people experiencing parental separation with information and support services. The advantages of an online model are first, that it would be easily accessed given the high rates of internet usage amongst young people and second, that it would not suffer from the negative connotations that can be associated with consulting a mental health professional. The disadvantage is that any support services provided through a website can not be tailored to the needs of the individual in the way that formal support services can. However, any online model might seek to supplement rather than replace these services. The mechanics of an online model would require careful planning, including careful consideration of search terms children might use. Any such planning should involve children who have experienced parental separation given that they are in the best position to offer advice as to the types of information that other children are likely to find beneficial.

The importance of the family environment. This study highlights the importance of the family environment in generating protective factors and stressors. Several protective factors, such as family cohesion and communication, were correlated with positive child outcomes, while certain stressors, such as poor parent-child relationships and conflict, were correlated with negative outcomes. Parental conflict was repeatedly referred to by participants. For example, the absence of parental conflict was the most commonly reported positive outcome of young people's new living arrangements. Children in this study were also adept at identifying parental behaviour changes and stonewalling. Thus, while any future efforts to educate parents about the potential risks to children's outcomes from exposure to conflict are likely to be beneficial, any public information campaign 
should extend to include non-verbal forms of conflict as well as physical and verbal forms.

The other important aspect of the family environment in this study was the association between multiple stressors or protective factors across time. For example, family cohesion at Time 1 (protective factor) was positively correlated with positive perceptions of mothers and fathers at Time 2 (protective factor). This 'snowball' effect, where stressors or protective factors build on the existence of other stressors or protective factors, has important implications for government policy. Given that children's post-separation wellbeing is of central importance, those policies that prevent the onset or development of risk factors, and those that generate or enhance protective factors, should be encouraged, for example publicly funded parenting skills courses. The benefit of these policies is not only that they can affect a single stressor or protective factor, but they can stymie the development of further stressors, or promote the existence of additional protective factors. In this way, government policies can facilitate positive rather than negative life trajectories for children whose parents separate (Elder, 1998).

Children's adjustment over time. The longitudinal aspect of this study showed that children's individual and family wellbeing improved over time. In terms of group comparisons, by Time 2 the early-stage separation group had reached similar levels of wellbeing to the later-stage separation group, which had reported high levels of wellbeing at both Time 1 and Time 2 . These results suggest that it is important not to catastrophise the impact of parental separation on young people. While they can find the separation process emotionally painful and difficult to navigate at times, the findings of this study clearly show that these young people had adjusted to post-separation life. Moreover, the adjustment for the early-stage separation group occurred within a 19 to 28 month period, which is earlier than commonly thought to be the case. It is hoped that the results from this study contribute to a shift in public debate in New Zealand away from an emotive argument about whether separation harms children, to a more objective 
discussion about the policies that may contribute to good post-separation outcomes for children.

The findings of Study Two also contain valuable insights into the experiences of young people whose parents have separated. Their experiences, and in particular the factors that helped them to cope with their new circumstances, could be included in any future print or online resources aimed at young people experiencing family structure change.

\subsection{In Conclusion}

Study One and Study Two provide much needed insight into the views of New Zealand children and adolescents regarding families and family transitions. The young people's inclusive and realistic definitions of families in Study One, illustrates their flexibility and willingness to accept a variety of configurations as families. In Study Two the young people's resiliency is evident in their experiences and adjustment to parental separation over time.

Including young people as active participants and listening to their point-of-view were guiding principles in both studies. It is evident that children can express reasoned opinions and are able to provide valuable information that can in turn be used to understand and support them. These studies provide important insight into young people's perceptions at this time. Furthermore, the emphasis on young people's experiences post-separation adds a new dimension to the large body of research that tends to focus on children from intact families and pre and post-separation adjustment.

In conclusion, this study has given voice to the views of children and adolescents in areas crucial to their wellbeing and day to day lives. It has demonstrated remarkable adaptability in the face of change, and identified factors that enhance adaptability and resilience. It provides a strong message that parental separation 
need not be a catastrophic event; rather, that children are active in managing these transitions themselves and, given the right support, can thrive. 
"The family is dynamic because of its relationship quality. It is fragile while durable, and tentative while permanent.

The family is adaptable."

(Peters, 1995, p.77). 


\section{REFERENCES}

Acock, A. C., \& Demo, D. H. (1994). Family diversity and well-being. Thousand Oaks, California: Sage.

Amato, P. R. (1987). Children's reactions to parental separation and divorce: The views of children and custodial mothers. Australian Journal of Social Issues, 22(4), 610623.

Amato, P. R. (1993). Children's adjustment to divorce: Theories, hypotheses, and empirical support. Journal of Marriage and the Family, 55, 23-8.

Amato, P. R. (2000). The consequences of divorce for adults and children. Journal of Marriage and the Family, 62, 1269-1287.

Amato, P. R., \& Booth, A. (1995). Changes in gender role attitudes and perceived marital quality. American Sociological Review, 60, 58-66.

Amato, P. R., \& Booth, A. (1996). A prospective study of divorce and parent-child relationships. Journal of Marriage and the Family, 58, 356-65.

Amato, P. R., \& Gilbreth, J. G. (1999). Nonresident fathers and children's wellbeing: A meta analysis. Journal of Marriage and the Family, 61, 557-573.

Amato, P. R., \& Keith, B. (1991). Parental divorce and the wellbeing of children: A metaanalysis. Psychological Bulletin, 110, 26-46.

Anyan, S. (1998). Adolescent's perceptions of family. Unpublished master's thesis, University of Auckland, Auckland, New Zealand.

Anyan, S., \& Pryor, J. (2002). What is in a family? Adolescent perceptions. Children \& Society, 16, 306-317.

Atkin, B., Caldwell, J., Clarkson, D.F., Henaghan, M., Partridge, D., Treadwell, P., Webb, P. R. H. (2007). Butterworths family law in New Zealand (Volume $1,13^{\text {th }}$ edition). Wellington, New Zealand: LexisNexis.

Bagshaw, D. (1998, October). Determining the best interests of the child: A grief and loss perspective. Paper presented at the Third National Family Court Conference, Melbourne, Australia.

Baker, M (2001). Families, labour and love: Family diversity in a changing world. Sydney, Australia: Allen \& Unwin.

Bernardes, J. (1999). We must not define 'the family'! Marriage \& Family Review, 28(34), 21-41. 
Booth, A. (1999). Causes and consequences of divorce: Reflections on recent research. In R. A. Thompson, \& P. R. Amato. (Eds.). The postdivorce family (pp 29-48). Thousand Oaks, California: Sage.

Booth, A., \& Amato, P. R. (1991). Divorce and psychological stress. Journal of Health and Social Behaviour, 32, 396-407.

Booth, A., \& Amato, P. R. (1994). Parental marital conflict, parental divorce, and relations with parents. Journal of Marriage and the Family, 56, 21-35.

Borduin, C., Mann, B., Cone, L., \& Borduin, B. (1990). Development of the concept of family in elementary school children. Journal of Genetic Psychology, 151, 33-43.

Bradshaw, J. (1998). International comparisons of support for lone parents. In R. Ford, \& J. Miller. (Eds.). Private lives and public responses: Lone parenthood and future policy in the UK (pp. 154-168). London: Policy Studies Institute.

Brannen, J., Heptinstall, E., \& Bhopal, K. (1999). Connecting children: Care and family life in later childhood. London: Routledge Fëlmer.

Brannen, J., Heptinstall, E., \& Bhopal, K. (2000). Care and family life in later childhood. London: Thomas Coram Research Unit, Institute of Education.

Brannen, J. (2005). Mixing methods: The entry of qualitative and quantitative approaches. International Journal of Social Research Methodology, 8(3), 173184.

Bray, J. H., \& Kelly, J. (1998). Stepfamilies: Love, marriage, and parenting in the first decade. New York: Broadway Books.

Bream, V., \& Buchanan, A. (2003). Distress among children whose separated or divorced parents cannot agree arrangements for them. British Journal of Social Work, 33, 227-238.

Bronfenbrenner, V. (1979). The ecology of human development. Cambridge, Massachusetts: Harvard University Press.

Bryman, A. (2001). Social Research Methods. Oxford: Oxford University Press.

Buehler, C., Krishnakumar, A., Stone, G., Anthony, C., Pemberton, S., Gerard, J., \& Barber, B. K. (1998). Interparental conflict styles and youth problem behaviours: A two-sample replication study. Journal of Marriage and the Family, 60, 119-132.

Burgoyne, J. \& Clark, D. (1984). Making a go of it: A Study of stepfamilies in Sheffield. London: Routledge and Kegan Paul.

Bussell, D. A. (1995). A pilot study of African American children's cognitive and emotional reactions to parental separation. Journal of Divorce and Remarriage, 25, 3-15. 
Butler I., Scanlan, L., Robinson, M., Douglas, G., \& Murch, M. (2002). Children's involvement in their parents' divorce: Implications for practice. Children \& Society, 16, 89-102.

Burns, A., \& Dunlop, R. (1999). How did you feel about it? Children's feelings about their parent's divorce at the time and three and ten years later. Journal of Divorce and Remarriage, 31, 19-36.

Capaldi, D. M., \& Patterson, G. R. (1991). Relation of parental transitions to boy's adjustment problems: I. A linear hypothesis. II. Mothers at risk for transitions and unskilled parenting. Developmental Psychology, 27, 489-504.

Cartwright, C., \& Seymour, F. (2002). Young adults' perceptions of parents' responses in stepfamilies: What hurts? What helps? Journal of Divorce and Remarriage, 37, 123-142.

Cherlin, A. J., Furstenberg, F. F., Chase-Lansdale, P. L., Kiernan, K. E., Robins, P. K., Morrison, D. R., \& Teitler, J. O. (1991). Longitudinal studies of effects of divorce on children in Great Britain and the United States. Science, 252, 1386-9.

Cherlin, A. J., \& Furstenberg, F. F. (1986). The new American grandparent: A place in the family, a life apart. New York: Basic Books.

Cherlin, A. J., Chase-Lansdale, P. L., \& McRae, C. (1998). Effects of divorce on mental health throughout the life course. American Sociological Review, 63, 239-249.

Coleman, J. S. (1998). Social capital in the creation of human capital. American Journal of Sociology, 94, S95-S120.

Coleman, M., Ganong, L., \& Fine, M. (2000). Reinvestigating remarriage: Another decade of progress. Journal of Marriage and the Family, 62, 1288-1307.

Columbia Encyclopedia (2001). "Family". Retrieved on 13 April, 2007, from http://www.encyclopedia.com/

Coney, S. (1993). Standing in the sunshine: A history of New Zealand women since they won the vote. Auckland, New Zealand: Viking.

Connell, J. P. (1985). A new multi dimensional measure of children's perceptions of control. Child Development, 56, 1018-1041.

Coser, R. L. (1964). Introduction. In R. L. Coser (Ed.). The family: Its structures and functions (pp. $x v-x x v i i i)$. New York: St. Martin's Press Inc.

Cowan, P. A., Cowan, C. P., \& Schulz, M. S. (1996). Thinking about risk and resilience in families. In E. M. Hetherington \& E. A. Blechman (Eds.), Stress, coping, and resiliency in children and families (pp. 1-38 ). Mahwah, New Jersey: Erlbaum.

Crawford, A. (2002). The silent effect of parental emotional conflict on adolescent adjustment. Unpublished master's thesis, Victoria University of Wellington, Wellington, New Zealand. 
Creswell, J. W. (2003). Research design: Qualitative, quantitative, and mixed methods approaches. Thousand Oaks, California: Sage Publications.

Cummings, E. M., \& Davies, P. T. (2002). Effects of marital conflict on children: Recent advances and emerging themes in process-orientated research. Journal of Child Psychology and Psychiatry, 43, 31-63.

Dalziel, L. (2004). New Zealand Parliamentary Debates. 23 June 2004. Wellington, New Zealand: House of Representatives.

Davidson, C. (1991). The 'family' in New Zealand. New Zealand Population Review, 17(2), 4-26.

DeGarmo, D. S., \& Forgatch, M. S. (1999). Contexts as predictors of changing parenting practices in diverse family structures: A social interactional perspective of risk and resilience. In E. M. Hetherington (Ed.). Coping with divorce, single parenting, and remarriage: A risk and resiliency perspective (pp. 253-271). Mahwah, New Jersey: Lawrence Erlbaum Associates.

Dekovic, M. (1999). Risk and protective factors in the development of problem behaviour during adolescence. Journal of Youth and Adolescence, 28, 667-685.

Demo, D. H., \& Acock, A. C. (1988). The impact of divorce on children. Journal of Marriage and the Family, 50, 619-648.

Dharmalingam, A., Pool, I., Sceats, J., \& Mackay, R. (2004). Patterns of family formation and change in New Zealand. Wellington, New Zealand: Ministry of Social Development.

Diez-Martinez Day, E., \& Remigy, M. J. (1999). Mexican and French children's conceptions about family: A developmental approach. Journal of Comparative Family Studies, 30(1), 95-112.

Douglas, J. W. B. (1970). Broken families and child behaviour. Journal of the Royal College of Physicians London, 4, 203-210.

Duke, M. D. \& Lancaster, W. (1976). A note on locus of control as a function of father absence. Journal of Genetic Psychology, 129, 335-336.

Dunn, J. (2003). Contact and children's perspectives on parental relationships. In A. Bainham, B. Lindley, L. Trinder, \& M. Richards (Eds.). Children's relationships: Welfare, rights and contact (pp. 15-32). Oxford, UK: Hart.

Dunn, J. (2004). Understanding children's family worlds: Family transitions and children's outcomes. Merrill-Palmer Quarterly, 50, 224-235.

Dunn, J., Davies, L. C., O'Connor, T. G., \& Sturgess, W. (2001). Family lives and friendships: The perspectives of children in step-, single-parent and nonstep families. Journal of Family Psychology, 15(2), 272-287. 
Dunn, J., \& Deater-Deckard, K. (2001). Children's views of their changing families. York, UK: Joseph Rowntree Foundation.

East, M. (1980). Home economics, past, present, and future. Boston: Allyn and Bacon.

Education Review Office (1998, Autumn). Good schools poor schools. (No. 4). Wellington, New Zealand: Author.

Elder, G. H. (1998). The life course as development theory. Child Development, 69, 112.

Emery, R. E. (1982). Interparental conflict and the children of discord and divorce. Psychological Bulletin, 92, 310-330.

Emery, R. E. (1999). Postdivorce family life for children: An overview of research and some implications for policy. In R. A. Thompson and P. R. Amato (Eds.). The postdivorce family (pp. 3-27). Thousand Oaks, California: Sage.

Emery, R. E., \& Forehand, R. (1994). Parental divorce and children's wellbeing: A focus on resilience. In R. J. Haggerty, L. R. Sherrod, N. Garmezy, \& M. Rutter (Eds.). Stress, risk, and resilience in children and adolescents (pp. 64-99). Cambridge, UK: Cambridge University Press.

English, B. (2003). New Zealand Parliamentary Debates. 13 May 2003. Wellington, New Zealand: House of Representatives.

Families Commission (2005). What we do. Family Voice, 1, 1.

Fawcett, M. (1998). What hurts? What helps?: A study of needs and services for young people whose parents separate and divorce. Belfast: RelateTeen.

Field, A. (2005). Discovering statistics using SPSS ( $2^{\text {nd }}$ edition). Thousand Oaks, California: Sage.

Finch, J., \& Mason, J. (1993). Negotiating family responsibilities. London: Routledge.

Fine, M. A., \& Demo, D. H. (2000). Divorce: Soci23wcgtr5f4etal ill or normative transition? In R. Milardo, \& S. Duck (Eds.). Families as relationships (pp. 135156). John Wiley and Sons Ltd., Chichester, NY.

Fleming, R. (1999). Families of a different kind. Wellington, New Zealand: Families of Remarriage Project.

Flowerdew, J., \& Neale, B. (2003). Trying to stay apace: Children with multiple challenges in their post divorce family lives. Childhood, 10(2), 147-161.

Frost, A. K., \& Pakiz, B. (1990). The effects of marital disruption on adolescents: Time as a dynamic. American Journal of Orthopsychiatry, 60, 544-555. 
Fu, V. R., Goodwin, M. P., Sporakowki, M. J., \& Hinkle, D. E. (1986). Children's thinking about family characteristics and parent attitudes. Journal of Genetic Psychology, 148(2), 153-166.

Funder, K. (1996). Remaking families: Adaptation of parents and children to divorce. Melbourne, Australia: Australian Institute of Family Studies.

Garfinkel, I., \& McLanahan S. S. (1986). Single mothers and their children: A new American dilemma. Washington, DC: Urban Institute Press.

Ganong, L. H., \& Coleman, M. (1994). Remarried family relationships. London: Sage.

Gerard, J. M., \& Beuhler, C. (1999). Multiple risk factors in the family environment and youth problem behaviours. Journal of Marriage and the Family, 61, 343-361.

Gilby, R. L., \& Pederson, D. R. (1982). The development of the child's concept of the family. Canadian Journal of Behavioural Science, 14(2), 110-121.

Gillard, L., \& Seymour, F. (2005). Children in the middle: A parent education programme for separated parents. Auckland, New Zealand: The University of Auckland.

Gittins, D. (1985). The family in question: Changing households and familiar ideologies. London: Macmillan Publishers Ltd.

Glaser, B. G. (1992). Basics of grounded theory analysis: Emergence versus forcing. Mill Valley, California: Sociology Press.

Goldberg, W. A., Greenberger, E., Hamill, S., \& O'Neil, R. (1992). Role demands in the lives of employed single mothers with preschoolers. Journal of Family Issues, 13, 312-333.

Gollop, M. M. (2000). Interviewing children: A research perspective. In A. B. Smith, N. J. Taylor, \& M. M. Gollop. (Eds.). Children's voices: Research, policy and practice (pp. 18-36). Auckland, New Zealand: Pearson Education New Zealand Limited.

Gollop, M. M., Taylor, N. J., \& Smith, A. B. (2000). Children's perspectives of their parent's separation. In A. B. Smith, N. J. Taylor, \& M. M. Gollop (Eds.). Children's voices: Research, policy and practice (pp. 134-156). Auckland, New Zealand: Pearson Education New Zealand Limited.

Goodman, R. (1997). The strengths and difficulties questionnaire: A research note. Journal of Child Psychology and Psychiatry, 38, 581-586.

Goodman, R., \& Scott, S. (1999). Comparing the strengths and difficulties questionnaire and the child behaviour checklist. Journal of Abnormal Child Psychology, 27(1), 17-24.

Gorrell Barnes, G., Thompson, P., Daniel, G., \& Burchardt, N. (1998). Growing up in stepfamilies. Oxford, Britain: Clarendon Press. 
Greene, S., \& Hill, M. (2005). Children's experience of parental separation: Methods and methodological issues. In S. Greene, \& D. Hogan. (Eds.). Researching children's experience: Approaches and methods. London: Sage.

Grych, J. H., \& Fincham, F. D. (1990). Marital conflict and children's adjustment: A cognitive-contextual framework. Psychological Bulletin, 108, 267-290.

Gubrium, J. F., \& Holstein, J. A. (1990). What is family? Mayfield: Mountain View.

Guidubaldi, J., Cleminshaw, H. K., Perry, J. D., McLoughlin, C. S. (1983). The impact of parental divorce on children: Report of the nationwide NASP study. School Psychology Review, 12, 300-323.

Hawthorne, J., Jessop, J., Pryor, J., \& Richards, M. (2003). Supporting children through family change: A review of interventions and services for children of divorcing and separating parents. York, UK: Joseph Rowntree Foundation.

Hair J. F., Black, W. C., Babin, B. J., Anderson, R. E., \& Tatham, R. L. (2006). Multivariate Data Analysis ( $6^{\text {th }}$ edition). New Jersey: Pearson Prentice Hall.

Hall, J. (1998). Children in stepfamilies. In M. MacLeod, J. Hall, G. Keep, A. Mason, C. Pegram (Eds.). Unhappy families, unhappy children. London: Childline.

Harold, G. T., Fincham, F. D., Osborne, L. N. \& Conger, R. D. (1997). Mom and Dad are at it again: Adolescent perceptions of marital conflict and adolescent psychological distress. Developmental Psychology, 33, 222-350.

Harold G. T., Shelton, K. H., Goeke-Morey, M. C., and Cummings, E. M. (2004). Martial conflict, child emotional security about family relationships and child adjustment. Social Development, 13, 350-376.

Hetherington, E. M. (1989). Coping with family transitions: Winners, losers and survivors. Child Development, 60, 1-14.

Hetherington, E. M. (1993). An overview of the Virginia longitudinal study of divorce and remarriage with a focus on early adolescence. Journal of Family Psychology, 7, 39-56.

Hetherington, E. M. (1999). Should we stay together for the sake of the children? In E. $\mathrm{M}$. Hetherington (Ed.). Coping with divorce, single parenting, and remarriage (pp. 93-116). Mahwah, New Jersey: Erlbaum.

Hetherington, E. M., Cox, M., \& Cox, R. (1982). Effects of divorce on parents and children. In M. Lamb (Ed.). Non-traditional families: Parenting and child development (pp. 233-288). Hillsdale, New Jersey: Lawrence Erlbaum.

Hetherington, E. M., Stanley-Hagan, M., \& Anderson, E. R. (1989). Marital transitions: A child's perspective. American Psychologist, 44, 303-312. 
Hetherington, E. M., \& Clingempeel, W. G. (1992). Coping with marital transitions: A family systems approach. Monographs of the Society for Research in Child Development, 57, 2-3.

Hetherington, E. M., \& Kelly, J. (2002). For better or for worse. New York: Norton.

Henaghan, M. (2004). Legally defining the family. In M. Henaghan, \& B. Atkin (Eds.). Family law policy in New Zealand ( $2^{\text {nd }}$ edition) (pp.1-40). Wellington: LexisNexis Butterworths.

Highet, G., \& Jamieson, L. (2005). Cool with change: Young people and family change. Edinburgh: Centre for Research on Families and Relationships.

Hogan, D., Halpenny, A. M., \& Greene, S. (2002). Children's Experiences of Parental Separation. Dublin: The Children's Research Centre, Trinity College Dublin.

Hogan, D. M., Halpenny, A., \& Greene, S. (2003). Change and continuity after parental separation: Children's experiences of family transition in Ireland. Childhood, (10)2, 163-180.

Horm-Wingerd, D. M., Groves, M. M., \& Nekovei, D. L. (1992). Children from divorced and intact homes: Similarities and differences in perceptions of family. Child Study Journal, 22(3), 185-200.

Jamison, A., \& Gilbert, L. (2000). Facilitating children's voices in the community and government. In A. B. Smith, N.J. Taylor \& M. M. Gollop (Eds.). Children's voices: Research, policy and practice (pp. 181-201). Auckland, New Zealand: Pearson Education New Zealand Limited.

Jekielek, S. M. (1998). Parental conflict, marital disruption and children's emotional wellbeing. Social Forces, 76, 905-935.

Jenson, J. M., \& Fraser, M. W. (2005). A risk and resilience framework for child, youth, and family policy. In J. M. Jenson, \& M. W. Fraser (Eds.). Social policy for children and families: A risk and resilience perspective (pp. 1-17). Thousand Oaks, California: Sage.

Johnston, J. R., \& Roseby, V. (1997). In the name of the child: A developmental approach to understanding and helping children of conflict and violent divorce. New York: Free Press.

Kalter, N., \& Rembar, J. (1981). The significance of a child's age at the time of parental divorce. American Journal of Orthopsychiatry, 51, 85-100.

Kalter, N., \& Plunkett, J. W. (1984). Children's perceptions of the causes and consequences of divorce. Journal of the American Academy of Child Psychiatry, 23(3), 326-334.

Kamerman, S. B. (1980). Parenting in an unresponsive society: Managing work and family life. New York: The Free Press. 
Keep, G., \& Pegram, J. (1998). Living with a lone parent. In M. MacLeod, J. Hall, G. Keep, A. Mason, C. Pegram (Eds.). Unhappy families, unhappy children. London: Childline.

Keller, S. (1974). Does the family have a future? In R. L. Coser (Ed.). The family: Its structures and functions (pp. 579-592). New York: St. Martin's Press Inc.

Kelly, J. B. (1998). Marital conflict, divorce and children's adjustment. Child and Adolescent Psychiatric Clinics of North America, 7, 259-271.

Kelly, J. B., \& Emery, R. E. (2003). Children's adjustment following divorce: Risk and resilience perspectives. Family Relations, 54, 352-362.

Kelly, J. B., \& Johnston, J. R. (2001). The alienated child: A reformulation of parental alienation syndrome. Family Court Review, 39, 249-266.

Kitson, G. C. (1992). Portrait of divorce: Adjustment to marital breakdown. New York: Guilford Press.

Kitson, G. C., \& Morgan, L. A. (1990). The multiple consequences of divorce: A decade review. Journal of Marriage and the Family, 52, 913-924.

Kline, M., Tschann, J. M., Johnston, J. R., \& Wallerstein, J. S. (1989). Children's adjustment in joint and sole physical custody families. Developmental Psychology, 25, 430-438.

Kovac, M. (1985). The children's depression inventory (CDI). Psychopharmacology Bulletin, 21(4), 995-998.

Kurdek, L. A., \& Siesky, A. E. (1980). Children's perceptions of their parents' divorce. Journal of Divorce, 3, 339-378.

Kurdek, C. A., Blisk, D., \& Siesky, A. E. (1981). Correlates of children's long-term adjustment to their parents' divorce. Developmental Psychology, 17, 565-79.

Kurdek, L. A., \& Berg, B. (1983). Correlates of children's adjustment to their parent's divorce. In L. A. Kurdek (Ed.). Child and divorce (pp. 47-60). San Francisco: Jossey-Bass.

Kurdek, L., \& Berg, B. (1987). Children's beliefs about parental divorce scale: Psychometric characteristics and concurrent validity. Journal of Consulting and Clinical Psychology, 55, 712-718.

Kurdek, L. A., \& Sinclair, R. J. (1988). Adjustment of young adolescents in two-parent nuclear, stepfather, and mother-custody families. Journal of Consulting and Clinical Psychology, 56, 91-96.

Lahey, B. B., Hartdagen, S. E., Frick, P. J., McBurnett, K., Connor, R., \& Hynd, G. W. (1988). Contact disorder: Parsing the confounded relation to parental divorce and antisocial personality. Journal of Abnormal Psychology, 97, 334-337. 
Lamb, M. E., Sternberg, K., \& Thompson, R. A. (1997). The effects of divorce and custody arrangements on children's behaviour, development, and adjustment. Expert Evidence, 5(1), 83-88.

Levin, I. (1999). What phenomenon is family? Marriage \& Family Review, 28(3-4), 93104.

Losoncz, I. (2008). Shared parental responsibility: Stability of arrangements among separated Australian families of young children across two years. Family Matters, 79, 26-33.

Lourenco, O., \& Machado, A. (1996). In defence of Piaget's theory: A reply to 10 common criticisms. Psychological Review, 103, 143-164.

Ludbrook, R., \& de Jong, L. (2005). Care of children in New Zealand: Analysis and expert commentary. Wellington, New Zealand: Brookers.

Lyon, C. M., Surrey, E., \& Timms, J. E. (1999). Effective support services for children and young people when parental relationships break down. Liverpool: Centre for the Study of the Child, the Family, and the Law.

Machida, S., \& Holloway, S. D. (1991). The relationship between divorced mothers perceived control over child-rearing and children's post-divorce adjustment. Family Relations, 40, 272-278.

MacLeod, M. (1998). Separation and divorce. In M. MacLeod, J. Hall, G. Keep, A. Mason, C. Pegram (Eds.). Unhappy families, unhappy children. London: Childline.

Mauldon, J. (1990). The effect of marital disruption on children's health. Demography, $27,431-446$.

Mazur, E. (1993). Developmental differences in children's understandings of marriage, divorce, and remarriage. Journal of Applied Developmental Psychology, 14, 191 212.

McCubbin, M. A., \& McCubbin, H. I. (1991). Family stress theory and assessment: The resiliency model of family stress, adjustment, and adaptation. In H. I. McCubbin, \& A. I. Thompson (Eds.). Family assessment inventories for research and practice ( $2^{\text {nd }}$ edition) (pp. 294-312). Madison, Wisconsin: University of Wisconsin.

McLanahan, S. S., \& Booth, K. (1989). Mother-only families: problems, prospects, and politics. Journal of Marriage and the Family, 51, 557-580.

Menaghan, E. G., \& Lieberman, M. A. (1986). Changes in depression following divorce: A panel study. Journal of Marriage and the Family, 48, 319-328.

Metge, J. (1995). New growth from old: The whānau in the modern world. Wellington, New Zealand: Victoria University Press. 
Mitchell, A. (1985). Children in the middle: Living through divorce. London: Tavistock Publications.

Ministry of Social Development. (2004). New Zealand families today: A briefing for the Families Commission. Wellington, New Zealand: Ministry of Social Development.

Moos, R., \& Moos, B. (1981). Family environment scale manual. Palo Alto, California: Consulting Psychologists Press.

Morgan, L. A. (1991). After marriage ends: Economic consequences for mid-life women. Newbury Park, California: Sage.

Morrow, V. (1998). Understanding families: Children's perspectives. London: National Children's Bureau Enterprises Ltd.

Moxnes, K. (1999). What are families after divorce? Marriage \& Family Review, 28(3-4), 105-120.

Murdock, G. P. (1949). Social Structure. New York: The Macmillan Company.

Neugebauer, R. (1989). Divorce, custody and visitation: The child's point of view. Journal of Divorce, 12, 153-168.

Newman, J. L., Roberts, L. R., \& Syre, C. R. (1993). Concepts of family among children and adolescents: Effect of cognitive level, gender, and family structure. Developmental Psychology, 29(6), 951-962.

O'Brien, M., Alldred, P., \& Jones, D. (1996). Children's constructions of family and kinship. In J. Brannen, \& M. O'Brien (Eds.). Children in families: Research and Policy (pp. 84-100). London: Falmar Press.

O'Connor, P. (2004). Voice and support: Programs for children experiencing parental separation and divorce. Ottawa, Canada: Department of Justice.

O'Quigley, A. (2000). Listening to children: The findings and recommendations of recent research. York, UK: Joseph Rowntree Foundation.

Pallant, J. (2005). SPSS survival manual: A step by step guide to data analysis using SPSS ( $2^{\text {nd }}$ edition). Sydney, Australia: Allen \& Unwin.

Parkinson, P., Cashmore, J., \& Single, J. (2005). Adolescents' views on the fairness of parenting and financial arrangements after separation. Family Court Review, 43(3), 429-444.

Parsons, T. (1965). The normal American family. In S. Farber, P. Mustacchi, \& R. H. L. Wilson (Eds.). Man and civilization: The family's search for survival (pp 31-49). New York: McGraw Hill.

Phares, V., \& Renk, K. (1998). Perceptions of parents: A measure of adolescents' feelings about their parents. Journal of Marriage and the Family, 60, 646-659. 
Pedro-Carroll, J. L. (2005). Fostering resilience in the aftermath of divorce: The role of evidence based programs for children. Family Court Review, 43, 52-64.

Peters, J. F. (1995). Canadian Families in year 2000. International Journal of Sociology of the Family, 25(1), 63-79.

Peters, J. F. (1999). Redefining western families. Marriage \& Family Review, 28(3-4), $55-66$.

Piaget, J. (1928). Judgment and reasoning in the child. New York: Kegan Paul, Trench, Trubner \& Co. Ltd.

Plunkett, J. W., \& Kalter, N. (1984). Children's beliefs about reactions to parental divorce. Journal of American Academy of Child Psychiatry, 23(5), 616-621.

Powell, J. A., Wiltcher, B. J., Wedemeyer, N. V., \& Claypool, P. L. (1981). The young child's developing concept of family. Home Economics Research Journal, 10(2), 137-149.

Pritchard, R. (1998). When parent's part: How children adapt. Auckland, New Zealand: Penguin.

Pryor, J. (1999). Waiting until they leave home: the experiences of young adults whose parents separate. Journal of Divorce and Remarriage, 32, 47-61.

Pryor, J. (2003). Not in front of the children? The impact of silent conflict. Unpublished manuscript.

Pryor, J. (2004). Stepfamilies and resilience: Final report. Wellington, New Zealand: Ministry of Social Development.

Pryor, J. (2005). Children in Changing Family Structures. Keynote presentation at the conference of the Australasian Human Development Association (AHDA), July, Perth, Australia.

Pryor, J., \& Daly-Peoples, R. (2001). Adolescent attitudes toward living arrangements after divorce. Child and Family Law Quarterly, 13(2), 197-208.

Pryor, J. \& Pattison, R. (2007). Adolescents' perceptions of parental conflict: The downside of silence. Journal of Family Studies, 13, 72-77.

Pryor, J., \& Roberts, J. (2005). What is commitment? How married and cohabiting parents talk about their relationships. Family Matters, 71 (Winter), 28-35.

Pryor, J., \& Rodgers, B. (2001). Children in changing families: Life after parental separation. Oxford, UK: Blackwell Publishers Ltd.

Pryor, J., \& Seymour, F. (1996). Making decisions about children after parental separation. Child and Family Law Quarterly, 8(3), 229-242. 
Raschke, H. J. (1987). Divorce. In M. B. Sussman, \& S. K. Steinmetz (Eds.). Handbook of marriage and the family (pp. 597-624). New York: Plenum.

Reinhard, D. W. (1977). The reaction of adolescent boys and girls to the divorce of their parents. Journal of Clinical Child Psychology, Summer, 21-23.

Reiss, I. L., \& Lee, G. R. (1988). Family systems in America (4 $4^{\text {th }}$ edition). New York: Holt, Rinehart and Winston, Inc.

Rigg, A., \& Pryor, J. (2007). Children's perceptions of families: What do they really think? Children \& Society, 21, 17-30.

Rodgers, B. (1990). Adult affective disorder and early environment. British Journal of Psychiatry, 157, 539-550.

Rodgers, B., \& Pryor, J. (1998). Divorce and separation: The outcomes for children. York, UK: Joseph Rowntree Foundation.

Rodgers, K. A., \& Rose, H. A. (2002). Risk and resiliency factors among adolescents who experience marital transitions. Journal of Marriage and Family, 64, 10241037.

Rutter, M. (1983). Stress, coping, and development: Some issues and some questions. In N. Garmezy, \& M. Rutter (Eds.). Stress, coping, and development in children (pp. 1-41). New York: McGraw Hill.

Rutter, M. (1987). Psychosocial resilience and protective mechanisms. American Journal of Orthopsychiatry, 57, 316-331.

Rutter, M. (1990). Psychosocial resilience and protective mechanisms. In J. Rolf, A. S. Masten, D. Cicchetti, K. H. Nuechterlein, \& S. Weintraub (Eds.). Risk and protective factors in the development of psychopathology (pp. 181-214). Cambridge, UK: Cambridge University Press.

Ruschena, E., Prior, M., Sanson, A., Smart, D. (2005). A longitudinal study of adolescent adjustment following family transitions. Journal of Child Psychology and Psychiatry, 46, 353-363.

Seasons for Growth. (1996). Companion program manual. Sydney, Australia: The Mary MacKillop Foundation Limited.

Settles, B. H. (1987). A perspective on tomorrow's families. In M. B. Sussman, \& S. K. Steinmetz (Eds.). Handbook of Marriage \& the Family (pp. 157-180). New York: Plenum Press.

Simons, R. L. (1996). Understanding differences between divorced and intact families: Stress, interaction, and child outcome. Thousand Oaks, California: Sage.

Simons, R. L., Lin, K., Gordon, L. C., Conger, R. D., Lorenz, F. O. (1999). Explaining the higher incidence of adjustment problems among children of divorce compared 
with those in two-parent families. Journal of Marriage and the Family, 61, 10201033.

Smart, C., \& Neale, B. (2000). 'It's my life too' - children's perspectives on post-divorce parenting. Family Law, March, 163-169.

Smart, C., Neale, B., \& Wade, A. (2001). The Changing experience of childhood: Families and divorce. Cambridge: Polity Press.

Smart, C., Wade, A., \& Neale, B. (1999). Objects of concern? Children and divorce. Child and Family Law Quarterly, 11(4), 365-376.

Smart, C., Wade, A., \& Neale, B. (2000). New childhoods: Children and co-parenting after divorce. Stirling, UK: Children 5-16 Research Programme.

Smith, A. B. (1993). Understanding children's development (3rd edition). Wellington, New Zealand, Bridget Williams Books.

Smith, A. B., \& Gollop, M. M. (2001). What children think separating parents should know. New Zealand Journal of Psychology, 30, 23-31.

Smith, A. B., \& Taylor, N., J. (2000). The sociocultural context of childhood: Balancing dependency and agency. In A. B. Smith, N. J. Taylor, \& M. M. Gollop (Eds.). Children's voices: Research, policy and practice (pp. 1-17). Auckland, New Zealand: Pearson Education New Zealand Limited.

Smith, A. B., Taylor, N. J., Gollop, M., Gaffney, M., Gold, M., \& Heneghan, M. (1997). Access and other post-separation issues. Dunedin, New Zealand: Children's Issues Centre.

Smith, A. B., Taylor, N. J., \& Tapp, P. (2003). Rethinking children's involvement in decision-making after parental separation. Childhood, 10, 201-216.

Smith, M., Robertson, J., Dixon , J., Quigley M., \& Whitehead, E. (2001). A study of stepchildren and step-parenting: Final report to the Department of Health. London: Thomas Coram Research Unit.

Smith, N. (2004). New Zealand Parliamentary Debates. 24 June 2004. Wellington, New Zealand: House of Representatives.

Spann, L. (1998). My life as a game piece: Kids talk about their experiences with parents' divorce. Children's Advocate, (January-February).

Stafford, A., Laybourn, A., Hill, M., \& Walker, M. (2003). Having a say: Children and young people talk about consultation. Children \& Society, 17(5), 361-373.

Statistics New Zealand (2002a). 2001 Census of population and dwellings: Ethnic groups. Wellington: Author.

Statistics New Zealand (2002b). 2001 Census of population and dwellings: Families and households. Wellington, New Zealand: Author. 
Statistics New Zealand (2005). National Family and Household Projections (2001 (base) - 2021) Update. Retrieved 27 June, 2008, from http://www.stats.govt.nz/products-and-services/media-releases/national-familyand-household-projections/national-family-and-household-projections-01-base21-update-mr.htm.

Statistics New Zealand (2006). Marriages, civil unions and divorces: Year ended December 2005. Wellington, New Zealand: Author.

Statistics New Zealand. (2008). 2006 Census. Retrieved 27 June, 2000, from http://www.stats.govt.nz/census/census-outputs/default.htm.

Stephens, W. N. (1963). The family in cross-cultural perspective. New York: Holt, Rinehart and Winston, Inc.

Sun, Y. (2001). Family environment and adolescents' well-being before and after parent's marital disruption: A longitudinal analysis. Journal of Marriage and Family, 63, 697-713.

Sviggum, G. (2000). How children view their parents' divorce. Family Matters, 55, 62-67.

Tabachnick, B. G., \& Fidell, L. S. (2001). Using multivariate statistics $\left(4^{\text {th }}\right.$ edition). Boston: Allyn and Bacon.

Te Ara: The Encyclopaedia of New Zealand (2006) Glossary. Retrieved 28 March, 2008, from

http://www.teara.govt.nz/NewZealanders/MaoriNewZealanders/TribalOrganisatio $\mathrm{n} / 4 / \mathrm{en}$

Temple, M. T., Fillmore, K. M., Hartke, E., Johnstone, B., Leino, E. V., \& Motoyoshi, M. (1991). A meta-analysis of change in marital and employment status as predictors of alcohol consumption on a typical occasion. British Journal of Addiction, 86, 1269-1281.

Thompson, R. A., \& Amato, P. (1999). The postdivorce family: Children, parenting and society. (Eds.). Thousand Oaks, California: Sage.

Thompson, R., Plumridge, L., \& Holland, J. (2003). Longitudinal qualitative research: A developing methodology. International Journal of Social Research Methodology, 6(3), 185-187.

Trost, J. (1988). Conceptualising the family. International Sociology, 3, 301-308.

Trost, J. (1990). Do we mean the same by the concept of family? Communication Research, 17(4), 431-443.

Tschann, J. M., Flores, E., Pasch, L. A., \& Marin, B. V. (1999). Assessing interparental conflict: Reports of parents and adolescents in European American and Mexican American families. Journal of Marriage and the Family, 61, 269-283. 
Videon, T. M. (2002). The effects of parent-adolescent relationships and parental separation on adolescent well-being. Journal of Marriage and the Family, 64, 489-503.

Wade, A., \& Smart, C. (2002). Facing family change: Children's circumstances, strategies, and resources. York, UK: Joseph Rowntree Foundation.

Wadsworth, M. (1979). Roots of delinquency: Infancy, adolescence and crime. Oxford, UK: Martin Robertson.

Wadsworth, M. E. J., \& Maclean, M. (1986). Parents' divorce and children's life chances. Children and Youth Services Review, 8, 145-159.

Walczak, Y., \& Burns, S. (1984). Divorce: The child's point of view. London: Harper and Row.

Wallerstein, J. S., \& Kelly, J. B. (1980). Surviving the breakup: How children and parents cope with divorce. Basic Books: New York.

Watson, M. W., \& Amgott-Kwan, T. (1984). Development of family-role concepts in school aged children. Developmental Psychology, 20(5), 953-959.

Weir, J. (1998). New Zealand wit \& wisdom: Quotations with attitude. Auckland, New Zealand: Tandem Press.

Werner, E. E. (1992). The children of Kauai: Resiliency and recovery in adolescence and adulthood. Journal of Adolescent Health, 13, 262-268.

Werner, E. E., \& Smith, R. S. (1982). Vulnerable but invincible: A longitudinal study of resilient children and youth. New York: Adams, Bannister, \& Cox.

Wedemeyer, N. V., Bickhard, M. H., \& Cooper, R. G. (1989). The development of structural complexity in the child's concept of family: The effect of cognitive stage, sex and intactness of family. Journal of Genetic Psychology, 150(4), 341357.

Wild, L. G., \& Richards, P. M. (2001). Perceptions of interparental conflict: Exploring parent and child perceptions of interparental conflict. International Journal of Law, Policy and the Family, 17, 366-384.

Williams, S., \& McGee, R. (1991). Adolescents' self-perceptions of their strengths. Journal of Youth and Adolescence, 20, 325-337.

Wolchik, S., Sandler, I. N., Braver, S. T., \& Fogas, B. (1985). Events of parental divorce: Stressfulness ratings by children, parents, and clinicians. American Journal of Community Psychology, 14, 59-74.

Woodruff, D., \& Birren, J. (1972). Age changes and cohort differences in personality. Developmental Psychology, 6, 252-259. 
Woodward, L., Fergusson, D., \& Belsky, J. (2000). Timing of parental separation and attachment to parents in adolescence: Results of a prospective study from birth to age 16. Journal of Marriage and the Family, 62, 162-174.

Zill, N., Morrison, D. R., \& Coiro, M. J. (1993). Long-term effects of parental divorce on parent-child relationships, adjustment, and achievement in young adulthood. Journal of Family Psychology, 7, 91-103.

Zinn, M. B., \& Eitzen, D. S. (1999). Diversity in families (5 ${ }^{\text {th }}$ edition). New York: Addison Wesley Longman, Inc. 


\section{APPENDIX A}

Demographic Form (Study One) 


\section{DEMOGRAPHIC FORM}

\section{Victoria University of Wellington}

PARENTS/CAREGIVERS: If you consent to your child's participation in this study then please complete this form. All information you provide will be kept strictly confidential.

\section{Please answer these questions with reference to the child who will be participating in this research.}

1. What is the name of the child? (First name).

(Surname)

2. Date of birth of the child:

3. Is the child... Male / Female (circle one)

4. Who are the child's caregivers at home?

(e.g. biological mother/father, adoptive mother/father, stepmother/father, grandmother/grandfather, aunt, uncle, brother/sister, family friend etc.). List as many as are applicable.

Caregiver (1).

Caregiver (2).

Caregiver (3).

Other caregivers

5. How would you describe the ethnicity of the caregivers listed above? (e.g. European New Zealander, Māori, Chinese, Samoan etc.).

The ethnicity of Caregiver (1):

The ethnicity of Caregiver (2):

The ethnicity of Caregiver (3):

The ethnicity of others:

6. How many sister(s)/brother(s) does the child have?
a. sister(s)/brother(s)
b. half sister(s)/brother(s)
c. step sister(s)/brother(s).......
d. N/A (circle)
e. Other (explain). 
7. Apart from those already listed, does anyone else live in the same household?... $\mathbf{Y} / \mathbf{N}$

(circle one)

If yes, please list who these people are in relation to the child:

8. How would you describe the ethnicity of the child? (e.g. European New Zealander, Māori, Chinese, Samoan etc.).

The ethnicity of the child:

9. Has your child only lived with the people described above?....Y / N

(circle one)

If no, what other family structures has s/he lived in? Tick as many as are applicable.

- two-parent (biological or adoptive)

- lone-parent.

- stepparent

- extended family

- other(s) (please specify)

a. Altogether, how many family structures has s/he lived in?

10. If the child's parents/caregivers have been divorced or separated, please answer the following questions. If not, please skip to section 12.

a. How old was the child when his/her parents separated?..... years.......months

b. If the child is living with only one of his/her parents, how often does s/he see the other parent? Please circle the number that best applies to the child:
1. Weekly
2. Fortnightly
3. Once a month

4. Once every 6 mths or less

5. Once a year or more 6 . Never

7. $\mathrm{N} / \mathrm{A}$ 
11. At the time of your separation were you provided with any support/information relating to the wellbeing of your child/children? (circle one)

\section{YES NO}

If yes, what was the source of the information? (e.g. book, information sheet, support worker, counsellor, family friend etc.). List all sources of information below.

a. How much information was provided? Please mark the appropriate area on the line.

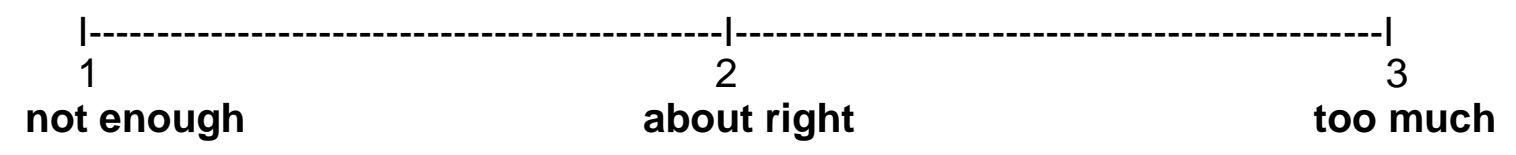

b. How useful was the information? Please mark the appropriate area on the line.

$\begin{array}{lcc}1 & 2 & 3 \\ \text { not at all useful } & \text { moderately useful } & \text { extremely } \\ \text { useful } & \end{array}$

\section{Thank you for providing the information above.}

It would be most appreciated if you could:

- Please make sure the consent form has been completed.

- Please make sure you have answered all the questions that you wish to on the demographic form.

ONCE THE FORMS ARE COMPLETED AND SEALED IN THE ENVELOPE PROVIDED COULD YOUR CHILD PLEASE RETURN THEM TO THE SCHOOL OFFICE 


\section{APPENDIX B}

Questionnaire (Study One) 


\section{QUESTIONNAIRE: Study One}

\section{Children's perceptions of families}

FAMILY CONCEPTS: The following three sections address the way children define family and investigate what kind of relationships children consider to be family.

\section{Section A: Children's perceptions of 'family'}

1. What do you think 'family' is?

2. Do you think 'family' is important?

How come?

3. Who do you think the members of a 'family' are?

4. If someone in your family goes to live in another house, does he (or she) still belong to your family?

Y I N

How come?

5. If someone from another family comes to live in your house, does he (or she) become part of your family?

Y IN

How come?

6. Does a mother alone with her children form a family?

$$
\mathrm{Y} / \mathrm{N} \quad \text { How come? }
$$

7. Does a father alone with his children form a family?

$$
\mathbf{Y} / \mathbf{N}
$$

How come?

\section{Section B: $\quad$ VIGNETTES: Children's perceptions of 'family'}

8. Mr Stephens and Ms Green are not married. They live together. They have no children. Are they a family?

How come?

9. Mr Stephens married Ms Green. Ms Green changed her name to Mrs Stephens. They live together. They have no children. Are they a family?

$$
\mathbf{Y} / \mathbf{N}
$$

How come?

10. Mr and Mrs Stephens have a son named Sam. They all live together. Sam has a friend called Leung who also lives with them. Is Leung in Sam's family?

$$
\mathbf{Y} / \mathbf{N}
$$

How come? 
11. Sam has a grandmother and a grandfather. Are they in Sam's family?

How come?

12. What if Sam's grandparents live in a different city and he never sees them. Then, are they in his family?

How come?

13. Sam has an aunt, an uncle and two cousins. Are they in Sam's family?

$\mathbf{Y} / \mathbf{N}$

How come?

14. Sam has a brother, Robbie, and a sister Kiri. They live together, just the three of them. Are they a family?

How come?

15. Mr and Mrs Stephens and their son Sam live together, but they don't love each other. Are they a family?

$\mathbf{Y} / \mathbf{N}$

How come?

16. John and Semesi are two men aged 30. They live together. Neither of them have a child. Are they a family?

$\mathbf{Y} / \mathbf{N}$

How come?

17. John and Semesi are two men aged 30. John has a child named Rangi. The three of them live together. Are they a family? $\mathbf{Y} / \mathbf{N}$

How come?

18. Anita and Rachel are two women aged 30. They live together. Neither of them have a child. Are they a family?

$\mathbf{Y} / \mathbf{N}$

How come?

19. Anita and Rachel are two women aged 30. Anita has a child called Christine.

The three of them all live together. Are they a family?

$\mathrm{Y} / \mathrm{N} \quad$ How come?

Section C: VIGNETTES: Children's perceptions of family transitions

20. Mr Stephens and Ms Green are not married. They have a son named Sam. They all live together. Are they a family?

$\mathbf{Y} / \mathbf{N}$

How come?

21. Mr Stephens married Ms Green. Ms Green changed her name to Mrs Stephens. They have a son named Sam. They all live together. Are they a family?

$$
\mathbf{Y} / \mathbf{N}
$$

How come? 
22. Mr Stephens and Mrs Stephens are divorced. Mrs Stephens and her son Sam live together, just the two of them. Are they a family?

How come?

23. Mr Stephens and Mrs Stephens live in separate houses. Mrs Stephens and her son Sam live together. Is Mr Stephens in Sam's family?

$\mathbf{Y} / \mathbf{N} \quad$ How come?

24. Mrs Stephens has a new partner called Mr Ngati. Mrs Stephens and her son Sam live together. Mr Ngati visits Mrs Stephens and Sam often. Are they a family?

$$
\mathrm{Y} / \mathrm{N} \quad \text { How come? }
$$

25. Mrs Stephens marries Mr Ngati. Mrs Stephens and her son Sam move in with Mr Ngati. Are they a family?

How come?

26. Mrs Stephens, her new husband Mr Ngati, and her son Sam live together. Is $\mathrm{Mr}$ Ngati Sam's father?

$\mathbf{Y} / \mathbf{N}$

How come?

27. Mrs Stephens's new husband, Mr Ngati, has a daughter called Hinemoa. Mrs Stephens and her son Sam move in with Mr Ngati and his daughter, Hinemoa. Are they a family?

How come?

28. Now that Mrs Stephens's son Sam, and Mr Ngati's daughter Hinemoa live in the same house are they brother and sister?

How come?

29. Mrs Stephens and her son Sam, and Mr Ngati and his daughter Hinemoa have all lived together now for 10 years. Are they a family?

$$
\mathrm{Y} / \mathrm{N} \quad \text { How come? }
$$

30. Mrs Stephens and her son Sam, and Mr Ngati and his daughter Hinemoa have all lived together now for 10 years. Is Mr Ngati Sam's father?

$$
\mathbf{Y} / \mathbf{N} \quad \text { How come? }
$$

31. Mrs Stephens and her son Sam, and Mr Ngati and his daughter Hinemoa have all lived together now for 10 years. Is Mrs Stephens Hinemoa's mother? 


\section{APPENDIX C}

Examples of Vignette Pictures (Study One) 


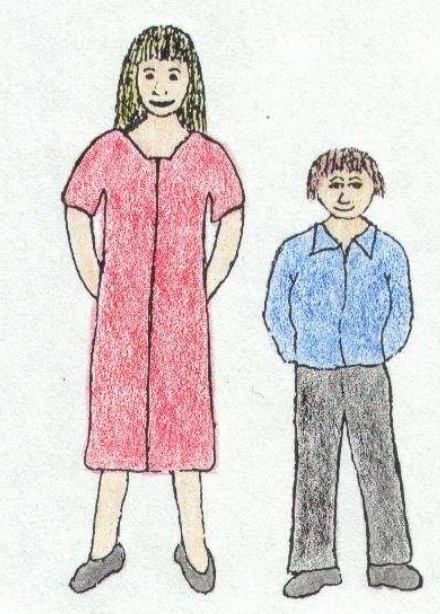

Mrs Stephens Sam

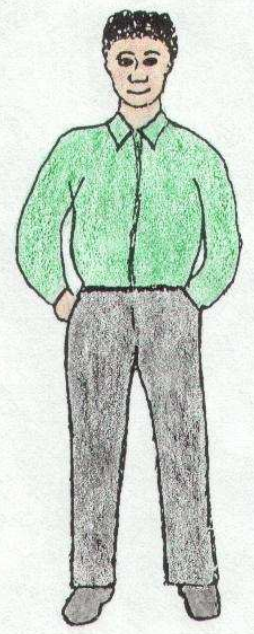

Mr Ngati 


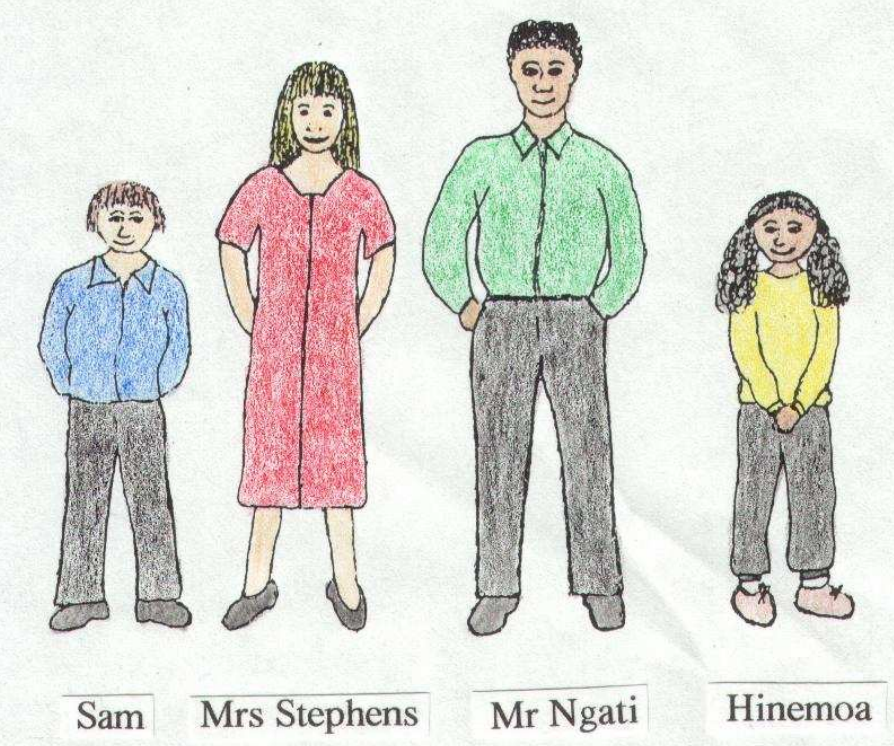




\section{APPENDIX D}

Letter for Principal (Study One) 
Dear (Principal),

\section{RE: CHLDREN'S PERCEPTIONS OF 'FAMILY' STUDY}

My name is Andrea Rigg; I am currently enrolled as a postgraduate student at the School of Psychology, Victoria University of Wellington. I am undertaking research and will be completing a thesis as part of my degree requirements. My supervisor is Dr. Jan Pryor.

My thesis will involve examining children's perceptions of 'family' and family change. The research participants will be 9-13 year old students from several Wellington primary and intermediate schools. The children will be questioned for information about their perceptions and definitions of 'family'. Parental/caregiver consent will be required before any child participates in the study. All the information gained from the questionnaires will be kept strictly confidential. The questions have been approved by the Victoria University of Wellington Human Ethics Committee.

With your help it will be possible to further our understanding of children's views about 'family'. This is especially important when we consider the different ethnic groups and family structures that children come from, such as original two-parent families, lone-parent, stepparent, and extended families. In New Zealand, it is estimated that one third of all recent marriages will end in divorce, and that approximately half of all divorces involve children. Such statistics accentuate the importance of this research topic as it is clear that a number of children experience, and are affected by, changes to their family structure. Adequate support for children can only be provided if we understand what family means to them. There is, however, a large gap in the research as there are no New Zealand based studies investigating children's perceptions of family and family change.

A major outcome of my thesis will be to collate information from this and other studies in order to prepare an information sheet that can be used by parents, professionals, and others working with children and families. In terms of the benefits for your school, providing information to parents and professionals about children's perceptions of family may assist in the provision of adequate support and understanding of the children and, therefore, a smoother transition for children in the event of family change. Additionally, the findings may be used by school counsellors supporting children who are experiencing family transitions.

It would be greatly appreciated if you could assist me in sending out letters to parents/caregivers of 9-13 year olds attending your school. Parents/caregivers will be provided with a letter outlining the research topic, a consent form for their child's participation, and a demographic form. A summary of results will be sent to the schools involved in the project on completion of the research.

I will phone within the next week to discuss the possibility of conducting this project in your school. Any assistance you can provide would be greatly appreciated. If you have any questions, please phone my supervisor on $463-5233$ ext. 8130.

Yours sincerely,

Andrea Rigg 


\section{APPENDIX E}

Letter for Parents/Caregivers (Study One) 
Dear parent/caregiver,

\section{RE: $\quad$ CHILDREN'S PERCEPTIONS OF 'FAMILY' STUDY}

My name is Andrea Rigg; I am currently enrolled as a postgraduate student at the School of Psychology, Victoria University of Wellington. I am undertaking research and will be completing a thesis as part of my degree requirements. My supervisor is Dr. Jan Pryor.

My thesis will involve the investigation of children's perceptions of 'family' and family change. I need 9-13 year old students as participants in this study. The children will be questioned about their perceptions and definitions of 'family' and different family structures. Note that the questionnaire will not ask for perceptions of the child's own family, but will use general examples. Parental/caregiver consent will be required before any child participates in the study. All the information collated from the questionnaires will be kept strictly confidential. Your child's name will not appear on the questionnaire. If you would like a copy of the questions, before you consent to your child's participation, then please feel free to contact my supervisor.

If you are happy for your child to participate in this study then please sign the consent form and complete the demographic form. All the information from the consent and demographic forms will be kept strictly confidential. Once the forms are completed, please arrange for your child to return them to the school office. With the assistance of the school principal we will arrange a time for your child to answer the questions at school. The questionnaire will only take approximately 20 minutes to complete.

A major outcome of my thesis will be to collate information from this and other studies in order to understand what 'family' means to children. This information will be distributed to parents, professionals, and others working with children and families. Your child's participation would be very much appreciated as a contribution to furthering our understanding and our ability to support children. I would also be happy to provide you with a report on the study.

If you have any questions you are welcome to contact my supervisor, or the Head of the School of Psychology.

Supervisor: Dr. Jan Pryor - School of Psychology

Ph.: $\quad$ (04) 463-5233, ext. (8130)

Thank you for taking the time to read this information sheet.

With kind regards,

Andrea Rigg 


\section{APPENDIX F}

Consent Form (Study One) 


\section{PARENTAL/CAREGIVER CONSENT FORM Victoria University of Wellington}

You are invited to give consent for your child's participation in this study on children's perceptions of 'family'.

*I have read the letter which explains this research project.

* I understand that any information my child or I provide will be kept confidential to the researcher.

* I understand that my child's name will not be used, and that no opinions of my child will be attributed to him/her in any way that will identify him/her.

* I understand that I may withdraw my child (or any information s/he or I have provided) from this project (before data collection and analysis is complete) without having to give reasons or without penalty of any sort.

* I understand that the data provided will not be used for any other purpose or released to others without my written consent.

I would like to receive a summary of the results of this research when it is completed....Y / $\mathbf{N}$

(circle one)

[If you answer Yes please supply contact details:] ADDRESS:

I have read this letter and understood its terms. to participate in this research.

SIGNED:

DATE: 


\section{APPENDIX G}

Letter for Parents/Caregivers (Study Two) 


\section{CAN YOU HELP?}

\section{VUW STUDY: Young People's Experiences of Separation}

What are the experiences of children and adolescents when their parents separate? I am investigating this question as part of a PhD degree at Victoria University. This study is being supervised by Jan Pryor, Associate Professor at the School of Psychology, and Director of the Roy McKenzie Centre for the Study of Families. We are inviting your child to take part in this research.

\section{Why study young people and family transitions?}

The aim of this study is to gain a greater understanding of young people's perspectives and experiences of family structure change over a period of time. Of particular importance is understanding what their needs are and what would make the family transition process easier for them.

\section{How would you and your child be involved?}

For you, this would involve reading this information sheet, filling out the attached consent form and returning it in the envelope provided. This form gives you the opportunity to consent for your child to participate in this study. Your child will then be interviewed either at home, at school, or at the university (which ever you prefer) at a time that suits you. The final part of the study is a follow-up interview with your child approximately 18 months later.

\section{What are the benefits of this research?}

Providing information to parents and professionals about young people's perceptions and experiences will allow for a greater level of understanding, and assist in the provision of adequate support and consequently a smoother transition in the event of family change.

\section{Are you interested in this study?}

If you would like your child to be involved in this study then please complete, and return, the consent form in the envelope provided. I will then be in touch to arrange an appropriate time and place for your child to be interviewed. Please feel free to contact us if you would like to make any enquires about this research.

\begin{tabular}{lrr} 
Andrea Rigg & or & Dr. Jan Pryor \\
PhD student & ph. 4636962 \\
andy.rigg@vuw.ac.nz & & jan.pryor@vuw.ac.nz \\
\hline
\end{tabular}

Kind regards,

Andrea Rigg 


\section{APPENDIX H}

Consent Form for Parents/Caregivers (Study Two) 


\section{PARENTAL/CAREGIVER CONSENT FORM}

You are invited to give consent for your child's participation in this study of young people's experiences of family change.

* I have read the information sheet which explains this research project.

* I understand that any information my child or I provide will be kept confidential to the researcher.

* I understand that my child's name will not be used, and that no opinions given my child will be attributed to him/her in any way that will identify him/her.

* I understand that I may withdraw my child (or any information s/he or I have provided) from this project (before data collection and analysis is complete) without having to give reasons of any sort.

Please provide your contact details:

ADDRESS:

PHONE:

EMAIL:

I would like to receive a summary of the results of this research when it is completed....... / $\mathbf{N}$

(circle one)

I have read this letter and understood its terms. to participate in this research.

SIGNED:

DATE: 1 


\section{APPENDIX I}

Demographic Form for Parents/Caregivers (Study Two) 


\section{DEMOGRAPHIC FORM}

\section{Victoria University of Wellington}

PARENTS/CAREGIVERS: If you consent to your child's participation in this study then please complete this form. All information you provide will be kept strictly confidential.

\section{Please answer these questions with reference to the child who will be participating in this research.}

1. What is the name of the child? (First name)

(Surname).

2. Date of birth of the child:

3. Is the child..... Male / Female (circle one)

4. Who are the child's caregivers?

(e.g. biological mother/father, adoptive mother/father, stepmother/father, grandmother/grandfather, aunt, uncle, brother/sister, family friend, a partner etc.).

List as many as are applicable:

Caregiver (1).

Caregiver (2).

Caregiver (3).

Other caregivers:

5. How would you describe the ethnicity of the caregivers listed above?

(e.g. European New Zealander, Māori New Zealander, Chinese, Samoan etc.).

The ethnicity of Caregiver (1):

The ethnicity of Caregiver (2):

The ethnicity of Caregiver (3):

The ethnicity of others:

6. How many sisters/brothers does the child have?
a. sister(s)/brother(s)
b. half sister(s)/brother(s)
c. step sister(s)/brother(s).......
d. N/A (circle)
e. Other (explain). 
7. Who lives in the child's household? Please list who these people are in relation to the child. (If the child spends equal time in 2 or more households list the people who live in each house separately).

8. How would you describe the ethnicity of your child?

(e.g. European New Zealander, Māori, Chinese, Samoan etc.).

\section{The ethnicity of the child:}

9. Of the family structures mentioned below which ones has your child lived in? Tick as many as are applicable:

- two-parent (biological or adoptive) .........

- lone-parent.

- stepparent.

- extended family.

- other(s) (please specify)

a. Altogether, how many family structures has s/he lived in?

10. If applicable, can you please explain why your child is participating in the Seasons for Growth education programme? 
11. Are the child's parents/caregivers separated?... $\mathbf{Y} / \mathbf{N} \quad$ (circle one)

a. If yes, how old was the child when his/her parents separated?

years months

b. If the child is living with only one of his/her parents, how often does s/he see the other parent? Please circle the number that best applies to the child:
1. Weekly
2. Fortnightly
3. Once a month

4. Approx. once every 6 mths

5. Approx. once a year

6. Never

7. Shared care / joint custody (i.e. the child spends equal time with both parents)

8. Other answer (please explain)

12. At the time of your separation were you provided with any support/information relating to the wellbeing of your child/children?

$$
\text { (circle one) }
$$

\section{YES NO}

If yes, what was the source of the information/support? (e.g. books, pamphlets, internet sites, counsellor, social worker, support group, family court etc.). List all sources below.

a. How much information was provided? Please mark the appropriate area on the line.

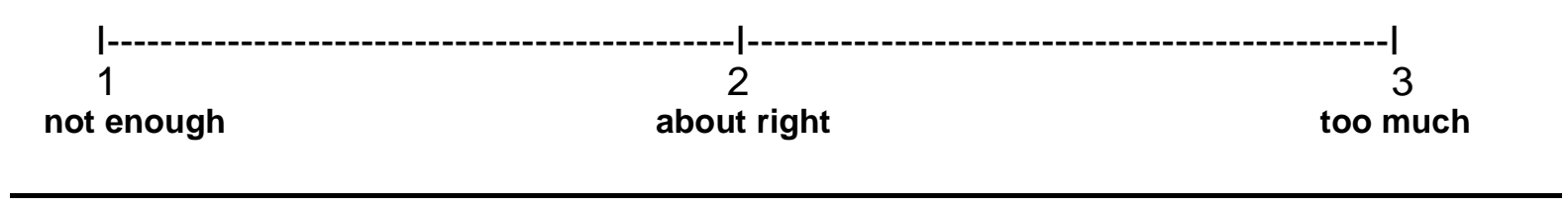

b. How useful was the information? Please mark the appropriate area on the line.

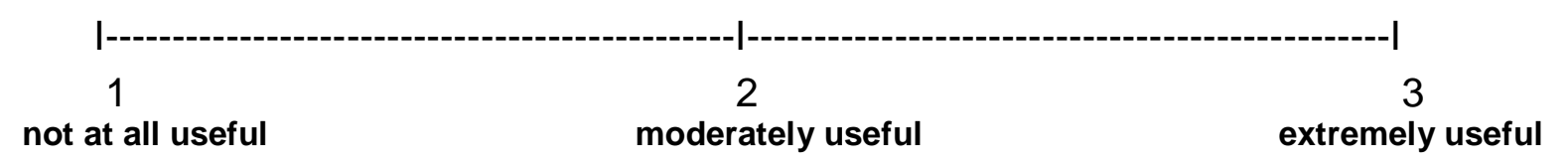




\section{APPENDIX J}

Contact Details Form for Parents/Caregivers (Study Two) 


\section{CONTACT DETAILS FORM}

\section{Victoria University of Wellington}

PARENTS/CAREGIVERS: The last part of your child's interview will be undertaken in approximately 18 months time. In this 18 month period your contact details may change. We do not want to lose touch with you; so it would be greatly appreciated if you could provide us with alternative ways that we could use to contact you, if necessary.

\section{Please provide details for as many contacts as possible - thank you!}

\section{1.) YOUR CONTACT DETAILS:}

Name:

Street address:

Suburb:

City/Town:

Phone number:

e-mail:

\section{2.) CONTACT DETAILS OF $2^{\mathrm{ND}}$ PARENT/CAREGIVER: [if different from the details in 1.]} Name:

Street address:

Suburb:

City/Town:

Phone number:

e-mail:

\section{3.) CONTACT DETAILS OF A GRANDPARENT:}

Name:

Street address:

Suburb:

City/Town:

Phone number:

e-mail: 
4.) CONTACT DETAILS OF AN AUNT, UNCLE OR OTHER CLOSE RELATIVE: Name:

Street address:

Suburb:

City/Town:

Phone number:

e-mail:

5.) CONTACT DETAILS OF A FAMILY FRIEND OR OF A CLOSE FRIEND OF YOUR CHILD:

Name:

Street address:

Suburb:

City/Town:

Phone number:

e-mail:

\section{Thank you for providing the information above.}

It would be most appreciated if you could:

- Please make sure the consent form has been completed.

- Please make sure you have answered all the questions that you wish to on the demographic form. 


\section{APPENDIX K}

Letter for Participants (Study Two) 


\section{CAN YOU HELP?}

\section{VUW STUDY: Young People's Experiences of Separation}

What are the experiences of children and adolescents when their parents separate or divorce? I am investigating this question as part of a PhD degree at Victoria University. This study is being supervised by Jan Pryor, Associate Professor at the School of Psychology, and Director of the Roy McKenzie Centre for the Study of Families. We are inviting you to take part in this research.

\section{Why study young people and family transitions?}

The aim of this study is to gain a greater understanding of young people's perspectives and experiences of family structure change over a period of time. Of particular importance is understanding what their needs are and what would make the family transition process easier for them.

\section{How would you be involved?}

For you, this would involve reading this information sheet, filling out the attached consent form and returning it in the envelope provided. You will then be interviewed either at home, at school, or at the university (which ever you prefer) at a time that suits you. The final part of the study is a follow-up interview approximately 18 months later.

\section{What are the benefits of this research?}

Providing information to parents and professionals about young people's perceptions and experiences will allow for a greater level of understanding, and assist in the provision of adequate support and consequently a smoother transition in the event of family change.

\section{Are you interested in this study?}

If you would like to be involved in this study then please complete and return the consent form in the envelope provided. I will then be in touch to arrange an appropriate time and place for you to be interviewed. Please feel free to contact us if you would like to make any enquires about this research.

Andy Rigg

PhD student

andy.rigg@vuw.ac.nz or

Dr. Jan Pryor

ph. 4636962

jan.pryor@vuw.ac.nz

Kind regards, 


\section{APPENDIX L}

Consent Form for Participants (Study Two) 


\section{PARTICIPANT CONSENT FORM}

You are invited to participate in this study of young people's experiences of family change.

* I am 16 years of age or older.

*I have read the information sheet which explains this research project.

*I understand that any information I provide will be kept confidential to the researcher.

* I understand that my name will not be used, and that my opinions will not be attributed to me in any way that will identify me.

* I understand that I may withdraw from this project (before data collection and analysis is complete) without having to give reasons of any sort.

Please provide your contact details:

ADDRESS:

PHONE:

EMAIL:

I would like to receive a summary of the results of this research when it is completed....... / $\mathbf{N}$

(circle one) have read this letter and understood its terms, and I am willing to participate in this research.

SIGNED:

DATE: 1 


\section{APPENDIX M}

Demographic Form for Participants (Study Two) 


\section{DEMOGRAPHIC FORM \\ Victoria University of Wellington}

PARTICIPANT (aged 16 years or older): If you give your consent to participate in this study then please complete this form. All information you provide will be kept strictly confidential.

1. What is your name? (First name).

(Surname)

2. Date of birth:

Age:

3. Gender: Male / Female (circle one)

4. Who are your caregivers?

(e.g. biological mother/father, adoptive mother/father, stepmother/father, grandmother/grandfather, aunt, uncle, brother/sister, family friend, a parent's partner etc.).

List as many as are applicable:

Caregiver (1).

Caregiver (2).

Caregiver (3).

Other caregivers:

5. How would you describe the ethnicity of the caregivers listed above?

(e.g. European New Zealander, Māori, Chinese, Samoan etc.).

The ethnicity of Caregiver (1):

The ethnicity of Caregiver (2):

The ethnicity of Caregiver (3):

The ethnicity of others:

6. How many sisters/brothers do you have?
a. sister(s)/brother(s)
b. half sister(s)/brother(s)
c. step sister(s)/brother(s)
d. N/A (circle)
e. Other (explain). 
7. Who lives in your household? Please list who these people are in relation to you. (If you spend equal time in 2 or more households list the people who live in each household separately).

8. How do you describe your ethnicity?

(e.g. European New Zealander, Māori, Chinese, Pacific Islander etc.).

\section{My ethnic group is:}

9. Of the family structures mentioned below which ones have you lived in?

Tick as many as are applicable:

- two-parent (biological or adoptive)

- lone-parent.

- stepparent....

- extended family

- other(s) (please specify)

a. Altogether, how many family structures have you lived in?

10. If applicable, can you please explain why you are participating in the Seasons for Growth education programme? 
11. Are your parents/caregivers separated? .... $\mathbf{Y} / \mathbf{N} \quad$ (circle one)

a. If yes, how old were you when your parents separated?

years months

b. If you are living with one of your parents, how often do you see your other parent? Please circle the number that best applies to your situation:
1. Weekly
2. Fortnightly
3. Once a month

4. Approx. once every 6 mths

5. Approx. once a year 6. Never

7. Shared care / joint custody (i.e. you spend equal time with both parents)

8. Other answer (please explain)

12. At the time of your parents' separation were you provided with any support or information?

(circle one)

YES

NO

If yes, what was the source of the information/support? (e.g. books, pamphlets, internet sites, counsellor, social worker, support group, family court etc.). List all sources below.

a. How much information was provided? Please mark the appropriate area on the line.

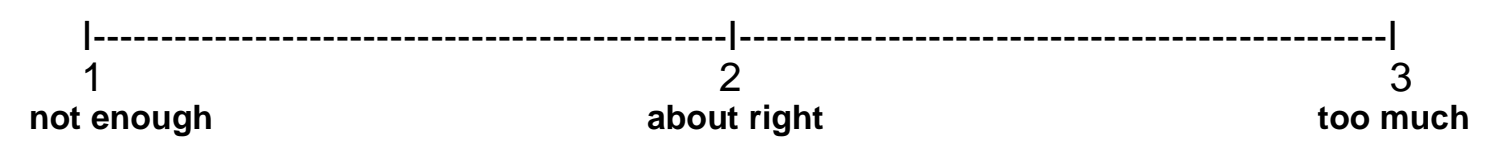

b. How useful was the information? Please mark the appropriate area on the line.

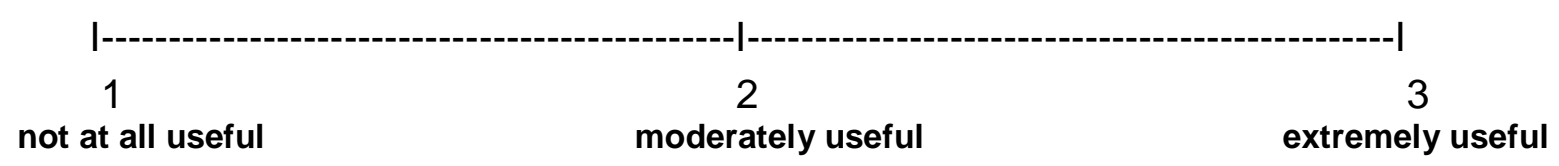




\section{APPENDIX N}

Contact Details Form for Participants (Study Two) 


\section{CONTACT DETAILS FORM}

\section{Victoria University of Wellington}

PARTICIPANT (aged 16 years or older): The last part of your interview will be undertaken in approximately 18 months time. In this 18 month period your contact details may change. We do not want to lose touch with you; so it would be greatly appreciated if you could provide us with alternative ways that we could use to contact you, if necessary.

Please provide details for as many contacts as possible - thank you!

\section{1.) YOUR CONTACT DETAILS:}

Name:

Street address:

Suburb:

City/Town:

Phone number:

e-mail:

2.) CONTACT DETAILS OF A PARENT: [if different from the details in 1.]

Name:

Street address:

Suburb:

City/Town:

Phone number:

e-mail:

\section{3.) CONTACT DETAILS OF A GRANDPARENT:}

Name:

Street address:

Suburb:

City/Town:

Phone number:

e-mail: 
4.) CONTACT DETAILS OF AN AUNT, UNCLE OR OTHER CLOSE RELATIVE: Name:

Street address:

Suburb:

City/Town:

Phone number:

e-mail:

5.) CONTACT DETAILS OF A CLOSE FRIEND OR FAMILY FRIEND:

Name:

Street address:

Suburb:

City/Town:

Phone number:

e-mail:

\section{Thank you for providing the information above.}

It would be most appreciated if you could:

- Please make sure the consent form has been completed.

- Please make sure you have answered all the questions that you wish to on the demographic form. 


\section{APPENDIX $O$}

Questionnaire: Interview 1 (Study Two) 


\section{INTERVIEW QUESTIONS: Study Two}

\section{Young people's experiences of family transition}

\section{INTERVIEW 1: Subsequent to parental separation}

\section{- FAMILY CONCEPT}

1. What do you think 'family' is?

2. Do you think 'family' is important? How come?

\section{- FAMILY STRUCTURE}

\section{Family composition:}

3. Who are the members of your family? Family map: [Interviewer and participant map out the family grouping in diagram form.]

4. What is your relationship with these people?

Feelings about living arrangements:

5. Who do you live with?

6. Are you happy with your current living arrangements? What makes you happy/unhappy?

\section{Feelings about contact arrangements:}

7. How often do you see your parent that you don't live with? How do you feel about the amount of time you have with him/her?

8. How would you describe your relationship with him/her?

9. Who lives in that household?

\section{- VIEWS AND REACTIONS}

\section{Separation definition:}

10. What does separation mean to you?

\section{Finding out about the separation:}

11. How did you find out that your parents were separating?

Initial reactions to the separation:

12. How did you react when you found out that your parents were separating? 


\section{Feelings about the separation at the time:}

13. How did you feel when you found out that your parents were separating?

\section{Feelings about the separation now:}

14. How do you feel about your mum and dad's separation now?

\section{Reason for the separation:}

15. Why do you think your mum and dad don't live together anymore? If you don't know, do you wish they had explained to you why they separated?

\section{Cognisance of problems with parents' relationship:}

16. Did you know that your parents were having problems in their relationship before they separated?

\section{Outlook for the separation:}

17. Do you think your mum and dad will ever get back together? Do you wish they would?

\section{Blame for the separation:}

18. Do you think anyone is to blame for your mum and dad not being together like they used to be?

\section{Negative and positive aspects of the separation:}

19. What are some of the bad things about your parents' separation?

20. What are some of the good things about your parents' separation?

21. What do you miss the most?

22. What do you like about living in the household/s (with the people) you do now?

23. What do you dislike about living in the household/s (with the people) you do now?

24. Do you have any ideas on how to improve life in your household/s? What would make things better?

\section{Challenges encountered:}

25. What problems have you faced since your parents separated?

26. What do you think would help you better deal with these challenges?

\section{Reminiscing:}

27. Do you think about life before your family structure changed? If so, what do you think about?

28. What three memories do you have that stand out the most to you about your family life before your parents separated?

29. What three memories do you have that stand out the most to you about your family life now? 


\section{- SUPPORT AND COPING}

What young people say they need:

30. What have you needed most during this period of change? (i.e. the separation)

\section{Formal \& informal sources of support:}

31. Has anyone given you help and support during this time? If yes, who? Also check: Have any of the following people supported you?

$\begin{array}{lll}\text { Parent/s? } & \text { Sibling/s? } & \text { Friend/s? } \\ \text { Grandparent/s? } & \text { Another relative? } & \text { Teacher/s? } \\ \text { Family friend/s? } & \text { Counsellor or psychologist? } & \text { Support group? } \\ \text { Another adult? } & \text { Education programme? } & \text { Anyone else? }\end{array}$

\section{Coping strategies:}

32. What have you personally done to cope during this time?

\section{Availability of support:}

33. Do you feel you are getting enough support? If not, who would you want to give you help and support?

\section{Finding support:}

34. Do you know where to find support if you need it? If yes, where would you go?

35. Would you feel comfortable receiving support from: a.) A support group or education programme? b.) A community counsellor, therapist or psychologist? c.) A school counsellor? d.) An online source?

\section{Access to resources:}

36. Have you been given any information that has helped you understand your parents' separation? (e.g. books, pamphlets, DVD / video, CD-ROMS, websites etc.).

37. Do you feel you have been given enough information? If not, what kind of information do you need? What information would help?

\section{Ideas on coping:}

38. Is there anything else that would help make your parents' separation easier for you to cope with? 


\section{- COMMUNICATION}

\section{Being informed:}

39. Do you feel your parents have kept you informed of any decisions that have been made about the family situation?

40. Do you like the idea of your parents keeping you informed of any decisions that are made?

\section{Being involved in decision making:}

41. Have your parents asked you to have your say in any decisions being made about the family situation?

42. Do you like the idea of your parents asking you for your opinion about any decisions being made?

43. Would you feel comfortable telling your parents how you were feeling and what you wanted? If yes, how come? If no, what would make it easier for you to talk to them about these things?

\section{What young people want others to know about separation:}

44. What advice would you give to a child whose parents are about to separate? Is there anything you would want them to know?

45. What advice would you give to parents who are about to separate? Is there anything you would want them to know?

\section{- THE FUTURE}

\section{Family:}

46. How do you feel when you think about your family's future?

\section{Marriage:}

47. Do you think you will ever get married? How come?

48. Does marriage mean a lot to you?

\section{Children:}

49. Do you think you will ever have children? How come?

50. Does having children mean a lot to you?

Finally, is there anything we haven't talked about that you think is important to add? 


\section{APPENDIX P}

Questionnaire: Interview 2 (Study Two) 


\section{INTERVIEW QUESTIONS: Study Two}

\section{Young people's experiences of family transition}

\section{INTERVIEW 2: Approximately 18 months following interview A}

\section{- FAMILY STRUCTURE}

\section{Family composition:}

1. Who are the members of your family? Family map: [Interviewer and participant map out the family grouping in diagram form.]

2. What is your relationship with these people?

3. [The participant is shown the family maps from interview $A$ and interview B.] Has your family changed much in the past year and a half? If so, how do you feel about those changes?

\section{Feelings about living arrangements:}

4. Who do you live with?

5. Are you happy with your current living arrangements? What makes you happy/unhappy?

\section{Feelings about contact arrangements:}

6. How often do you see your parent that you don't live with? How do you feel about the amount of time you have with him/her?

\section{- VIEWS AND REACTIONS}

Feelings about the separation at the time:

7. How did you feel when you found out that your parents were separating? Feelings about the separation now:

8. How do you feel about your mum and dad not living together?

\section{Reason for the separation:}

9. Why do you think your mum and dad don't live together anymore? If you don't know, do you wish they had explained to you why they separated?

\section{Outlook for the separation:}

10. Do you think your mum and dad will ever get back together? Do you wish they would? 


\section{Blame for the separation:}

11. Do you think anyone is to blame for your mum and dad not being together like they used to be?

\section{Negative and positive aspects of separation:}

12. What are some of the bad things about your parents' separation?

13. What are some of the good things about your parents' separation?

14. What do you miss the most?

15. What do you like about living in the household/s (with the people) you do now?

16. What do you dislike about living in the household/s (with the people) you do now?

17. Do you have any ideas on how to improve life in your household/s? What would make things better?

\section{Challenges encountered:}

18. What problems have you faced since your parents separated?

19. What do you think would help you better deal with these challenges?

\section{Reminiscing:}

20. Do you think about life before your family structure changed? If so, what do you think about?

21. What three memories do you have that stand out the most to you about your family life before your parents separated?

22. What three memories do you have that stand out the most to you about your family life now?

\section{- $\quad$ SUPPORT AND COPING}

\section{What young people say they need:}

23. What have you needed most during this period of change? (i.e. the separation)

Formal \& informal sources of support:

24. Has anyone given you help and support during this time? If yes, who? Also check: Have any of the following people supported you?

Parent/s?

Grandparent/s?

Family friend/s?

Another adult?
Sibling/s?

Another relative?

Counsellor or psychologist?

Education programme?
Friend/s?

Teacher/s?

Support group?

Anyone else? 


\section{Coping strategies:}

25. What have you personally done to cope during this time?

\section{Availability of support:}

26. Do you feel you are getting enough support? If not, who would you want to give you help and support?

\section{Finding support:}

27. Do you know where to find support if you need it? If yes, where would you go?

28. Would you feel comfortable receiving support from: a.) A support group or education programme? b.) A community counsellor, therapist or psychologist? c.) A school counsellor? d.) An online source?

\section{Access to resources:}

29. Have you been given any information that has helped you understand your parents' separation? (e.g., books, pamphlets, video recordings, CD-ROMS, web sites etc.).

30. Do you feel you have been given enough information? If not, what kind of information do you need? What information would help?

\section{Ideas on coping:}

31. Is there anything else that would help make your parents' separation easier for you to cope with?

\section{- COMMUNICATION}

\section{Being informed:}

32. Do you feel your parents have kept you informed of any decisions that have been made about the family situation?

33. Do you like the idea of your parents keeping you informed of any decisions that are made?

\section{Being involved in decision making:}

34. Have your parents asked you to have your say in any decisions being made about the family situation?

35. Do you like the idea of your parents asking you for your opinion about any decisions being made? 
36. Would you feel comfortable telling your parents how you were feeling and what you wanted? If yes, how come? If no, what would make it easier for you to talk to them about these things?

\section{What young people want others to know about separation:}

37. What advice would you give to a child whose parents are about to separate? Is there anything you would want them to know?

38. What advice would you give to parents who are about to separate? Is there anything you would want them to know?

\section{- THE FUTURE}

\section{Family:}

39. How do you feel when you think about your family's future?

\section{Marriage:}

40. Do you think you will ever get married? How come?

41. Does marriage mean a lot to you?

\section{Children:}

42. Do you think you will ever have children? How come?

43. Does having children mean a lot to you?

Finally, is there anything we haven't talked about that you think is important to add? 


\section{APPENDIX Q}

Questionnaire: Scales (Study Two) 


\section{YOU \& YOUR FAMILY (Family Environment Scale)}

The following statements are about families. We would like to know how your family feels to you. Please decide which is true of your family, overall.

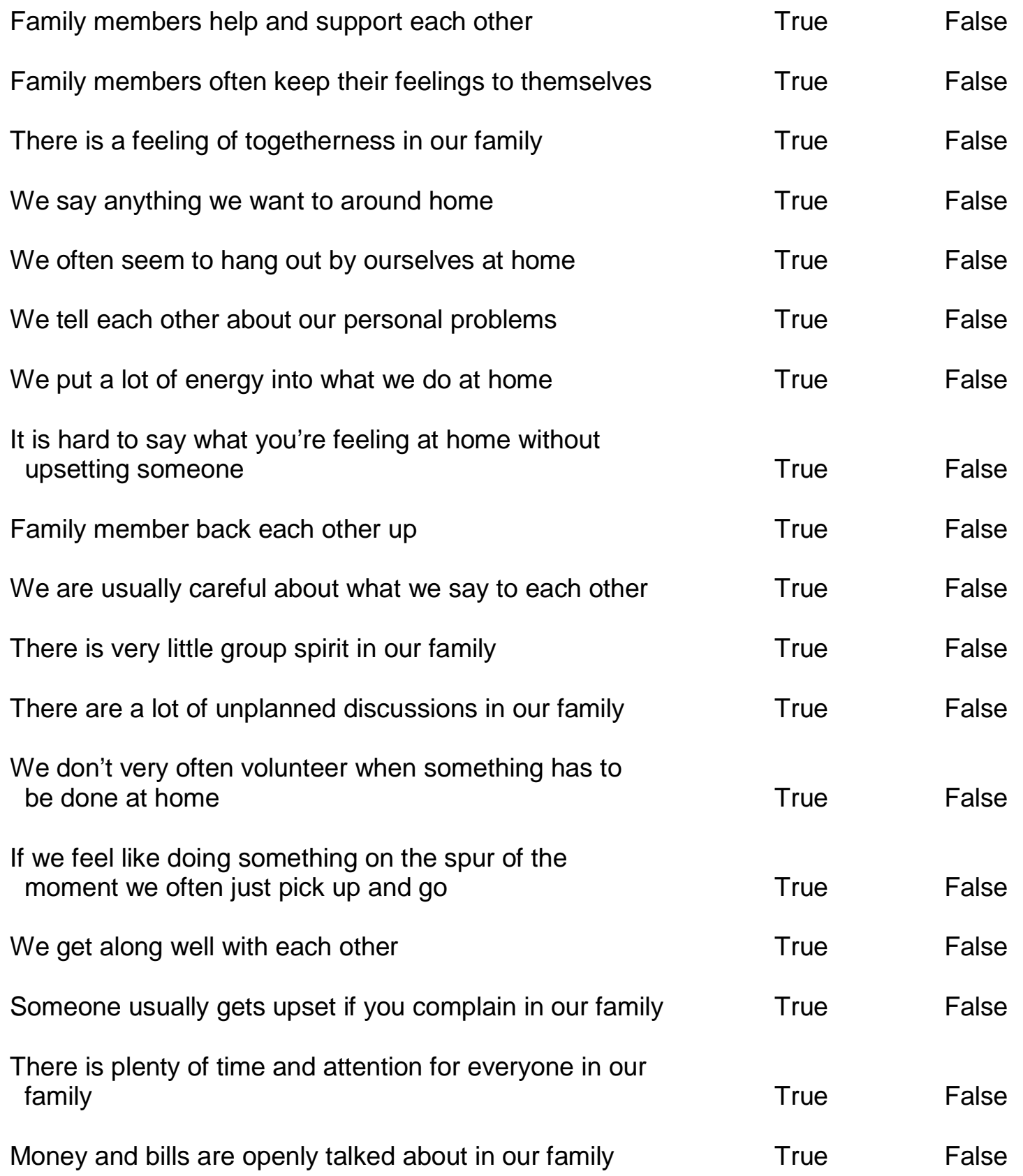




\section{YOUR PARENTS (Perception of Parents Scale)}

Young people often have many different feelings towards their mother and father. Even if they do not have contact with their mother or father anymore, they may still have feelings or opinions about them. Please think about your own mother and father when answering the following questions. Please decide which answer best describes how you feel about your mother and your father.

\begin{tabular}{|c|c|c|c|c|c|}
\hline $\begin{array}{c}1=\text { Not at all } \\
\text { or Never }\end{array}$ & $\begin{array}{c}2=\text { Not much } \\
\text { or Rarely }\end{array}$ & $\begin{array}{l}3=\text { Somewhat } \\
\text { or Sometimes }\end{array}$ & $\begin{array}{l}4=\text { Pretty much } \\
\text { or Pretty often }\end{array}$ & $\begin{array}{l}\mathbf{5}=\text { Very much } \\
\text { or Very often }\end{array}$ & $\begin{array}{c}\mathbf{6}=\text { Extremely } \\
\text { or Always }\end{array}$ \\
\hline
\end{tabular}

THINKING ABOUT EACH OF YOUR PARENTS, HOW MUCH DO YOU FEEL:

\section{MOTHER}

Respect towards your:

Anger towards your:

Happy towards your:

Love toward your:

Grateful for your:

Proud of your:

Caring toward your:

Confused or puzzled by your:

Disappointed or let down by your:

Comforted thinking about your:

Anxious/nervous about your:

Closeness toward your:

Upset when you think about your:

Appreciative of (thankful for) your:

Positive feelings toward your: $\begin{array}{llllll}1 & 3 & 4 & 5 & 6\end{array}$

$\begin{array}{llllll}1 & 2 & 3 & 4 & 5 & 6\end{array}$

$\begin{array}{llllll}1 & 2 & 3 & 4 & 5 & 6\end{array}$

$\begin{array}{llllll}1 & 2 & 3 & 4 & 5 & 6\end{array}$

$\begin{array}{llllll}1 & 2 & 3 & 4 & 5 & 6\end{array}$

$\begin{array}{llllll}1 & 2 & 3 & 4 & 5 & 6\end{array}$

$\begin{array}{llllll}1 & 2 & 3 & 4 & 5 & 6\end{array}$

$\begin{array}{llllll}1 & 2 & 3 & 4 & 5 & 6\end{array}$

$\begin{array}{llllll}1 & 2 & 3 & 4 & 5 & 6\end{array}$

$\begin{array}{llllll}1 & 2 & 3 & 4 & 5 & 6\end{array}$

$\begin{array}{llllll}1 & 2 & 3 & 4 & 5 & 6\end{array}$

$\begin{array}{llllll}1 & 2 & 3 & 4 & 5 & 6\end{array}$

$\begin{array}{llllll}1 & 2 & 3 & 4 & 5 & 6\end{array}$

$\begin{array}{llllll}1 & 2 & 3 & 4 & 5 & 6\end{array}$

$\begin{array}{llllll}1 & 2 & 3 & 4 & 5 & 6\end{array}$

\section{FATHER}

$\begin{array}{llllll}1 & 2 & 3 & 4 & 5 & 6\end{array}$

$\begin{array}{llllll}1 & 2 & 3 & 4 & 5 & 6\end{array}$

123456

$\begin{array}{llllll}1 & 2 & 3 & 4 & 5 & 6\end{array}$

$\begin{array}{llllll}1 & 2 & 3 & 4 & 5 & 6\end{array}$

$\begin{array}{llllll}2 & 2 & 4 & 5 & 6\end{array}$

$\begin{array}{llllll}1 & 2 & 3 & 4 & 5 & 6\end{array}$

$\begin{array}{llllll}1 & 2 & 3 & 4 & 5 & 6\end{array}$

$\begin{array}{llllll}1 & 2 & 3 & 4 & 5 & 6\end{array}$

123456

$\begin{array}{llllll}1 & 2 & 3 & 4 & 5 & 6\end{array}$

$\begin{array}{llllll}1 & 2 & 3 & 4 & 5 & 6\end{array}$

$\begin{array}{llllll}1 & 2 & 3 & 4 & 5 & 6\end{array}$

$\begin{array}{llllll}1 & 2 & 3 & 4 & 5 & 6\end{array}$

$\begin{array}{llllll}1 & 2 & 3 & 4 & 5 & 6\end{array}$ 


\section{YOUR PARENTS \& CONFLICT (Marital Conflict Scale)}

Now I want to ask you some questions about how your parents get on. In most families parents sometimes disagree and even argue. We are interested to know what happens in your family. Please decide which answer is most true for your parents.

1. When they argue, one parent makes the other one feel ashamed

Never Sometimes Often Very often

2. My parents raise their voices when they argue

Never Sometimes Often Very often

3. My parents push and shove each other when they are cross
Never
Sometimes
Often
Very often

4. When my parents are angry one won't speak to the other
Never
Sometimes
Often
Very often

5. When my parents are cross with each other they argue a lot
Never
Sometimes
Often
Very often

6. My parents throw things at each other when they have a fight
Never
Sometimes
Often
Very often

7. One of my parents feels rejected when they have an argument
Never
Sometimes
Often
Very often

8. My parents yell a lot when they are cross with each other

Never

Sometimes

Often

Very often 
9. One of my parents hits the other when they are having an argument Never Sometimes

Often Very often

10. One of my parents makes the other one feel guilty when they are fighting Never Sometimes Often Very often

11. When my parents are cross, they swear at each other Never Sometimes Often Very often

12. Things get broken when my parents are having a fight
Never
Sometimes
Often
Very often

13. Fighting makes one or other of my parents sulk
Never
Sometimes
Often
Very often

14. There is shouting when my parents are having an argument
Never
Sometimes
Often
Very often

15. One parent slaps the other when they are having a fight
Never
Sometimes
Often
Very often

16. My parents hurt each others' feelings when they argue
Never
Sometimes
Often
Very often

17. When they argue my parents criticise each other
Never
Sometimes
Often
Very often

18. One parent punches the other when my parents are cross with each other Never Sometimes Often Very often 


\section{YOU \& YOUR BEHAVIOUR (Strengths \& Difficulties Questionnaire)}

Next, I would like you to answer some questions about how you behave.

Remember, no one will see your answers.

Please decide which answer best describes how things have been for you in the past six months.

\section{Not true Somewhat Certainly true true}

I try to be nice to other people. I care about their feelings

I get a lot of headaches, stomach aches or sickness

I am helpful if someone is hurt, upset, feeling ill

I fight a lot and sometimes bully other people. 


\begin{tabular}{|c|c|c|c|}
\hline & Not true & $\begin{array}{l}\text { Somewhat } \\
\text { true }\end{array}$ & $\begin{array}{c}\text { Certainl } \\
\text { true }\end{array}$ \\
\hline $\begin{array}{l}\text { I am often unhappy, downhearted or } \\
\text { tearful }\end{array}$ & 1 & 2 & 3 \\
\hline Other people of my age generally like me & 1 & 2 & 3 \\
\hline $\begin{array}{l}\text { I am easily distracted, I find it difficult to } \\
\text { concentrate }\end{array}$ & 1 & 2 & 3 \\
\hline $\begin{array}{l}\text { I am nervous in new situations, I easily } \\
\text { lose confidence }\end{array}$ & 1 & 2 & 3 \\
\hline I am kind to younger children & 1 & 2 & 3 \\
\hline I am often accused of lying or cheating & 1 & 2 & 3 \\
\hline $\begin{array}{l}\text { Other children or young people pick on } \\
\text { me or bully me }\end{array}$ & 1 & 2 & 3 \\
\hline $\begin{array}{l}\text { I often volunteer to help others (teachers, } \\
\text { other children, parents) }\end{array}$ & 1 & 2 & 3 \\
\hline I think before I do things & 1 & 2 & 3 \\
\hline $\begin{array}{l}\text { I take things that are not mine from home, } \\
\text { school, or elsewhere }\end{array}$ & 1 & 2 & 3 \\
\hline $\begin{array}{l}\text { I get on better with adults than with people } \\
\text { my own age }\end{array}$ & 1 & 2 & 3 \\
\hline I have many fears, I am easily scared & 1 & 2 & 3 \\
\hline $\begin{array}{l}\text { I finish the work l'm doing. My attention } \\
\text { is good }\end{array}$ & 1 & 2 & 3 \\
\hline
\end{tabular}




\section{YOU \& YOUR FEELINGS (Children's Feelings Scale)}

Finally, here are some words that people sometimes use to describe their feelings. Please decide which answer is most true for you.

1.) "I feel happy"
Not at all true
Not very true
Sort of true
Very true

2.) "I feel angry"

Not at all true

Not very true

Sort of true

Very true

3.) "I feel scared"

Not at all true

Not very true

Sort of true

Very true

4.) "I feel loved"

Not at all true

Not very true

Sort of true

Very true

5.) “I feel excited"

Not at all true

Not very true

Sort of true

Very true

6.) "I feel lonely"

Not at all true

Not very true

Sort of true

Very true

7.) "I feel successful"

Not at all true

Not very true

Sort of true

Very true

8.) "I feel sad"

Not at all true

Not very true

Sort of true

Very true 
9.) "I feel safe"

Not at all true

Not very true

Sort of true

Very true

10.) "I feel worried"

Not at all true

Not very true

Sort of true

Very true

11.) "I feel guilty"

Not at all true

Not very true

Sort of true

Very true

12.) "I feel special"

Not at all true

Not very true

Sort of true

Very true

13.) "I feel jealous"

Not at all true

Not very true

Sort of true

Very true

14.) "I feel relaxed"

Not at all true

Not very true

Sort of true

Very true

15.) "I feel confused"

Not at all true

Not very true

Sort of true

Very true

16.) "I feel hopeful"

Not at all true

Not very true

Sort of true

Very true

17.) "I feel shocked"

Not at all true

Not very true

Sort of true

Very true 
18.) "I feel disappointed"

Not at all true

19.) "I feel strong"

Not at all true

20.) "I feel normal"

Not at all true
Not very true

Sort of true

Very true

Not very true

Sort of true

Very true

Not very true
Sort of true

Very true 


\section{YOU \& CONTROL (Locus of Control Scale)}

People think about the world and what they can do in different ways. These questions suggest different ways that you might feel about what happens to you. l'd like you to tell me which answer best matches what you think.

1. When good things happen to me, many times there doesn't seem to be a good reason why.

Very true Sort of true Not very true Not at all true

2. To get what I want I have to please people who are in charge.

Very true $\quad$ Sort of true Not very true Not at all true

3. I can pretty much control what will happen in my life.

$\begin{array}{llll}\text { Very true } & \text { Sort of true } \quad \text { Not very true } \quad \text { Not all true }\end{array}$

4. Many times I can't figure out why good things happen to me.

Very true Sort of true Not very true Not at all true

5. If there is something that I want to get, I usually have to please important people to get it.

$\begin{array}{llll}\text { Very true } & \text { Sort of true } \quad \text { Not very true } \quad \text { Not all true }\end{array}$

6. I can pretty much decide what will happen in my life.

$\begin{array}{llll}\text { Very true } & \text { Sort of true Not very true } \quad \text { Not all true }\end{array}$

7. A lot of times I don't know why something goes wrong for me.

Very true $\quad$ Sort of true Not very true Not all true

8. If an adult doesn't want me to do something I want to do, I probably won't be able to do it

$\begin{array}{llll}\text { Very true } & \text { Sort of true Not very true } \quad \text { Not all true }\end{array}$ 
9. When I am unsuccessful, it is usually my own fault.

Very true $\quad$ Sort of true Not very true Not at all true

10. When something goes wrong for me, I usually can't work out why it happened.

Very true $\quad$ Sort of true Not very true Not at all true

11. I don't have much chance of doing what I want if adults don't want me to do it.

Very true Sort of true Not very true Not at all true

12. When I don't do well at something, it is usually my own fault.

Very true Sort of true Not very true Not at all true 


\section{YOUR WELLBEING (Children's Depression Inventory)}

Children and adolescents have different feelings and ideas. The next set of questions list feelings and ideas in groups. From each group, pick one sentence that best describes how you have been feeling over the past two weeks.

1. $\square \quad$ I am sad once in a while

$\square \quad$ I am sad many times

$\square \quad$ I am sad all the time

2. $\square \quad$ Nothing will ever work out for me

$\square \quad$ I am not sure if things will work out for me

$\square \quad$ Things will work out okay for me

3. $\square \quad$ I do most things okay

$\square \quad$ I do many things okay

$\square \quad$ I do everything wrong

4. $\square \quad$ I have fun with most things

I have fun with some things

Nothing is fun at all

5. $\square \quad$ I am bad all the time

I am bad many times

I am bad once in a while

6. $\square$ I think about bad things happening to me once in a while

I worry that bad things will happen to me

I am sure that terrible things will happen to me

7. $\square \quad$ I hate myself

I do not like myself

I like myself

8. $\square \quad$ All bad things are my fault

Many bad things are my fault

Bad things are usually not my fault 
9. $\square \quad$ I feel like crying everyday

$\square \quad$ I feel like crying many days

$\square \quad$ I feel like crying once in a while

10. $\square \quad$ Things bother me all the time

$\square \quad$ Things bother me many times

$\square \quad$ Things bother me once in a while

11. $\square \quad$ I like being with people

$\square \quad$ I do not like being with people many times

$\square \quad$ I do not want to be with people at all

12. $\square \quad$ I cannot make up my mind about things

$\square \quad$ It is hard to make up my mind about things

$\square \quad$ I make up my mind about things easily

13. $\square \quad$ I look okay

$\square \quad$ There are some bad things about my looks

$\square \quad$ I look ugly

14. $\square \quad$ I have to push myself all the time to do my school work

$\square \quad$ I have to push myself many times to do my school work

$\square \quad$ Doing school work is not a big problem

15. $\square \quad$ I have trouble sleeping every night

$\square \quad$ I have trouble sleeping many nights

$\square \quad$ I sleep pretty well

16. $\square \quad$ I am tired once in a while

$\square \quad$ I am tired many days

$\square \quad$ I am tired all the time

17. $\square \quad$ Most days I do not feel like eating

$\square \quad$ Many days I do not feel like eating

$\square \quad$ I eat pretty well 
18. $\square \quad$ I do not worry about aches and pains

$\square \quad$ I worry about aches and pains

$\square \quad$ I worry about aches and pains all the time

19. $\square \quad$ I do not feel alone

$\square \quad$ I feel alone many times

$\square \quad$ I feel alone all the time

20. $\square \quad$ I never have fun at school

$\square \quad$ I have fun at school once in a while

$\square \quad$ I have fun at school many times

21. $\square \quad$ I have many friends

$\square \quad$ I have many friends but I wish I had more

$\square \quad$ I do not have any friends

22. $\square \quad$ My school work is alright

$\square \quad$ My school work is not as good as before

$\square \quad$ I do very badly in subjects I used to be good in

23. $\square \quad$ I can never be as good as other kids

$\square \quad$ I can be as good as other kids if I want to

$\square \quad$ I am just as good as other kids

24. $\square \quad$ Nobody really loves me

$\square \quad$ I am not sure if anybody loves me

$\square \quad$ I am sure that somebody loves me

25. $\square \quad$ I usually do what I am told

$\square \quad$ I do not do what I am told most times

$\square \quad$ I never do what I am told

26. $\square \quad$ I get along with other people

$\square \quad$ I get into fights many times

$\square \quad$ I get into fights all the time 


\section{MORE ABOUT YOU (Perception of Strengths Scale)}

Here is a list of words that people sometimes use to describe themselves. Please pick the ones that describe you. Pick as many as you like.

Friendly

Good with pets

Reliable

Helpful

Kind

Independent

Lots of common sense

Confident

Popular

Lots of hobbies

Good at music/art
Trustworthy

Healthy

Sense of humour

Easygoing

Careful

Lively

Good at sports

Outgoing

Affectionate

Creative

Attractive 


\section{YOUR STEPPARENTS (Perception of Stepparents Scale)}

Young people often have many different feelings towards their stepmother and stepfather (or towards your parents' partners). Please think about your own stepmum or stepdad (or your parents' partners) when answering the following questions.

Please decide which answer best describes how you feel about your stepmum and stepdad.

THINKING ABOUT EACH OF YOUR STEPPARENTS, HOW MUCH DO YOU FEEL:

\section{STEPMOTHER}

\section{STEPFATHER}

Respect towards your:

Anger towards your:

Happy towards your:

Love toward your:

Grateful for your:

Proud of your:

Caring toward your:

Confused or puzzled by your:

Disappointed or let down by your:

Comforted thinking about your:

Anxious/nervous about your:

Closeness toward your:

Upset when you think about your:

Appreciative of (thankful for) your:

Positive feelings toward your: $\begin{array}{llllll}1 & 2 & 3 & 4 & 5 & 6\end{array}$

$\begin{array}{llllll}1 & 2 & 3 & 4 & 5 & 6\end{array}$

$\begin{array}{llllll}1 & 2 & 3 & 4 & 5 & 6\end{array}$

$\begin{array}{llllll}1 & 2 & 3 & 4 & 5 & 6\end{array}$

$\begin{array}{llllll}1 & 2 & 3 & 4 & 5 & 6\end{array}$

$\begin{array}{llllll}1 & 2 & 3 & 4 & 5 & 6\end{array}$

$\begin{array}{llllll}1 & 2 & 3 & 4 & 5 & 6\end{array}$

$\begin{array}{llllll}1 & 2 & 3 & 4 & 5 & 6\end{array}$

$\begin{array}{llllll}1 & 2 & 3 & 4 & 5 & 6\end{array}$

$\begin{array}{llllll}1 & 2 & 3 & 4 & 5 & 6\end{array}$

$\begin{array}{llllll}1 & 2 & 3 & 4 & 5 & 6\end{array}$

$\begin{array}{llllll}1 & 2 & 3 & 4 & 5 & 6\end{array}$

$\begin{array}{llllll}1 & 2 & 3 & 4 & 5 & 6\end{array}$

$\begin{array}{llllll}1 & 2 & 3 & 4 & 5 & 6\end{array}$

$\begin{array}{llllll}1 & 2 & 3 & 4 & 5 & 6\end{array}$ $\begin{array}{llllll}1 & 2 & 3 & 4 & 5 & 6\end{array}$

$\begin{array}{llllll}1 & 2 & 3 & 4 & 5 & 6\end{array}$

$\begin{array}{llllll}1 & 2 & 3 & 4 & 5 & 6\end{array}$

$\begin{array}{llllll}1 & 2 & 3 & 4 & 5 & 6\end{array}$

$\begin{array}{llllll}1 & 2 & 3 & 4 & 5 & 6\end{array}$

$\begin{array}{llllll}1 & 2 & 3 & 4 & 5 & 6\end{array}$

$\begin{array}{llllll}1 & 2 & 3 & 4 & 5 & 6\end{array}$

$\begin{array}{llllll}1 & 2 & 3 & 4 & 5 & 6\end{array}$

$\begin{array}{llllll}1 & 2 & 3 & 4 & 5 & 6\end{array}$

$\begin{array}{llllll}1 & 2 & 3 & 4 & 5 & 6\end{array}$

$\begin{array}{llllll}1 & 2 & 3 & 4 & 5 & 6\end{array}$

$\begin{array}{llllll}1 & 2 & 3 & 4 & 5 & 6\end{array}$

$\begin{array}{llllll}1 & 2 & 3 & 4 & 5 & 6\end{array}$

$\begin{array}{llllll}1 & 2 & 3 & 4 & 5 & 6\end{array}$

$\begin{array}{llllll}1 & 2 & 3 & 4 & 5 & 6\end{array}$ 


\section{APPENDIX R}

Estimated Marginal Means: Stage of Separation and Individual Wellbeing at Time 1 and Time 2 
Table R.

The estimated marginal means for the stage of separation groups and their individual wellbeing at Time 1 and Time 2.

\begin{tabular}{|c|c|c|c|c|c|c|}
\hline \multirow{2}{*}{$\begin{array}{l}\text { Dependent } \\
\text { Variables: } \\
\text { Individual } \\
\text { Wellbeing }\end{array}$} & \multirow{2}{*}{$\begin{array}{c}\text { Separation } \\
\text { Group }\end{array}$} & \multirow[b]{2}{*}{ Time } & \multirow[b]{2}{*}{ Mean } & \multirow{2}{*}{$\begin{array}{l}\text { Std. } \\
\text { Error }\end{array}$} & \multicolumn{2}{|c|}{$\begin{array}{c}95 \% \text { Confidence } \\
\text { Interval }\end{array}$} \\
\hline & & & & & $\begin{array}{l}\text { Lower } \\
\text { Bound }\end{array}$ & $\begin{array}{l}\text { Upper } \\
\text { Bound }\end{array}$ \\
\hline \multirow{2}{*}{$\begin{array}{l}\text { Perception of } \\
\text { Strengths }\end{array}$} & ESG & $\begin{array}{l}1 \\
2\end{array}$ & $\begin{array}{l}12.696 \\
16.696\end{array}$ & $\begin{array}{l}.600 \\
.603\end{array}$ & $\begin{array}{l}11.491 \\
15.484\end{array}$ & $\begin{array}{l}13.900 \\
17.908\end{array}$ \\
\hline & LSG & $\begin{array}{l}1 \\
2\end{array}$ & $\begin{array}{l}18.655 \\
18.069\end{array}$ & $\begin{array}{l}.534 \\
.537\end{array}$ & $\begin{array}{l}17.583 \\
16.990\end{array}$ & $\begin{array}{l}19.728 \\
19.148\end{array}$ \\
\hline \multirow{2}{*}{ Positive Feelings } & ESG & $\begin{array}{l}1 \\
2\end{array}$ & $\begin{array}{l}28.348 \\
34.565\end{array}$ & $\begin{array}{l}.852 \\
.489\end{array}$ & $\begin{array}{l}26.637 \\
33.583\end{array}$ & $\begin{array}{l}30.058 \\
35.547\end{array}$ \\
\hline & LSG & $\begin{array}{l}1 \\
2\end{array}$ & $\begin{array}{l}35.897 \\
35.517\end{array}$ & $\begin{array}{l}.758 \\
.435\end{array}$ & $\begin{array}{l}34.373 \\
34.643\end{array}$ & $\begin{array}{l}37.420 \\
36.392\end{array}$ \\
\hline \multirow{2}{*}{$\begin{array}{l}\text { Negative } \\
\text { Feelings }\end{array}$} & ESG & $\begin{array}{l}1 \\
2\end{array}$ & $\begin{array}{l}25.565 \\
17.348\end{array}$ & $\begin{array}{l}.978 \\
.588\end{array}$ & $\begin{array}{l}23.600 \\
16.167\end{array}$ & $\begin{array}{l}27.530 \\
18.528\end{array}$ \\
\hline & LSG & $\begin{array}{l}1 \\
2\end{array}$ & $\begin{array}{l}16.241 \\
16.000\end{array}$ & $\begin{array}{l}.871 \\
.523\end{array}$ & $\begin{array}{l}14.491 \\
14.949\end{array}$ & $\begin{array}{l}17.992 \\
17.051\end{array}$ \\
\hline \multirow{2}{*}{$\begin{array}{l}\text { Pro-social } \\
\text { Behaviour }\end{array}$} & ESG & $\begin{array}{l}1 \\
2\end{array}$ & $\begin{array}{l}10.870 \\
13.478\end{array}$ & $\begin{array}{l}.226 \\
.242\end{array}$ & $\begin{array}{l}10.416 \\
12.992\end{array}$ & $\begin{array}{l}11.323 \\
13.965\end{array}$ \\
\hline & LSG & $\begin{array}{l}1 \\
2\end{array}$ & $\begin{array}{l}11.000 \\
13.724\end{array}$ & $\begin{array}{l}.201 \\
.216\end{array}$ & $\begin{array}{l}10.596 \\
13.291\end{array}$ & $\begin{array}{l}11.404 \\
14.158\end{array}$ \\
\hline \multirow{2}{*}{ Hyperactivity } & ESG & $\begin{array}{l}1 \\
2\end{array}$ & $\begin{array}{l}9.478 \\
8.783\end{array}$ & $\begin{array}{l}.420 \\
.379\end{array}$ & $\begin{array}{l}8.634 \\
8.022\end{array}$ & $\begin{array}{c}10.323 \\
9.543\end{array}$ \\
\hline & LSG & $\begin{array}{l}1 \\
2\end{array}$ & $\begin{array}{l}9.138 \\
8.414\end{array}$ & $\begin{array}{l}.374 \\
.337\end{array}$ & $\begin{array}{l}8.386 \\
7.736\end{array}$ & $\begin{array}{l}9.890 \\
9.091\end{array}$ \\
\hline \multirow{2}{*}{ Internalising } & ESG & $\begin{array}{l}1 \\
2\end{array}$ & $\begin{array}{l}9.826 \\
7.478\end{array}$ & $\begin{array}{l}.445 \\
.377\end{array}$ & $\begin{array}{l}8.933 \\
6.720\end{array}$ & $\begin{array}{c}10.719 \\
8.236\end{array}$ \\
\hline & LSG & $\begin{array}{l}1 \\
2\end{array}$ & $\begin{array}{l}6.828 \\
7.000\end{array}$ & $\begin{array}{l}.396 \\
.336\end{array}$ & $\begin{array}{l}6.032 \\
6.325\end{array}$ & $\begin{array}{l}7.623 \\
7.675\end{array}$ \\
\hline
\end{tabular}




\begin{tabular}{|l|c|c|c|c|c|c|}
\hline \multirow{3}{*}{ Externalising } & ESG & 1 & 8.609 & .336 & 7.934 & 9.283 \\
& & 2 & 7.478 & .328 & 6.819 & 8.137 \\
\cline { 2 - 7 } & LSG & 1 & 6.828 & .299 & 6.227 & 7.428 \\
& & 2 & 7.172 & .292 & 6.585 & 7.759 \\
\hline \multirow{3}{*}{$\begin{array}{l}\text { Peer } \\
\text { Relationship } \\
\text { Problems }\end{array}$} & ESG & 1 & 7.652 & .349 & 6.951 & 8.353 \\
& & 2 & 7.304 & .269 & 6.764 & 7.844 \\
& LSG & 1 & 7.207 & .311 & 6.583 & 7.831 \\
& & 2 & 7.310 & .239 & 6.830 & 7.791 \\
& & & & & & \\
\hline \multirow{3}{*}{ Dysphoria } & ESG & 1 & 16.000 & 1.625 & 12.737 & 19.263 \\
& & 2 & 9.783 & .804 & 8.168 & 11.397 \\
\cline { 2 - 7 } & LSG & 1 & 7.276 & 1.447 & 4.370 & 10.182 \\
& & 2 & 6.759 & .716 & 5.321 & 8.197 \\
\hline
\end{tabular}




\section{APPENDIX S}

Estimated Marginal Means: Stage of Separation and Family Dynamics at Time 1 and Time 2 
Table S.

The estimated marginal means for the stage of separation groups and their family dynamics at Time 1 and Time 2.

\begin{tabular}{|c|c|c|c|c|c|c|}
\hline \multirow{2}{*}{$\begin{array}{c}\text { Dependent } \\
\text { Variables: } \\
\text { Family } \\
\text { Dynamics }\end{array}$} & \multirow{2}{*}{$\begin{array}{c}\text { Separation } \\
\text { Group }\end{array}$} & \multirow[b]{2}{*}{ Time } & \multirow[b]{2}{*}{ Mean } & \multirow{2}{*}{$\begin{array}{l}\text { Std. } \\
\text { Error }\end{array}$} & \multicolumn{2}{|c|}{$\begin{array}{c}\text { 95\% Confidence } \\
\text { Interval }\end{array}$} \\
\hline & & & & & $\begin{array}{l}\text { Lower } \\
\text { Bound }\end{array}$ & $\begin{array}{l}\text { Upper } \\
\text { Bound }\end{array}$ \\
\hline \multirow{2}{*}{ Family Cohesion } & ESG & $\begin{array}{l}1 \\
2\end{array}$ & $\begin{array}{l}5.652 \\
7.435\end{array}$ & $\begin{array}{l}.464 \\
.255\end{array}$ & $\begin{array}{l}4.721 \\
6.923\end{array}$ & $\begin{array}{l}6.583 \\
7.946\end{array}$ \\
\hline & LSG & $\begin{array}{l}1 \\
2\end{array}$ & $\begin{array}{l}8.000 \\
7.966\end{array}$ & $\begin{array}{l}.413 \\
.227\end{array}$ & $\begin{array}{l}7.171 \\
7.510\end{array}$ & $\begin{array}{l}8.829 \\
8.421\end{array}$ \\
\hline \multirow{2}{*}{$\begin{array}{l}\text { Family } \\
\text { Communication }\end{array}$} & ESG & $\begin{array}{l}1 \\
2\end{array}$ & $\begin{array}{l}4.174 \\
6.217\end{array}$ & $\begin{array}{l}.457 \\
.396\end{array}$ & $\begin{array}{l}3.255 \\
5.421\end{array}$ & $\begin{array}{l}5.092 \\
7.013\end{array}$ \\
\hline & LSG & $\begin{array}{l}1 \\
2\end{array}$ & $\begin{array}{l}6.552 \\
6.897\end{array}$ & $\begin{array}{l}.407 \\
.353\end{array}$ & $\begin{array}{l}5.734 \\
6.188\end{array}$ & $\begin{array}{l}7.370 \\
7.605\end{array}$ \\
\hline \multirow{2}{*}{$\begin{array}{l}\text { Positive } \\
\text { Perceptions of } \\
\text { Mother }\end{array}$} & ESG & $\begin{array}{l}1 \\
2\end{array}$ & $\begin{array}{l}46.174 \\
52.696\end{array}$ & $\begin{array}{l}1.051 \\
.540\end{array}$ & $\begin{array}{l}44.063 \\
51.611\end{array}$ & $\begin{array}{l}48.285 \\
53.780\end{array}$ \\
\hline & LSG & $\begin{array}{l}1 \\
2\end{array}$ & $\begin{array}{l}53.517 \\
53.655\end{array}$ & $\begin{array}{l}.936 \\
.481\end{array}$ & $\begin{array}{l}51.637 \\
52.689\end{array}$ & $\begin{array}{l}55.397 \\
54.621\end{array}$ \\
\hline \multirow{2}{*}{$\begin{array}{l}\text { Positive } \\
\text { Perceptions of } \\
\text { Father }\end{array}$} & ESG & $\begin{array}{l}1 \\
2\end{array}$ & $\begin{array}{l}43.435 \\
51.174\end{array}$ & $\begin{array}{l}1.309 \\
.820\end{array}$ & $\begin{array}{l}40.805 \\
49.527\end{array}$ & $\begin{array}{l}46.064 \\
52.821\end{array}$ \\
\hline & LSG & $\begin{array}{l}1 \\
2\end{array}$ & $\begin{array}{l}49.586 \\
53.069\end{array}$ & $\begin{array}{c}1.166 \\
.730\end{array}$ & $\begin{array}{l}47.245 \\
51.602\end{array}$ & $\begin{array}{l}51.928 \\
54.536\end{array}$ \\
\hline \multirow{2}{*}{$\begin{array}{l}\text { Negative } \\
\text { Perceptions of } \\
\text { Mother }\end{array}$} & ESG & $\begin{array}{l}1 \\
2\end{array}$ & $\begin{array}{c}15.304 \\
9.913\end{array}$ & $\begin{array}{l}.760 \\
.499\end{array}$ & $\begin{array}{c}13.777 \\
8.912\end{array}$ & $\begin{array}{l}16.832 \\
10.914\end{array}$ \\
\hline & LSG & $\begin{array}{l}1 \\
2\end{array}$ & $\begin{array}{l}9.690 \\
9.000\end{array}$ & $\begin{array}{l}.677 \\
.444\end{array}$ & $\begin{array}{l}8.329 \\
8.108\end{array}$ & $\begin{array}{l}11.050 \\
9.892\end{array}$ \\
\hline \multirow{2}{*}{$\begin{array}{l}\text { Negative } \\
\text { Perceptions of } \\
\text { Father }\end{array}$} & ESG & $\begin{array}{l}1 \\
2\end{array}$ & $\begin{array}{l}14.478 \\
10.391\end{array}$ & $\begin{array}{l}.768 \\
.538\end{array}$ & $\begin{array}{c}12.936 \\
9.310\end{array}$ & $\begin{array}{l}16.021 \\
11.473\end{array}$ \\
\hline & LSG & $\begin{array}{l}1 \\
2\end{array}$ & $\begin{array}{c}10.897 \\
9.276\end{array}$ & $\begin{array}{l}.684 \\
.479\end{array}$ & $\begin{array}{l}9.523 \\
8.313\end{array}$ & $\begin{array}{l}12.270 \\
10.239\end{array}$ \\
\hline
\end{tabular}




\begin{tabular}{|l|c|c|c|c|c|c|}
\hline \multirow{4}{*}{ Parental Conflict } & ESG & 1 & 37.696 & 1.159 & 35.367 & 40.025 \\
& & 2 & 29.652 & .688 & 28.270 & 31.034 \\
\cline { 2 - 6 } & & & & & & \\
\hline & & 1 & 29.552 & 1.033 & 27.478 & 31.626 \\
& & 2 & 28.034 & .613 & 26.804 & 29.265 \\
\hline
\end{tabular}




\section{APPENDIX T}

Estimated Marginal Means: Individual Wellbeing at Time 1 and Time 2 
Table T.

The estimated marginal means for individual wellbeing at Time 1 and Time 2.

\begin{tabular}{|c|c|c|c|c|c|}
\hline \multirow{2}{*}{$\begin{array}{l}\text { Dependent Variables: } \\
\text { Individual Wellbeing }\end{array}$} & \multirow[b]{2}{*}{ Time } & \multirow[b]{2}{*}{ Mean } & \multirow{2}{*}{$\begin{array}{l}\text { Std. } \\
\text { Error }\end{array}$} & \multicolumn{2}{|c|}{$\begin{array}{l}\text { 95\% Confidence } \\
\text { Interval }\end{array}$} \\
\hline & & & & $\begin{array}{l}\text { Lower } \\
\text { Bound }\end{array}$ & $\begin{array}{l}\text { Upper } \\
\text { Bound }\end{array}$ \\
\hline Perception of Strengths & $\begin{array}{l}1 \\
2\end{array}$ & $\begin{array}{l}15.675 \\
17.382\end{array}$ & $\begin{array}{l}.401 \\
.404\end{array}$ & $\begin{array}{l}14.869 \\
16.571\end{array}$ & $\begin{array}{l}16.482 \\
18.194\end{array}$ \\
\hline Positive Feelings & $\begin{array}{l}1 \\
2\end{array}$ & $\begin{array}{l}32.122 \\
35.041\end{array}$ & $\begin{array}{l}.570 \\
.327\end{array}$ & $\begin{array}{l}30.977 \\
34.384\end{array}$ & $\begin{array}{l}33.267 \\
35.699\end{array}$ \\
\hline Negative Feelings & $\begin{array}{l}1 \\
2\end{array}$ & $\begin{array}{l}20.903 \\
16.674\end{array}$ & $\begin{array}{l}.655 \\
.393\end{array}$ & $\begin{array}{l}19.587 \\
15.884\end{array}$ & $\begin{array}{l}22.219 \\
17.464\end{array}$ \\
\hline Pro-social Behaviour & $\begin{array}{l}1 \\
2\end{array}$ & $\begin{array}{l}10.935 \\
13.601\end{array}$ & $\begin{array}{l}.151 \\
.162\end{array}$ & $\begin{array}{l}10.631 \\
13.275\end{array}$ & $\begin{array}{l}11.238 \\
13.927\end{array}$ \\
\hline Hyperactivity & $\begin{array}{l}1 \\
2\end{array}$ & $\begin{array}{l}9.308 \\
8.598\end{array}$ & $\begin{array}{l}.281 \\
.254\end{array}$ & $\begin{array}{l}8.743 \\
8.089\end{array}$ & $\begin{array}{l}9.873 \\
9.108\end{array}$ \\
\hline Internalising & $\begin{array}{l}1 \\
2\end{array}$ & $\begin{array}{l}8.327 \\
7.239\end{array}$ & $\begin{array}{l}.298 \\
.253\end{array}$ & $\begin{array}{l}7.729 \\
6.732\end{array}$ & $\begin{array}{l}8.925 \\
7.747\end{array}$ \\
\hline Externalising & $\begin{array}{l}1 \\
2\end{array}$ & $\begin{array}{l}7.718 \\
7.325\end{array}$ & $\begin{array}{l}.225 \\
.220\end{array}$ & $\begin{array}{l}7.267 \\
6.884\end{array}$ & $\begin{array}{l}8.170 \\
7.767\end{array}$ \\
\hline $\begin{array}{l}\text { Peer Relationship } \\
\text { Problems }\end{array}$ & $\begin{array}{l}1 \\
2\end{array}$ & $\begin{array}{l}7.430 \\
7.307\end{array}$ & $\begin{array}{l}.234 \\
.180\end{array}$ & $\begin{array}{l}6.960 \\
6.946\end{array}$ & $\begin{array}{l}7.899 \\
7.669\end{array}$ \\
\hline Dysphoria & $\begin{array}{l}1 \\
2\end{array}$ & $\begin{array}{c}11.638 \\
8.271\end{array}$ & $\begin{array}{c}1.088 \\
.538\end{array}$ & $\begin{array}{l}9.453 \\
7.190\end{array}$ & $\begin{array}{c}13.823 \\
9.352\end{array}$ \\
\hline
\end{tabular}




\section{APPENDIX U}

Estimated Marginal Means: Family Dynamics at Time 1 and Time 2 
Table U.

The estimated marginal means for family dynamics at Time 1 and Time 2.

\begin{tabular}{|c|c|c|c|c|c|}
\hline \multirow{2}{*}{$\begin{array}{c}\text { Dependent Variables: } \\
\text { Family Dynamics }\end{array}$} & \multirow[b]{2}{*}{ Time } & \multirow[b]{2}{*}{ Mean } & \multirow{2}{*}{$\begin{array}{l}\text { Std. } \\
\text { Error }\end{array}$} & \multicolumn{2}{|c|}{$\begin{array}{l}\text { 95\% Confidence } \\
\text { Interval }\end{array}$} \\
\hline & & & & $\begin{array}{l}\text { Lower } \\
\text { Bound }\end{array}$ & $\begin{array}{l}\text { Upper } \\
\text { Bound }\end{array}$ \\
\hline Family Cohesion & $\begin{array}{l}1 \\
2\end{array}$ & $\begin{array}{l}6.826 \\
7.700\end{array}$ & $\begin{array}{l}.310 \\
.171\end{array}$ & $\begin{array}{l}6.203 \\
7.358\end{array}$ & $\begin{array}{l}7.450 \\
8.043\end{array}$ \\
\hline Family Communication & $\begin{array}{l}1 \\
2\end{array}$ & $\begin{array}{l}5.363 \\
6.557\end{array}$ & $\begin{array}{l}.306 \\
.265\end{array}$ & $\begin{array}{l}4.748 \\
6.024\end{array}$ & $\begin{array}{l}5.978 \\
7.090\end{array}$ \\
\hline $\begin{array}{l}\text { Positive Perceptions of } \\
\text { Mother }\end{array}$ & $\begin{array}{l}1 \\
2\end{array}$ & $\begin{array}{l}49.846 \\
53.175\end{array}$ & $\begin{array}{l}.704 \\
.362\end{array}$ & $\begin{array}{l}48.432 \\
52.449\end{array}$ & $\begin{array}{l}51.259 \\
53.902\end{array}$ \\
\hline $\begin{array}{l}\text { Positive Perceptions of } \\
\text { Father }\end{array}$ & $\begin{array}{l}1 \\
2\end{array}$ & $\begin{array}{l}46.510 \\
52.121\end{array}$ & $\begin{array}{l}.876 \\
.549\end{array}$ & $\begin{array}{l}44.750 \\
51.019\end{array}$ & $\begin{array}{l}48.271 \\
53.224\end{array}$ \\
\hline $\begin{array}{l}\text { Negative Perceptions of } \\
\text { Mother }\end{array}$ & $\begin{array}{l}1 \\
2\end{array}$ & $\begin{array}{c}12.497 \\
9.457\end{array}$ & $\begin{array}{l}.509 \\
.334\end{array}$ & $\begin{array}{l}11.474 \\
8.786\end{array}$ & $\begin{array}{l}13.520 \\
10.127\end{array}$ \\
\hline $\begin{array}{l}\text { Negative Perceptions of } \\
\text { Father }\end{array}$ & $\begin{array}{l}1 \\
2\end{array}$ & $\begin{array}{c}12.687 \\
9.834\end{array}$ & $\begin{array}{l}.514 \\
.360\end{array}$ & $\begin{array}{l}11.655 \\
9.110\end{array}$ & $\begin{array}{l}13.720 \\
10.558\end{array}$ \\
\hline Parental Conflict & $\begin{array}{l}1 \\
2\end{array}$ & $\begin{array}{l}33.624 \\
28.843\end{array}$ & $\begin{array}{l}.776 \\
.461\end{array}$ & $\begin{array}{l}32.064 \\
27.918\end{array}$ & $\begin{array}{l}35.183 \\
29.768\end{array}$ \\
\hline
\end{tabular}




\section{APPENDIX V}

Estimated Marginal Means: Stage of Separation and Individual Wellbeing at Time 1 
Table V.

The estimated marginal means for the stage of separation groups and their individual wellbeing at Time 1.

\begin{tabular}{|c|c|c|c|c|c|}
\hline \multirow{2}{*}{$\begin{array}{l}\text { Dependent Variables: } \\
\text { Individual Wellbeing }\end{array}$} & \multirow[b]{2}{*}{ Group } & \multirow[b]{2}{*}{ Mean } & \multirow{2}{*}{$\begin{array}{l}\text { Std. } \\
\text { Error }\end{array}$} & \multicolumn{2}{|c|}{$\begin{array}{l}\text { 95\% Confidence } \\
\text { Interval }\end{array}$} \\
\hline & & & & $\begin{array}{l}\text { Lower } \\
\text { Bound }\end{array}$ & $\begin{array}{l}\text { Upper } \\
\text { Bound }\end{array}$ \\
\hline Perception of Strengths 1 & $\begin{array}{l}\text { ESG } \\
\text { LSG }\end{array}$ & $\begin{array}{l}12.696 \\
18.655\end{array}$ & $\begin{array}{l}.600 \\
.534\end{array}$ & $\begin{array}{l}11.491 \\
17.583\end{array}$ & $\begin{array}{l}13.900 \\
19.728\end{array}$ \\
\hline Positive Feelings 1 & $\begin{array}{l}\text { ESG } \\
\text { LSG }\end{array}$ & $\begin{array}{l}28.348 \\
35.897\end{array}$ & $\begin{array}{l}.852 \\
.758\end{array}$ & $\begin{array}{l}26.637 \\
34.373\end{array}$ & $\begin{array}{l}30.058 \\
37.420\end{array}$ \\
\hline Negative Feelings 1 & $\begin{array}{l}\text { ESG } \\
\text { LSG }\end{array}$ & $\begin{array}{l}25.565 \\
16.241\end{array}$ & $\begin{array}{l}.978 \\
.871\end{array}$ & $\begin{array}{l}23.600 \\
14.491\end{array}$ & $\begin{array}{l}27.530 \\
17.992\end{array}$ \\
\hline Pro-social Behaviour 1 & $\begin{array}{l}\text { ESG } \\
\text { LSG }\end{array}$ & $\begin{array}{l}10.870 \\
11.000\end{array}$ & $\begin{array}{l}.226 \\
.201\end{array}$ & $\begin{array}{l}10.416 \\
10.596\end{array}$ & $\begin{array}{l}11.323 \\
11.404\end{array}$ \\
\hline Hyperactivity 1 & $\begin{array}{l}\text { ESG } \\
\text { LSG }\end{array}$ & $\begin{array}{l}9.478 \\
9.138\end{array}$ & $\begin{array}{l}.420 \\
.374\end{array}$ & $\begin{array}{l}8.634 \\
8.386\end{array}$ & $\begin{array}{c}10.323 \\
9.890\end{array}$ \\
\hline Internalising 1 & $\begin{array}{l}\text { ESG } \\
\text { LSG }\end{array}$ & $\begin{array}{l}9.826 \\
6.828\end{array}$ & $\begin{array}{l}.445 \\
.396\end{array}$ & $\begin{array}{l}8.933 \\
6.032\end{array}$ & $\begin{array}{l}10.719 \\
7.623\end{array}$ \\
\hline Externalising 1 & $\begin{array}{l}\text { ESG } \\
\text { LSG }\end{array}$ & $\begin{array}{l}8.609 \\
6.828\end{array}$ & $\begin{array}{l}.336 \\
.299\end{array}$ & $\begin{array}{l}7.934 \\
6.227\end{array}$ & $\begin{array}{l}9.283 \\
7.428\end{array}$ \\
\hline $\begin{array}{l}\text { Peer Relationship } \\
\text { Problems } 1\end{array}$ & $\begin{array}{l}\text { ESG } \\
\text { LSG }\end{array}$ & $\begin{array}{l}7.652 \\
7.207\end{array}$ & $\begin{array}{l}.349 \\
.311\end{array}$ & $\begin{array}{l}6.951 \\
6.583\end{array}$ & $\begin{array}{l}8.353 \\
7.831\end{array}$ \\
\hline Dysphoria 1 & $\begin{array}{l}\text { ESG } \\
\text { LSG }\end{array}$ & $\begin{array}{l}16.000 \\
7.276\end{array}$ & $\begin{array}{l}1.624 \\
1.447\end{array}$ & $\begin{array}{c}12.737 \\
4.370\end{array}$ & $\begin{array}{l}19.263 \\
10.182\end{array}$ \\
\hline
\end{tabular}




\section{APPENDIX W}

Estimated Marginal Means: Stage of Separation and Family Dynamics at Time 1 
Table W.

The estimated marginal means for the stage of separation groups and their family dynamics at Time 1.

\begin{tabular}{|c|c|c|c|c|c|}
\hline \multirow{2}{*}{$\begin{array}{c}\text { Dependent } \\
\text { Variables: Family } \\
\text { Dynamics }\end{array}$} & \multirow[b]{2}{*}{ Group } & \multirow[b]{2}{*}{ Mean } & \multirow{2}{*}{$\begin{array}{l}\text { Std. } \\
\text { Error }\end{array}$} & \multicolumn{2}{|c|}{$\begin{array}{c}\text { 95\% Confidence } \\
\text { Interval }\end{array}$} \\
\hline & & & & $\begin{array}{l}\text { Lower } \\
\text { Bound }\end{array}$ & $\begin{array}{l}\text { Upper } \\
\text { Bound }\end{array}$ \\
\hline Family Cohesion 1 & $\begin{array}{l}\text { ESG } \\
\text { LSG }\end{array}$ & $\begin{array}{l}5.652 \\
8.000\end{array}$ & $\begin{array}{l}.464 \\
.413\end{array}$ & $\begin{array}{l}4.721 \\
7.171\end{array}$ & $\begin{array}{l}6.583 \\
8.829\end{array}$ \\
\hline $\begin{array}{l}\text { Family } \\
\text { Communication } 1\end{array}$ & $\begin{array}{l}\text { ESG } \\
\text { LSG }\end{array}$ & $\begin{array}{l}4.174 \\
6.552\end{array}$ & $\begin{array}{l}.457 \\
.407\end{array}$ & $\begin{array}{l}3.255 \\
5.734\end{array}$ & $\begin{array}{l}5.092 \\
7.370\end{array}$ \\
\hline $\begin{array}{l}\text { Positive Perceptions } \\
\text { of Mother } 1\end{array}$ & $\begin{array}{l}\text { ESG } \\
\text { LSG }\end{array}$ & $\begin{array}{l}46.174 \\
53.517\end{array}$ & $\begin{array}{l}1.051 \\
.936\end{array}$ & $\begin{array}{l}44.063 \\
51.637\end{array}$ & $\begin{array}{l}48.285 \\
55.397\end{array}$ \\
\hline $\begin{array}{l}\text { Positive Perceptions } \\
\text { of Father } 1\end{array}$ & $\begin{array}{l}\text { ESG } \\
\text { LSG }\end{array}$ & $\begin{array}{l}43.435 \\
49.586\end{array}$ & $\begin{array}{l}1.309 \\
1.166\end{array}$ & $\begin{array}{l}40.805 \\
47.245\end{array}$ & $\begin{array}{l}46.064 \\
51.928\end{array}$ \\
\hline $\begin{array}{l}\text { Negative Perceptions } \\
\text { of Mother } 1\end{array}$ & $\begin{array}{l}\text { ESG } \\
\text { LSG }\end{array}$ & $\begin{array}{c}15.304 \\
9.690\end{array}$ & $\begin{array}{l}.760 \\
.677\end{array}$ & $\begin{array}{c}13.777 \\
8.329\end{array}$ & $\begin{array}{l}16.832 \\
11.050\end{array}$ \\
\hline $\begin{array}{l}\text { Negative Perceptions } \\
\text { of Father } 1\end{array}$ & $\begin{array}{l}\text { ESG } \\
\text { LSG }\end{array}$ & $\begin{array}{l}14.478 \\
10.897\end{array}$ & $\begin{array}{l}.768 \\
.684\end{array}$ & $\begin{array}{l}12.936 \\
9.523\end{array}$ & $\begin{array}{l}16.021 \\
12.270\end{array}$ \\
\hline Parental Conflict 1 & $\begin{array}{l}\text { ESG } \\
\text { LSG }\end{array}$ & $\begin{array}{l}37.696 \\
29.552\end{array}$ & $\begin{array}{l}1.159 \\
1.033\end{array}$ & $\begin{array}{l}35.367 \\
27.478\end{array}$ & $\begin{array}{l}40.025 \\
31.626\end{array}$ \\
\hline
\end{tabular}




\section{APPENDIX $X$}

Estimated Marginal Means: Stage of Separation and Individual Wellbeing at Time 2 
Table X.

The estimated marginal means for the stage of separation groups and their individual wellbeing at Time 2.

\begin{tabular}{|c|c|c|c|c|c|}
\hline \multirow{2}{*}{$\begin{array}{l}\text { Dependent Variables: } \\
\text { Individual Wellbeing }\end{array}$} & \multirow[b]{2}{*}{ Group } & \multirow[b]{2}{*}{ Mean } & \multirow{2}{*}{$\begin{array}{l}\text { Std. } \\
\text { Error }\end{array}$} & \multicolumn{2}{|c|}{$\begin{array}{l}\text { 95\% Confidence } \\
\text { Interval }\end{array}$} \\
\hline & & & & $\begin{array}{l}\text { Lower } \\
\text { Bound }\end{array}$ & $\begin{array}{l}\text { Upper } \\
\text { Bound }\end{array}$ \\
\hline Perception of Strengths 2 & $\begin{array}{l}\text { ESG } \\
\text { LSG }\end{array}$ & $\begin{array}{l}16.696 \\
18.069\end{array}$ & $\begin{array}{l}.603 \\
.537\end{array}$ & $\begin{array}{l}15.484 \\
16.990\end{array}$ & $\begin{array}{l}17.908 \\
19.148\end{array}$ \\
\hline Positive Feelings 2 & $\begin{array}{l}\text { ESG } \\
\text { LSG }\end{array}$ & $\begin{array}{l}34.565 \\
35.517\end{array}$ & $\begin{array}{l}.489 \\
.435\end{array}$ & $\begin{array}{l}33.583 \\
34.643\end{array}$ & $\begin{array}{l}35.547 \\
36.392\end{array}$ \\
\hline Negative Feelings 2 & $\begin{array}{l}\text { ESG } \\
\text { LSG }\end{array}$ & $\begin{array}{l}17.348 \\
16.000\end{array}$ & $\begin{array}{l}.588 \\
.523\end{array}$ & $\begin{array}{l}16.167 \\
14.949\end{array}$ & $\begin{array}{l}18.528 \\
17.051\end{array}$ \\
\hline Pro-social Behaviour 2 & $\begin{array}{l}\text { ESG } \\
\text { LSG }\end{array}$ & $\begin{array}{l}13.478 \\
13.724\end{array}$ & $\begin{array}{l}.242 \\
.216\end{array}$ & $\begin{array}{l}12.992 \\
13.291\end{array}$ & $\begin{array}{l}13.965 \\
14.158\end{array}$ \\
\hline Hyperactivity 2 & $\begin{array}{l}\text { ESG } \\
\text { LSG }\end{array}$ & $\begin{array}{l}8.783 \\
8.414\end{array}$ & $\begin{array}{l}.379 \\
.337\end{array}$ & $\begin{array}{l}8.022 \\
7.736\end{array}$ & $\begin{array}{l}9.543 \\
9.091\end{array}$ \\
\hline Internalising 2 & $\begin{array}{l}\text { ESG } \\
\text { LSG }\end{array}$ & $\begin{array}{l}7.478 \\
7.000\end{array}$ & $\begin{array}{l}.377 \\
.336\end{array}$ & $\begin{array}{l}6.720 \\
6.325\end{array}$ & $\begin{array}{l}8.236 \\
7.675\end{array}$ \\
\hline Externalising 2 & $\begin{array}{l}\text { ESG } \\
\text { LSG }\end{array}$ & $\begin{array}{l}7.478 \\
7.172\end{array}$ & $\begin{array}{l}.328 \\
.292\end{array}$ & $\begin{array}{l}6.819 \\
6.585\end{array}$ & $\begin{array}{l}8.137 \\
7.759\end{array}$ \\
\hline $\begin{array}{l}\text { Peer Relationship } \\
\text { Problems } 2\end{array}$ & $\begin{array}{l}\text { ESG } \\
\text { LSG }\end{array}$ & $\begin{array}{l}7.304 \\
7.310\end{array}$ & $\begin{array}{l}.296 \\
.239\end{array}$ & $\begin{array}{l}6.764 \\
6.830\end{array}$ & $\begin{array}{l}7.844 \\
7.791\end{array}$ \\
\hline Dysphoria 2 & $\begin{array}{l}\text { ESG } \\
\text { LSG }\end{array}$ & $\begin{array}{l}9.783 \\
6.759\end{array}$ & $\begin{array}{l}.804 \\
.716\end{array}$ & $\begin{array}{l}8.168 \\
5.321\end{array}$ & $\begin{array}{c}11.397 \\
8.197\end{array}$ \\
\hline
\end{tabular}




\section{APPENDIX Y}

Estimated Marginal Means: Stage of Separation and Family Dynamics at Time 2 
Table Y.

The estimated marginal means for the stage of separation groups and their family dynamics at Time 2.

\begin{tabular}{|c|c|c|c|c|c|}
\hline \multirow{2}{*}{$\begin{array}{c}\text { Dependent } \\
\text { Variables: Family } \\
\text { Dynamics }\end{array}$} & \multirow[b]{2}{*}{ Group } & \multirow[b]{2}{*}{ Mean } & \multirow{2}{*}{$\begin{array}{l}\text { Std. } \\
\text { Error }\end{array}$} & \multicolumn{2}{|c|}{$\begin{array}{l}\text { 95\% Confidence } \\
\text { Interval }\end{array}$} \\
\hline & & & & $\begin{array}{l}\text { Lower } \\
\text { Bound }\end{array}$ & $\begin{array}{l}\text { Upper } \\
\text { Bound }\end{array}$ \\
\hline Family Cohesion 2 & $\begin{array}{l}\text { ESG } \\
\text { LSG }\end{array}$ & $\begin{array}{l}7.435 \\
7.966\end{array}$ & $\begin{array}{l}.255 \\
.227\end{array}$ & $\begin{array}{l}6.923 \\
7.510\end{array}$ & $\begin{array}{l}7.946 \\
8.421\end{array}$ \\
\hline $\begin{array}{l}\text { Family } \\
\text { Communication } 2\end{array}$ & $\begin{array}{l}\text { ESG } \\
\text { LSG }\end{array}$ & $\begin{array}{l}6.217 \\
6.897\end{array}$ & $\begin{array}{l}.396 \\
.353\end{array}$ & $\begin{array}{l}5.421 \\
6.188\end{array}$ & $\begin{array}{l}7.013 \\
7.605\end{array}$ \\
\hline $\begin{array}{l}\text { Positive Perceptions } \\
\text { of Mother } 2\end{array}$ & $\begin{array}{l}\text { ESG } \\
\text { LSG }\end{array}$ & $\begin{array}{l}52.696 \\
53.655\end{array}$ & $\begin{array}{l}.540 \\
.481\end{array}$ & $\begin{array}{l}51.611 \\
52.689\end{array}$ & $\begin{array}{l}53.780 \\
54.621\end{array}$ \\
\hline $\begin{array}{l}\text { Positive Perceptions } \\
\text { of Father } 2\end{array}$ & $\begin{array}{l}\text { ESG } \\
\text { LSG }\end{array}$ & $\begin{array}{l}51.174 \\
53.069\end{array}$ & $\begin{array}{l}.820 \\
.730\end{array}$ & $\begin{array}{l}49.527 \\
51.602\end{array}$ & $\begin{array}{l}52.821 \\
54.536\end{array}$ \\
\hline $\begin{array}{l}\text { Negative Perceptions } \\
\text { of Mother } 2\end{array}$ & $\begin{array}{l}\text { ESG } \\
\text { LSG }\end{array}$ & $\begin{array}{l}9.913 \\
9.000\end{array}$ & $\begin{array}{l}.499 \\
.444\end{array}$ & $\begin{array}{l}8.912 \\
8.108\end{array}$ & $\begin{array}{c}10.914 \\
9.892\end{array}$ \\
\hline $\begin{array}{l}\text { Negative Perceptions } \\
\text { of Father } 2\end{array}$ & $\begin{array}{l}\text { ESG } \\
\text { LSG }\end{array}$ & $\begin{array}{c}10.391 \\
9.276\end{array}$ & $\begin{array}{l}.538 \\
.479\end{array}$ & $\begin{array}{l}9.310 \\
8.313\end{array}$ & $\begin{array}{l}11.473 \\
10.239\end{array}$ \\
\hline Parental Conflict 2 & $\begin{array}{l}\text { ESG } \\
\text { LSG }\end{array}$ & $\begin{array}{l}29.652 \\
28.034\end{array}$ & $\begin{array}{l}.688 \\
.613\end{array}$ & $\begin{array}{l}28.270 \\
26.804\end{array}$ & $\begin{array}{l}31.034 \\
29.265\end{array}$ \\
\hline
\end{tabular}




\section{APPENDIX Z}

Non parametric Results 


\section{Non parametric results}

\section{Interaction effects (Mann-Whitney $U$ test)}

A Mann-Whitney test was performed to ascertain whether there were differences in individual wellbeing and family dynamics from Time 1 to Time 2 for the ESG and the LSG, and the child and adolescent groups. In a Mann-Whitney $U$ test the distribution of the scores is unimportant because the scores for each group are converted to ranks. The Mann-Whitney test then assesses whether there is a significant difference in the ranks of the two groups (Pallant, 2005). In order to carry out this test the difference in the two time points was calculated, creating one score for each individual, which was then ranked. A higher mean rank signified a greater difference between the Time 1 and Time 2 scores. Field (2005) recommended that in non parametric tests the median for each group should be compared, in place of the mean, because the median is a more appropriate statistic for non parametric analyses. For that reason, the medians are reported below.

\section{Individual wellbeing at Time 1 vs. Time 2 for early-stage group and later-stage}

group. There were a number of significant differences between the ESG and LSG across time. Firstly, there was a greater difference between the Time 1 and Time 2 perceptions of strengths scores for the ESG $(M d n=4.00)$ than there was for the LSG $(M d n=.00), U=53.00, p=.000, r=-.72$. There was also a greater difference between the ESGs' Time 1 and Time 2 positive feelings scores than there was for the LSG $(M d n=6.00 \& M d n=.00$, respectively), $U=44.50, p=$ $.000, r=-.74$. These results confirm that there was a difference between the ESGs' perception of strengths and positive feelings scores at Time 1 and Time 2. More specifically, the ESGs' scores increased over time; in comparison the LSGs' scores remained relatively stable.

In terms of the negative feelings variable, there was a greater difference between the ESGs' Time 1 and Time 2 scores than there was for the LSG (Mdn $=-8.00$ \& 
$M d n=.00$, in that order), $U=50.50, p=.000, r=-.72$. For the internalising behaviour variable there was also a greater difference between the Time 1 and Time 2 scores for the ESG $(M d n=-2.00)$ versus the LSG $(M d n=.00), U=67.00$, $p=.000, r=-.69$. Similarly, there was a greater difference between the externalising behaviour scores across time for the ESG $(M d n=-1.00)$ than there was for the LSG $(M d n=1.00), U=161.50, p=.001, r=-.45$. For the final significant individual wellbeing variable - dysphoria - there was a greater difference between the Time 1 and Time 2 scores for the ESG $(M d n=-5.00)$ compared to the LSG $(M d n=.00), U=131.50, p=.000, r=-.52$. These results demonstrate a difference between the ESGs' negative feelings, internalising behaviour, externalising behaviour, and dysphoria scores at Time 1 and Time 2. More specifically, the ESGs' scores decreased over time and the LSGs' scores remained relatively stable.

With regard to the pro-social behaviour variable, there was no difference between the Time 1 and Time 2 scores for the ESG $(M d n=3.00)$ and the LSG $(M d n=3.00), U=323.50, n s, r=-.03$. Similarly, there was no difference in the hyperactivity scores across time for the ESG $(M d n=-1.00)$ and the LSG $(M d n=-$ 1.00), $U=324.50, n s, r=-.02$. There was also no difference between the Time 1 and Time 2 peer relationship scores for the ESG $(M d n=.00)$ and the LSG $(M d n$ $=.00), U=255.00, n s, r=-.21$.

All of these non parametric results support the univariate MANOVA results for research question 11 , which are reported in section 9.7.1.

\section{Family dynamics at Time 1 vs. Time 2 for early-stage group and later-stage}

group. There were significant differences between the ESG and LSG across time for all of the family wellbeing variables. For the ESG there was a greater difference between the Time 1 and Time 2 family cohesion scores $(M d n=1.00)$ than there was for the LSG $(M d n=.00), U=189.00, p=.007, r=-.38$. There was also a greater difference between the Time 1 and Time 2 family 
communication scores for the ESG $(M d n=2.00)$ versus the LSG $(M d n=.00), U$ $=185.50, p=.006, r=-.38$. These results confirm that there was a difference between the ESGs' family environment scores at Time 1 and Time 2. More specifically, the ESGs' scores increased over time and the LSGs' scores remained relatively stable.

For the positive perceptions of mother variable there was a greater difference between the Time 1 and Time 2 scores for the ESG $(M d n=7.00)$ than there was for the LSG $(M d n=.00), U=91.00, p=.000, r=-.62$. With regard to the positive perceptions of father variable, there was also a greater difference between the Time 1 and Time 2 scores for the ESG $(M d n=8.00)$ compared to the LSG (Mdn $=3.00), U=160.00, p=.001, r=-.44$. These results reveal disparity between the ESGs' positive perceptions of mother scores and their positive perceptions of father scores from Time 1 to Time 2. More specifically, the ESGs' scores increased over time, whereas the LSGs' scores remained relatively stable.

In terms of the negative perceptions of mother variable, there was more of a difference between the Time 1 and Time 2 scores for the ESG $(M d n=-6.00)$ than there was for the LSG $(M d n=-1.00), U=60.00, p=.000, r=-.70$. Similarly, for the negative perceptions of father variable there was a greater difference between the Time 1 and Time 2 scores for the ESG $(M d n=-4.00)$ versus the LSG $(M d n=-2.00), U=173.00, p=.003, r=-.41$. For the final significant family wellbeing variable, there was a greater difference between the Time 1 and Time 2 parental conflict scores for the ESG $(M d n=-8.00)$ compared to the LSG $(M d n$ $=-1.00), U=78.50, p=.000, r=-.65$. These results illustrate a difference between the ESGs' negative perceptions of mother, negative perceptions of father, and parental conflict scores from Time 1 to Time 2. More specifically, the ESGs' scores decreased over time, whereas the LSGs' scores were reasonably constant. 
The univariate MANOVA results for research question 12 (reported in section 9.7.1), are reinforced by these non parametric findings.

Individual wellbeing at Time $1 \mathrm{vs}$. Time 2 for child group and adolescent group. There were no significant differences between the child participants and the adolescent participants across time for all nine of the individual wellbeing variables. These results support the univariate MANOVA results for research question 13, which are reported in section 9.7.1.

\section{Family dynamics at Time $1 \mathrm{vs}$. Time 2 for child group and adolescent group.}

Furthermore, there were no significant differences between the child participants and the adolescent participants from Time 1 to Time 2 for all seven of the family wellbeing variables. These results strengthen the univariate MANOVA analyses for research question 14, as reported in section 9.7.1.

\section{Main effects for time (Wilcoxon signed-rank test)}

A Wilcoxon signed-rank test was employed to establish whether there were any differences in individual wellbeing and family dynamics from Time 1 to Time 2. In a Wilcoxon test the variation between the scores of the repeatedly measured variables is calculated and the differences are then ranked. Most importantly, the sign of the difference (positive or negative) is taken into account in the ranking (Field, 2005). The results for the main effects over time are reported below.

Individual wellbeing at Time $1 \mathrm{vs}$. Time 2. There were a number of significant differences in individual wellbeing across time. Starting with the positive variables, the young people's perceptions of strengths were significantly higher at Time $2(M d n=18.00)$ compared to Time $1(M d n=17.00), T=253, p<.05, r=-$ .40. The young people also had significantly higher pro-social behaviour scores at Time $2(M d n=11.00)$ versus Time $1(M d n=14.00), T=.00, p<.05, r=-.85$. With regard to the young people's positive feelings, there was a significantly higher score at Time $2(M d n=35.00)$ compared to Time $1(M d n=33.00), T=$ 
260, $p<.05, r=-.49$. These results, therefore, verify that the young people's perception of strengths, pro-social behaviour and positive feelings increased over time.

In terms of the young people's negative feelings, their scores were significantly lower at Time $2(M d n=16.50)$ compared to Time $1(M d n=20.00), T=223.50, p$ $<.05, r=-.57$. Their hyperactivity scores were also significantly lower at Time 2 $(M d n=16.50)$ in comparison to their earlier scores $(M d n=20.00), T=223.50, p$ $<.05, r=-.57$. Similarly, the young people's internalising scores were lower at Time $2(M d n=16.50)$ versus Time $1(M d n=20.00), T=223.50, p<.05, r=-.57$. Finally, with regard to the young people's levels of dysphoria, their scores were significantly lower at Time $2(M d n=16.50)$ in comparison to their Time 1 scores $(M d n=20.00), T=223.50, p<.05, r=-.57$. These results demonstrate that the participants' negative feelings, hyperactivity, internalising behaviour, and dysphoria all decreased over time.

With regard to the externalising behaviour variable, there was no significant difference between the Time 1 and Time 2 scores $(M d n=8.00 \& M d n=7.00$, respectively), $T=379.50, n s, r=-.19$. There was also no difference between the Time 1 and Time 2 scores for peer relationship problems $(M d n=7.00 \& M d n=$ 7.00 , in that order), $T=258.00, n s, r=-.06$.

These non parametric findings are consistent with the univariate MANOVA results for research question 15, which are depicted in section 9.7.2.

Family dynamics at Time $1 \mathrm{vs}$. Time 2. There were significant differences across time for all of the family wellbeing variables. The young people's family cohesion scores were significantly higher at Time $2(M d n=7.00)$ compared to Time 1 $(M d n=8.00), T=193.50, p<.05, r=-.31$. Their family communication scores were also significantly higher at Time $2(M d n=7.00)$ versus Time $1(M d n=$ $5.00), T=170.50, p<.05, r=-.45$. With regard to the young people's positive 
perceptions of their mother, there was a significantly higher score at Time 2 (Mdn $=53.50)$ in comparison to Time $1(M d n=52.00), T=244.50, p<.05, r=-.47$. Similarly, the participants' positive perceptions of father scores were higher at Time $2(M d n=53.00)$ than they were at Time $1(M d n=47.00), T=101.50, p<$ $.05, r=-.73$. These results verify that the young people's family environment, and positive perceptions of their parents, increased with time.

In relation to the young people's negative perceptions of their parents, the results showed significantly lower scores for the negative perceptions of mother variable at Time $2(M d n=9.00)$ compared to Time $1(M d n=11.00), T=84.50, p<.05, r$ $=-.67$. These results were reiterated for the negative perceptions of father variable at Time $2(M d n=9.00)$ versus Time $1(M d n=12.00), T=72.00, p<.05$, $r=-.69$. The parental conflict scores were also significantly lower at Time 2 ( $M d n$ $=29.00)$ compared to the initial score at Time $1(M d n=32.00), T=75.50, p<$ $.05, r=-.72$. These results clearly demonstrate that the participants' negative perceptions of their parents, and parental conflict, decreased with time.

Yet again, the non parametric results above are entirely supportive of the univariate MANOVA results, as reported in section 9.7.2 (vis-à-vis question 16).

\section{Main effects for the groups (Mann-Whitney $U$ test)}

Mann-Whitney analyses were performed in order to detect whether there were differences in individual wellbeing and family dynamics at Time 1 and at Time 2 for the ESG versus the LSG. The non parametric results regarding the main effects for these two groups are reported below.

\section{Individual wellbeing for early-stage group vs. later-stage group at Time 1. There} were a number of differences in individual wellbeing between the ESG and the LSG at Time 1. To begin with, significant differences were detected for both of the positive wellbeing variables. The LSG exhibited significantly higher perception of strengths scores than the ESG $(M d n=19.00 \& M d n=13.00$, 
respectively) at Time $1, U=44.00, p=.000, r=-.74$. There was also a difference between the positive feelings scores of the two groups, with the LSG displaying significantly higher scores than the ESG $(M d n=37.00 \& M d n=30.00$, respectively), $U=58.50, p=.000, r=-.70$. These results confirm a difference between the ESGs' and the LSGs' perception of strengths and positive feelings scores at Time 1. To be exact, the LSGs' positive wellbeing scores were significantly higher than the ESGs' scores.

In terms of the negative wellbeing variables, the ESG revealed significantly higher negative feelings scores than the LSG $(M d n=26.00 \& M d n=15.00$, in that order), $U=62.00, p=.000, r=-.70$. For the internalising behaviour variable the ESG also displayed significantly higher scores than the $L S G(M d n=10.00$ \& $M d n=6.00$, respectively), $U=102.00, p=.000, r=-.60$. This was similarly the case for the externalising behaviour variable (ESG Mdn $=9.00$, LSG $M d n=$ 6.00), $U=141.00, p=.000, r=-.50$. For the final individual wellbeing variable dysphoria - the ESG exhibited higher scores than the LSG $(M d n=15.00 \& M d n$ $=4.00$, in that order), $U=137.50, p=.000, r=-.50$. These results illustrate the clear differences between the ESGs' and the LSGs' negative feelings, internalising, externalising, and dysphoria scores at Time 1; with the ESGs' negative wellbeing scores being significantly higher than the LSGs' scores.

In relation to the pro-social behaviour variable, the Time 1 scores for the ESG and the LSG were not significantly different $(M d n=11.00 \& M d n=11.00$, respectively), $U=300.50, n s, r=-.09$. Similarly, there was no difference between the Time 1 hyperactivity scores of the ESG $(M d n=9.00)$ and the LSG $(M d n=$ 9.00), $U=310.50, n s, r=-.06$. There was also no difference between the peer relationship scores of the two groups (ESG $M d n=7.00$, LSG $M d n=7.00$ ), $U=$ $279.50, n s, r=-.14$.

These non parametric results are consistent with the univariate MANOVA results for research question 17, which are cited in section 9.7.3. 
Family dynamics for early-stage group vs. later-stage group at Time 1. Significant differences were found between the ESG and the LSG for all of the Time 1 family dynamics variables. In terms of the family environment variables, the LSG produced significantly higher family cohesion scores than the ESG (Mdn $=9.00$ \& $M d n=6.00$, respectively) at Time $1, U=167.50, p=.002, r=-.44$. Similarly, significantly higher family communication scores were reported by the LSG (Mdn $=7.00$, ESG Mdn = 4.00), $U=152.50, p=.001, r=-.47$. For the positive perceptions of mother variable, the LSG had significantly higher scores than the $\mathrm{ESG}(M d n=55.00 \& M d n=48.00$, respectively), $U=88.50, p=.000, r=-63$. This was similarly the case for the positive perceptions of father scores (ESG $M d n=45.00$, LSG $M d n=57.00), U=131.00, p=.000, r=-.52$. These results verify that there were differences between the ESGs' and the LSGs' family environment, and positive perception of parents, at Time 1. To be exact, the LSGs' positive family wellbeing scores were consistently higher than the ESGs' scores.

For the negative family wellbeing variables, the ESG revealed significantly higher negative perceptions of mother scores at Time 1 than the LSG (Mdn $=15.00$ \& $M d n=9.00$, in that order), $U=81.50, p=.000, r=-.65$. Similarly, the negative perceptions of father scores were higher for the ESG $(M d n=15.00)$ than the LSG $(M d n=10.00), U=154.00, p=.001, r=-.46$. In terms of the parental conflict variable, the ESG also had significantly higher scores $(M d n=36.00$, LSG $M d n=29.00), U=97.00, p=.000, r=-.61$. These results provide confirmation that there were differences between the two groups' negative perceptions of parents and parental conflict scores at Time 1. The ESGs' negative family wellbeing scores were significantly higher than the scores of the LSG.

The univariate MANOVA results for research question 18 (as reported in section 9.7.3) are verified by these non parametric findings. 
Individual wellbeing for early-stage group vs. later-stage group at Time 2. There were no significant differences between the ESG and the LSG for the large majority of the Time 2 individual wellbeing variables. The only noteworthy variable was dysphoria. The ESGs' dysphoria score at Time 2 was significantly higher than the LSGs' score $(M d n=9.00 \& M d n=6.00$, respectively), $U=$ 192.50, $p=.009, r=-.36$. Overall these findings confirm that there were no major differences in the individual wellbeing of the two groups at Time 2, with the exception of the dysphoria variable. These results strengthen the MANOVA results in section 9.7.3, vis-à-vis research question 19.

Family dynamics for early-stage group vs. later-stage group at Time 2. There were no significant differences between the ESG and the LSG for all of the family wellbeing variables at Time 2 . Once again these results reinforce the MANOVA analyses for research question 20 (in section 9.7.3). 


\section{APPENDIX AA}

Young People's Feelings about their Parents' Separation in Retrospect (as Reported at Time 1 and Time 2) 


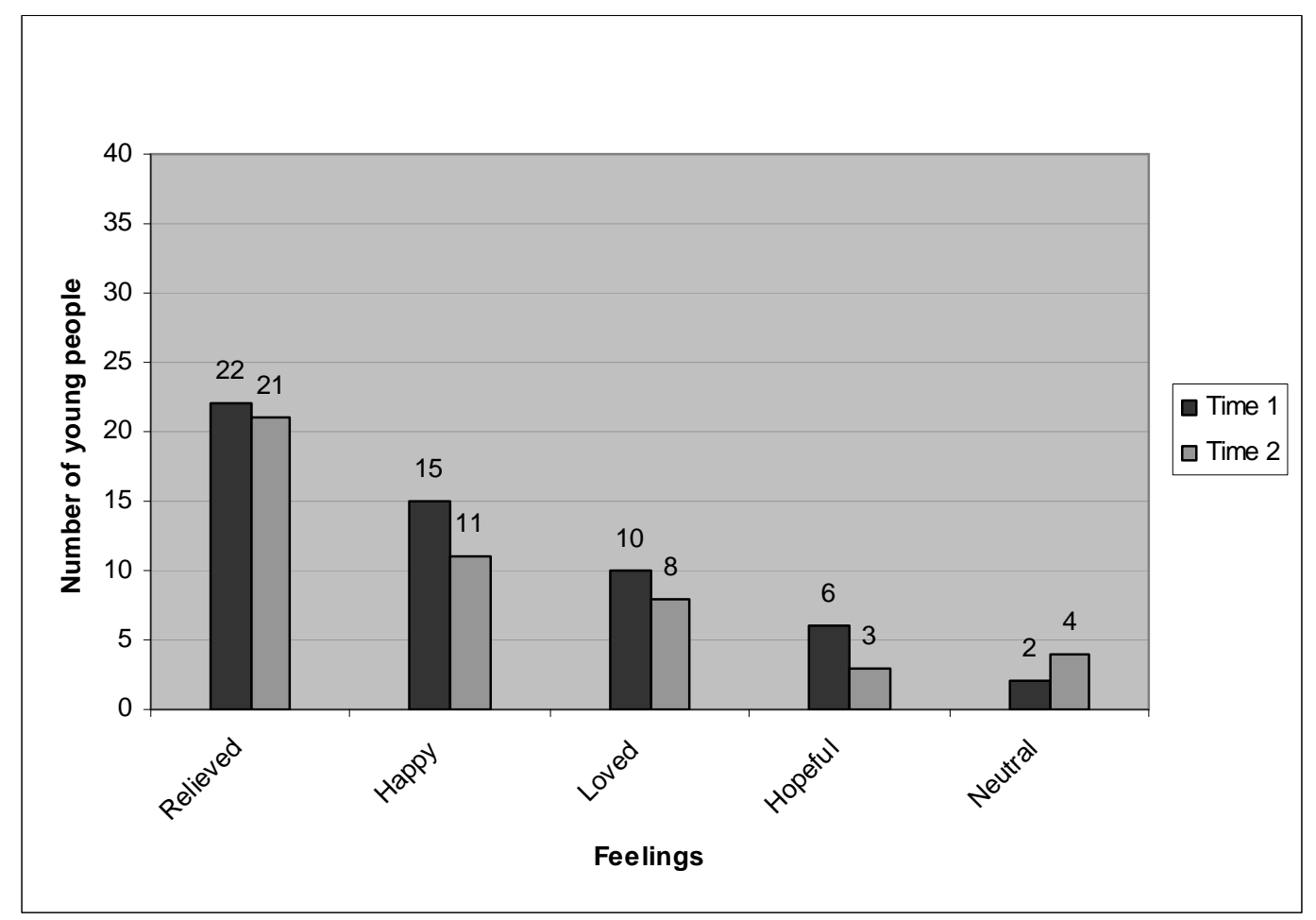

Figure AA1. The young people's positive and neutral feelings about their parents' separation in retrospect (as reported at Time 1 and Time 2).

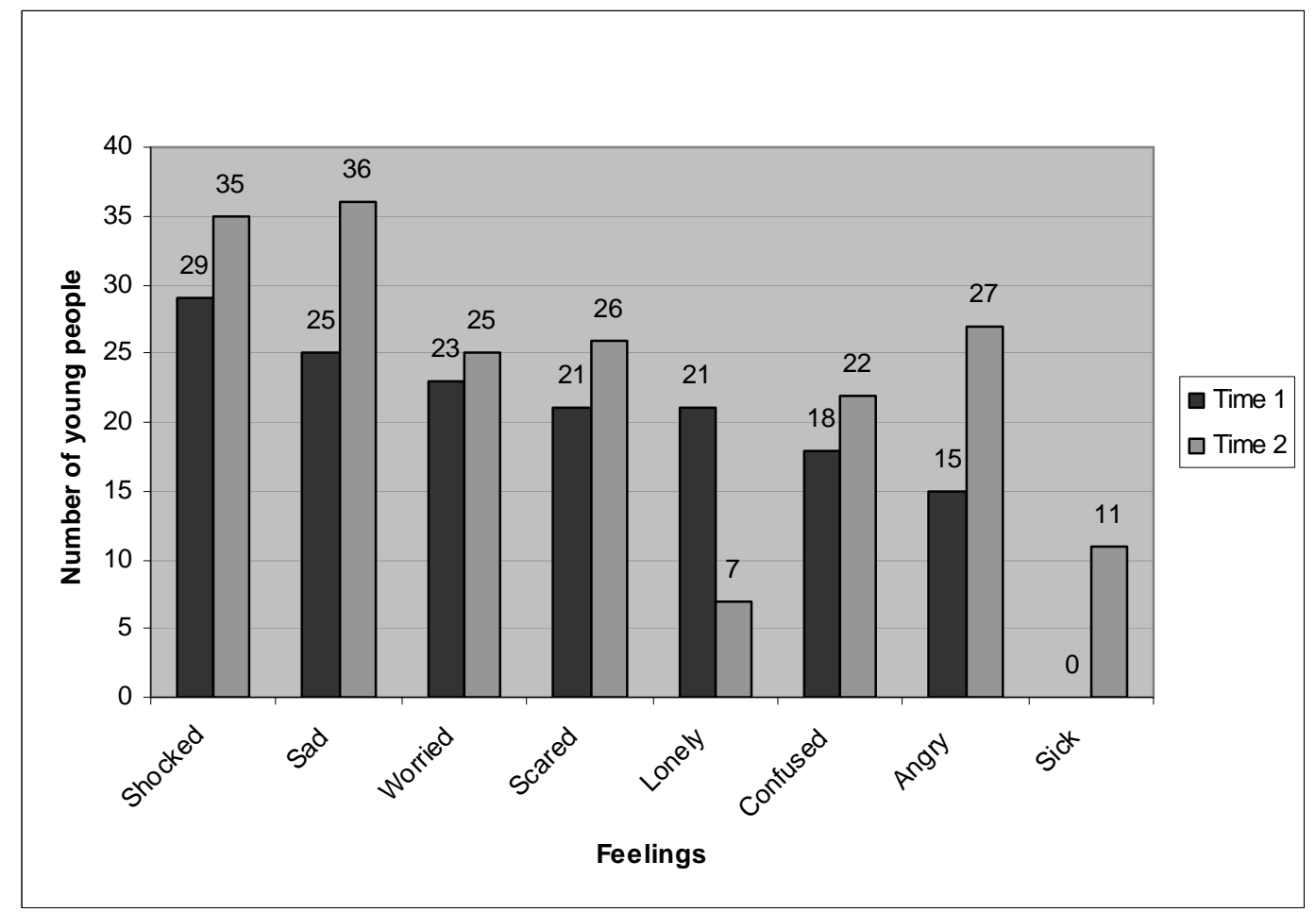

Figure AA2. The young people's negative feelings about their parents' separation in retrospect (as reported at Time 1 and Time 2). 


\section{APPENDIX BB}

Young People's Feelings about their Parents' Separation at Time 1 and Time 2 


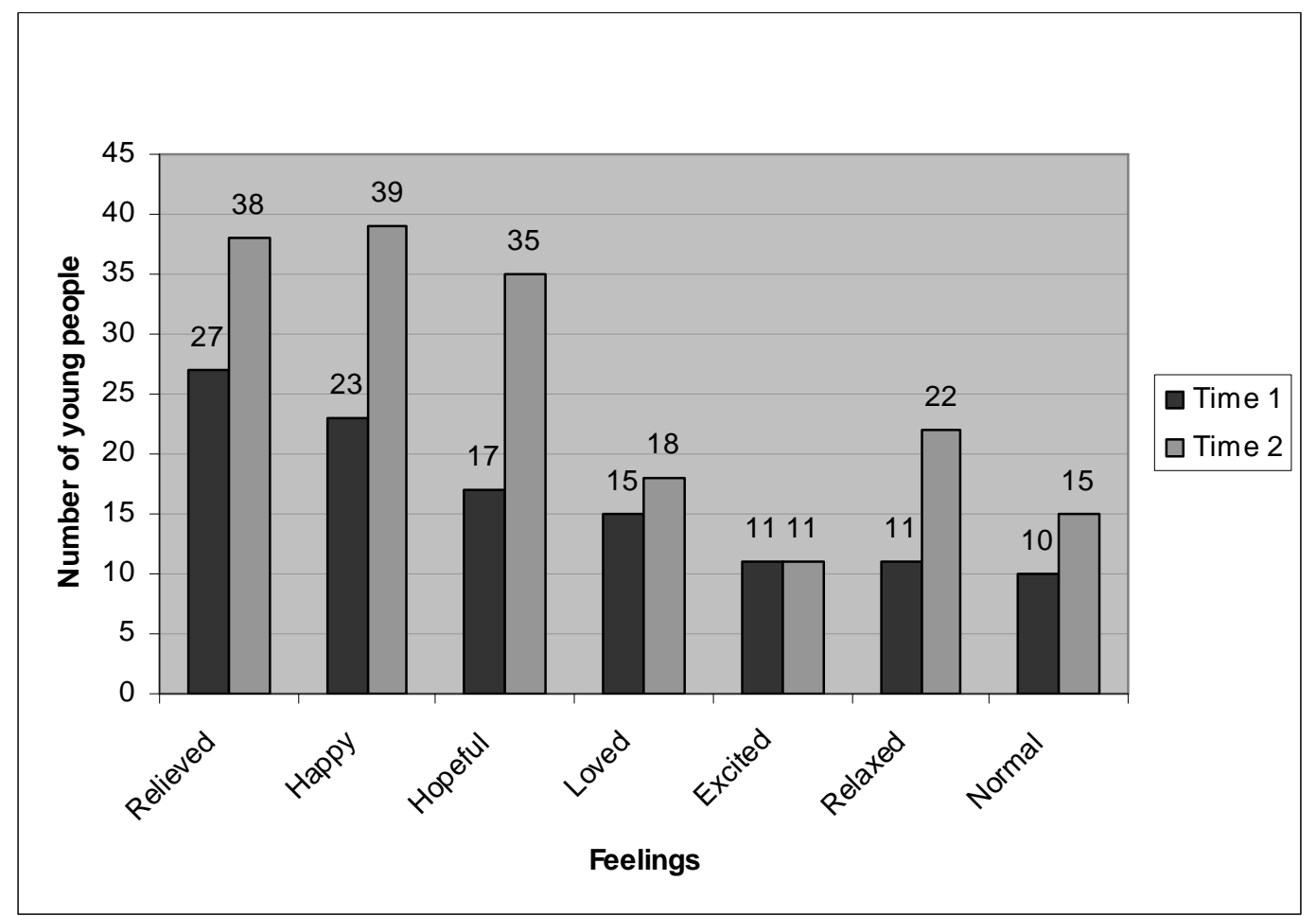

Figure BB1. The young people's positive feelings about their parents' separation at Time 1 and Time 2.

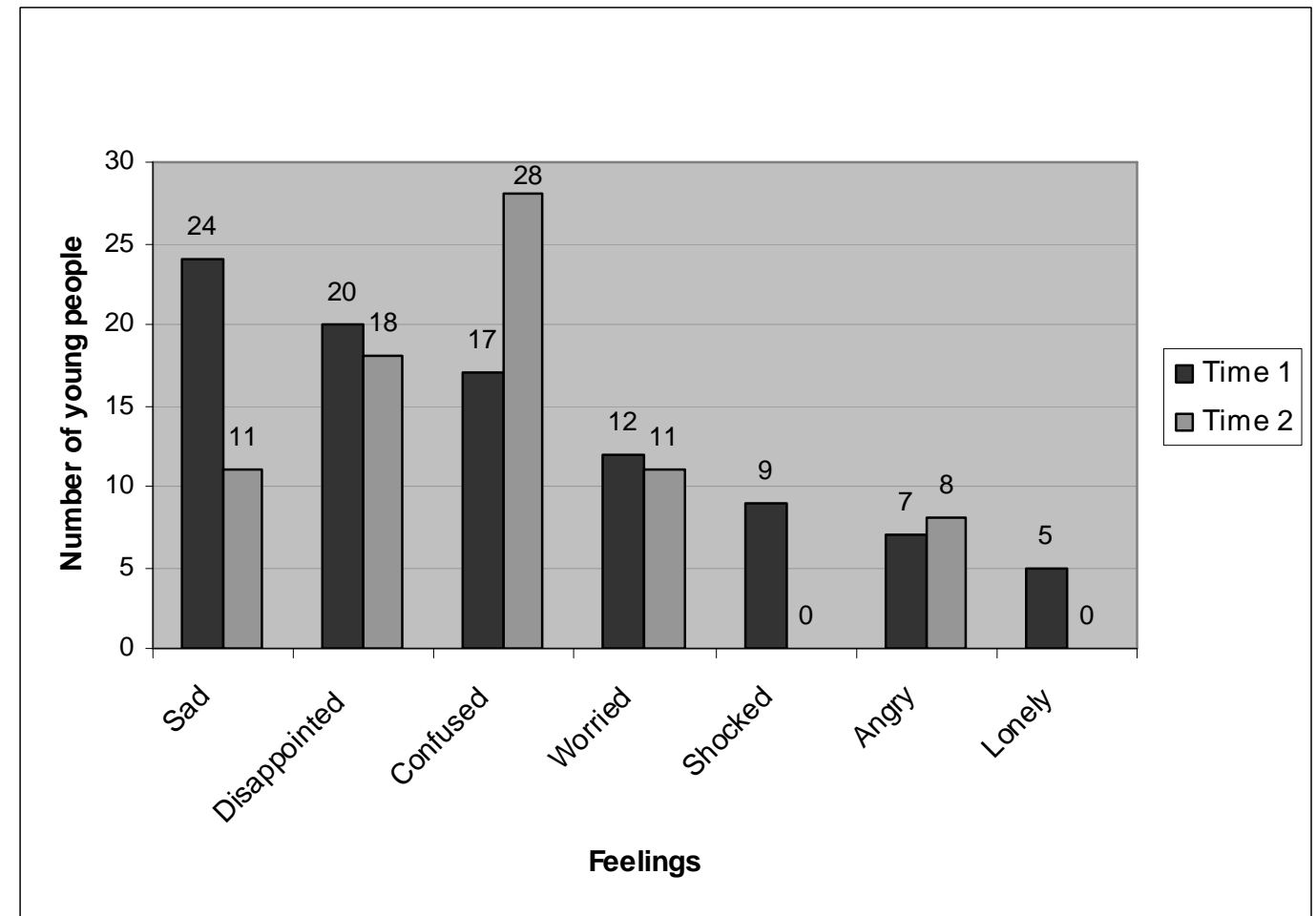

Figure BB2. The young people's negative feelings about their parents' separation at Time 1 and Time 2. 


\section{APPENDIX CC}

Early-Stage Separation Participants' Feelings about their

Parents' Separation at Time 1 and Time 2 


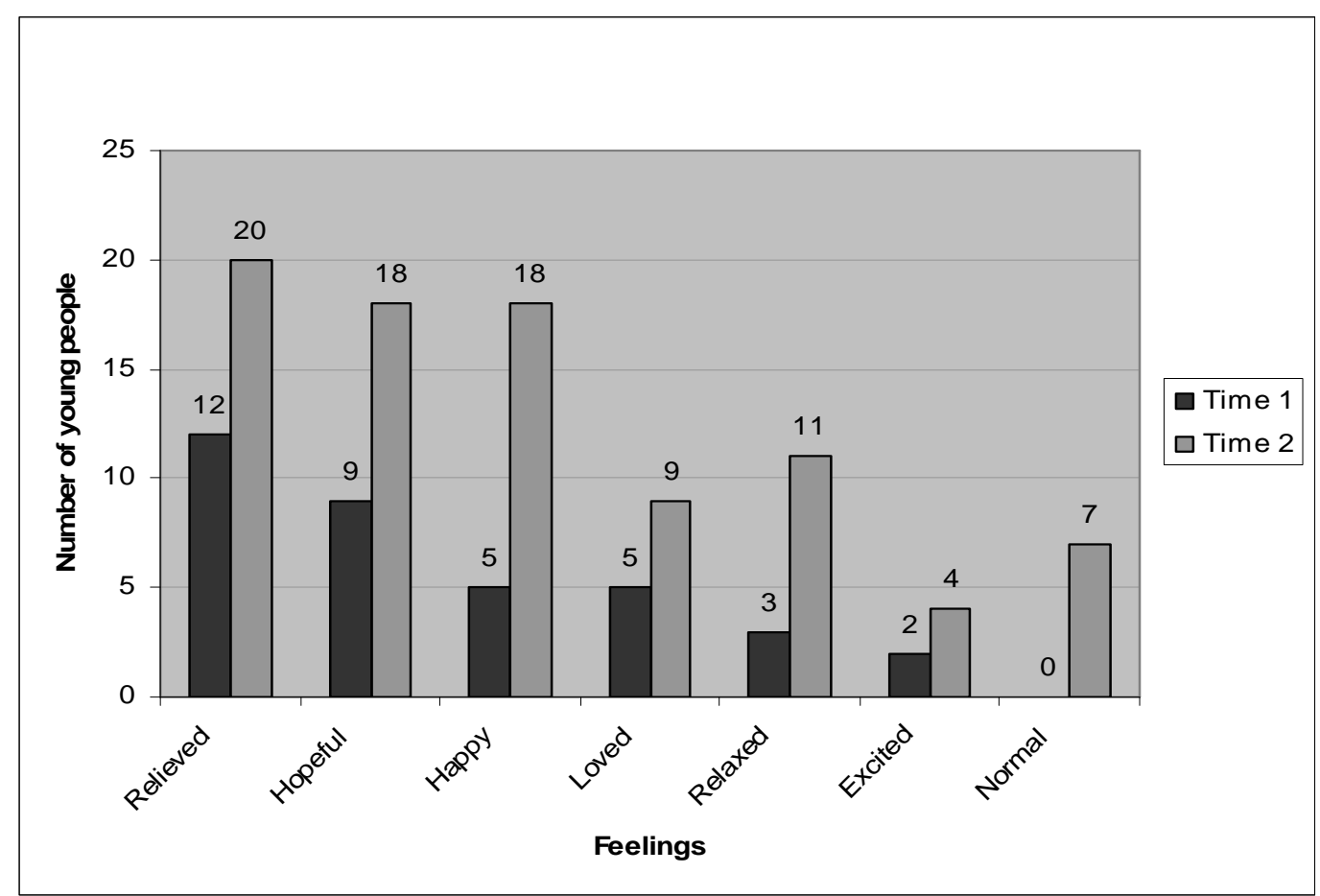

Figure CC1. The early-stage separation participants' positive feelings about their parents' separation at Time 1 and Time 2.

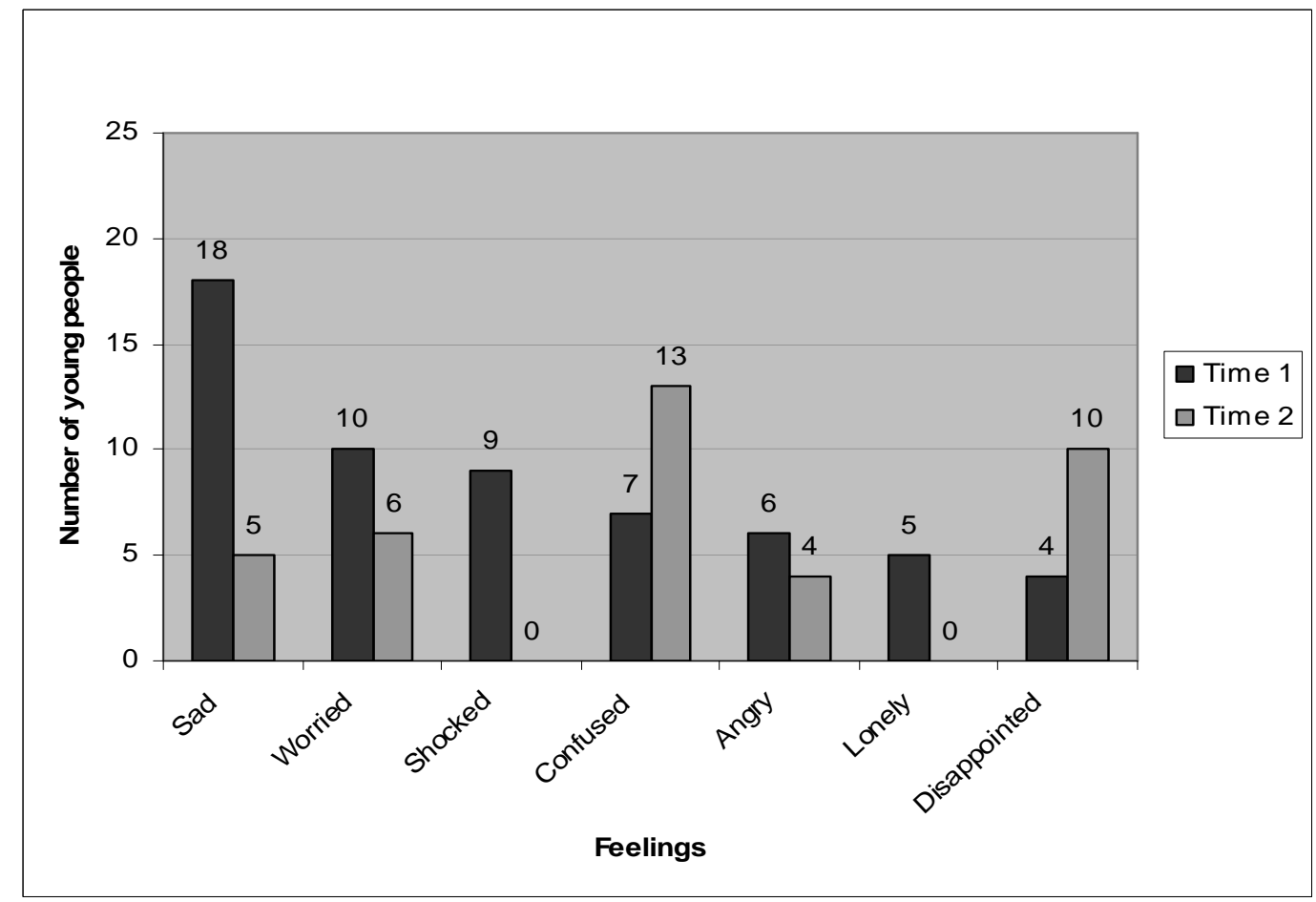

Figure CC2. The early-stage separation participants' negative feelings about their parents' separation at Time 1 and Time 2. 


\section{APPENDIX DD}

Later-Stage Separation Participants' Feelings about their Parents' Separation at Time 1 and Time 2. 


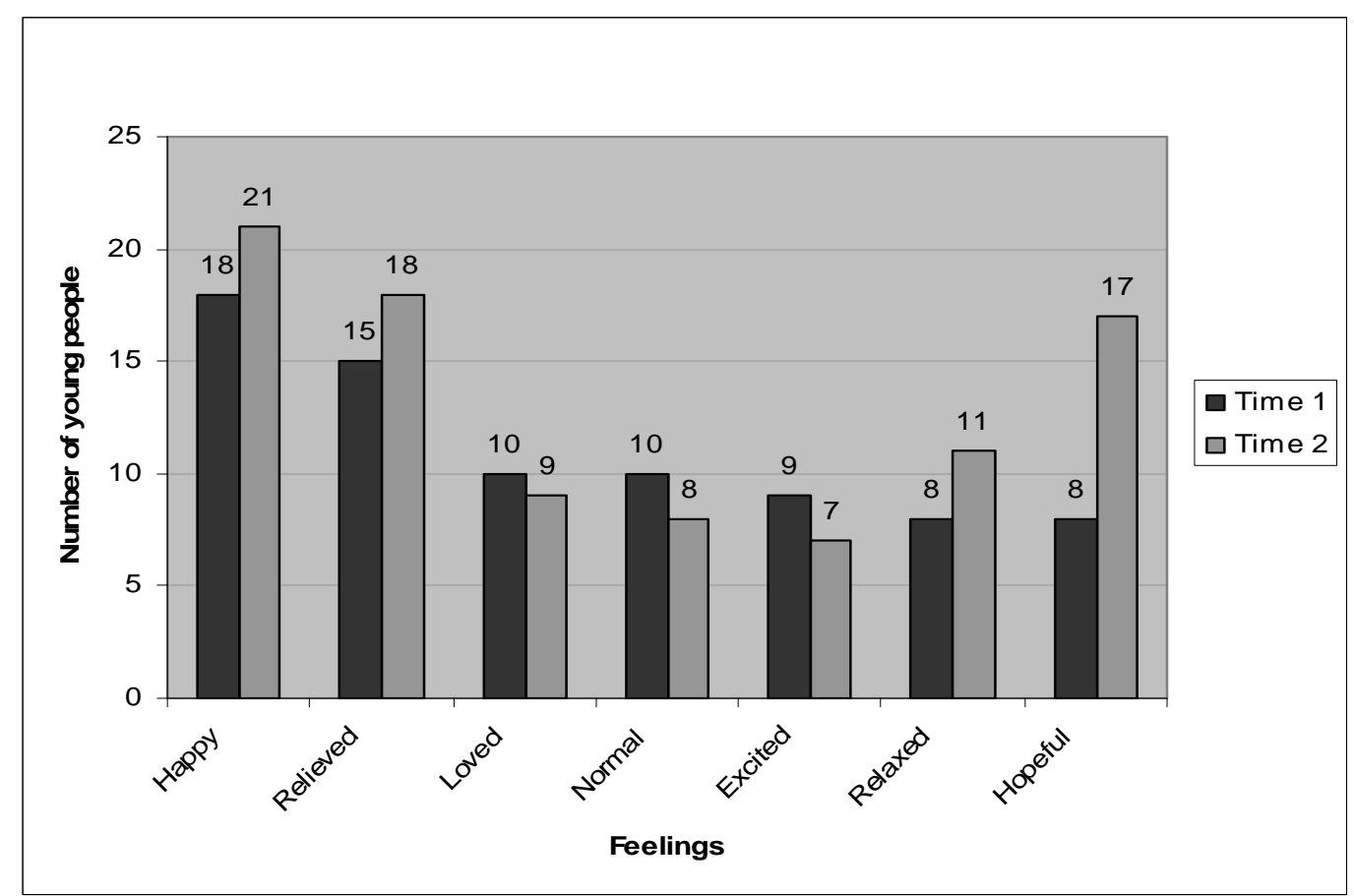

Figure DD1. The later-stage separation participants' positive feelings about their parents' separation at Time 1 and Time 2.

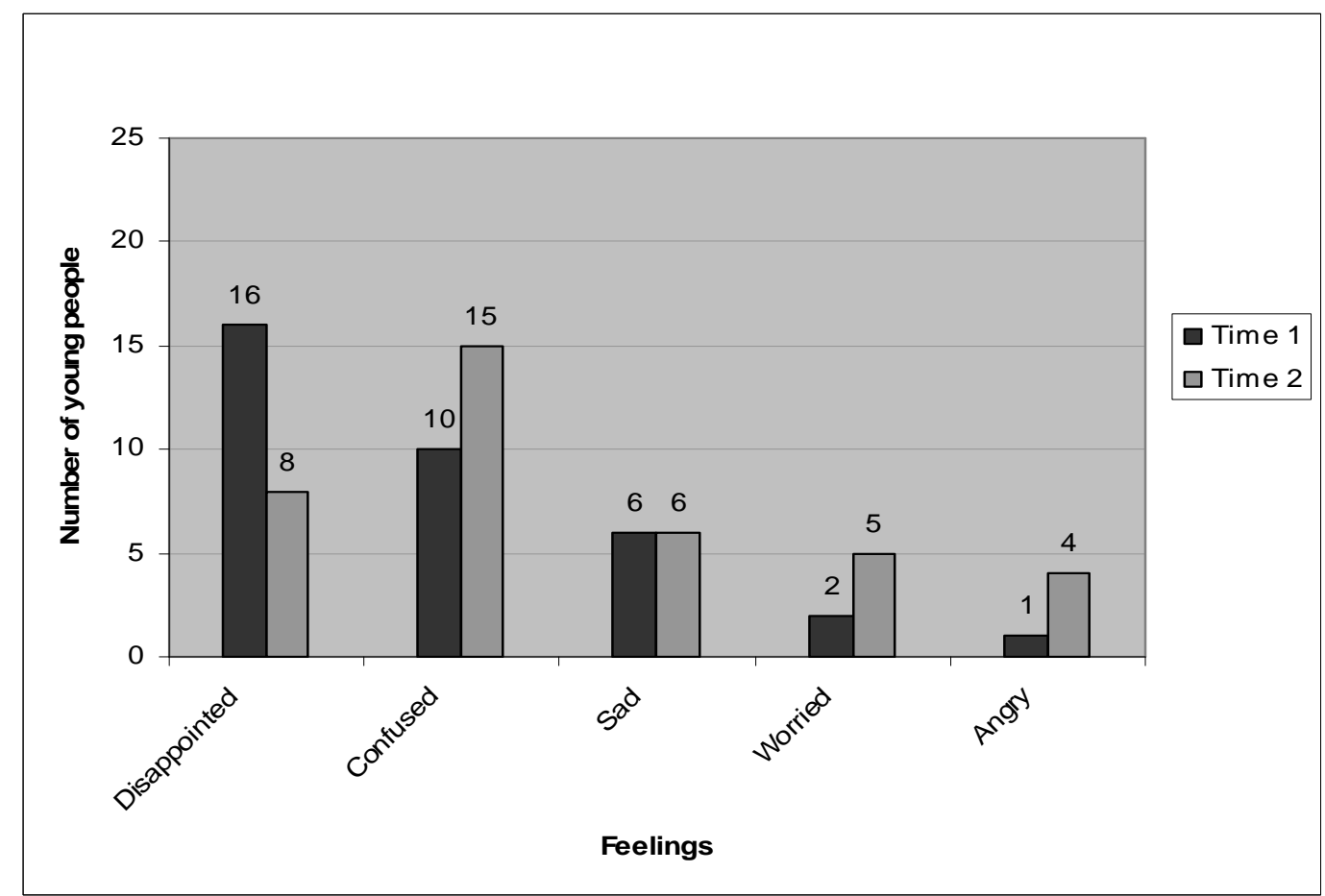

Figure DD2. The later-stage separation participants' negative feelings about their parents' separation at Time 1 and Time 2. 
